\title{
ABSTRACT \\ QUANTITATIVE 2-D FUEL VAPOR CONCENTRATION MEASUREMENTS \\ IN AN EVAPORATING DIESEL SPRAY \\ USING THE EXCIPLEX FLUORESCENCE METHOD
}

\author{
Tongwoo Kim
}

\author{
Under the Supervision of Professor Jaal B. Ghandhi \\ at the University of Wisconsin - Madison
}

To experimentally investigate evaporating sprays under conditions experienced in high speed direct-injection (HSDI) diesel engines, the exciplex (excited state complex) laser-induced fluorescence technique and high-speed natural luminosity cinematography were applied for non-reacting and reacting diesel sprays respectively, in a combustiontype constant-volume spray chamber. The combustion-type spray chamber was developed and provides conditions representative of a diesel engine at the start of fuel injection with good repeatability.

A detailed set of calibration experiments were performed in order to quantify the TMPD (tetramethyl-p-phenylene-diamine) fluorescence signal. The effects of pressure and collision partner were found to be negligible. The effect of temperature was found to increase the fluorescent yield up to $600 \mathrm{~K}$, then decrease it for further increases in temperature. An adiabatic mixing model for the estimation of the temperature reduction due to vaporization allowed correction of the temperature effects, and laser beam absorption and laser spatial non-uniformity were also corrected in the final calibration procedure. 
To assess the accuracy of the calibration procedure, the fuel vapor concentration was integrated and found to agree well with the mass of fuel injected $(<10 \%)$ after the end of injection when all the liquid fuel was vaporized. Estimation of the uncertainty of the measurements was $21 \%$.

Using a density of $15 \mathrm{~kg} / \mathrm{m}^{3}$ the effects of three ambient gas temperatures (800, 1000 and $1200 \mathrm{~K})$, three peak injection pressures (60, 90 and $150 \mathrm{MPa}$ ) and three nozzle hole sizes $(0.14,0.158$ and $0.2 \mathrm{~mm})$ were investigated based on the calibrated exciplex concentration measurements. Limited experiments were performed at $7.5 \mathrm{~kg} / \mathrm{m}^{3}$.

The data indicate that early in the injection event liquid and vapor coexist at the spray leading edge, however the liquid length reaches a terminal value and the vapor phase continues to penetrate. Lower ambient gas density were shown to provide faster vapor penetration and longer liquid lengths. Higher ambient gas temperatures were shown to produce a wider radial vapor extent with higher equivalence ratios and higher gradients at the edge of the jet. Distributions of the vapor concentration for higher injection pressures showed faster fuel vaporization rates and larger spray head volumes. Larger nozzle hole sizes were shown to have faster vapor-phase penetration rates and longer liquid lengths. The effects of the aforementioned parameters on the sprayspreading angle were shown to be transient in nature although as injection progressed the steady values were achieved.

Natural luminosity images from reacting diesel sprays were acquired and compared with the exciplex image data to understand the equivalence ratio distribution during the ignition and initial flame development period. As a result, the first detection of 
the chemiluminescence signals seems to occur in fuel-rich vapor regions near the boundary of the liquid core with an equivalence ratio near 2 and a temperature of approximately $800 \mathrm{~K}$. These conditions were found to be independent of injection pressure and nozzle diameter for the condition tested (15 kg/m $\mathrm{m}^{3}$ and $1000 \mathrm{~K}$ ambient). 
To my mother, Sook-Ja Moon 


\section{ACKNOWLEDGEMENTS}

I would like to appreciate many people who have contributed to this work.

First and foremost I would like to thank my advisor, Professor Jaal B. Ghandhi, for his support, idea and leadership in this study. I am truly thankful for the opportunity I have received from him. I would also like to thank Professor Patrick V. Farrell for useful discussions, and Professor Rolf D. Reitz, Professor David E. Foster and Professor Michael L. Corradini for helpful comments.

I would like to thank Caterpillar Engine Co. and TACOM through the DUAP program for funding this project, and Dr. Cathy Y. Choi for kind arrangement for HI90 injectors.

I would like to thank Mark Beckman and Dongryul Rhim for their help as sharing the evaporating spray lab. Mark was also a co-worker for the exciplex LIF experiments. I wish them successfully completing their projects and degrees.

Many of ERC people deserve my gratitude for their help and assistance. Among whom I would like to thank Ralph Braun for nice assistance, and John Plackman, Dr. Mitchell Patrie, Dr. Lyle Pickett and Dr. Jeff Hoerning for helping my better adaptation during the early part of my tenure.

Finally I have to thank my family for everything: my mother and sisters, Soomi, Sookyung, Yunah and Yoo. I owe too much to them. And above all special thanks go to my wife, Hyunsihn, and my son, Wonjung, for their love, patience and encouragement. 


\title{
TABLE OF CONTENTS
}

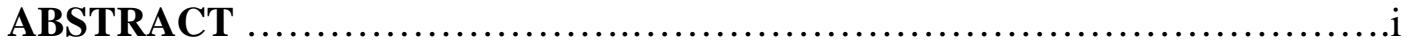

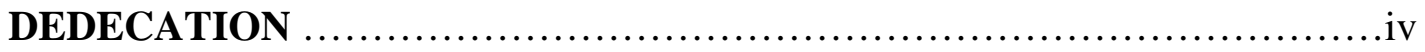

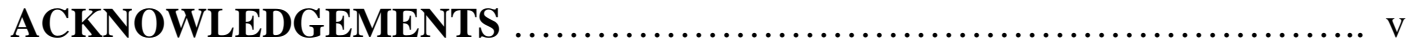

TABLE OF CONTENTS $\ldots \ldots \ldots \ldots \ldots \ldots \ldots \ldots \ldots \ldots \ldots \ldots \ldots \ldots \ldots \ldots \ldots \ldots \ldots \ldots$

LIST OF FIGURES..............................................

LIST OF TABLES ................................................ xvii

NOMENCLATURES .............................................. xviii

\section{INTRODUCTION}

1.1 Motivation........................................................ 1

1.2 Objective.................................................... 3

1.3 Method.................................................... 4

\section{REVIEW OF LITERATURE}

2.1 Characteristics of Diesel Spray................................ 6

2.1.1 Non-evaporating Spray Penetration Studies..................... 6

2.1.2 Evaporating Spray Experiments under Modern Diesel Engine

Condition.................................................. 11

2.2 Visualization and Measurement of Vapor-fuel Concentration........... 17

2.3 Exciplex LIF................................................ 22

2.3.1 Photophysics........................................... 22

2.3.2 Exciplex LIF Application to Engine Sprays.......................... 24 


\section{EXPERIMENTAL SETUP}

3.1 Combustion-type Spray Chamber........................................... 30

3.1.1 Modification from the Engine-Fed Chamber..........................33

3.1.2 Safety Concerns............................................... 35

3.1.3 Ignition System................................................ 35

3.1.4 Preparation of Pre-Charged Mixture............................... 36

3.1.5 Pressure Measurement.......................................... 36

3.1.6 Temperature Measurement..................................... 36

3.2 Verification of the Spray Chamber................................. 38

3.2.1 Premixed Reactants.............................................. 38

3.2.2 Pressure Data....................................................... 42

3.2.3 Temperature Data.............................................. 44

3.2.4 Confirmation from Mie Scattering Images of Hot Bomb and Cold Bomb................................................... 47

3.3 High Pressure Fuel Injection System................................... 49

3.3.1 Injection Driver System................................... 51

3.3.2 Fuel Delivery System.........................................51

3.3.3 Comparison Between Caterpillar and Siemens Injection Driver...... 52

3.4 Data Acquisition and Control System..................................53

3.4.1 Experimental Procedure............................................. 53

3.5 Exciplex Imaging System........................................... 55

\section{EXCIPLEX LIF CALIBRATION METHOD}

4.1 Consideration for the Quantitative Vapor Phase........................ 57

4.2 Calibration and Results

4.2.1 Absolute Calibration between TMPD Fluorescence and Concentration.................................................... 59 
4.2.2 Phtophysical Parameter Effects.............................. 62

4.2.2.1 Pressure Effect on TMPD Fluorescence.................. 62

4.2.2.2 Collision Partner Effects on TMPD Fluorescence........ 64

4.2.2.3 Temperature Effect on TMPD Fluorescence............. 66

4.2.3 Extinction of the Laser Sheet through the Vapor Phase............ 69

4.2.4 Estimation of Local Temperature............................. 70

4.2.5 TMPD Vapor Concentration Indicative of Total Vapor Concentration................................................73

4.2.6 Cross-talk between the Liquid and Vapor Phase................... 74

4.3 Calibration Procedure...................................................... 75

\section{RESULT AND DISCUSSION I \\ - EXCIPLEX LIF CONCENTRATION MEASUREMENTS}

5.1 Exciplex LIF Application for the Qualitative Liquid and Quantitative

Vapor Phase ....................................................... 77

5.1.1 Qualitative Liquid Phase.................................. 77

5.1.2 Quantitative Vapor Phase................................ 78

5.1.3 Discussion on the Verification of the Measurement................ 83

5.1.3.1 Comparison of the measured mass with the injected mass..... 83

5.1.3.2 Run-to-Run variation................................... 87

5.1.3.3 Comparison with other's work.............................. 88

5.2 Uncertainties in the Concentration Measurements....................... 91

5.2.1 Uncertainties Related to Calibration Quality .................. 91

5.2.2 Uncertainties Related to Capturing Fluorescence Signal.......... 92

5.2.2.1 Uncertainty from Background and Dark Noise............. 92

5.2.2.2 Uncertainty from Pixel Responsivity........................ 93

5.2.2.3 Uncertainty from Camera Noise.............................. 93

5.2.2.4 Estimated Uncertainty from Normalized Laser Sheet Profiles.. 94

5.2.3 Uncertainties Related to Incident Laser Intensity................ 96 
5.2.4 Uncertainties Related to the Quality of the Temperature Dependence Function.................................... 96

5.2.5 Uncertainty from Estimation of Temperature Field..................97

5.2.6 Uncertainty from Estimation of TMPD Absorption Coefficient...... 98

5.2.7 Overall Uncertainty for the Measurements.................... 100

5.3 Effects of Ambient Gas Temperature and Density.................... 100

5.4 Effects of Injection Pressure..................................... 104

5.5 Effects of Nozzle Hole Size....................................... 112

5.6 Summary.................................................... 118

\section{RESULT AND DISCUSSION II}

- REACTING FUEL SPRAY AND FUEL CONCENTRATION.

6.1 Reacting Spray Experiments..................................... 122

6.2 Equivalence Ratio Distribution at the Ignition Time..................... 125

6.2.1 Effect of Injection Pressure on Reacting Spray................... 125

6.2.2 Effect of Nozzle Hole Size on Reacting Spray.................... 133

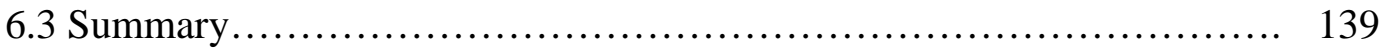

\section{CONCLUSION AND RECOMMENDATIONS}

7.1 Conclusion....................................................... 141

7.2 Recommendations................................................... 144

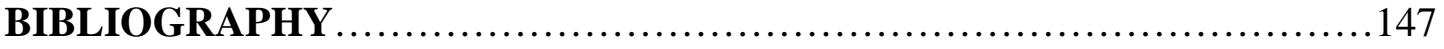

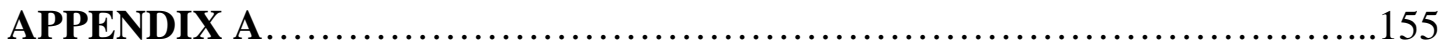

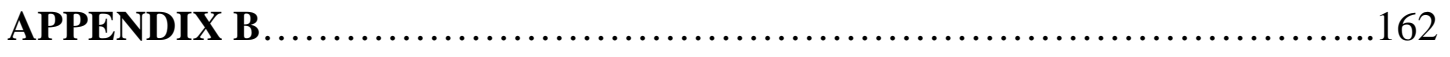

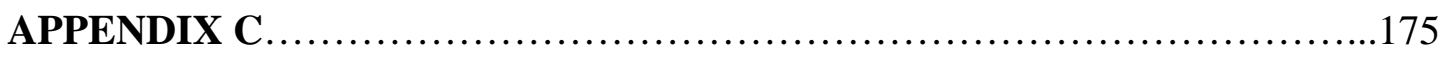

APPENDIX D.................................................... 177 


\section{LIST OF FIGURES}

Figure

pages

2.1 Schematic cross-section of the combustion vessel of the combustion

Research Facility in Sandia National Laboratories, taken from [17]....

2.2 Time averaged Mie-scattered light images superimposed on the schlieren images of the spray spreading angle, taken from [17]................... 14

2.3 Schematic of the idealized spray model, taken from [2]................... 15

2.4 Liquid lengths expected in small-bore diesel engines, taken from [2]......... 16

2.5 Geometry and optical configuration for quantitative 2-D Rayleigh scattering fuel-concentration measurements, taken from [43]........................ 19

2.6 Quantitative images of equivalence ratio of leading portion of diesel jet at $0.63 \mathrm{~ms}$ ASI. The top image is based on isothermal calculation, bottom image on adiabatic mixing assumption, taken from [44].............. 20

2.7 Temperature distributions obtained from adiabatic mixing approximation,

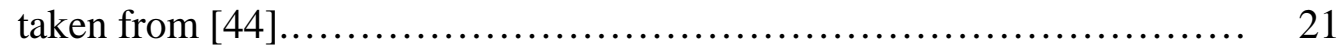

2.8 Laser induced exciplex fluorescence system, (a) separate wavelength for fuel liquid / vapor visualization, (b) photophysical processes, taken from [46]

2.9 Schematic diagram of the potential energy for an exciplex system,

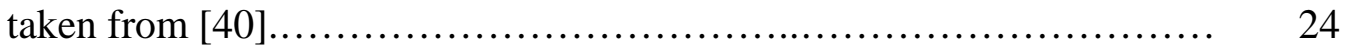

2.10 TMPD absorption at 355nm versus temperature, taken from [30].......... 25

2.11 TMPD vapor absorbance versus temperature (left), and the calibration curve of fluorescence intensity versus temperature (right), taken from [32]........ 26

2.12 2-D fuel vapor concentration and temperature distribution in an evaporating

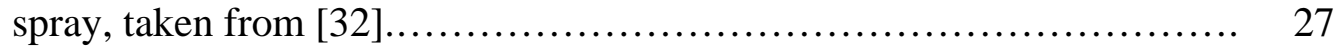

2.12 Change in impinging spray with elapsed time from injection, taken from [35] 
3.1 Schematic of experimental apparatus composed of the constant volume combustion-type spray chamber system (I), the high-pressure fuel injection system(II), the data acquisition and control system (III), and the exciplex imaging system(IV)................................................

3.2 Equilibrium pressure and temperature at the chamber gas density of $25 \mathrm{~kg} / \mathrm{m}^{3}$ results from the STANJAN program with respect to combination of fuel and inert gas.

3.3 Schematic cross-section of the constant-volume combustion-type spray chamber.

3.4 High speed cinematography in the combustion chamber from spark ignition at the total density of $7.5 \mathrm{~kg} / \mathrm{m}^{3}, 532 \mathrm{~nm}$ incident laser sheet without any filter in front of the camera

3.5 Window contamination at injection with respect to premixed combustion of twodifferent fuels, $\left(\rho=7.5 \mathrm{~kg} / \mathrm{m}^{3}, 1000 \mathrm{~K}\right)$, direct images from high-speed camera (2 ms shutter time), (a) Hydrogen (b) Acetylene. ..

3.6 Pressure history of the combustion-type spray chamber system at the density of $7.5 \mathrm{~kg} / \mathrm{m}^{3}$ at the pre-charge compositions of $16 \%$ of $\phi=1.05$ acetylene and oxygen, and $84 \% \mathrm{~N}_{2}$

3.7 Pressure history of the combustion-type spray chamber system at the density of $15 \mathrm{~kg} / \mathrm{m}^{3}$, the circled areas show the effect of fuel vaporization on the chamber pressure.

3.8 Temperature traces at four radial locations in the chamber for the case of density $7.5 \mathrm{~kg} / \mathrm{m}^{3}$

3.9 Temperature traces at four radial locations in the chamber for the case of density of $15 \mathrm{~kg} / \mathrm{m}^{3}$....

3.11 Run-to-run repeatability at the probe position of $\mathrm{r} / \mathrm{r}_{\text {wall }}=0.25 \ldots \ldots \ldots \ldots$

3.12 Mie scattering images from high-speed camera, $18000 \mathrm{f} / \mathrm{s}(55 \mu \mathrm{sec})$, $532 \mathrm{~nm}$ band pass filter in front of camera, $\rho=7.5 \mathrm{~kg} / \mathrm{m}^{3}$.

3.13 Injection rate profile with $0.158 \mathrm{~mm}$ diameter nozzle size and $90.1 \mathrm{MPa}$ peak injection pressure. 
3.14 Penetration length with respect to four combinations of different injection drive and fuel delivery systems, measured from high speed cinematography at cold bomb, $298 \mathrm{~K}$ and $7.5 \mathrm{~kg} / \mathrm{m}^{3}, 1.4 \mathrm{~ms}$ injection duration, 90.3 MPa peak injection pressure.

3.15 Schematic of the optical imaging system........................... 55

3.16 Normalized laser sheet profile obtained by imaging an uniform distribution of TMPD vapor inside the chamber................................ 56

4.1 Schematic of apparatus for absolute TMPD calibration at a reference temperature

4.2 Calibration relationship between TMPD concentration and fluorescence intensity

4.3 TMPD fluorescence dependence on laser intensity at a TMPD concentration of $6.8 \times 10^{-5} \mathrm{~mol} / \mathrm{l}$.

4.4 TMPD fluorescence dependence on ambient pressure.

4.5 TMPD fluorescence dependence on collision partner.

65

4.6 TMPD fluorescence dependence on water vapor concentration. 65

4.7 Schematic of dual heated jet system to determine the TMPD temperature dependence.

4.8 TMPD fluorescence dependence on temperature.

4.9 Algorithm for the vapor signal calibration.

5.1 Comparison of liquid penetration length between Mie scattering signal and the exciplex (liquid) fluorescence signal at a density of $15 \mathrm{~kg} / \mathrm{m}^{3}$, and temperature of $1200 \mathrm{~K}$

5.2 Quantitative images of equivalence ratio (left) and temperature (right) at the ambient density of $15 \mathrm{~kg} / \mathrm{m}^{3}$ and temperature of $800 \mathrm{~K} . .$.

5.3 Quantitative images of equivalence ratio (left) and temperature (right) at the ambient density of $15 \mathrm{~kg} / \mathrm{m}^{3}$ and temperature of $1000 \mathrm{~K}$ 
5.4 Quantitative images of equivalence ratio (left) and temperature (right) at the ambient density of $15 \mathrm{~kg} / \mathrm{m}^{3}$ and temperature of $1200 \mathrm{~K}$

5.5 Integrated fuel vapor mass versus time after the start of injection using nozzle hole diameter of $0.158 \mathrm{~mm}$ at an ambient density of $15 \mathrm{~kg} / \mathrm{m}^{3}$....

5.6 Integrated fuel vapor mass versus time after the start of injection using nozzle hole diameter of $0.14 \mathrm{~mm}$ at an ambient density of $15 \mathrm{~kg} / \mathrm{m}^{3}$.

5.7 Integrated fuel vapor mass versus number of occurrences of a specific normalized mass from a total of 18 images captured at the time when all of the fuel is vaporized.

5.8 Images on run-to-run variation at a density of $15 \mathrm{~kg} / \mathrm{m}^{3}, 1000 \mathrm{~K}$, captured at $1.0 \mathrm{~ms}$ ASI.

5.9 Equivalence ratios throughout the cross section of the leading portion of the diesel jet ( $25 \mathrm{~mm}$ downstream from the injection nozzle) around the time of start of ignition time at the ambient density of $15 \mathrm{~kg} / \mathrm{m}^{3}$, (a) at temperature of $1000 \mathrm{~K}$ and (b) $1200 \mathrm{~K}$

5.10 Run-to-run variation of 16 normalized and corrected laser sheet profiles ....

5.11 Equivalence ratio profiles along the axis of spray, obtained to see the $50 \mathrm{~K}$ uncertainty of ambient gas temperature

5.12 Equivalence ratio profiles on the effect of TMPD absorbance along the axis of spray

5.13 Penetration rate of the liquid and vapor phases obtained from the exciplex technique, (a) at the ambient gas density of $7.5 \mathrm{~kg} / \mathrm{m}^{3}$, and (b) at the ambient gas density of $15 \mathrm{~kg} / \mathrm{m}^{3}$

5.14 Spray spreading angle with respect to ambient gas temperature, based on vapor phases images obtained from the exciplex technique, at the ambient gas density of $15 \mathrm{~kg} / \mathrm{m}^{3}$

5.15 Injection rate profiles at three different peak injection pressures, obtained from Bosch-type flow rate bench experiments

5.16 Quantitative images of equivalence ratio (left) and temperature (right) with the peak injection pressure of $60 \mathrm{MPa}$ at the ambient density of 
$15 \mathrm{~kg} / \mathrm{m}^{3}$ and temperature of $1000 \mathrm{~K}$

5.17 Quantitative images of equivalence ratio (left) and temperature (right) with the peak injection pressure of $90 \mathrm{MPa}$ at the ambient density of $15 \mathrm{~kg} / \mathrm{m}^{3}$ and temperature of $1000 \mathrm{~K}$

5.18 Quantitative images of equivalence ratio (left) and temperature (right) with the peak injection pressure of $150 \mathrm{MPa}$ at the ambient density of $15 \mathrm{~kg} / \mathrm{m}^{3}$ and temperature of $1000 \mathrm{~K}$

5.19 Penetration rates of the liquid and vapor phases at three different peak injection pressures, obtained from the exciplex technique.

5.20 Spray spreading angle with respect to peak injection pressure, based on vapor phases images obtained from the exciplex technique.

5.21 Injection rate profiles at three different nozzle hole sizes, obtained from Bosch-type flow rate bench experiments.

5.22 Quantitative images of equivalence ratio (left) and temperature (right) with $0.14 \mathrm{~mm}$ diameter nozzle hole at the ambient density of $15 \mathrm{~kg} / \mathrm{m}^{3}$ and temperature of $1000 \mathrm{~K}$

5.23 Quantitative images of equivalence ratio (left) and temperature (right) with $0.20 \mathrm{~mm}$ diameter nozzle hole at the ambient density of $15 \mathrm{~kg} / \mathrm{m}^{3}$ and temperature of $1000 \mathrm{~K}$

5.24 Penetration rates of the liquid and vapor phases at three different nozzle hole sizes, obtained from the exciplex technique

5.25 Spray spreading angle with respect to nozzle hole size, based on vapor phases images obtained from the exciplex technique

6.1 Pressure history of the combustion-type spray chamber system at the ambient gas density of $15 \mathrm{~kg} / \mathrm{m}^{3}$

6.210 sequential images for reacting spray using the $0.158 \mathrm{~mm}$ nozzle hole diameter, $90 \mathrm{MPa}$ peak injection pressure, $15 \mathrm{~kg} / \mathrm{m}^{3}$ ambient gas density and $1000 \mathrm{~K}$ ambient gas temperature.

6.3 (a) equivalence ratio at 0.6 and $0.8 \mathrm{~ms}$ ASI, (b) temporal sequence of luminosity images with $0.158 \mathrm{~mm}$ nozzle hole diameter, $60 \mathrm{MPa}$ peak injection pressure, ambient gas density of $15 \mathrm{~kg} / \mathrm{m}^{3}$ and ambient gas temperature of $1000 \mathrm{~K}$ 
6.4 (a) equivalence ratio at 0.6 and $0.7 \mathrm{~ms}$ ASI, (b) temporal sequence of luminosity images with $0.158 \mathrm{~mm}$ nozzle hole diameter, $90 \mathrm{MPa}$ peak injection pressure, ambient gas density of $15 \mathrm{~kg} / \mathrm{m}^{3}$ and ambient gas temperature of $1000 \mathrm{~K}$

6.5 (a) equivalence ratio at 0.4 and $0.6 \mathrm{~ms}$ ASI, (b) temporal sequence of luminosity images with $0.158 \mathrm{~mm}$ nozzle hole diameter, $150 \mathrm{MPa}$ peak injection pressure, ambient gas density of $15 \mathrm{~kg} / \mathrm{m}^{3}$ and ambient gas temperature of $1000 \mathrm{~K}$

6.6 Ignition delay time vs. injection pressures with the $0.158 \mathrm{~mm}$ hole diameter, at an ambient gas temperature of $1000 \mathrm{~K}$ and density of $15 \mathrm{~kg} / \mathrm{m}^{3}$.

6.7 Flame lift-off height vs. injection pressures with the $0.158 \mathrm{~mm}$ hole diameter, at an ambient gas temperature of $1000 \mathrm{~K}$ and density of $15 \mathrm{~kg} / \mathrm{m}^{3}$.

6.8 (a) equivalence ratio at 0.7 and $1.0 \mathrm{~ms}$ ASI, (b) temporal sequence of luminosity images with $0.14 \mathrm{~mm}$ nozzle hole diameter, $90 \mathrm{MPa}$ peak injection pressure, ambient gas density of $15 \mathrm{~kg} / \mathrm{m}^{3}$ and ambient gas temperature of $1000 \mathrm{~K}$.

6.9 (a) equivalence ratio at 0.4 and $0.6 \mathrm{~ms}$ ASI, (b) temporal sequence of luminosity images with $0.20 \mathrm{~mm}$ nozzle hole diameter, $90 \mathrm{MPa}$ peak injection pressure, ambient gas density of $15 \mathrm{~kg} / \mathrm{m}^{3}$ and ambient gas temperature of $1000 \mathrm{~K}$

6.10 Ignition delay time vs. nozzle hole size with a $90 \mathrm{MPa}$ peak injection pressure and an ambient gas temperature of $1000 \mathrm{~K}$ and density of $15 \mathrm{~kg} / \mathrm{m}^{3}$.

6.11 Flame lift-off height vs. nozzle hole size with a $90 \mathrm{MPa}$ peak injection pressure and an ambient gas temperature of $1000 \mathrm{~K}$ and density of $15 \mathrm{~kg} / \mathrm{m}^{3}$.

B.1 Example of fitting relationships to match the vapor concentration with temperature obtained from the subroutine in this section.

D.1 Quantitative images of equivalence ratio (left) and temperature (right) with $0.158 \mathrm{~mm}$ nozzle hole diameter, $90 \mathrm{MPa}$ peak injection pressure, the ambient density of $7.5 \mathrm{~kg} / \mathrm{m}^{3}$ and ambirnt temperature of $800 \mathrm{~K} \ldots \ldots \ldots \ldots \ldots \ldots . . . . . . . .178$

D.2 Quantitative images of equivalence ratio (left) and temperature (right) with $0.158 \mathrm{~mm}$ nozzle hole diameter, $90 \mathrm{MPa}$ peak injection pressure, the ambient density of $7.5 \mathrm{~kg} / \mathrm{m}^{3}$ and ambirnt temperature of $1000 \mathrm{~K} \ldots \ldots \ldots \ldots . . . . . . .179$ 
D.3 Quantitative images of equivalence ratio (left) and temperature (right) with $0.158 \mathrm{~mm}$ nozzle hole diameter, $90 \mathrm{MPa}$ peak injection pressure, the ambient

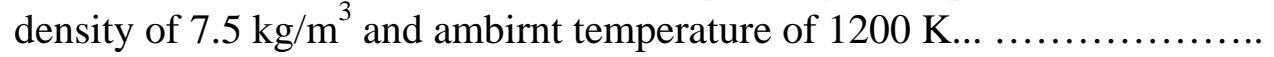




\section{LIST OF TABLES}

Table

pages

2.1 Typical correlation for spray tip penetration rate................... 7

2.2 Test conditions for Vaporizing spray experiments..................... 9

2.3 Specifications of the fuel injector and engine operating conditions, taken from [26]

3.1 Calculated TDC conditions ................................... 32

3.2 Ambient conditions investigated................................ 41

3.3 Injector system specification and the condition used ............... 50

4.1 Estimation of $T_{\text {mix }}$ with respect to the change of $T_{f i} \ldots \ldots \ldots \ldots \ldots \ldots \ldots$

4.2 Doped fuel system........................................ 74

6.1 Ignition delay, equivalence ratio and temperature at autoignition $\cdots \cdots$

6.2 Ignition delay, equivalence ratio and temperature at autoignition $\cdots \cdots$.

A.1 Confirmation on the application of Siebers' relation............... 158

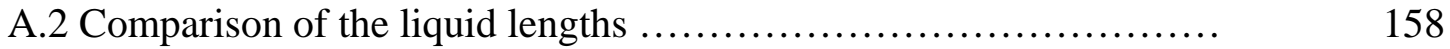

A.3 Parameter sensitivity on liquid length estimation.................... 158 


\section{NOMENCLATURE}

$\begin{array}{ll}\text { ASI } & \text { After the start of injection } \\ \text { a.u. } & \text { Arbitrary unit } \\ \text { BTD } & \text { Bottom dead center } \\ \text { EOI } & \text { End of injection } \\ \text { exciplex } & \text { Excited state complex } \\ \text { F/A } & \text { Fuel to air ratio } \\ \text { HEUI } & \text { Hydraulic-actuated electronically controlled unit injector } \\ \text { HSDI } & \text { High-speed (small-bored) direct injection } \\ \text { LIF } & \text { Laser-induced fluorescence } \\ \text { SMD } & \text { Sauter mean diameter } \\ \text { SNR } & \text { Signal to noise ratio } \\ \text { SOI } & \text { Start of injection } \\ \text { TDC } & \text { Top dead center } \\ \text { TMPD } & \text { Tetramethyl-p-phenylene-diamine }\end{array}$
A
Absorbance
$C_{\text {gas }}$
Concentration of the in-cylinder gas [mol/l]
$C_{V}$
Velocity Coefficient
$C_{a}$
Area contraction coefficient
$C_{d}$
Discharge coefficient
$C_{p}$
Specific heat at constant pressure [J/mol-K] 


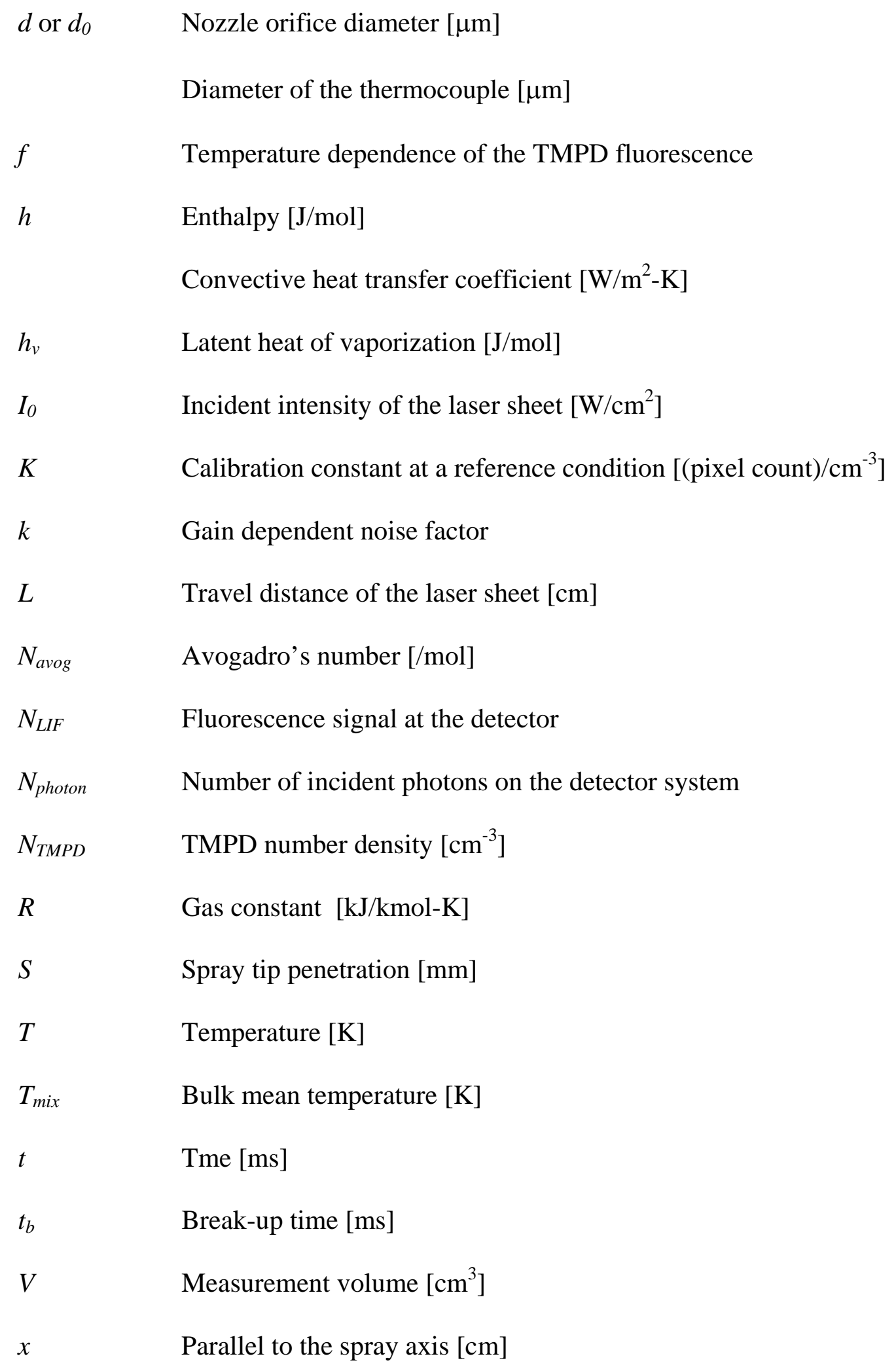


$y$

Z

$\chi$

$\varepsilon$

$\begin{array}{ll} & \text { Emissivity } \\ \phi_{T M P D} & \text { TMPD fluorescence efficiency (Stern-Vollmer factor) } \\ \Phi & \text { Equivalence ratio } \\ \eta_{c} \text { or } \eta_{\text {det }} & \text { Detection efficiency } \\ \theta & \text { Spray speading angle }\left[^{\circ}\right] \\ \rho & \text { Density [kg/m }{ }^{3} \text { ] } \\ \sigma & \text { Unit standard deviation } \\ \tau & \left.\text { Stefan-Bolzman constant } \mathrm{W} / \mathrm{m}^{2}-\mathrm{K}^{4}\right] \\ \sigma_{T M P D} & \text { Absorption cross-section of the TMPD fluorescence }\left[\mathrm{cm}^{2} / \mathrm{sr}\right] \\ & \text { Time constant of thermocouple [ms] } \\ & \text { Collection solid angle [sr] }\end{array}$

Normal to the spray axis $[\mathrm{cm}]$

Compressibility factor

Mole fraction

Extinction coefficient in the vapor phase $[1 / \mathrm{mol}-\mathrm{cm}]$

Emissivity

TMPD fluorescence efficiency (Stern-Vollmer factor)

Equivalence ratio 
l or liquid Liquid

mix or mixture Adiabatic (final) mixture state

REF Reference condition

$S$

Saturated fuel condition

TC Thermocouple bead

$v$ or vapor Vapor 


\section{Chapter 1. INTRODUCTION}

\subsection{Motivation}

High-speed direct injection (HSDI) diesel engines have received increasing attention for automotive applications due to their high thermal efficiency and low $\mathrm{CO}_{2}$ emissions, which arise from the relatively high compression ratio, the lower pumping loss and overall lean combustion process. However, in order to meet stringent modern emission standards, advanced engine systems (exhaust gas recirculation, high-pressure injection, injection timing and rate optimization, and swirl intake port, etc.) have been required. These improvements ultimately provide a better temporal and spatial mixture distribution of the diesel fuel and ambient gas in the combustion chamber. The typical TDC (Top Dead Center) condition experienced in the engines has gas density greater than $25 \mathrm{~kg} / \mathrm{m}^{3}$ and temperatures around $1000 \mathrm{~K}$.

However, most previous spray experiments have been performed at room temperature with changes of ambient gas density, injection pressure, orifice diameter, fuel, etc. While these studies help for better understanding of the non-evaporating spray phenomena, interpreting them to better understand evaporating spray or diesel engine studies may not be successful.

Recently, diesel engine research has been performed under realistic modern engine conditions. From these studies a phenomenological description of diesel combustion [1] based on mixing-limited vaporization [2] has been developed. The liquidphase fuel penetration length is relatively short, and all the fuel in the main combustion 
zone is in the vapor phase. The primary source of energy for fuel vaporization is hot air entrained into the spray and not energy from combustion. The SMD (Sauter Mean Diameter) becomes less important since vaporization is limited not by droplet surface phenomena but by the turbulent mixing processes generated by the penetrating spray. Injection pressure has little effect on liquid penetration length, but greater emissions can occur if liquid fuels impinge on the piston bowl wall.

In addition to the liquid-phase fuel penetration length, there is another fundamental injector-related issue that impacts diesel combustion, which is the air-fuel mixing process in the combustion chamber. Although liquid penetration lengths are not changed, higher injection pressures may induce a better temporal local air-fuel distribution due to the larger momentum of air entrainment. Furthermore, F/A (fuel to air) ratio distribution at the ignition time defines the following combustion and production of pollutant emissions. Therefore, investigation of temporal and spatial fuel distribution is required to accurately model the injection and combustion process. However, spray vaporization and mixing process are occurring in a limited space, of the order of 20 millimeters, and in a short injection period, of the order of one millisecond.

While several techniques have been developed for investigation of evaporating sprays, quantitative investigations of the vapor-fuel phase of the whole spray structure, especially at the TDC conditions experienced in HSDI engines, have been limited. The exciplex LIF (Excited state Complex Laser-Induced Fluorescence) technique with TMPD (tetramethyl-p-phenylene-diamine) / naphthalene dopant might be a promising tool for this purpose. The exciplex technique allows simultaneous visualization of the vapor and 
liquid phase in an evaporating spray. However, for the quantitative application it is necessary to understand the known difficulties that arise from the temperature dependence of the monomer fluorescence and cross talk between monomer (vapor) fluorescence and exciplex (liquid) fluorescence due to an overlap of the emission spectra.

Single-hole injectors have been used for most spray experiments, but multi-hole nozzles are used in engines. The spray characteristics of a muti-hole injector were reported to be different from that of a single hole [3,4]. Therefore, it is not appropriate to apply most of the correlations obtained from the single-hole nozzle to the spray from muti-hole nozzles. For this project, a six-hole HEUI Caterpillar commercial injector system is used to better address spray behavior in small-bore automotive DI diesels. As well, using a commercial state-of-art injector eliminates uncertainty about the effects of nozzle micro-geometry, cavitation, etc..

\subsection{Objective}

The objective of this project is to study the characteristics of evaporating sprays under conditions experienced in HSDI diesel engines. The thesis organization is as follows;

1) Development of a constant-volume combustion-type spray chamber to simulate conditions experienced in HSDI diesel engines.

2) Development of the exciplex LIF technique for quantitative vapor phase and the qualitative liquid phase measurement of evaporating sprays. 
3) Provision of temporal and spatial F/A ratios in evaporating sprays under variations of ambient gas temperature, ambient gas density, injection pressure and nozzle hole size.

4) Comparison with previous evaporating spray data - liquid penetration length and local vapor fuel/air ratio.

The findings of this study can also be used to develop and validate spray models for a numerical simulation code such as KIVA to better describe evaporating injection phenomena.

\subsection{Method}

A constant-volume chamber allows spark ignition and combustion of a pre-mixed combustible mixture composed of acetylene, oxygen and nitrogen in order to generate the high temperature inert gases to simulate in-cylinder diesel engine temperatures and pressures near TDC. When the products of this combustion event cool to a preselected temperature, an injection of diesel fuel starts. An exciplex-forming dopant (Naphthalene/TMPD) is added to the fuel to apply the exciplex fluorescence technique. The monomer, TMPD, absorbs the laser light and directly fluoresces in the vapor phase while in the liquid phase the excited monomer preferentially reacts with the second dopant, naphthalene, to form an excited complex, the exciplex.

In this study a detailed set of calibration experiments for the exciplex LIF technique were performed, and the quantitative fuel vapor distribution past the qualitative liquid fuel extent was investigated. The details are as follows: The absolute calibration between TMPD fluorescence and concentration was performed in the spray chamber. 
Separately the effect of photophysical parameters on the fluorescence due to the thermodynamic variables such as temperature, pressure and collision partner were investigated. Lastly, TMPD fluorescence images of the spray were calibrated to planar concentration fields of the vapor phase by iteratively solving to find the concentration and temperature field including the effect of the laser sheet extinction and laser sheet profile variations. Here, the temperature field around an evaporating spray will be estimated from a simple mixing model.

The remainder of this document is organized as follows; Chapter 2 is a review of literature, Chapter 3 is the description of the experimental setup, Chapter 4 presents the exciplex LIF calibration method, Chapter 5 presents the results and discussion for the quantitative exciplex vapor measurements, Chapter 6 shows the results and discussion for a reacting diesel spray, and Chapter 7 is the conclusion and recommendations. 


\section{Chapter 2. LITERATURE REVIEW}

\subsection{Characteristics of Diesel Spray}

Most diesel spray studies [2-21] have been performed to characterize certain spray parameters that represent the structure of a diesel spray. The main spray parameters are spray tip penetration, spray angle, break-up length (or intact core length), and droplet size. These parameters have been investigated as functions of the following variables:

- $\quad$ Ambient gas conditions, i.e. density, temperature, and pressure

- Injection characteristics, i.e. injected pressure, injection rate shape, and injection duration

- Nozzle orifice configuration, i.e. diameter, aspect (length to diameter) ratio, edge sharpness, contraction ratio, discharge coefficient, and effects for multi-holes spray

- Fuel characteristics, i.e. volatility, temperature, and viscosity

Among the parameters, spray penetration studies were chosen for review since they are relatively well characterized and include the effect of elevated temperature.

\subsubsection{Non-evaporating Spray Penetration Studies}

Diesel spray penetration investigations began as early as the 1920s [5]. Table 2.1 shows a summary of typical correlations for the spray penetration rate. A review in 1972, [6], recommended two relations, those of Wakuri et al. [7] and Dent [8].

Wakuri et al. [7] showed that the relative velocity between the droplets and the air in a spray is negligible when small droplets travel in a dense ambient gas, such as in diesel engines, and the theory of momentum for the spray penetration holds. Based on the 
Table 2.1 Typical correlation for spray tip penetration rate

\begin{tabular}{|c|c|c|}
\hline Ref. & Correlation for Penetration length & Comment \\
\hline $\begin{array}{l}\text { Wakuri } \\
\text { et al. } \\
\text { [7] }\end{array}$ & $S=\left(\frac{\sqrt{\left(2 C_{a}\right)}}{\tan (\theta / 2)}\right)^{0.5}\left(\frac{\Delta P}{\rho_{g}}\right)^{0.25}\left(d_{O} t\right)^{0.5}$ & $\begin{array}{l}\text { Non- } \\
\text { vaporizing } \\
\text { Spray } \\
\text { (1960) }\end{array}$ \\
\hline $\begin{array}{l}\text { Dent } \\
\text { [8] }\end{array}$ & $S=3.07 \cdot\left(\frac{294}{T_{g}}\right)^{0.25}\left(\frac{\Delta P}{\rho_{g}}\right)^{0.25}\left(d_{o} t\right)^{0.5}$ & $\begin{array}{c}\text { Vaporizing / } \\
\text { Non- } \\
\text { vaporizing } \\
\text { (1971) }\end{array}$ \\
\hline $\begin{array}{l}\text { Hiroyasu } \\
\text { et al. } \\
\text { [9] }\end{array}$ & $\begin{array}{ll}S=0.39\left(\frac{2 \Delta P}{\rho_{f}}\right)^{0.5} \cdot t \quad & \text { for } t<t_{b}=28.6 \rho_{f} d_{O} /\left(\rho_{g} \Delta P\right) \quad \text { EQ (2.3) } \\
S=2.95\left(\frac{\Delta P}{\rho_{g}}\right)^{0.25} \cdot\left(d_{O} t\right)^{0.5} & \text { for } t>t_{b}\end{array}$ & $\begin{array}{l}\text { Non- } \\
\text { vaporizing } \\
\text { Spray } \\
\text { (1990) }\end{array}$ \\
\hline $\begin{array}{l}\text { Naber } \\
\text { et al.* } \\
\text { [5] }\end{array}$ & 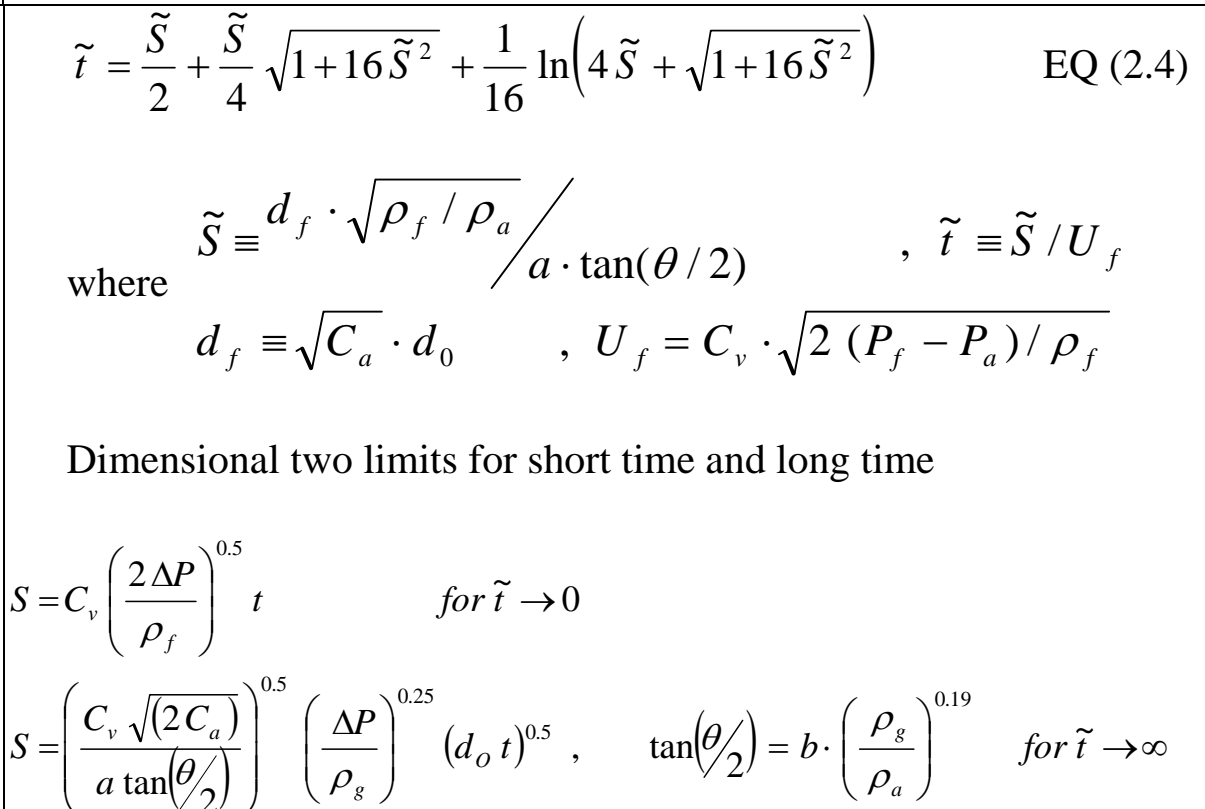 & $\begin{array}{c}\text { Non- } \\
\text { vaporizing } \\
\text { Spray } \\
\& \\
\text { Non- } \\
\text { dimensional } \\
\text { form by } \\
\text { introducing } \\
\text { a scaling of } \\
\text { length and } \\
\text { time } \\
\text { (1996) }\end{array}$ \\
\hline
\end{tabular}

* $C_{v}$ : the velocity coefficient $\left(U_{f}=C_{v} U_{\text {Bernoulli }}\right)$

$C_{a}$ : the area-contraction coefficient $\left(A_{f}=C_{a} A_{\text {orifice }}\right)$

$C_{d}$ : the discharge coefficient $\left(C_{d}=C_{a} C_{v}\right)$ 
momentum theory and experiments, they developed EQ (2.1), and showed a close connection between the spray cone angle and penetration distance through correction of momentum of entrained air. The correlation is a function of nozzle hole diameter, pressure difference between injected fuel and ambient gas, ambient gas density, and spray cone angle, but the effect of gas viscosity is negligible.

Dent [8] developed EQ (2.2) by applying jet mixing theory and correlating the data from cold bombs, hot bombs, and engine tests which had been previously reported by others. EQ (2.2) includes the effect of elevated ambient gas temperature as the factor $\left(294 / T_{g}\right)^{0.25}$. The ranges covered in the correlation included gas temperatures up to 1000 $\mathrm{K}$, gas densities up to $25 \mathrm{~kg} / \mathrm{m} 3$, gas pressures up to $70 \mathrm{bar}$, and injection pressures up to 650 bar. The author showed good agreement with experimental data from a wide range of sources.

Hiroyasu and Arai [9] measured spray tip penetration at various ambient temperatures (22, 150 , and $320{ }^{\circ} \mathrm{C}$ ), ambient pressures (up to 20 bar), injection pressures (70, 100 and 150 bar) and injection durations. The results showed the linear relationship with two different slopes (1 and 0.5 ) between logarithmic expressions of penetration and time. The time at the intersection of the two lines (defined as the break-up time) decreased with an increase in injection pressure. They developed a two-zone model by applying the jet integration theory and their experimental results. EQ (2.3) is composed of the linear part for initial time and the square root part for later time against the breakup time, $\mathrm{t}_{\mathrm{b}}$. The linear part is 0.39 times Bernoulli's velocity while the square root part is similar to EQ (2.2). They also showed that when increasing injection pressure, the Sauter 
mean diameter (SMD) decreased, but SMD also depended on the fuel viscosity (when fuel viscosity exceeded a certain value, SMD increases rapidly).

Naber and Siebers [5] developed a dimensionless relation, EQ (2.4), by introducing the proper scaling for length and time, and following the model by Wakuri et al [7]. The characteristic penetration time and length includes a term for spray angle which accounts for the dependence of penetration on ambient density. The authors showed close agreement between EQ (2.4) and measured non-vaporizing data over a wide range (about twice) of gas density representative of modern diesel technology, shown in Table 2.2. Their results showed that ambient gas density has a significantly larger effect on spray penetration and a small effect on spray dispersion than had been previously reported.

Summarizing, for an early period a spray penetrates linearly with time, and for the later period, it penetrates with square root dependence on time like a steady gas jet. For the linear period, the spray penetration rate is proportional to Bernoulli's velocity. For the later part, all correlations on Table 2.1 agree that the spray length is the same function of orifice diameter (square root) and pressure difference between injected fuel and ambient gas (power of 0.25 ). But, a spray penetrates differently due to the effect of ambient gas density, since EQ (2.1) and EQ (2.4) include the spray angle term as a function of the density ratio of injected fuel and ambient gas. Also, since orifice geometry characteristics can significantly affect liquid lengths [10-13], EQ (2.1) and EQ (2.4) include the discharge coefficient or area-contraction coefficient as well as orifice diameter. The different contributions of ambient gas density and orifice geometry characteristics may 
induce a difference among the correlations when fitting with experimental data over different ranges of operating conditions.

\subsubsection{Vaporizing Spray Experiments under Modern Diesel Engine Conditions}

Table 2.2 summarizes evaporating spray research performed at a typical TDC condition of modern diesel engines.

Browne et al. [14] presented initial data on liquid length penetration in an engine. Three orifice diameters $(0.2,0.25$, and $0.28 \mathrm{~mm}$ ), four fuels (U.K. diesel, toluene, ethanol, and sunflower oil), and two intake temperatures were considered. They showed that a maximum liquid fuel length of 26 to $38 \mathrm{~mm}$ depending on the engine intake conditions and injector hole diameter, i.e., a decrease in the nozzle diameter led to a shorter liquid length. Also, the authors showed that the liquid length was strongly influenced by the vapor pressure characteristics of the fuel.

Kamimoto et al. [15] showed the characteristics of a diesel spray and flame as a function of injection pressure ranging from 30 to $110 \mathrm{MPa}$. They showed that the liquidphase fuel did not penetrate further than $25 \mathrm{~mm}$ at the conditions studied, and the length was independent of injection pressure. Also, the authors showed that as the injection pressure was increased for non-evaporating sprays, the SMD decreased, and the rate of air entrainment increased at the same time. They also showed that higher injection pressure decreases soot concentration in the flame and shortens combustion duration.

Espey and Dec [16] showed the strong effect of TDC temperature and density on the liquid length. Liquid lengths varied from 13 to $30 \mathrm{~mm}$ at the conditions studied. Also, 
the authors showed that liquid-phase fuel penetration length is relatively short, and all the fuel in the main combustion zone is in a vapor phase. The liquid length did not shorten significantly after ignition, and vaporization occurred largely upstream of the combustion zone formed after ignition. The primary source of energy for fuel vaporization is hot air entrained into the spray and not energy from combustion.

Naber and Siebers [17] showed that the effect of vaporization decreases penetration and dispersion by as much as $20 \%$ relative to a non-vaporizing spray. Also, the effect of vaporization decreases with increasing gas density. By an ambient density of $60 \mathrm{~kg} / \mathrm{m} 3$ and for longer penetration distances, the effect of vaporization becomes smaller.

Verhoeven et al. [19] showed that liquid penetration is strongly dependent on gas temperature, gas density, fuel, and injector hole size. Contrary to others observations $[6,10]$, the author showed that the liquid length has a weak positive dependence on the injection pressure (15\% change when increasing the injection pressure from 40 to 150 $\mathrm{MPa})$.

Siebers [2] showed that liquid length decreased linearly with orifice diameter, and it decreases with increasing gas density and temperature with a declining sensitivity to each. The author constructed a scaling law for maximum liquid lengths $(S)$, as follows;

$$
\begin{aligned}
& S=\frac{b}{a} \cdot \sqrt{\frac{\rho_{f}}{\rho_{a}}} \cdot \frac{\sqrt{C_{a}} \cdot d}{\tan (\theta / 2)} \cdot \sqrt{\left(\frac{2}{B\left(T_{a}, P_{a}, T_{f}\right)}+1\right)^{2}-1} \\
& B=\frac{Z_{a}\left(T_{s}, P_{a}-P_{s}\right) \cdot P_{s} \cdot M_{f}}{Z_{f}\left(T_{s}, P_{s}\right) \cdot\left(P_{a}-P_{s}\right) \cdot M_{a}}=\frac{h_{a}\left(T_{a}, P_{a}\right)-h_{a}\left(T_{s}, P_{a}-P_{s}\right)}{h_{f}\left(T_{s}\right)-h_{f}\left(T_{f}, P_{a}\right)}
\end{aligned}
$$


where $a$ and $b$ are constants, $\rho$ is density, $C_{\mathrm{a}}$ is orifice area-contraction coefficient, $d$ is orifice diameter, $\theta$ is full cone angle of the real spray, $B$ is the ratio of the fuel and ambient gas mass flow rates, $T$ is temeprature, $P$ is Pressure, $Z$ is compressibility factor, $M$ is molecular weight, $h$ is enthalpy and as subscripts, $a$ is ambient gas, $f$ is fuel, and $s$ is saturated fuel vapor condition at the liquid length. Since Siebers' work will be referred to extensively in this study, it is shown here in detail.

Figure 2.1 shows a cross-section schematic of the combustion vessel used. It has 35 MPa pressure capacity, and the cubic-shaped chamber is $108 \mathrm{~mm}$ on a side. Two spark plugs and a mixing fan are mounted on the top wall of the chamber to allow rapid combustion and create a homogeneous temperature field.

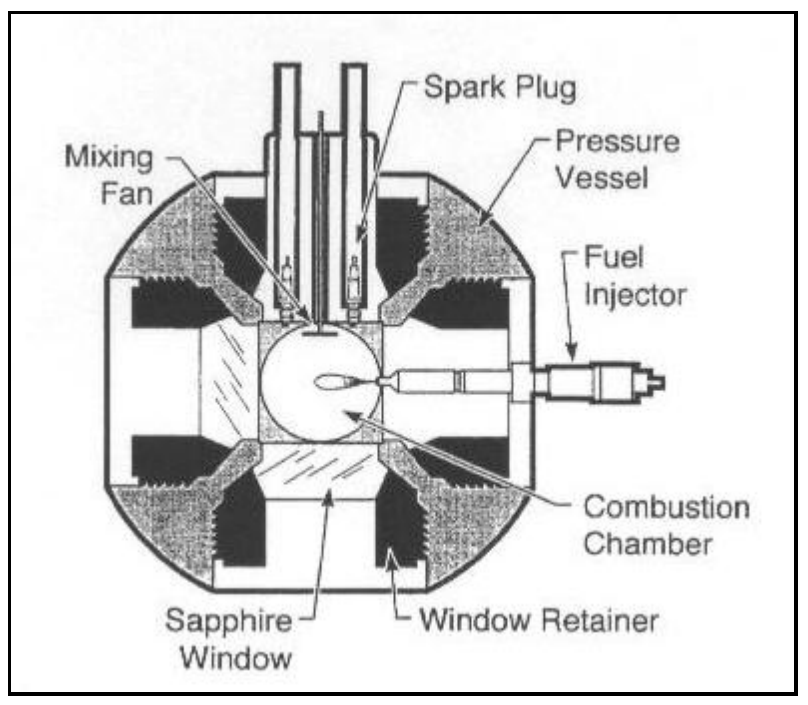

Figure 2.1 Schematic cross-section of the combustion vessel of the combustion Research Facility in Sandia National Laboratories, taken from [17].

Figure 2.2 shows a sample of time averaged Mie-scattered light images superimposed on schlieren images of the spray spreading angle. Figure 2.2 shows that the 
outline of a vaporizing diesel fuel jet has a nearly constant cone angle beginning at the injector and spreading outward downstream. The figure also showed that liquid length shortens and the spreading angle widens as ambient density increases. Based on liquid lengths and spray spreading angles obtained from such images, Siebers developed a scaling law for liquid length, Eq. (2.5). Figure 2.3 shows the schematic of the spray model used to develop the scaling law. The downstream side of the control surface $(\mathrm{x}=\mathrm{L})$ is defined as the axial location in the spray where the fuel has just completely vaporized.

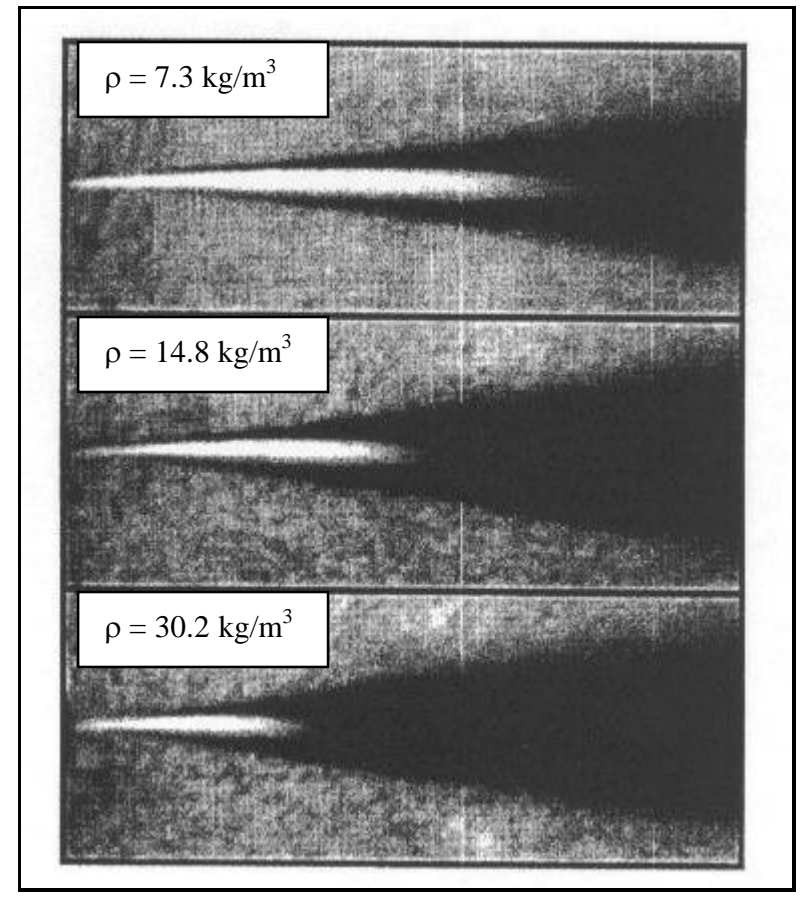

Figure 2.2 Time averaged Mie-scattered light images superimposed on the schlieren images of the spray spreading angle, taken from [17].

Thus, EQ (2.5) is based on mixing-limited vaporization from the standpoint of macroscopic characteristics, which is the law of conservation of energy assuming 
adiabatic saturation. The mixture ratio, $B$ in EQ (2.5), was derived from the mass and energy balances for the control surfaces shown in Figure 2.3, and a real gas equation of the state. Siebers showed a close agreement between the scaling law and measured data over the conditions introduced in Table 2.2. Siebers also suggested that vaporization in sprays from current-technology, direct-injection diesel injectors is limited by the mixing process in the spray, and not by the processes of atomization and the ensuing inter-phase transport of mass and energy at droplet surfaces.

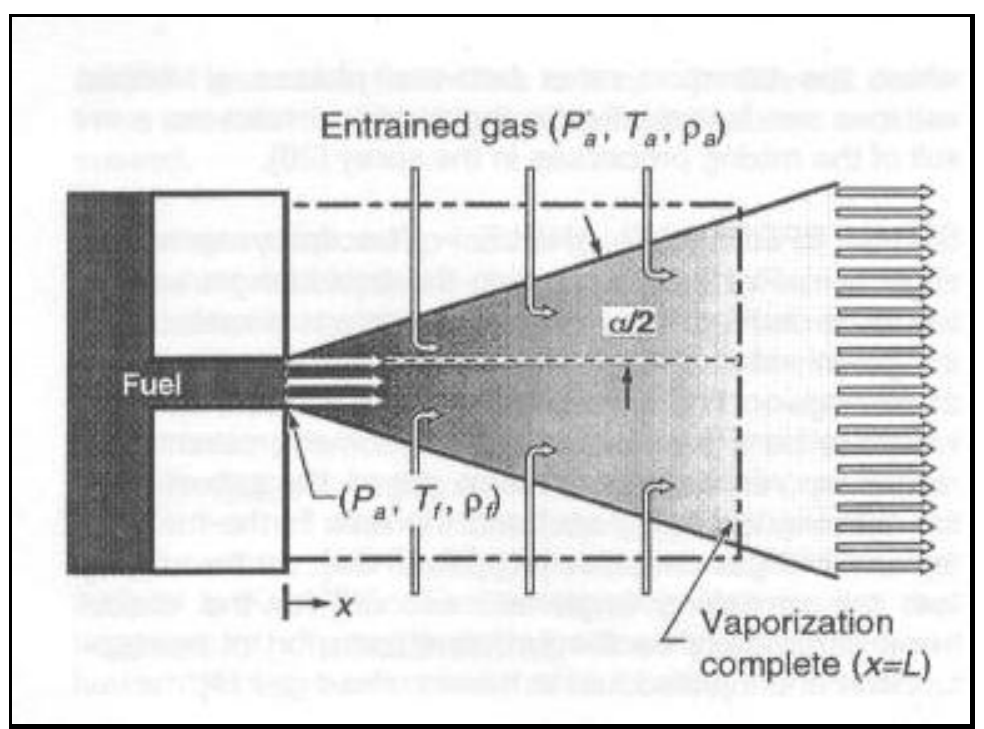

Figure 2.3 Schematic of the idealized spray model, taken from [2].

Figure 2.4 shows the-scaling-law estimated liquid lengths expected in small-bore diesel engines. The parameters used for the small-bore engines were a compression ratio of 19, orifice diameter of $0.16 \mathrm{~mm}$, orifice Ca of 0.84 . For warm engine conditions 
intake temperatures of $45-120{ }^{\circ} \mathrm{C}$, intake pressures of $0.7-2.3 \mathrm{~atm}$, and fuel temperatures of $100{ }^{\circ} \mathrm{C}$ were used. Cold start conditions were intake temperatures of 0 $40{ }^{\circ} \mathrm{C}$, intake pressures of $0.7-1 \mathrm{~atm}$, and fuel temperatures of 0 - $40 \mathrm{C}$. Figure 2.4 shows that liquid-phase fuel impingement on the piston bowl walls might be an issue in small-bore engines.

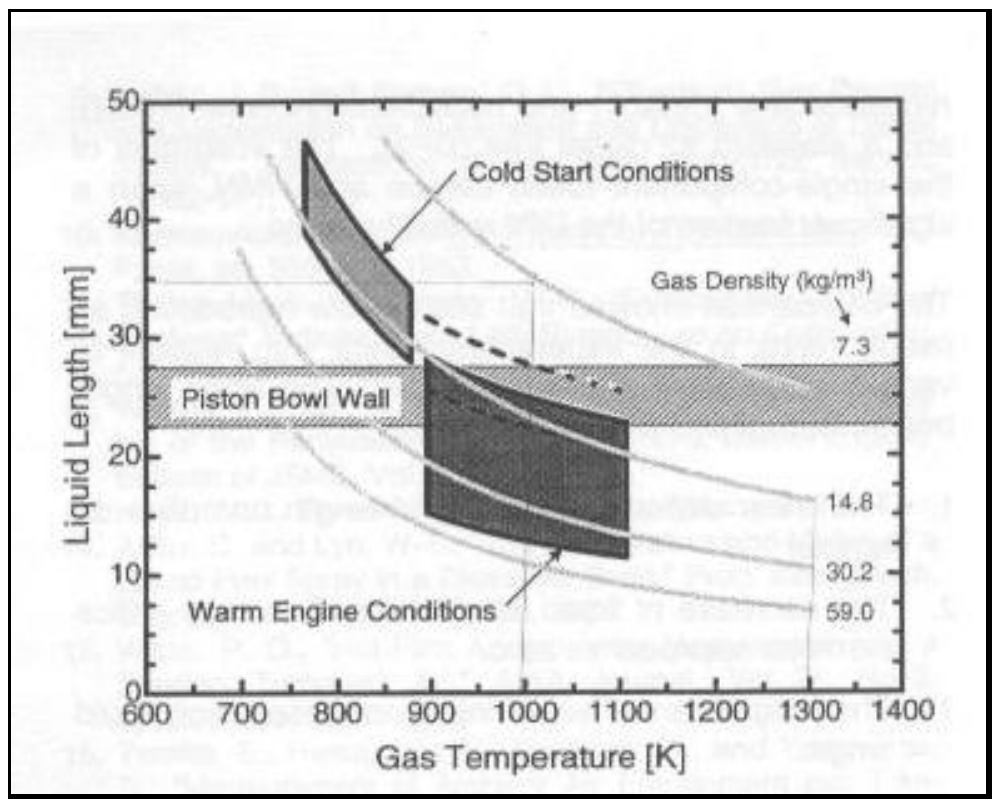

Figure 2.4 Liquid lengths expected in small-bore diesel engines, taken from [2].

Summarizing this section, the liquid-phase fuel of the vaporized diesel spray ceases penetration after an equilibrium is achieved between the evaporation rate and the fuel injection rate. The primary source of energy for fuel vaporization is hot air entrained into the spray. The liquid penetration is strongly dependent on gas temperature, gas 
density, fuel characteristics, and injector hole size. Additionally, the liquid penetration has a weak positive, or no dependence on the injection pressure. The vaporization in sprays from current-technology direct injection diesel engines is believed to be limited by the mixing process.

\subsection{Visualization and Measurement of Vapor-Fuel Concentration}

Direct, backlight, and schlieren photography have been used for the visualization of the liquid and vapor fuel measurements as shown in Table 2.2. However, these techniques can not provide spatially resolved information due to the line of sight measurements through the test section.

Using two-wavelength absorption / scattering techniques, researchers were able to separate the liquid and vapor phases [22,23], but the method used local time-averaged vapor concentrations as well as being an intrinsic line of sight measurement.

Raman spectroscopy was used for single point measurements of the local fuel-air ratio in a diesel combustion chamber [24]. While the ability to quantify Raman scattering is good, single-point measurements require a long time to completely characterize the spatial and temporal fuel distribution. In addition, since diesel sprays are inherently turbulent single point measurements do not povide a completely accurate measurement of fuel concentration. To overcome this limitation, planar laser-based imaging diagnostics were applied.

The exciplex LIF (Excited state Complex Laser-Induced Fluorescence) technique has been most frequently used [25-41] after Melton published it in 1983. This technique 
relies on the spectral shift between liquid and vapor phase fluorescence to allow simultaneous visualization of the vapor and liquid phase in an evaporating spray. However, difficulties arise from the temperature dependence of the monomer fluorescence, fluorescence quenching by oxygen, and cross talk between the monomer (vapor) and exciplex (liquid) fluorescence due to an overlap of the emission spectra.

2-D Mie-scattering techniques have been used with silicone oil [42] or lubricant oil droplets [18] as a marker for the vapor fuel. But, this technique experiences limitations due to the drop size dependence on Mie scattering as well as the limited operating temperature range, which must be less than the boiling point of the additive oil.

2-D Rayleigh scattering has the advantage that it uses no tracer [43-45], but it can not be used to investigate the whole spray structure due to elastic scattering from droplets. Since Espey et al.'s work [43, 44] will be referred to extensively in this study it will be discussed in detail. They acquired planar Rayleigh scattering images of the fuel vapor vapor concentration past the intact liquid length on a plane oblique to the spray axis in an optical-access diesel engine. Figure 2.5 shows a side view of the combustion chamber and the laser-sheet orientation as well as a field of view for Rayleigh scattering. They confirmed that the fuel was entirely vaporized in the region of interest, which is oblique to the spray axis. Also, Table 2.3 shows the specifications of the fuel injector and the engine operating conditions used. The ambient temperature and pressure were estimated to be $1050 \mathrm{~K}$ and $5.0 \mathrm{MPa}$ (a calculated density of $16.6 \mathrm{~kg} / \mathrm{m}^{3}$ ). 


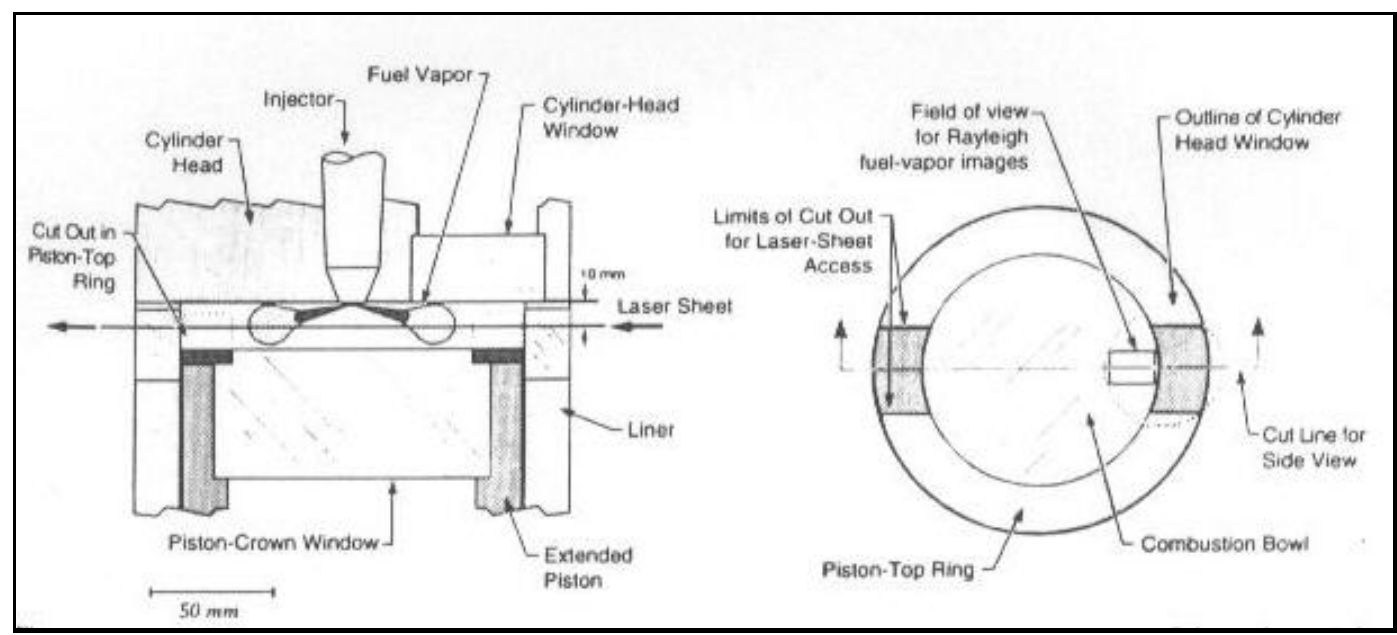

Figure 2.5 Geometry and optical configuration for quantitative 2-D Rayleigh scattering fuel-concentration measurements. Schematic on the left shows a side view of the combustion chamber and the laser-sheet orientation. Schematic on the right shows the top view of the piston and the field of view for Rayleigh fuel vapor images. The piston is shown at the TDC position, taken from [43].

Table 2.3 Specifications of the fuel injector and engine operating conditions, taken from [43]

\begin{tabular}{|c|c|c|c|}
\hline \multicolumn{2}{|c|}{ Specifications of the Fucl Injector } & \multicolumn{2}{|c|}{ Engine Operating Conditions } \\
\hline Type & Cummins CELECT ${ }^{\mathrm{TM}}$ & Engine speed & $1200 \mathrm{cpm}$ \\
\hline \multirow[t]{2}{*}{ Design } & \multirow{2}{*}{$\begin{array}{l}\text { Closed-nozzle, } \\
\text { unit injector }\end{array}$} & Intake air temperaturc & $433 \mathrm{~K}\left(160^{\circ} \mathrm{C}\right)$ \\
\hline & & Intake air pressure & $206 \mathrm{kPa}$ (absolute) \\
\hline Number of holes & 8 , uniformly spaced & Water temperature & $95^{\circ} \mathrm{C}$ \\
\hline Hole diameter & $0.194 \mathrm{~mm}$ & Oil temperature & $95^{\circ} \mathrm{C}$ \\
\hline \multirow{2}{*}{$\begin{array}{l}\text { Length/diameter } \\
\text { of holes }(I / d)\end{array}$} & \multirow[b]{2}{*}{4.1} & Firing rate & Every 20th cycle \\
\hline & & Start of injection & $11.5^{\circ} \mathrm{BTDC}$ \\
\hline \multirow{2}{*}{$\begin{array}{l}\text { Angle of fuel-jet axis } \\
\text { (from horizontal) }\end{array}$} & & Fuel injected per cycle & $0.0857 \mathrm{ml}$ \\
\hline & $14^{\circ}$ & Average equivalence ratio & 0.25 \\
\hline & & Peak injection piessure & $00 \mathrm{Mina}$ \\
\hline
\end{tabular}


Espey et al. showed the quantitative fuel distribution in the leading portion of the fuel jet just prior to ignition, i.e. at the time of first indicated heat release, as shown on Figure 2.6. The first image in Figure 2.6 is based on the isothermal calculation, and the

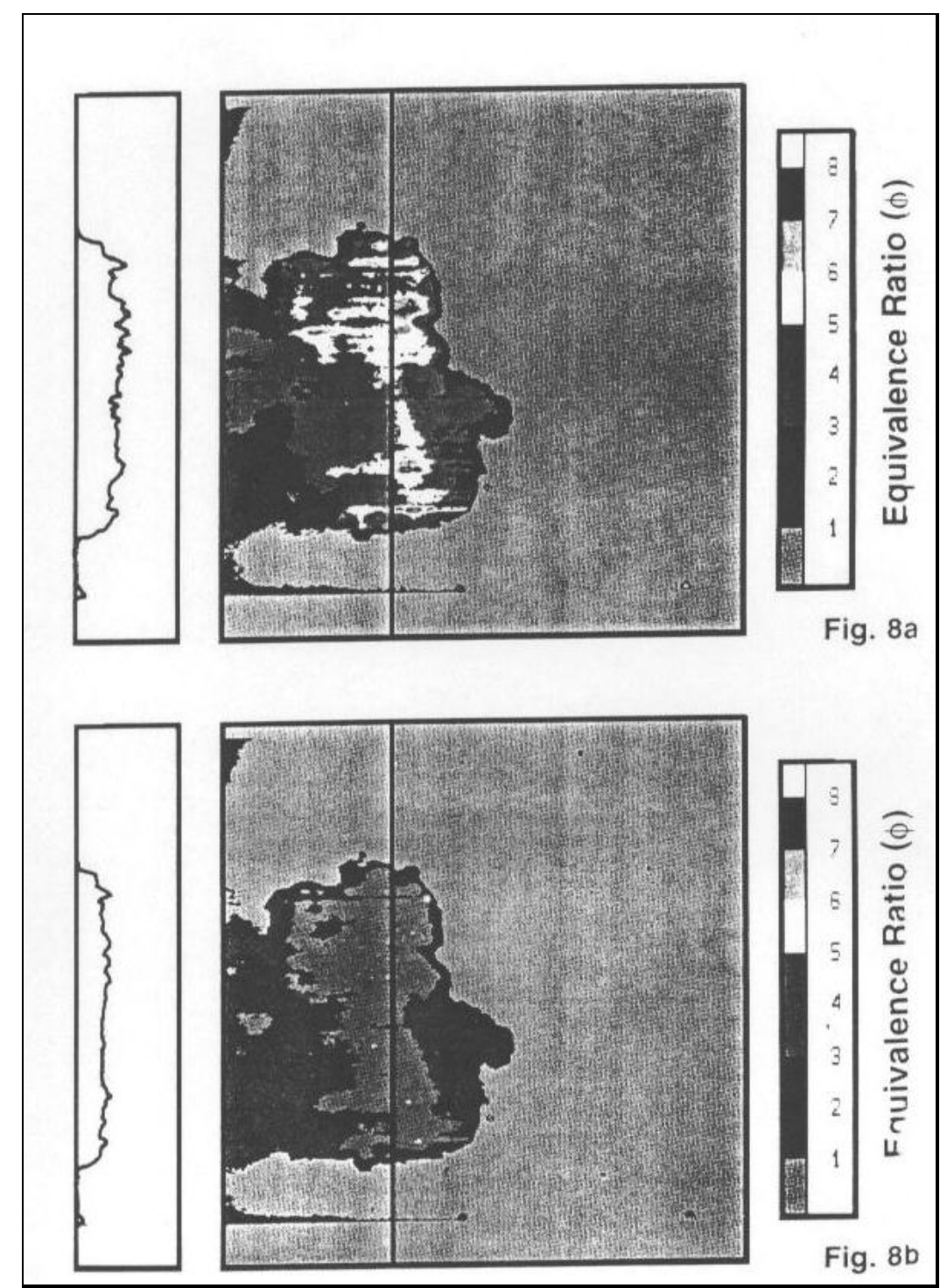

Figure 2.6 Quantitative images of equivalence ratio of leading portion of diesel jet at $0.63 \mathrm{~ms}$ ASI. The top image is based on isothermal calculation, bottom image on adiabatic mixing assumption, taken from [44]. 
second image is computed using the adiabatic mixing assumption. These images show that the fuel and the air are relatively well mixed throughout the cross section of the leading portion of the diesel jet. The equivalence ratio within the jet generally ranges from 2 to 4 . As clearly indicated by intensity profiles obtained along the black line, the edges of the jet are well defined with the signal level rising sharply from air level up to equivalence ratio of 3 to 4 . Similar observations can be made at the front of the jet.

Figure 2.7 shows the temperature distribution obtained from the adiabatic mixing assumption, and shows that a significant temperature decrease occurs in some portions of the jet (300 K drop from ambient temperature in some locations). These results of the quantitative fuel distribution assisted Dec [1] to propose a phenomenological description of DI diesel combustion.

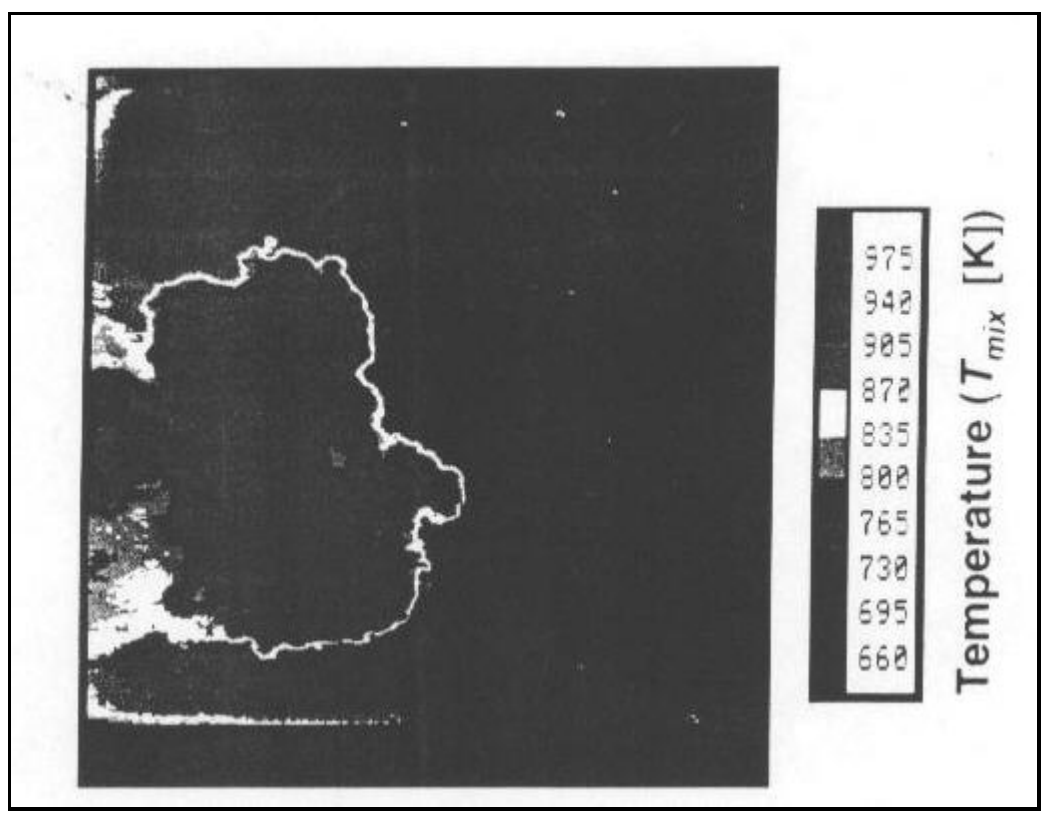

Figure 2.7 Temperature distributions obtained from adiabatic mixing approximation, taken from [44]. 
Among the mentioned techniques, the exciplex LIF technique with TMPD/naphthalene dopant was selected for this study as the best tool to quantitatively investigate the fuel vapor distribution, and qualitatively investigate the liquid fuel extent for the whole spray structure. The following section reviews research on quantitative fuel vapor concentration measurements using the exciplex LIF technique.

\subsection{Exciplex LIF}

\subsubsection{Photophysics}

The exciplex LIF systems are based on the following reaction [25];

$$
M^{*}+G \Leftrightarrow E^{*}
$$

" $M^{*}$ is the first excited singlet state of the monomer $M$, typically an unsaturated olefin or aromatic. $G$ is an appropriately chosen ground state reactant. The exciplex, $E^{*}$, is in a reversible equilibrium with $M^{*}$ and $G$. By setting the concentration of $G$ in the liquid phase sufficiently high, the exciplex, $E^{*}$, becomes the predominant emitter. In the vapor, the emission from $M^{*}$ becomes predominant because of the much less stable exciplex and the lower $G$ concentration. The exciplex, $E^{*}$, is red-shifted with respect to $M^{*}$ [25]”. Therefore, two dopants are added to the fuel in the exciplex technique; for diesel fuel experiments TMPD (tetramethyl-p-phenylene-diamine) and naphthalene are the most common dopants used. The monomer, TMPD (as $M$ ), absorbs the laser light and directly fluoresces in the vapor phase. In the liquid phase the excited monomer preferentially reacts with the second dopant, naphthalene (as $G$ ), to form an excited complex, the exciplex. The fluorescence from the exciplex is red-shifted from the monomer 
fluorescence by an amount equivalent to the binding energy. The peaks of the TMPD fluorescence $(380 \mathrm{~nm})$ and the exciplex $(470 \mathrm{~nm})$ emissions are sufficiently separated to act as markers for the vapor and liquid phases respectively. The photophysical processes of the exciplex fluorescence system are shown in Fig. 2.8. There is some spectral overlap, but with appropriate filters the liquid and vapor fuel can be separately visualized.

After reading through the above general description concerning photophysics, questions about the mechanism which creates dominance of the monomer fluorescence in the vapor phase as well as that of the exciplex fluorescence in the liquid phase arises. Figure 2.9 can help answer this question using the concept of "intermolecular distance". Also from the figure, the red shift of the exciplex fluorescence compared to the monomer fluorescence may be higher than the binding energy by the amount equivalent to the Coulomb repulsion potential.

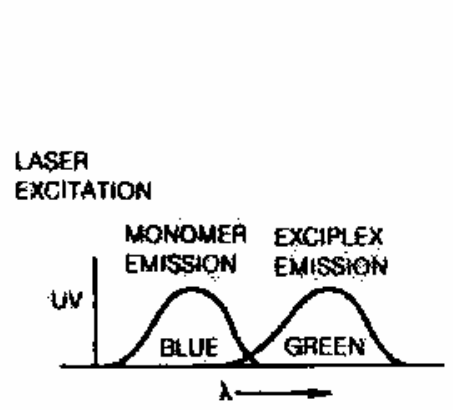

(a)

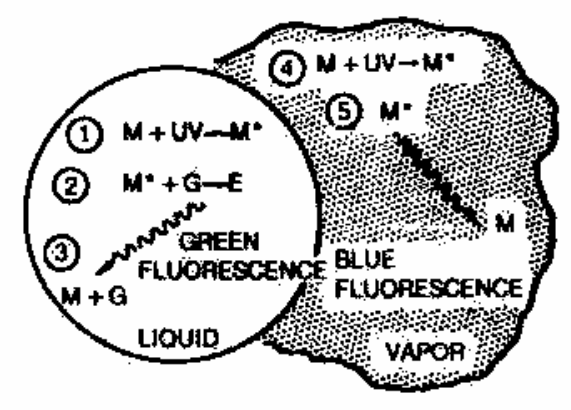

(b)

Figure 2.8 Laser induced exciplex fluorescence system, (a) separate wavelength for fuel liquid / vapor visualization, (b) photophysical processes, taken from [46]. 


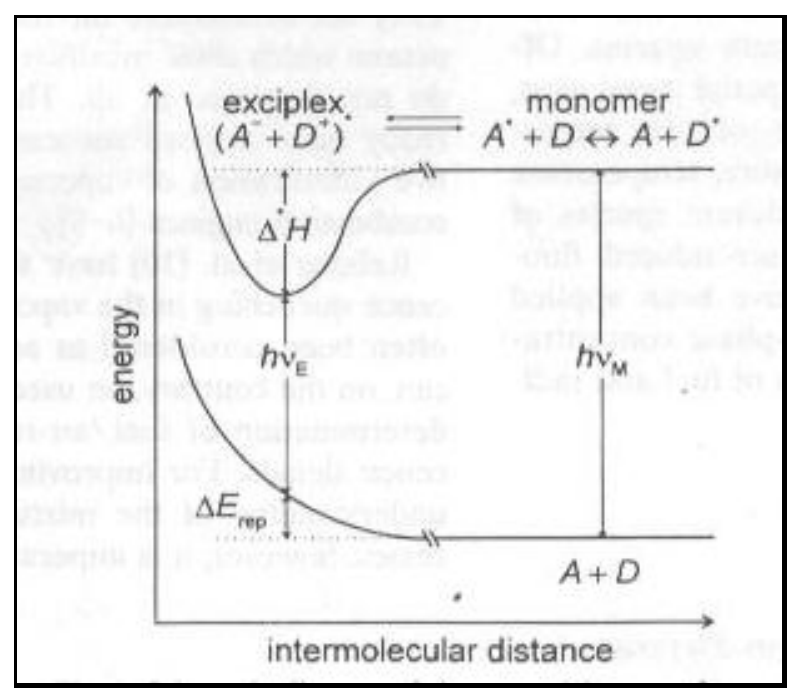

Figure 2.9 Schematic diagram of the potential energy for an exciplex system, where $\Delta^{*} \mathrm{H}$ is the binding energy of an exciplex, $\Delta \mathrm{E}_{\text {rep }}$ is the Coulomb repulsion potential of the two ground state molecules, the difference of $h v_{M}$ and $h v_{E}$ is responsible for the red shift of the exciplex fluorescence compared with the monomer fluorescence, taken from [40].

\subsubsection{Exciplex LIF Application to Engine Sprays}

Several studies have applied the exciplex technique to diesel sprays [26-37].

Rotunno et al. [26] presented a direct calibration procedure for the TMPD vapor phase concentration in the range from $313 \mathrm{~K}$ to $443 \mathrm{~K}$ using a known amount of TMPD/hexane solution in a heated cuvet assembly. They quantitatively showed the transient behavior of the vapor and liquid phases in an evaporating spray. They also showed the spectra of the liquid exciplex fluorescence changes with respect to temperature; its peak wavelength was reported to decrease about $25 \mathrm{~nm}$ as the temperature increases from $338 \mathrm{~K}$ to $532 \mathrm{~K}$. It was also shown that the fluorescence depends on droplet mass only for small droplets with optical densities up to about 2. 
Felton et al. [30] applied the technique to a hollow-cone spray in a two-stroke engine. For the TMPD calibration, a steady state method was applied with a temperaturecontrolled cell containing an excess of condensed phase TMPD. They reported that their TMPD vapor pressure measurements are about four times higher than those of Melton [25], and explained this discrepancy was most likely caused because the value for the TMPD absorptivity given in [47], which is for TMPD in a cyclohexane solution at room temperature whereas their measurements are in the vapor phase at an elevated temperature. Then, they compared the fluorescence measurement with the injected total mass after the end of injection, and they found an overestimation of vapor concentration at TDC. They attributed the reason for this discrepancy to the temperature dependence on the TMPD fluorescence since the absorption of the TMPD dopant was observed to increase sharply as the temperature exceeded $500 \mathrm{~K}$ as shown on Figure 2.10. Therefore, they concluded that quantitative measurement of vapor phase fuel concentration at temperatures above $500 \mathrm{~K}$ would require measurement of the local gas temperature.

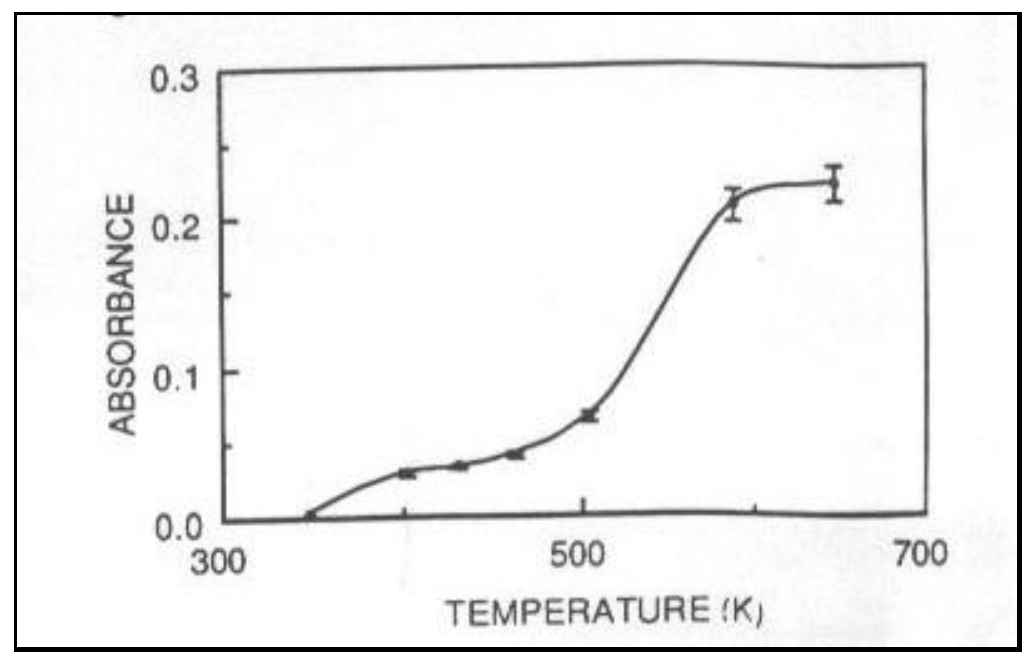

Figure 2.10 TMPD absorption at 355nm versus temperature, taken from [30]. 
Yeh et al. [32] reported on the quantitative fuel vapor concentration in a rapid compression machine. It was shown that thermal decomposition of TMPD during the injection and vaporization time, $10 \mathrm{~ms}$, was negligible at $2.0 \mathrm{MPa}$ and $750 \mathrm{~K}$. They calibrated the TMPD fluorescence intensity in a range from 500 to $800 \mathrm{~K}$. The method to achieve a known TMPD concentration was as follows. First, a TMPD/decane solution was injected into the chamber at BDC, then the TMPD vapor was allowed to be completely mixed with the ambient nitrogen gas, and finally the mixture was rapidly compressed (within $25 \mathrm{~ms}$ ) to form a high temperature and high pressure atmosphere. They showed that the absorbance of TMPD vapor was minimally affected by temperature, contrary to the result by Felton (see Figure 2.10 and 2.11). They attributed this discrepancy to the effect of thermal decomposition since Felton's calibration system had a finite (not fast) heating time. They also showed that the TMPD fluorescence is

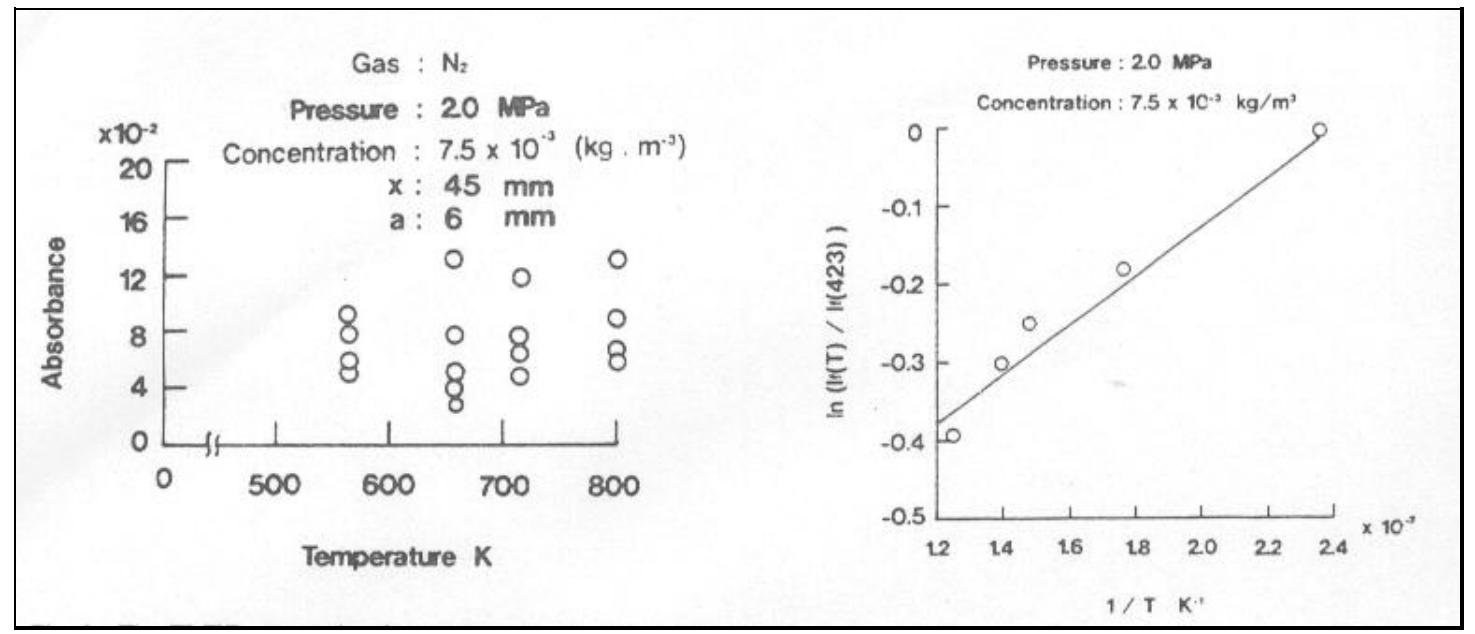

Figure 2.11 TMPD vapor absorbance versus temperature (left), and the calibration curve of fluorescence intensity versus temperature (right), taken from [32]. 


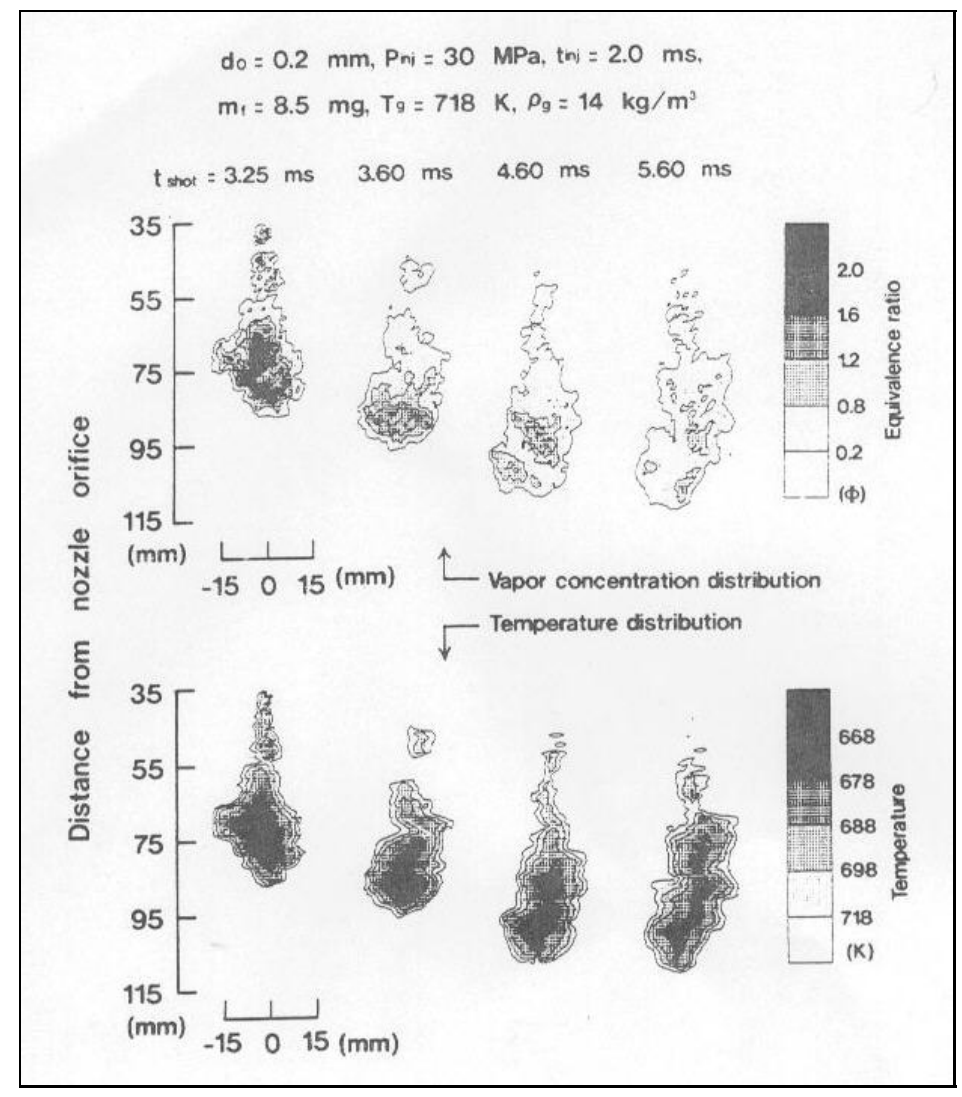

Figure 2.12 2-D fuel vapor concentration and temperature distribution in an evaporating spray, taken from [32].

independent of ambient pressure. Figure 2.12 shows the results of 2-D equivalent ratio and mixture temperature distributions in a transient evaporating spray after the end of injection. The injection pressure was $30 \mathrm{MPa}$ and the injection duration was $2.0 \mathrm{~ms}$. The images were acquired after the injected liquid fuel completed evaporation. At $1.25 \mathrm{~ms}$ after the end of the injection, the center region of the spray has an equivalence ratio of 2, and it decreases in the periphery of the spray. At a later time, the spray proceeds further in the axial direction the equivalence ratio becomes with more uniformly distributed with a value less than 1 . The temperature of the richest mixture is $50 \mathrm{~K}$ lower than the ambient 
gas. The authors assessed the accuracy of their measurements by comparing the total mass of the fuel vapor calculated from the measured 2-D fuel vapor concentration with the injected fuel amount.

Senda et al. [35] applied the exciplex method to an impinging spray in a heated chamber with a temperature of $700 \mathrm{~K}$ and a pressure of $2.5 \mathrm{MPa}$. The vapor concentration was assessed quantitatively by applying Lambert-Beer's law to the measured fluorescence intensity, and by considering the quenching process of the fluorescence emission by the fuel concentration over the temperature range from $550 \mathrm{~K}$ to $700 \mathrm{~K}$. For calibration, fuel of a known TMPD concentration was injected into an inlet hole of a cell installed on the hot surface inside the heated chamber. The liquid fuel vaporized quickly and mixed completely in the time of $20 \mathrm{~ms}$. They showed that the attenuation of the laser sheet intensity in the vapor phase was significant by using the absorption coefficient by Berlman [47], while most studies have regarded the light extinction effect to be small in the vapor phase (Melton [25] estimated the incident intensity decrease as 6\% per 1cm path for a large TMPD vapor concentration of $1.4 \times 10^{-5} \mathrm{~g} / \mathrm{cm}^{3}$, which is about $1.4 \%$ by weight in air). Figure 2.13 shows the temporal changes in the vapor concentration, the mixture temperature and the liquid fluorescence intensity. The vapor concentration has equivalence ratios between 0 and 2. The temperature has a range of 500 and $700 \mathrm{~K}$. The authors explained that the higher concentration region exists at the peripheral part of the wall spray flow, where the spray height is a maximum. They suggested that the mixing between the droplets or dense vapor and surrounding gas is increasing in the peripheral region with time, owing to the wall jet vortex. 

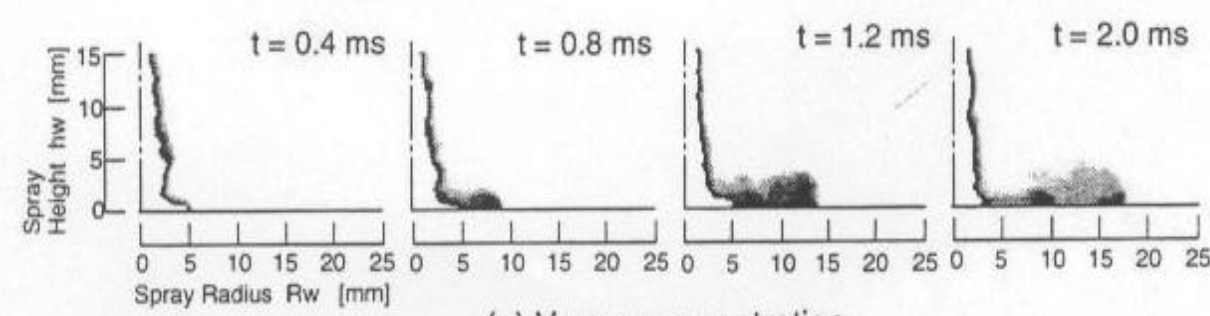

(a) Vapor concentration
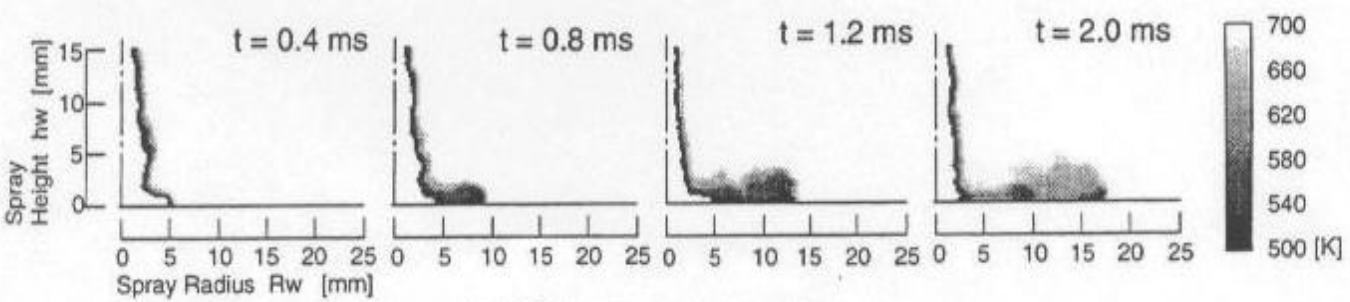

$8.9, \lambda=0.5$

$7.5, \lambda=0.6$

$6.1, \lambda=0.7$

$4.6, \lambda=0.9$

$3.2, \lambda=1,4$

$1.8, \lambda=2.5$

$0.4, \lambda=12$

$\left[\mathrm{mol} / \mathrm{m}^{3}\right]$

(b) Mixture temperature
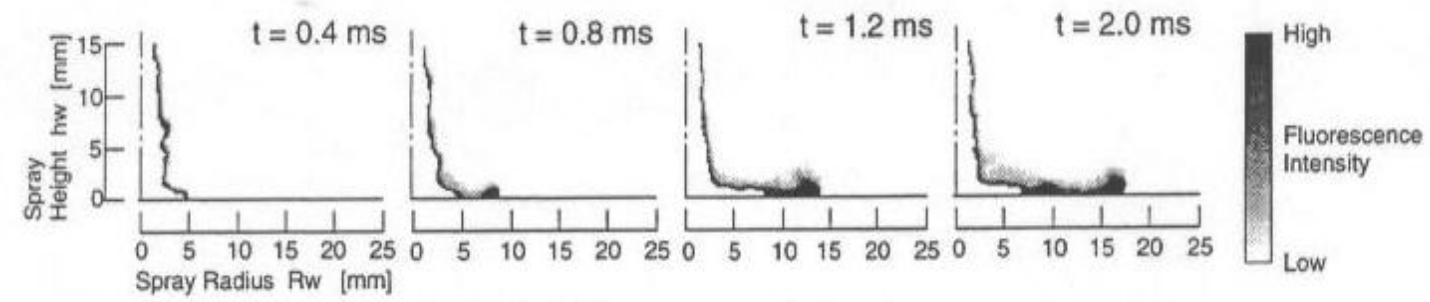

(c) Liquid fluorescence intensity

Figure 2.13 Change in impinging spray with elapsed time from injection, taken from [35].

In spite of these efforts, quantitative applications of the exciplex technique, especially at the TDC conditions experienced in HSDI engines where the gas density can be greater than $25 \mathrm{~kg} / \mathrm{m}^{3}$ and the temperature is near $1000 \mathrm{~K}$, have been limited. As well, the spray structure at the ignition time needs investigation. The exciplex LIF technique applied for this study will be described in Chapter 4 . 


\section{Chapter 3. EXPERIMENTAL SETUP}

A general schematic of the apparatus is shown in Figure 3.1. The major systems are circled in the figure. The experimental apparatus consists of the constant-volume combustion-type spray chamber system (§ 3.1), the high-pressure fuel injection system (§3.3), the data acquisition and control systems (§3.4), and the exciplex imaging system (§3.5). This chapter is divided into five main sections. § 3.1, 3.3, 3.4 and 3.5 describe each system, and $\S 3.2$ describes the verification of the spray chamber system performance.

\subsection{Constant-volume Combustion-type Spray Chamber}

A combustion-type spray chamber uses premixed combustion and the sequential cooling process in the constant volume chamber to match a state representative of the conditions in a diesel engine at the start of fuel injection. When compared to either a heated bomb or a rapid compression machine, the combustion-type spray chamber may be more compact and more easily fitted with complicated optical and probe accesses [48]. To simulate TDC conditions of a current DI diesel engine, one can refer to the experimental conditions of Table 2.2. As well, Table 3.1 shows a calculation with the assumption of a compression ratio of 18 and isentropic compression of air. Density and temperature at TDC depend on the initial or boost pressure and the initial temperature respectively. In-cylinder gas pressure has been shown to have practically no influence on the injected quantities, but gas density and gas temperature are known to be the most 
important parameters to simulate a TDC condition [16]. From the table, density and temperature at TDC are over $20 \mathrm{~kg} / \mathrm{m}^{3}$ and $900 \mathrm{~K}$ respectively.

With respect to excellent flammability and low ignition energy at very dilute conditions,

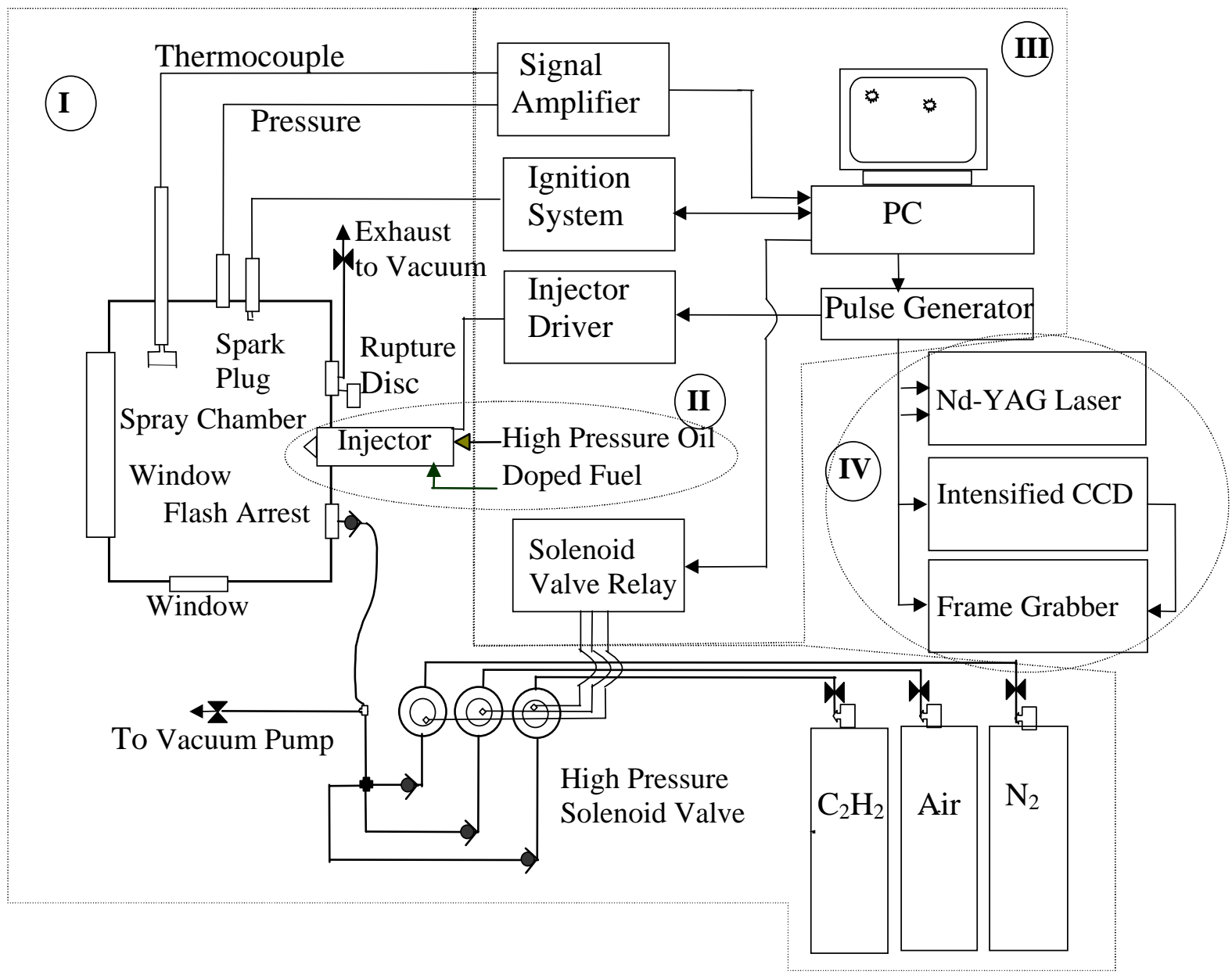

Figure 3.1 Schematic of experimental apparatus composed of the constant volume combustion-type spray chamber system (I), the high-pressure fuel injection system (II), the data acquisition and control system (III), and the exciplex imaging system(IV). 
Table 3.1 Calculated TDC conditions

\begin{tabular}{|c|c|c|c|c|}
\hline $\mathrm{P}_{\mathrm{BDC}}[\mathrm{atm}]$ & $\mathrm{T}_{\mathrm{BDC}}[\mathrm{K}]$ & $\rho_{\mathrm{TDC}}\left[\mathrm{kg} / \mathrm{m}^{3}\right]$ & $\mathrm{P}_{\mathrm{TDC}}[\mathrm{atm}]$ & $\mathrm{T}_{\mathrm{TDC}}[\mathrm{K}]$ \\
\hline 1 & 298 & 21.2 & 54 & 890 \\
\hline 2 & 298 & 42.4 & 108 & 890 \\
\hline 1 & 330 & 20.0 & 54 & 972 \\
\hline
\end{tabular}

either hydrogen or acetylene can be used as fuel for the pre-charge. Figure 3.2 shows calculated equilibrium pressure and temperature with respect to the amount of different diluents obtained from the STANJAN program. There are some constraints for selecting the composition of the pre-charge. The equilibrium pressure should not exceed the design pressure of the chamber, $13.8 \mathrm{MPa}$, and the equilibrium temperature should sufficiently exceed the selected temperature, $1000 \mathrm{~K}$. Using high diluent levels, both conditions can be satisfied with both hydrogen and acetylene. But, reliable ignition must be achieved at the selected composition of pre-charge.
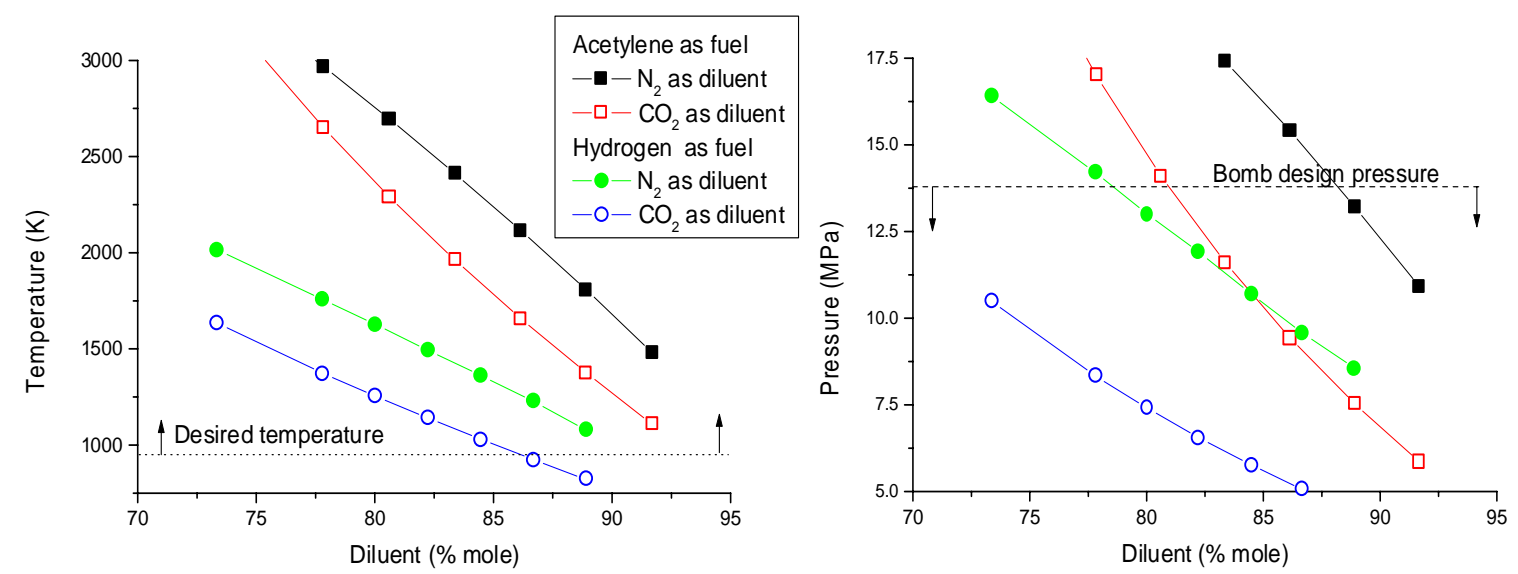

Figure 3.2 Equilibrium pressure and temperature at the chamber gas density of $25 \mathrm{~kg} / \mathrm{m}^{3}$ results from the STANJAN program with respect to combination of fuel and inert gas. 
The use of premixed combustion and the sequential cooling process in the constant volume spray chamber is similar to that of Oren et al. [48], Naber and Siebers [5,17] and Verhoeven et al.[18]. Compared to other combustion chambers, this system does not employ a mixing fan to increase the combustion rate, the chamber walls are not heated to prevent water condensation, and the premixed charge is prepared directly within the chamber rather than in an external tank. However, these systems were found not to be necessary in this configuration as repeatable and rapid combustion was achieved as will be described in $\S 3.2$.

\subsubsection{Modification from the Engine-Fed Chamber}

The engine-fed combustion chamber designed by Feierisen [49] has been modified for this study. Figure 3.3 shows a schematic cross-section of the constantvolume combustion-type spray chamber. The chamber is disk-shaped, with a 4 inch diameter and 2 inch depth. The designed maximum pressure was 138 bar based on limitations of the large quartz window, which is $101.6 \mathrm{~mm}$ in diameter and $50.4 \mathrm{~mm}$ thick. The main modified parts were mounting adapters for the HEUI 90 injector, the large quartz window, a small sapphire side window, and 4 small ports for gas inlet and exhaust.

The chamber was originally sealed with rigid copper gaskets that required a significant amount of bolt loading for effective sealing. Windows are relatively expensive and quite easily damaged against uneven loading and pre-loading fatigue. To protect the 


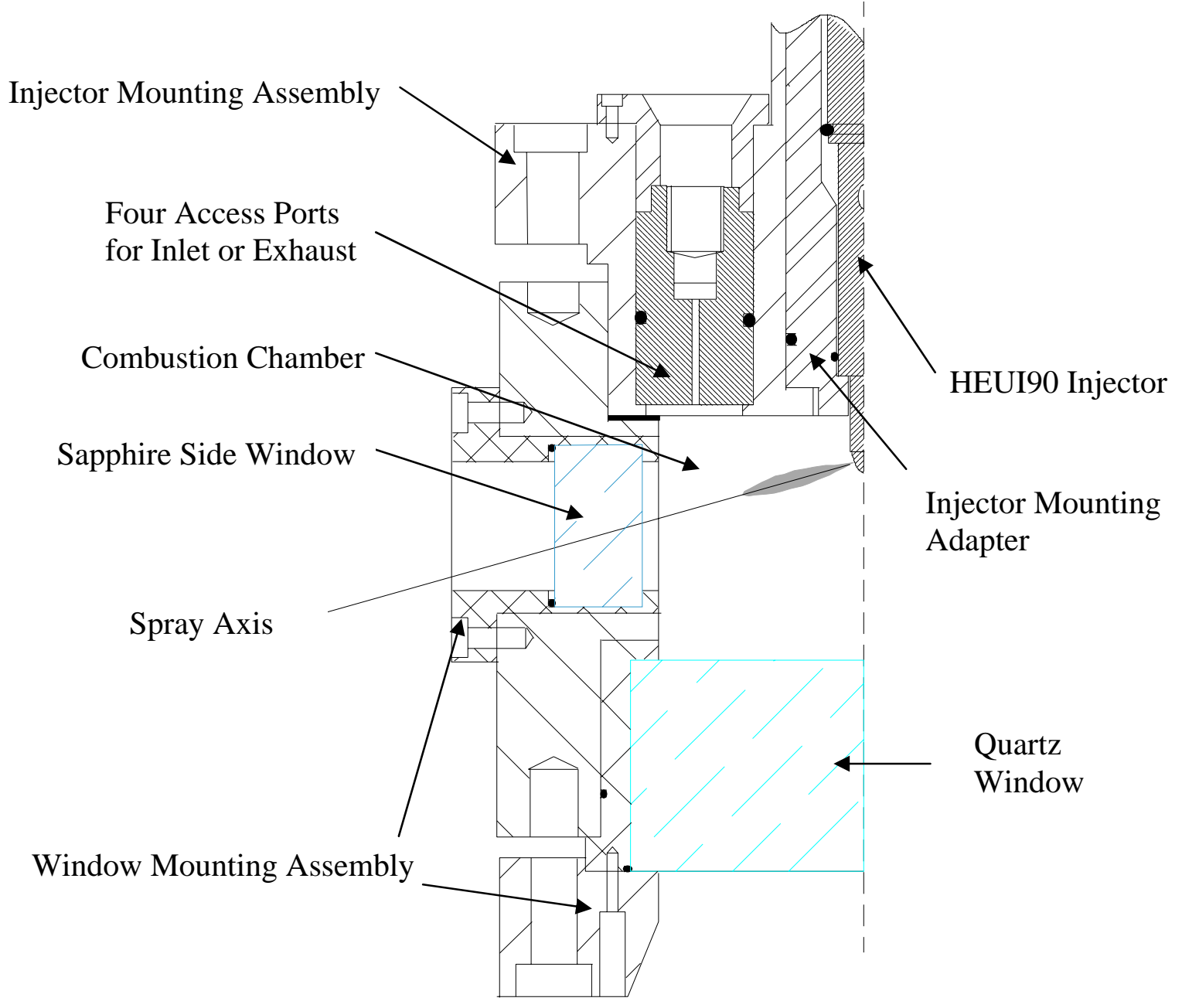

Figure 3.3 Schematic cross-section of the constant-volume combustion-type spray chamber.

windows and achieve better sealing, the copper gaskets were replaced with Viton material o-rings of 75 or 90-duro hardness. To avoid burning and extrusion of the o-rings, the diametrical clearance gaps were reduced, as well as using the higher hardness Viton material.

The large quartz window was fixed into a window mounting assembly since a major difficulty in operating the combustion chamber was associated with removing, 
cleaning and resealing it. With this system the window could be removed and cleaned without breaking the seal of the quartz.

\subsubsection{Safety Concerns}

A rupture disc relief valve (LaMot 316 SS, 16LS3-25M), designed to rupture at 11.5 $\mathrm{MPa}$ and $100{ }^{\circ} \mathrm{C}$, was installed to prevent over-pressurization. The time to reach peak pressure is about $70 \mathrm{~ms}$ so a fast response time was required from the relief valve as well as large area for flow. The maximum surface temperature was required for choosing the burst pressure of the diaphragm as well as for general o-ring selection. Using a temperature indicating crayon (Omegaprobe temperature test kit), the peak in-chamber surface temperature was estimated to be less than $100^{\circ} \mathrm{C}$.

Fine metal mesh screens were inserted into the inlet and exhaust ports as flash arrestors in order to quench any propagating flame. A check valve was used on the inlet port in order to seal against back flow of high temperature combustion products into the gas cylinders as well as restricting the chamber volume to $400 \mathrm{cc}$.

Finally, the chamber was fully covered with a safety shield made of carbon steel and Lexan.

\subsubsection{Ignition System}

The ignition system used was a production Mercury Marine spark ignition system, which is a CDI (Capacitive Discharge Ignition) type, providing $80 \mathrm{~mJ}$ of spark energy, and $70 \mu$ sec spark duration. The electrode gap of the spark plug was about $1 \mathrm{~mm}$. 


\subsubsection{Preparation of Pre-Charged Mixture}

Solenoid valves (ASCO Red-Hat II, 8262G19-120V) were used to meter the gas delivery to the chamber to obtain the desired premixed charge composition. Check valves were required downstream of the solenoid valves to prevent any back flow due to high combustion pressure. A quad solid-state relay (SSRQ-240D20) was used to electrically switch the solenoid valves.

\subsubsection{Pressure Measurement}

A piezoelectric transducer (Kistler 7061) and a charge amplifier (Kistler 5004) were used for pressure measurement. A dead weight tester was used to calibrate the system up to $15 \mathrm{MPa}$ with a long setting time constant. To minimize the possibility of error induced by the thermal shock of the flame, a thin ablative coating of hightemperature RTV silicon sealant was applied on the front surface of the transducer.

\subsubsection{Temperature Measurement}

To measure the transient temperature of the premixed combusted gases in the bomb with a fast response and high temperature range (2000 K) a $50 \mu \mathrm{m}$ (0.002 inch) diameter R-type (Pt - 13\% Rh/Pt) thermocouple was used. The signal conditioner was made with a AD595CD chip (Analog Device Inc.), which has an acquisition rate of 15 $\mathrm{kHz}$ and cold junction compensation. The time constant of the thermocouple was estimated to be on the order of thirty milliseconds. Since the AD595CD chip is originally designed for a K-type thermocouple with a range of -200 to $1250 \mathrm{C}$, to use an R-type 
thermocouple an increased gain was needed, and this was accommodated by adding a 70 $\mathrm{k} \Omega$ resistance in series. Two junctions between the thermocouple and supporting wires (0.015 inch in diameter with same material) were fabricated using a stored energy spot welder. The bead size of thermocouple was about $100 \mu \mathrm{m}$. The thermocouple was calibrated using a $12^{\text {th }}$ order polynomial fit to the NIST R-type thermocouple chart [50].

To interpret the real gas temperature from a thermocouple bead temperature, errors from catalytic effects, heat transfer effects and the finite thermocouple time constant must be compensated. Platinum and its alloys tend to react with chemically active species, i.e. act as a catalyst for exoergic chemical reactions. Premixed flames are particularly prone to this type of error due to the recombination of $\mathrm{OH}$ radical in the thermal boundary layer around the wire. To prevent error from catalytic effects, all thermocouples used were silicon coated since catalytic heating can be minimized with coating the wires with a suitable non-catalytic material [51]. The compound used was Hexamethyl Disioxane, $\left(\mathrm{CH}_{3}\right)_{3}$ SI O Si $\left(\mathrm{CH}_{3}\right)_{3}$, which was coated by “flame plating”. To minimize error from thermal conduction, the length-to-diameter ratio of the thermocouple used was about 200 (50 $\mu \mathrm{m}$ in diameter and roughly $10 \mathrm{~mm}$ in length) [51].

The true gas temperature, $T_{g}$, was obtained by correcting the thermocouple for its limited response time and radiation effects using the following relation [52]

$$
T_{g}=T_{T C}+\tau \cdot \frac{d T_{T C}}{d t}+\frac{\sigma \varepsilon}{h} \cdot\left(T_{T C}^{4}-T_{\text {wall }}^{4}\right)
$$

where $T_{T C}$ is the measured thermocouple temperature, $\tau$ is the time constant of the thermocouple with assuming cylinder shape across the flow field $(=\rho c d / 4 h), \sigma$ is the 
Stefan-Boltzman constant, $\varepsilon$ is the emissivity, $h$ is the convective heat transfer coefficient, $c$ is specific heat, and $d$ is the diameter of the thermocouple.

Neglecting the last term (approximately room temperature), then Equation (3.1) becomes

$T_{g}=T_{T C}+\tau \cdot\left(\frac{d T_{T C}}{d t}+\frac{4 \sigma \varepsilon}{\rho c d} \cdot T_{T C}^{4}\right)$

The time constant, $\tau$, was estimated by assuming that the peak gas temperature determined by Equation (3.2) was the adiabatic flame temperature of the mixture. The emissivity, $\varepsilon$, is difficult to determine due to its dependence on temperature and wavelength. The emissivity value used in this work was 0.095 , following the results of Ieda [53] who used the same silicon coated R-type thermocouple with a temperature of $1700 \mathrm{~K}$.

\subsection{Verification of the Combustion-type Spray Chamber}

\subsubsection{Premixed reactants}

Figure 3.4 shows the main events in the combustion-type spray chamber from the spark ignition to the end of injection. The fuel of the precharge was hydrogen, and the window contamination was not negligible as seen in the figure.

Figure 3.5 shows the effect of two different fuels, hydrogen and acetylene, on the window contamination. In Fig. 3.5 (a) the spray image is not clear due to water condensation by the hydrogen combustion. However, Fig. 3.5 (b) obtained using acetylene combustion shows a clear spray image. The lower corner of Fig. 3.5 (b) has some residual liquid fuel remaining from the previous run, but this can be eliminated by 


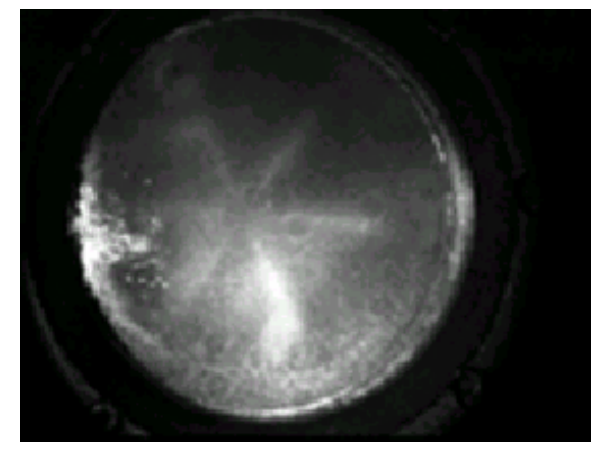

(a)

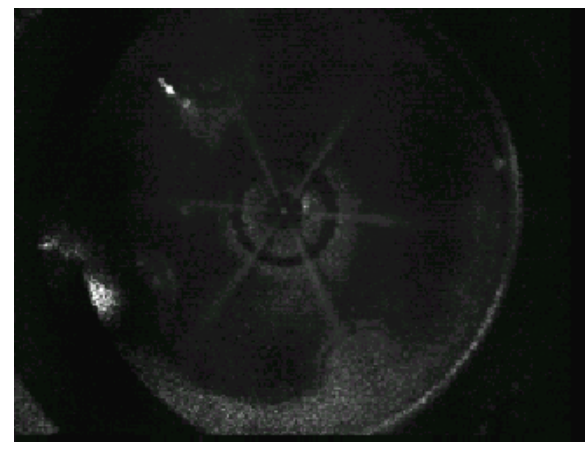

(b)

Figure 3.5 Window contamination at injection with respect to premixed combustion of two different fuels, ( $\left.\rho=7.5 \mathrm{~kg} / \mathrm{m}^{3}, 1000 \mathrm{~K}\right)$, direct images from high-speed camera (2 ms shutter time), (a) Hydrogen (b) Acetylene.

cleaning the window thoroughly. Therefore, acetylene was chosen as the premixed fuel due to the low window contamination that was observed during testing.

Nitrogen was used as the diluent because it has a negligible quenching effect on the exciplex fluorescence and fast combustion rates were achievable with high dilution levels. From measured pressure traces nitrogen had a higher combustion rate (70 ms to reach peak pressure) than $\mathrm{CO}_{2}$ (230 ms at the same diluent \%), although $\mathrm{CO}_{2}$ has an advantage of reduced gas pressure at the same density due to its higher molecular weight.

The equivalence ratio of the premixed charge was slightly rich, 1.05 , to avoid combustion of the diesel spray and to limit soot formation during the premixed combustion.

To maintain the TDC density, the amount of water condensation should be compensated by additional nitrogen. But, since the amount of water condensation at the injection time was estimated as less than $1 \%$ of total premixed gas mass, the effect of water condensation on the chamber density at the time of injection was considered 
negligible. Therefore, without heating the wall of the bomb, the contamination was not significant at the interested time over the entire injection duration.

From combustion tests, fast burning and reliable combustion was obtained with up to $84 \%$ nitrogen diluent. The method to prepare the mixture was that the chamber mixture was prepared by first evacuating the chamber, then filling the mixture sequentially with acetylene (4.7\%), air (53\%) and then nitrogen (42\%). The gases were well mixed by the momentum of the incoming mixtures. The resulting molar composition was $4.7 \%$ acetylene, $11 \%$ oxygen and $84 \%$ nitrogen.

From a combustion test with the density of $7.5 \mathrm{~kg} / \mathrm{m}^{3}$, the peak pressure reached was about $73 \%$ of the adiabatic equilibrium pressure. Using a $73 \%$ combustion efficiency, the expected peak pressure at $25 \mathrm{~kg} / \mathrm{m}^{3}$ with $84 \%$ nitrogen is about $13 \mathrm{MPa}$, which is under the design bomb pressure of 13.8 MPa. However, for safety reasons, the test conditions investigated were ambient densities of 7.5 and $15 \mathrm{~kg} / \mathrm{m}^{3}$ and temperatures of 800,1000 and $1200 \mathrm{~K}$. Table 3.2 shows the investigated ambient conditions. This range of temperatures span those expected in HSDI diesel operation, but the chamber density was limited by the peak pressure limitation of the large quartz window.

Table 3.2 Ambient conditions investigated

\begin{tabular}{|l|l|l||l|l|l|}
\hline Density & Temperature & Pressure & Density & Temperature & Pressure \\
\hline \hline \multirow{2}{*}{$15 \mathrm{~kg} / \mathrm{m}^{3}$} & $1200 \mathrm{~K}$ & $4.1 \mathrm{MPa}$ & $7.5 \mathrm{~kg} / \mathrm{m}^{3}$ & $1200 \mathrm{~K}$ & $2.0 \mathrm{MPa}$ \\
\cline { 3 - 3 } & $1000 \mathrm{~K}$ & $3.5 \mathrm{MPa}$ & & $1000 \mathrm{~K}$ & $1.7 \mathrm{MPa}$ \\
\cline { 2 - 3 } & $800 \mathrm{~K}$ & $3.0 \mathrm{MPa}$ & & $800 \mathrm{~K}$ & $1.5 \mathrm{MPa}$ \\
\cline { 5 - 6 } & & & & & \\
\hline
\end{tabular}




\subsubsection{Pressure Data}

To investigate the premixed combustion, the pressure traces can be used. Fast combustion is needed for producing homogeneous and inert combustion products at the selected temperature. Figure 3.6 shows average pressure traces acquired at a density of $7.5 \mathrm{~kg} / \mathrm{m}^{3}$ both without fuel injection (dashed) and with fuel injection occurring $600 \mathrm{~ms}$ after ignition (solid). The premixed combustion was started by the spark ignition and reached the peak pressure of $4.15 \mathrm{MPa}$, at $70 \mathrm{~ms}$ after the spark ignition. After the peak pressure, the pressure trace decreased as the thermal energy decreased due to heat loss. The difference between the two traces in the figure results from the energy consumed by the vaporizing liquid fuel. During the injection duration (1.4 ms) only a 0.1 bar decrease

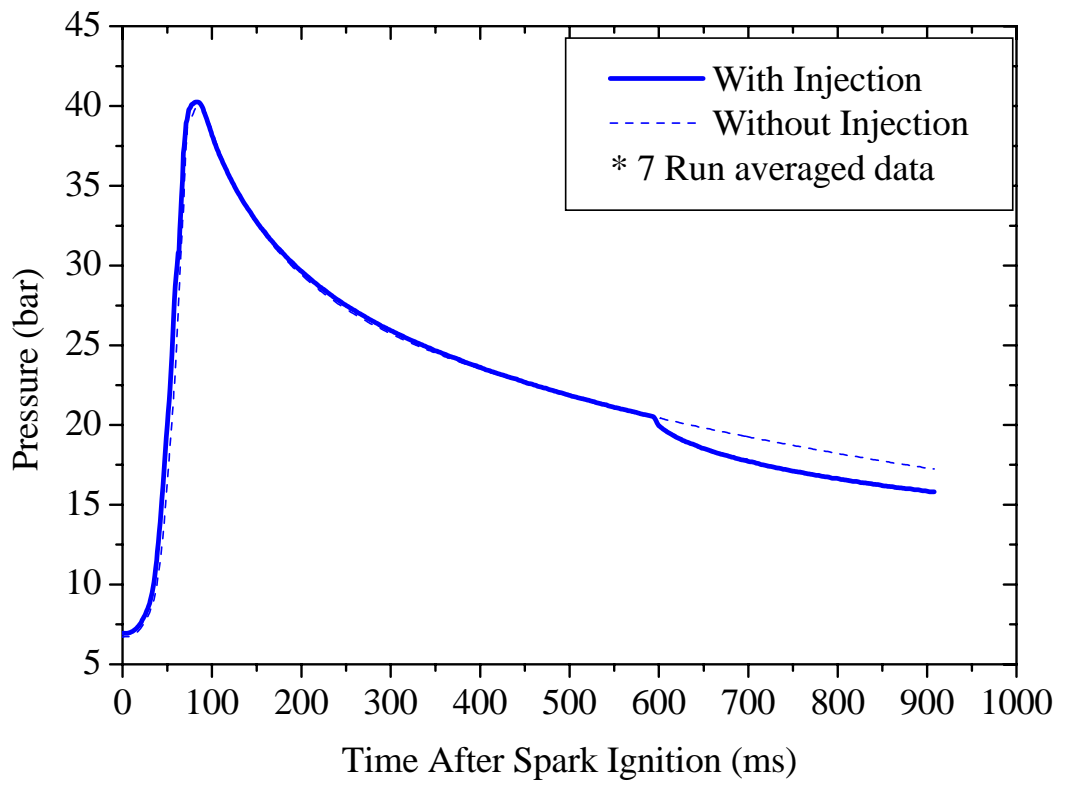

Figure 3.6 Pressure history of the combustion-type spray chamber system at the density of $7.5 \mathrm{~kg} / \mathrm{m}^{3}$ at the pre-charge compositions of $16 \%$ of $\phi=1.05$ acetylene and oxygen, and $84 \% \mathrm{~N}_{2}$. 


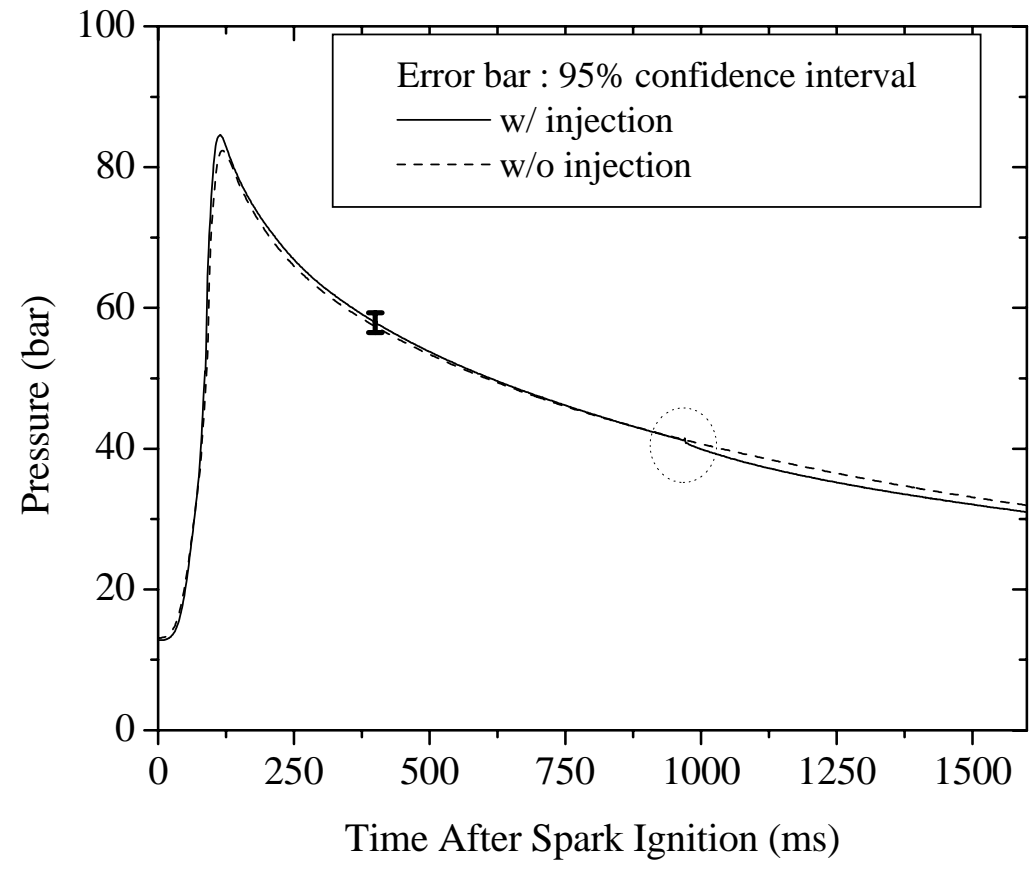

Figure 3.7 Pressure history of the combustion-type spray chamber system at the density of $15 \mathrm{~kg} / \mathrm{m}^{3}$, the circled areas show the effect of fuel vaporization on the chamber pressure.

of pressure was observed, so it can be assumed that the injection occurs at constant pressure. Figure 3.7 shows the case of a density of $15 \mathrm{~kg} / \mathrm{m}^{3}$ with fuel injection occurring $1 \mathrm{~s}$ after ignition. Also shown in Figure 3.7 at a time of $400 \mathrm{~ms}$ after spark ignition is the 95\% confidence interval for the chamber pressure, and shows that excellent run-to-run repeatability was achieved for the combustion.

Therefore, a fast and reliable premixed combustion was obtained at the pre-charge compositions of $16 \%$ of $\phi=1.05$ of acetylene and oxygen, and $84 \%$ nitrogen. 


\subsubsection{Temperature Data}

The gas temperature was measured using the thermocouple described in §3.1.6. Several radial positions for the thermocouple were used, horizontally at the same height as the spray axis. Figures 3.8 and 3.9 show uncorrected temperature traces acquired at four radial locations in the chamber for the case of 7.5 and $15 \mathrm{~kg} / \mathrm{m}^{3}$ respectively. Both figures show locally homogeneous temperature fields in the interested regions of temperature, 1200, 1000, and $800 \mathrm{~K}$.

The gas temperature can be calculated from Eq. (3.2) if the time constant of the thermocouple system, $\tau$, is known. The time constant was estimated to be 25 ms using the peak temperature matching procedure described in §3.1.6. Figure 3.10 shows the effect of compensating the temperature measurements. The two temperatures around $1000 \mathrm{~K}$, shown in the circled region, varied about $15 \mathrm{~K}$. Since the actual peak temperature will be less than the adiabatic equilibrium temperature, $15 \mathrm{~K}$ represents an upper limit on the correction associated with the temperature compensation. Figure 3.11 shows a typical run-to-run repeatability acquired at a radial location. Run-to-run variations of $50 \mathrm{~K}$ were observed in the temperature data for a given location, but the actual bulk gas temperature is expected to be more repeatable than the measured instantaneous local value based on the high degree of repeatability of the chamber pressure from run-to-run. 


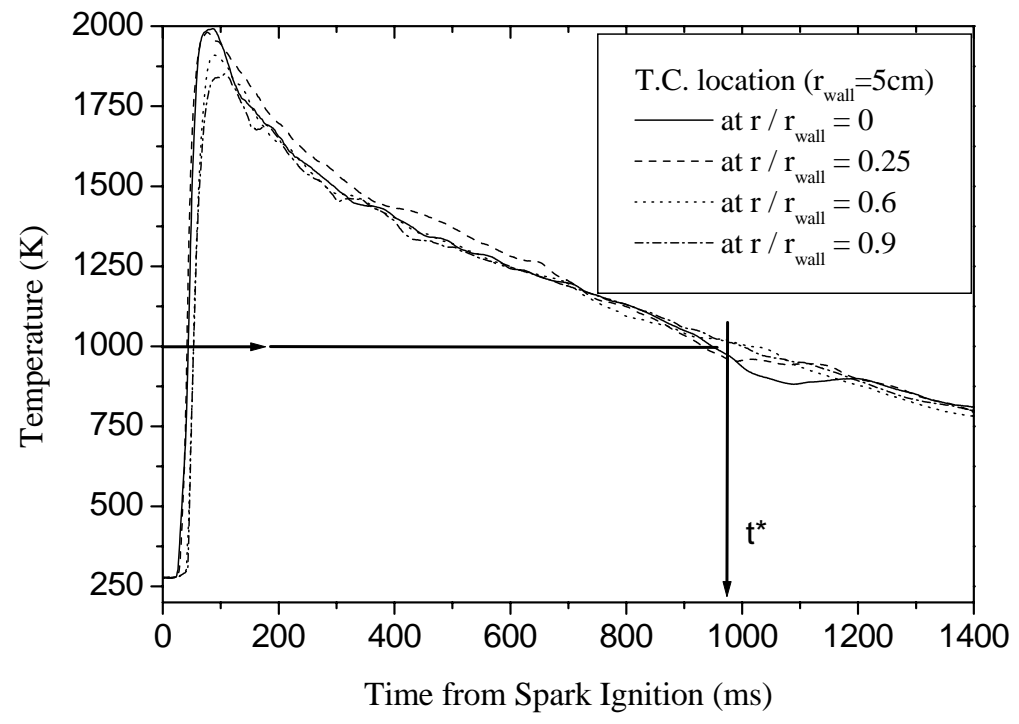

Figure 3.8 Temperature traces at four radial locations in the chamber for the case of density $7.5 \mathrm{~kg} / \mathrm{m}^{3}$.

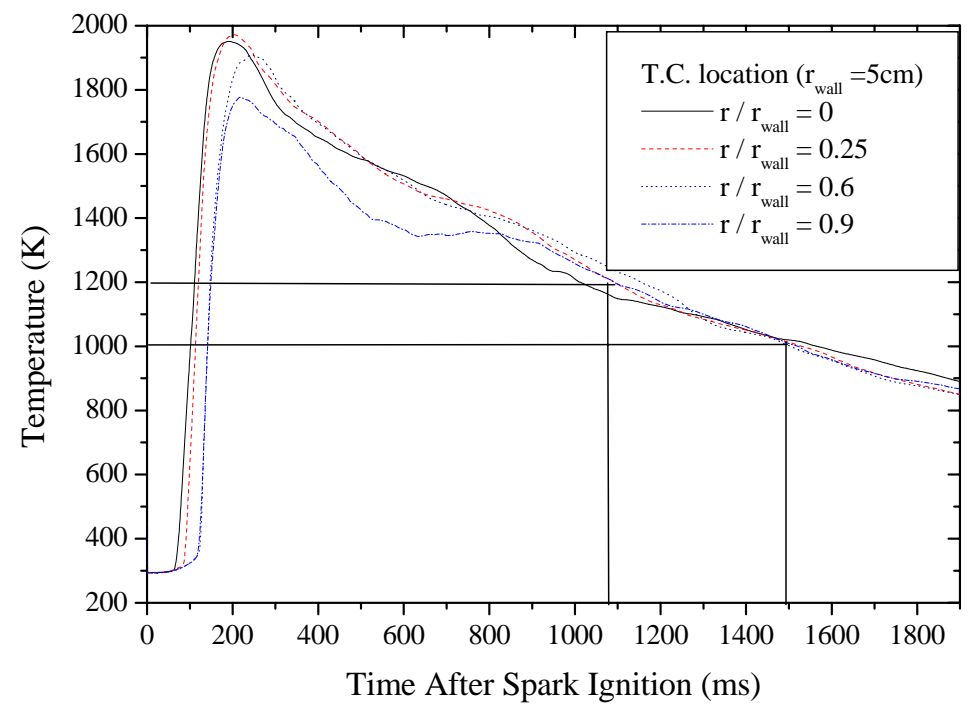

Figure 3.9 Temperature traces at four radial locations in the chamber for the case of density of $15 \mathrm{~kg} / \mathrm{m}^{3}$. 


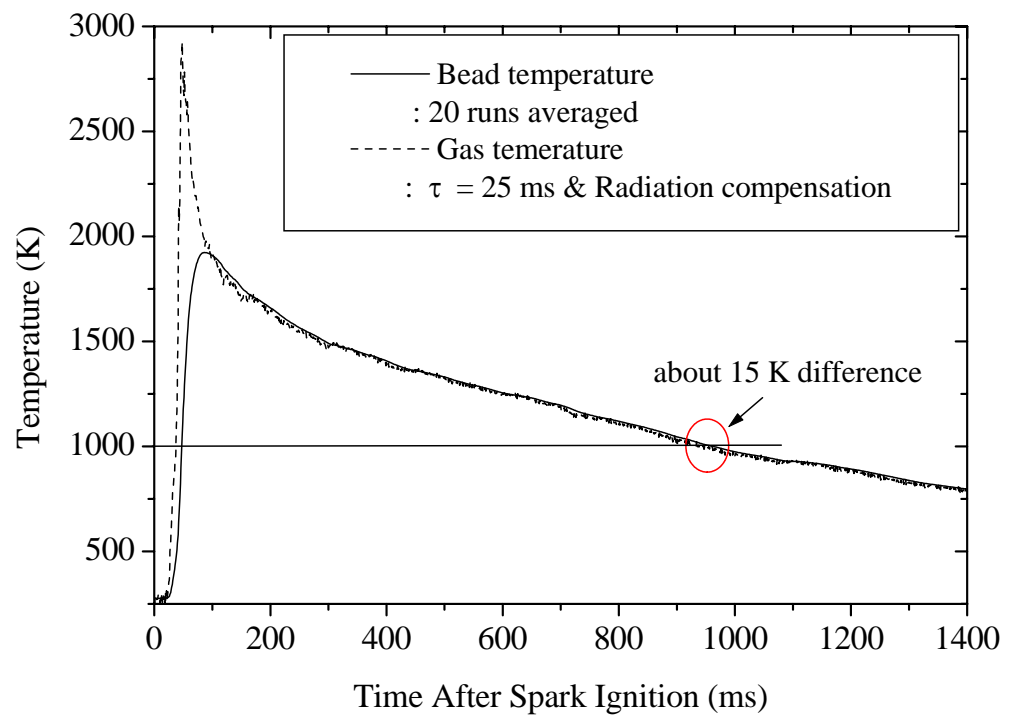

Figure 3.10 Compensation effect on temperature history.

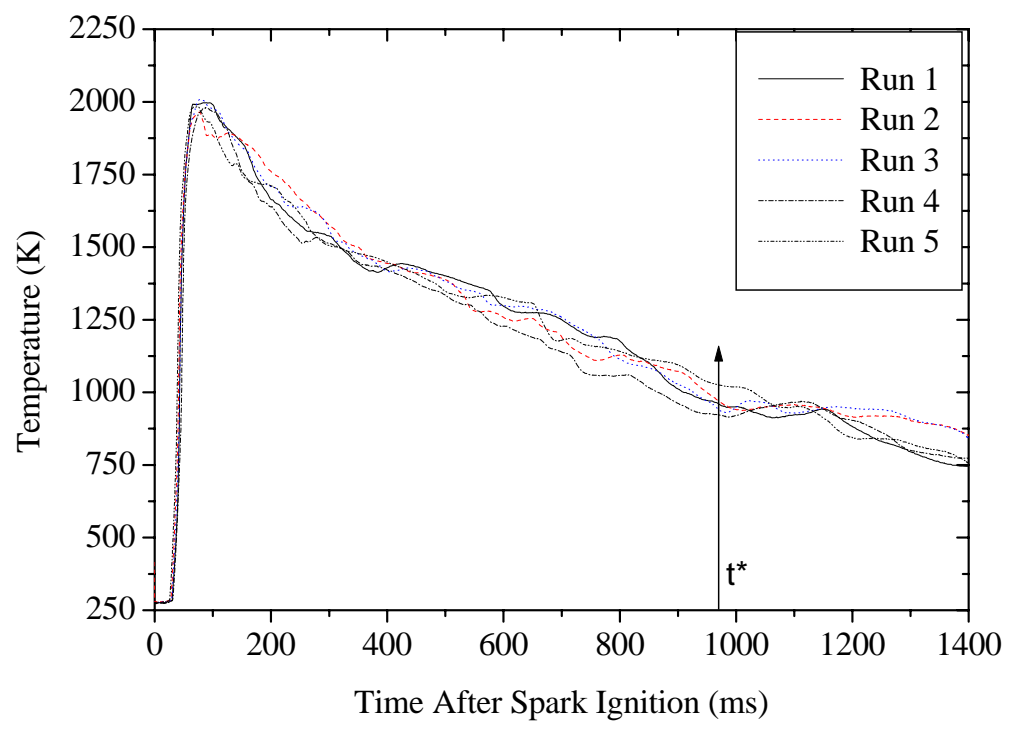

Figure 3.11 Run-to-run repeatability at the probe position of $\mathrm{r} / \mathrm{r}_{\text {wall }}=0.25$. 


\subsubsection{Confirmation from Mie scattering Images of Hot Bomb and Cold Bomb}

Figure 3.12 shows Mie scattering images of vaporizing and non-vaporizing diesel sprays from high-speed cinematography. The images were acquired using a high-speed camera (Kodak model 4540) combined with a high repetition rate diode-pumped Nd:YAG laser (Lee Laser Inc). A $532 \mathrm{~nm}$ narrow band pass filter was used to eliminate any residual flame luminosity of the hot bomb. The optical arrangement is similar to that described in §3.5. The Caterpillar HEUI 90 injector was used with a 1.4 msec injection duration and 90.3 MPa peak injection pressure. From the Mie scattering images, the liquid penetration length and the spray dispersion angle were obtained. The spray penetration length was defined as the furthest axial location where the signal exceeded a threshold of background noise level. While the liquid length of the cold bomb was relatively well defined due to the clear spray boundary, the liquid length of the hot bomb was not. A threshold of ( $3 \times$ the background noise) was used to define the spray penetration length along the spray-axis. From Figure 3.12, at the density of $7.5 \mathrm{~kg} / \mathrm{m}^{3}$, the effect of vaporization decreased liquid penetration length by up to $20 \%$ (40 $\mathrm{mm}$ for evaporating spray, $50 \mathrm{~mm}$ for non-evaporating spray), and it decreased the spray dispersion angle by about $28 \%$ ( $2 \theta=7.6^{\circ}$ for evaporating spray, $2 \theta=10.5^{\circ}$ for nonevaporating spray). 

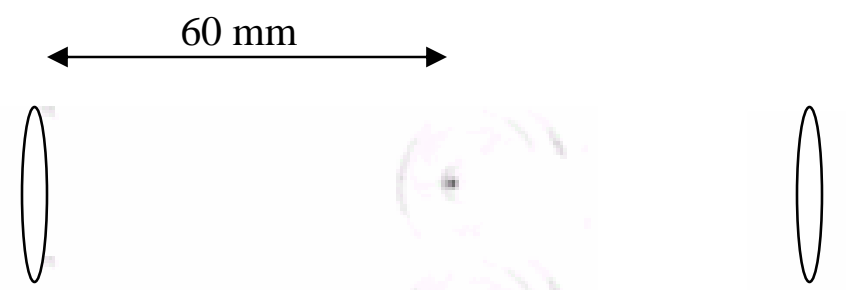

Time (ms)
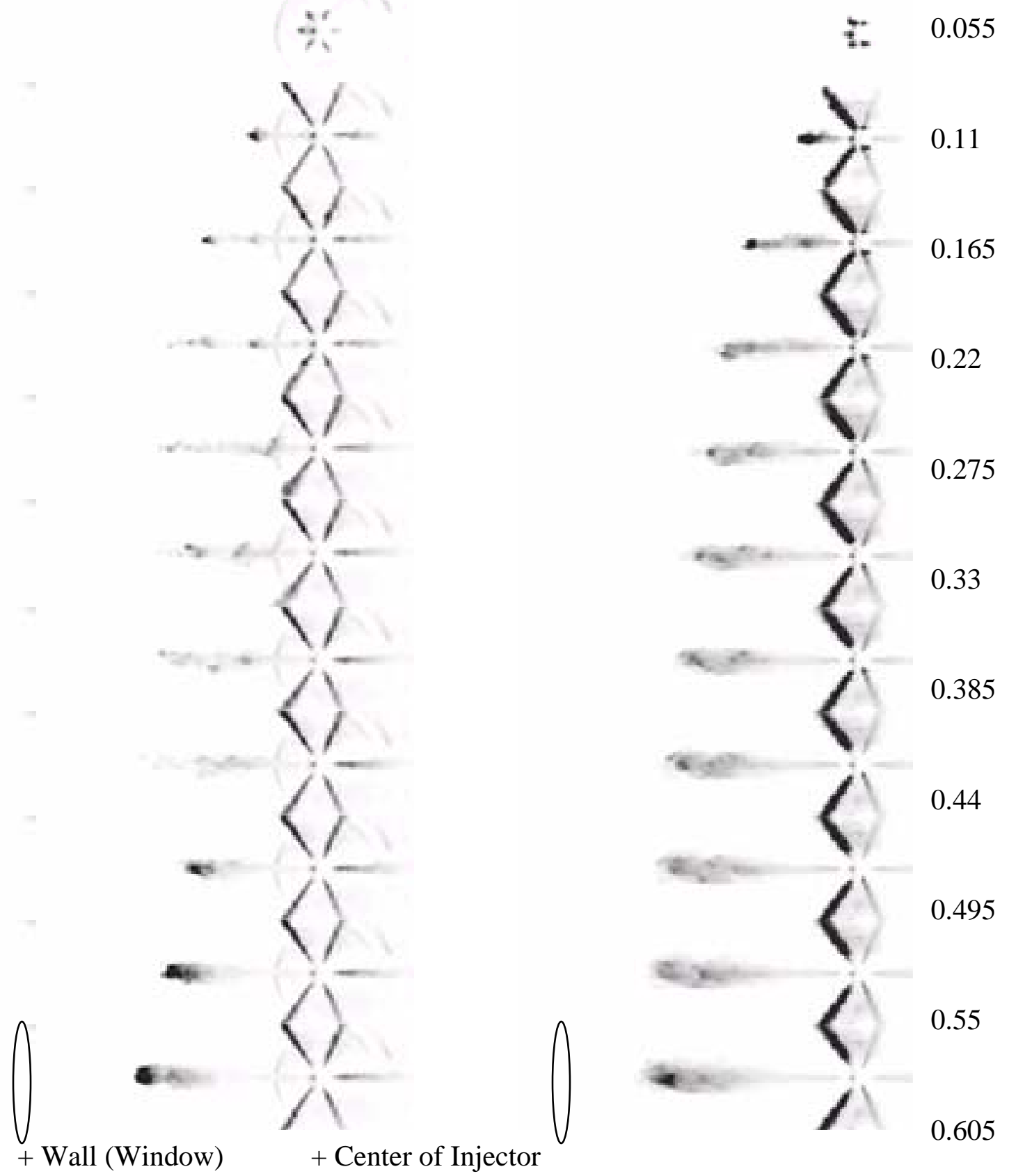

(a) Hot bomb $(1000 \mathrm{~K})$

(b) Cold bomb (298K)

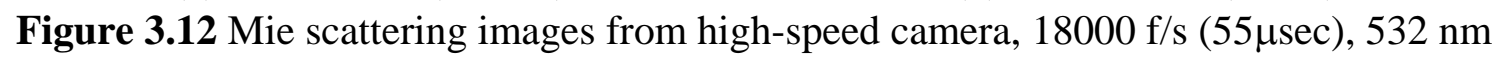
band pass filter in front of camera, $\rho=7.5 \mathrm{~kg} / \mathrm{m}^{3}$ 
As shown in results presented in this section, we can conclude that the combustion-type spray chamber was developed and provides conditions representative of a diesel engine at the start of fuel injection with good repeatability. Furthermore, negligible window contamination was observed (See §5.2.3).

\subsection{High Pressure Fuel Injection System}

The injector used in this study was a hydraulic-actuated electronically controlled unit injector (Caterpillar HEUI 90). A production oil manifold was used to eliminate any difference of injected fuel response characteristics related to manifold size and geometry of the inlet passage, line pressure drop, and time delay or dynamic wave time in accelerating the oil from manifold to injector [54]. Caterpillar Inc. developed the HUEI [54,55], and its reported advantages were the ability of injection pressure control independent of engine load or speed, and a lower engine noise level compared to common rail system [56]. Of the four injector-mounting ports on the manifold, only one was used with the injector while others were plugged. Details of the injector can be found in Table 3.3. The injectors used were the identical to the original HUEI injector except for nozzle hole size $(0.14,0.158$, and $0.2 \mathrm{~mm}$ diameter) on the injector tips, spray angles and injector hole length were the same as the baseline HEUI 90 of $0.158 \mathrm{~mm}$ diameter. Caterpillar provided the injectors with three kinds of tips, which eliminated effects other than nozzle hole size. The production six-hole nozzle was used, but only one spray plume was illuminated by the laser sheet. The injected fuel quantity (4.15 mg) was chosen to provide an overall equivalence ratio of 0.62 in a 500 cc displacement naturally aspirated 
engine as a baseline. The injection rate profile measured with a Bosch-type apparatus is shown in Figure 3.13.

Table 3.3 Injector system specification and the condition used

\begin{tabular}{|l|c|}
\hline \multicolumn{2}{|c|}{ Caterpillar HEUI 90 injector } \\
\hline Nozzle type & VCO nozzle \\
\hline Number of Nozzle & 6 holes \\
\hline Nozzle Diameter & 140,158, and $200 \mu \mathrm{m}$ \\
\hline Spray angle & 145 degree \\
\hline Injection duration & $1.3-1.6 \mathrm{~ms}$ \\
\hline Peak injection pressure & $60 \mathrm{MPa}(1300 \mathrm{psi}$ oil manifold $)$ \\
& $90 \mathrm{MPa}(2100 \mathrm{psi}$ oil manifold $)$ \\
\hline Injected fuel amount & $150 \mathrm{MPa}(3400 \mathrm{psi}$ oil manifold $)$ \\
\hline Fuel line temperature & $4.15 \mathrm{mg} / \mathrm{hole}$ \\
\hline
\end{tabular}

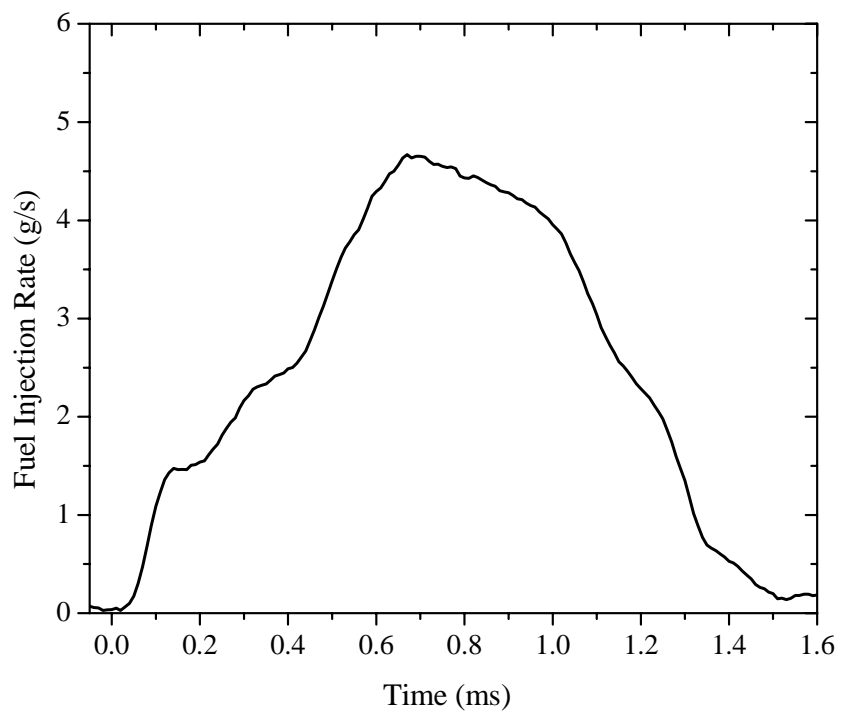

Figure 3.13 Injection rate profile with $0.158 \mathrm{~mm}$ diameter nozzle size and $90.1 \mathrm{MPa}$ peak injection pressure. 


\subsubsection{Injection Driver System}

The standard Caterpillar injector driver system is operated by its engine simulator. However, the simulator could not be set to the exact value of $1200 \mathrm{rpm}$ corresponding to a $10 \mathrm{~Hz}$ injection interval. The speed fluctuated $\pm 3 \mathrm{rpm}(0.25 \mathrm{msec})$. Not only is the fluctuation time significant from the standpoint of the injection duration of $1.4 \mathrm{msec}$, but also using the $10 \mathrm{~Hz}$ output of the simulator as the master clock of the experimental apparatus was not good from the viewpoint of timing control since the spark ignition event is the critical event for the system. Therefore, a Siemens high voltage injector driver replaced the Caterpillar (CAT) injector driver system to allow single-shot operation through triggering with an external TTL input. The characteristics of injection were not changed as will be shown in $\S$ 3.3.3.

\subsubsection{Fuel Delivery System}

For chemically doped fuels, the standard exciplex dopants were used for matching the conditions of diesel fuel, see Table 4.2. TMPD served as the monomer and naphthalene provided the exciplex-forming partner. A dead-headed fuel delivery system was used to limit the amount of doped fuel required, and also to isolate it from the oxygen. Nitrogen was used to pressurize the doped fuel to the same pressure, 30 psig, as the fuel pump system. To eliminate any trapped air or gas in the fuel line and inside the injector, the fuel line was flushed thoroughly using a valve located near the injector, as well as by performing hundreds of injections before an experiment. 


\subsubsection{Comparison between Caterpillar and Siemens Injection Driver}

Figure 3.14 shows a comparison of the spray penetration length between the original (Caterpillar) and replaced (Siemens) driver systems. The Mie scattering measurement used was the same as discussed in $\S 3.2 .4$. Since the magnitude of error in all 4 cases was about the same, error bars have been plotted on only one dataset. The original system was composed of the Caterpillar injector driver and fuel pump system. The replaced system was composed of the Siemens driver and the dead-head fuel system. From a comparison of the spray penetration data, there is no discernable difference between the modified injection system and the original injector driver and fuel pump system. Therefore, the replaced system can be used for this study.

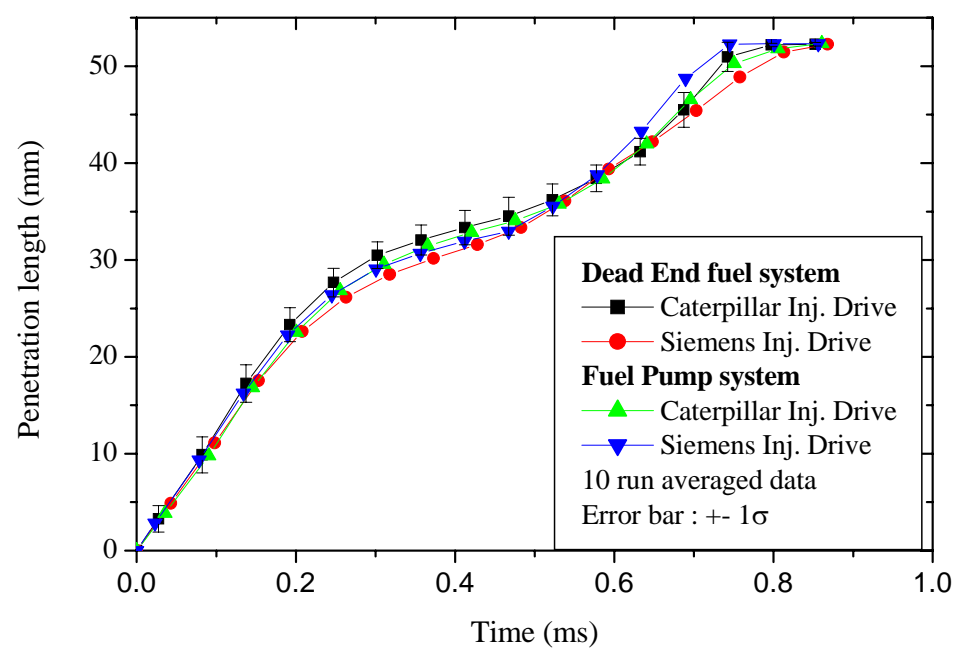

Figure 3.14 Penetration length with respect to four combinations of different injection drive and fuel delivery systems, measured from high speed cinematography at cold bomb, $298 \mathrm{~K}$ and $7.5 \mathrm{~kg} / \mathrm{m}^{3}$, $1.4 \mathrm{~ms}$ injection duration, $90.3 \mathrm{MPa}$ peak injection pressure. 


\subsection{Data Acquisition and Control Systems}

All measurement and control of the experiment was performed through two Labview programs (National Instruments, version 5.0). The first program is for gas preparation of the premixed charge, and the second is for the timing control of ignition, injection and data acquisition of pressure and temperature. All data were acquired with a DAQ board (AT-MIO-16E-10) providing $100 \mathrm{kHz}$ and 12-bit resolution.

A pulse/delay generator (Quantum composers model 9310) was used to more accurately control the injection and laser timing because the DAQ board used has only 2 TTL outputs. After receiveing an external trigger from the ignition Labview program, the pulse generator triggers the camera, frame grabber, and the flash-lamp and the Q-switch of the Nd:YAG laser (Continuum 2015).

The timing system controls the firing of the laser and the synchronization of the frame grabber (Data Translation model 3152), camera, and intensifier with the laser pulses. The camera system used was composed of CidTech 3710-D CID (Charge Injection Device) camera and DEP PP 0340 image intensifier (EOSI 9437/25 ICID system). To capture asynchronous images, a computer program was made to configure and operate the frame grabber, mainly composed of library functions of Data Translation SDK (Software Development Kit).

\subsubsection{Experimental Procedure}

1) After all sub-systems were ready, the chamber was evacuated using a vacuum pump. 
2) The premixed gas charge (acetylene (4.7\%), air (53\%) and nitrogen (42\%)) was synthesized by adding the required partial pressure of each gas slowly for isothermal mixing using the electrical solenoid valves controlled by the Labview program. Common inlet lines were evacuated before adding the next gas.

3) After the final gas has been added, a 30 second delay was used to allow for homogeneous mixing and quiescent gas motion. To determine the necessary delay time, the combustion pressure trace was used. The pressure trace did not change after waiting longer than 30 seconds.

4) The Labview timing and data acquisition program was executed. The Labview program triggered the ignition system with one TTL signal and triggered the pulse generator with a delayed second TTL signal. The delay time from the first TTL signal was selected as the time when the products of the combustion event cooled to the selected temperature, for instance $1000 \mathrm{~K}$.

5) The pulse generator triggered the injection driver system, the laser and intensified camera with the appropriate delays to acquire the image at the interested instant of the injection event.

Lastly, after each run, the large window supporting part was removed, several injections were performed, and then the inside chamber and windows were cleaned thoroughly. 


\subsection{Exciplex LIF Image System}

Figure 3.15 shows a schematic of the optical system used in this experiment. The frequency tripled output of a Nd:YAG laser (355nm, $13.5 \mathrm{~mJ}$ per pulse and 10 ns pulse width) was formed into a sheet using a $150 \mathrm{~mm}$ focal length cylindrical lens and a $1 \mathrm{~m}$ focal length plano-convex lens. The thickness of the laser sheet was approximately 400 $\mu \mathrm{m}$. The transverse laser profile is shown in Figure 3.16, and its non-uniformity was corrected for in the calibration procedure (described fully in §4.3). The laser sheet was aligned with the axis of a single spray plume, and the imaging system was oriented perpendicular to the laser sheet. For simultaneous detection of both the liquid and the vapor phases, two intensified 8-bit CID cameras were used in conjunction with a 45 degree angle of incidence a dichroic mirror (Corion CR500-S, 90\% reflectance for $380<$

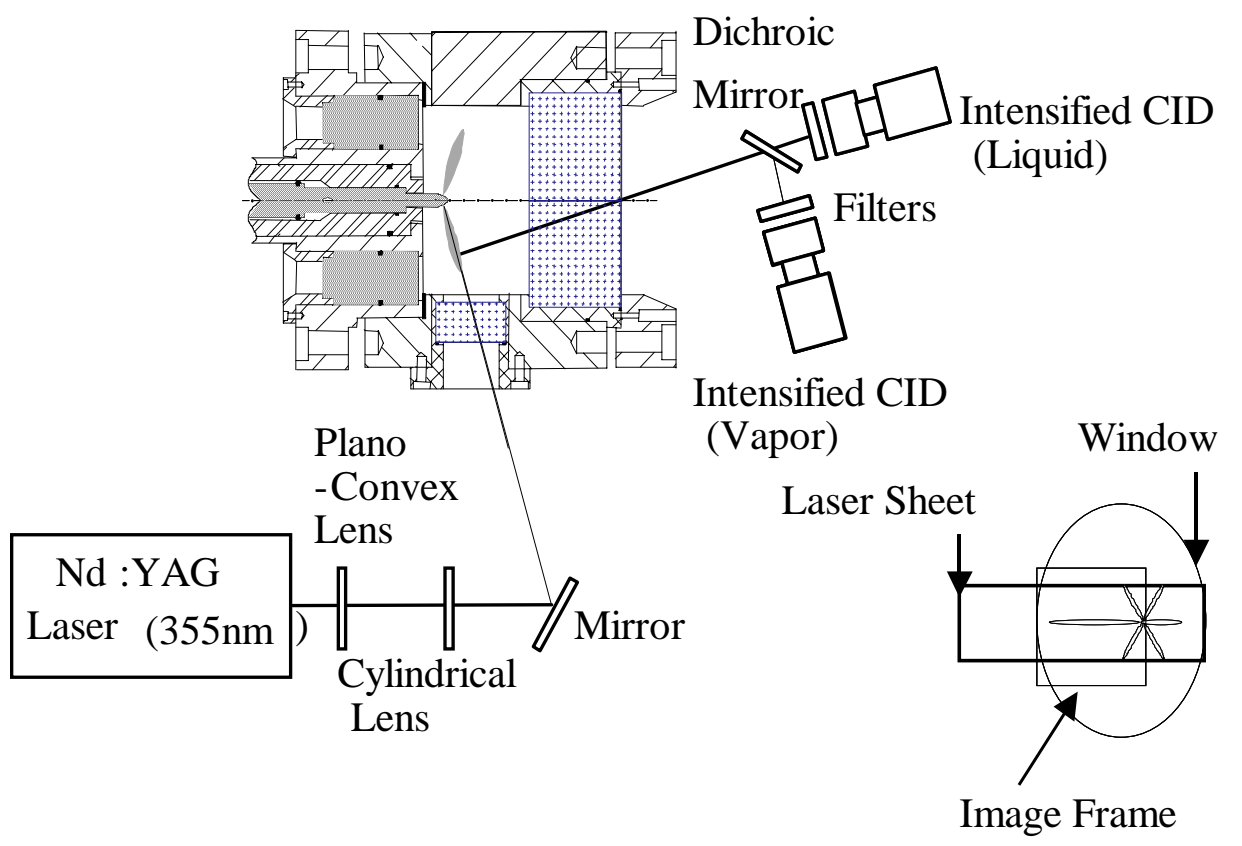

Figure 3.15 Schematic of the optical imaging system. 


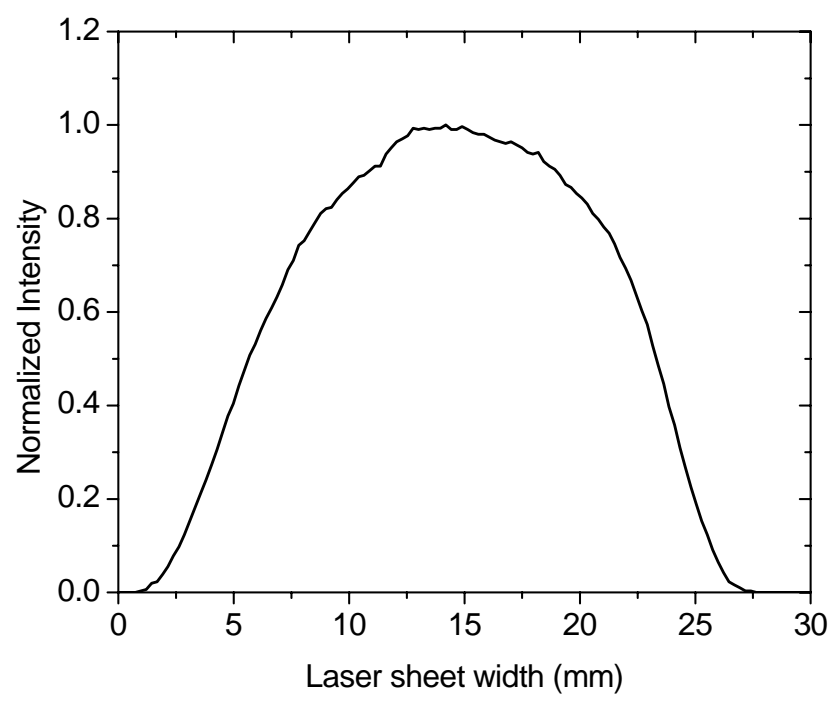

Figure 3.16 Normalized laser sheet profile obtained by imaging an uniform distribution of TMPD vapor inside the chamber.

$\lambda<450 \mathrm{~nm}$, and $85 \%$ transmittance for $\lambda>525 \mathrm{~nm})$. The intensifier gate width was 100 ns to isolate the fluorescence from luminosity of the premixed combustion. To isolate the exciplex fluorescence signal for the liquid phase, a long pass $(\lambda>505 \mathrm{~nm})$ filter was used. To isolate the TMPD fluorescence signal for the vapor phase, a broad band interference filter (CVI, F25-400-4, center at $400 \mathrm{~nm}$ with a full width at half maximum of $25 \mathrm{~nm}$ ) and a Schott glass filter (GG385) were used. 


\section{Chapter 4. EXCIPLEX LIF CALIBRATION METHOD}

The quantification of the liquid phase fluorescent signal is difficult. The spectra of the liquid exciplex fluorescence changes with temperature. Additionally, the fluorescence is known to be dependent on droplet mass only for small droplets. However, the quantification of the vapor phase is possible. In this study the exciplex LIF technique was applied to quantitatively investigate the fuel vapor distribution, and to qualitatively investigate the liquid fuel extent. This chapter is divided into three main sections. $§ 4.1$ discusses background and several issues that should be considered for the quantitative vapor phase. $\S 4.2$ describes the calibration and results. $\S 4.3$ describes the overall calibration procedure for the quantitative vapor concentration measurements.

\subsection{Consideration for the Quantitative Vapor Phase}

Based on photophysics, the fluorescence signal, $N_{L I F}$, at the detector [photon/s] can be written as

$$
N_{L I F}=\frac{I_{0} \cdot \eta_{c} \cdot \Omega \cdot V}{(h c / \lambda)} \cdot N_{T M P D} \cdot \sigma_{T M P D} / 4 \pi \cdot \phi_{T M P D}
$$

where $I_{0}$ is the incident intensity of the laser sheet $\left[\mathrm{W} / \mathrm{cm}^{2}\right], \eta_{c}$ is the detection efficiency composed of quantum efficiency, filter transmission and the camera fill factor, $\Omega$ is the collection solid angle [sr], $V$ is the measurement volume $\left[\mathrm{cm}^{3}\right]$, the denominator is the energy per photon [J], $N_{T M P D}$ is the number density of TMPD molecules $\left[\mathrm{cm}^{-3}\right], \sigma_{T M P D} /$ $4 \pi$ is the differential absorption cross-section of the TMPD fluorescence $\left[\mathrm{cm}^{2} / \mathrm{sr}\right]$, and 
$\phi_{T M P D}$ is the TMPD fluorescence efficiency (Stern-Vollmer factor) which is related to the ratio of the spontaneous emission rate to the sum of spontaneous emission and quenching rates.

By integrating with respect to time and collecting constant terms, Equation (4.1) for a data image can be written more simply as:

$N_{L I F}=K \cdot N_{T M P D} \cdot \bar{\sigma}_{T M P D} \cdot \bar{\phi}_{T M P D}$

where $N_{L I F}$ now represents the pixel intensity on the camera [pixel count], $K$ is a calibration constant at a reference condition [(pixel count)/(cm $\left.{ }^{-3}\right]$, and $\bar{\sigma}_{\text {TMPD }}$ and $\bar{\phi}_{\text {TMPD }}$ are relative photophysical parameters normalized by their values at the reference condition. From Eq (4.2) the calibration can be decoupled into the absolute TMPD calibration at a reference condition, and its correction due to the changing local thermodynamic variables.

To quantify the vapor phase fluorescence signal in an evaporating diesel spray in a combustion-type spray chamber, several considerations must be taken into account:

1. Absolute calibration of TMPD fluorescence and number density.

2. Changes in the calibration due to the thermodynamic variables such as:
a) Temperature
b) Pressure
c) Collision Partner $\left(\mathrm{H}_{2} \mathrm{O}\right.$ and $\left.\mathrm{CO}_{2}\right)$

3. Extinction of the laser sheet through the vapor phase.

4. Local temperature reduction in the evaporating spray in conjunction with \# 2 . 
5. TMPD vapor concentration indicative of total vapor concentration, i.e., similar vaporization characteristics of dopant and fuel.

6. Minimal cross-talk between the liquid and vapor phase due to an overlap of the emission spectra.

The following section, calibration and results, describes TMPD calibration methods as well as dealing with the six considerations.

\subsection{Calibration and Results}

\subsubsection{Absolute Calibration between TMPD Fluorescence and Concentration}

The absolute calibration was obtained by imaging a known concentration of TMPD at a reference condition. This provides the value for the constant $K$ and includes issues related to fluorescence linearity. Figure 4.1 shows a schematic of the absolute TMPD calibration system. A heated jet which issued a known concentration of TMPD was installed in the spray chamber, and fluorescence images were acquired using the same optical setup, detection system and laser power as used in the spray experiment in order to include any system dependence, $K$ of Equation (4.5). The jet temperature and pressure were $430 \mathrm{~K}$ and 1 bar, respectively, and the ambient gas was nitrogen. To provide a known concentration of TMPD, a solution of $1.6 \%$ of TMPD and $98.4 \%$ of dodecane was injected at a fixed rate into a heated nitrogen stream. The reason naphthalene was eliminated from the solution was to increase the concentration of TMPD in the solution. The effect of naphthalene on TMPD fluorescence was confirmed to be negligible. The liquid fuel flow rate was controlled to $2.4 \mathrm{cc} / \mathrm{min}$ (mass rate of TMPD, 
$5 \times 10^{-7} \mathrm{~kg} / \mathrm{s}$ ) by pressurizing the fuel reservoir to 7 bar and using a $50 \mu \mathrm{m}$ diameter sapphire orifice. The flow rate of hot nitrogen gas was adjustable from 1 to $9 \mathrm{l} / \mathrm{min}$ to allow variation in the TMPD concentration. To eliminate any buildup in the chamber, the jet was evacuated through a funnel located $2 \mathrm{~cm}$ downstream of the jet exit.

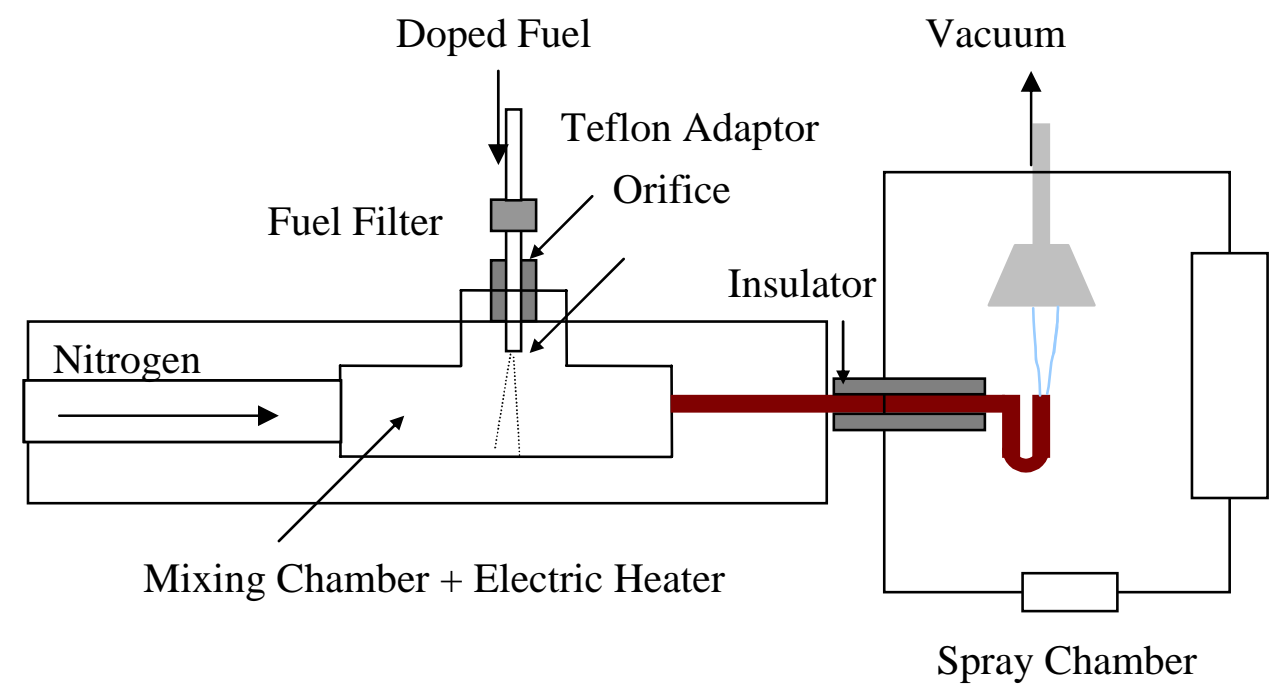

Figure 4.1 Schematic of apparatus for absolute TMPD calibration at a reference temperature.

Results from the absolute calibration experiment (which is performed at the start of each test run) are shown in Figure 4.2. The fluorescence signal is seen to exhibit excellent linearity with variations in the TMPD concentration in Figure 4.2. The mixture temperature at the exit of the jet varied slightly according to the selected nitrogen flow rate (428 K to $463 \mathrm{~K}$ ) and these data have been corrected for this effect (see Figure 4.8). The slope of the data in Figure 4.2 directly provides the calibration constant, $K$. The fact that the fit line has a zero intercept indicates that imaging at a single concentration is 
sufficient to provide an absolute calibration. The terms that comprise the calibration constant $K$ can be seen in Equation (4.2). By using the same setup for the calibration as in the final experiments all of the parameters associated with the collection optics are unchanged. Additionally, it was confirmed that the fluorescence was not saturated as a linear relationship between TMPD fluorescence and laser power was observed in Figure 4.3.

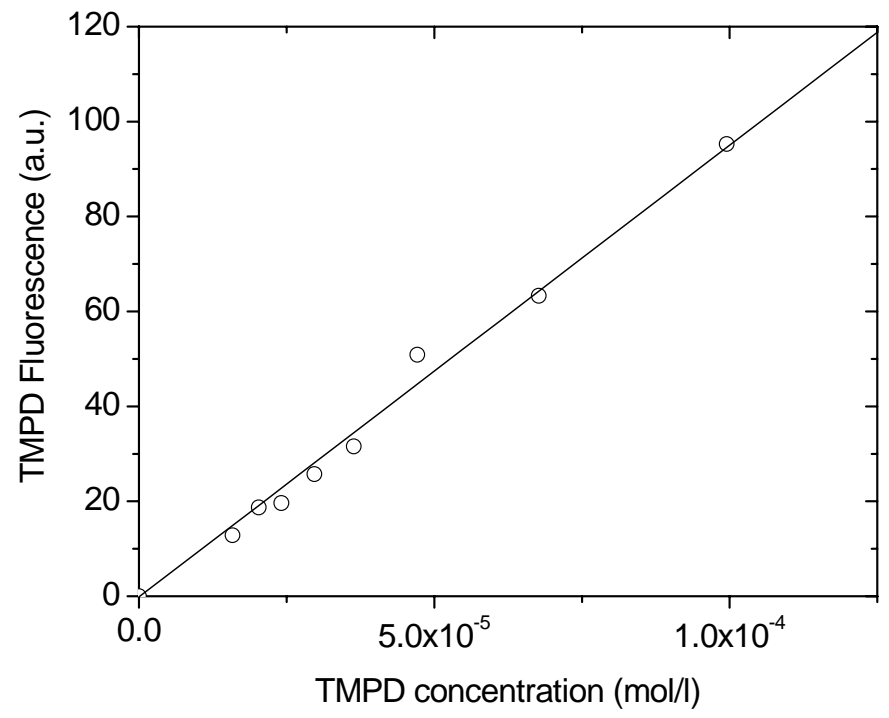

Figure 4.2 Calibration relationship between TMPD concentration and fluorescence intensity. 


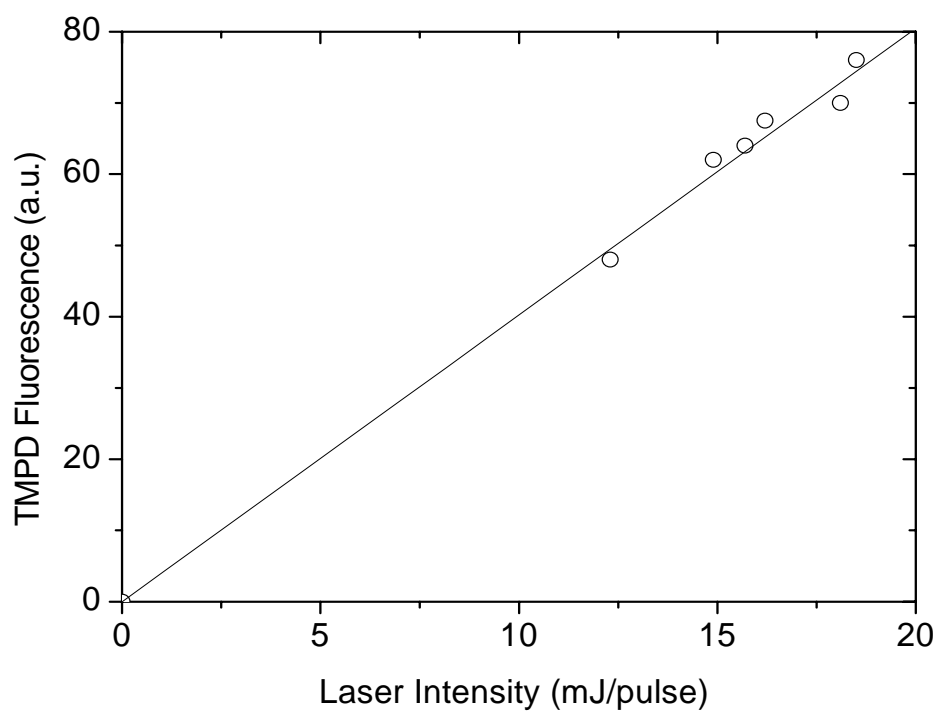

Figure 4.3 TMPD fluorescence dependence on laser intensity at a TMPD concentration of $6.8 \times 10^{-5} \mathrm{~mol} / \mathrm{l}$.

\subsubsection{Photophysical Parameter Effects}

As discussed briefly above, the photophysical parameters, the absorption crosssection and the fluorescence efficiency ( $\bar{\sigma}_{T M P D}$ and $\bar{\phi}_{T M P D}$ ), can be dependent on the local thermodynamic conditions. Therefore, a full calibration requires that the effects of pressure, collision partner and temperature be understood, and employed in the calibration scheme.

\subsubsection{Pressure Effect on TMPD Fluorescence}

In order to investigate the effect of pressure, the chamber was heated to $350 \mathrm{~K}$ with an excess amount of TMPD in a nitrogen atmosphere. The TMPD was allowed to reach its saturation vapor pressure at this condition, and then the chamber was progressively filled 
with nitrogen up to 15 bar while images of the TMPD fluorescence were acquired. The chamber temperature was fixed so the concentration of the TMPD was unchanged. The result of the bulk gas pressure effect is shown in Figure 4.4. It can be seen that the bulk gas pressure does not affect the TMPD fluorescence. This result allows all other evaluations of the photophysical parameters to be performed at ambient pressure. Also, the lack of a pressure effect indicates that collisional quenching is not responsible for the fluorescence behavior since the collision frequency varies by a factor of 15 in this data with no difference in the fluorescence signal.

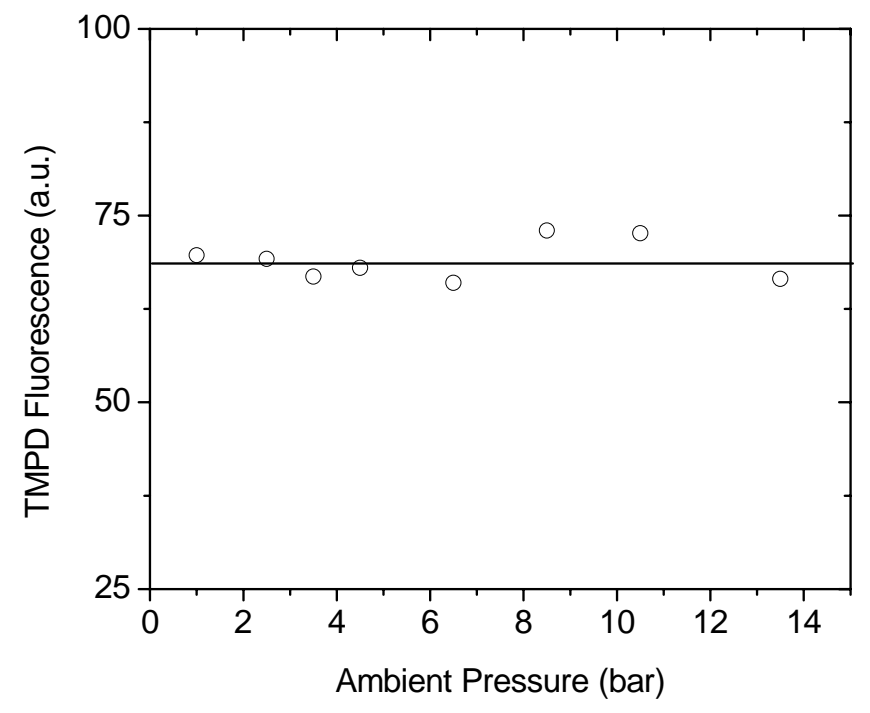

Figure 4.4 TMPD fluorescence dependence on ambient pressure. 


\subsubsection{Collision Partner Effect on TMPD Fluorescence}

The effect of collision partners on TMPD fluorescence was investigated using the absolute calibration jet described above with different gas streams. Carbon dioxide and argon were investigated for the heated gas stream following the same procedure as described for Figure 4.2. The results from these tests, along with those from the nitrogen experiments is shown in Figure 4.5, where it can be seen that fluorescence of TMPD is not affected by either $\mathrm{CO}_{2}$ or argon.

To evaluate the effect of water vapor (a major constituent of the combustion products in the chamber at the time of injection) the spray chamber was heated to $350 \mathrm{~K}$ with an excess amount of TMPD and a mass of water corresponding to saturation at that temperature. The pressure was $10 \mathrm{bar}$ and the atmosphere was nitrogen. By extracting a portion of the mixture and then refilling with nitrogen to 10 bar and allowing sufficient time for TMPD evaporation, the water concentration was decreased while all of the other conditions were unchanged. The results from these tests are shown in Figure 4.6 and confirm that water vapor has a minimal effect on the fluorescence of TMPD.

Therefore, it was found that the composition of the combustion products, especially $5 \%$ mole fraction of water vapor, $10 \%$ mole fraction of $\mathrm{CO}_{2}$, and $85 \%$ mole fraction of nitrogen, would not affect the calibration of the TMPD vapor signal. 


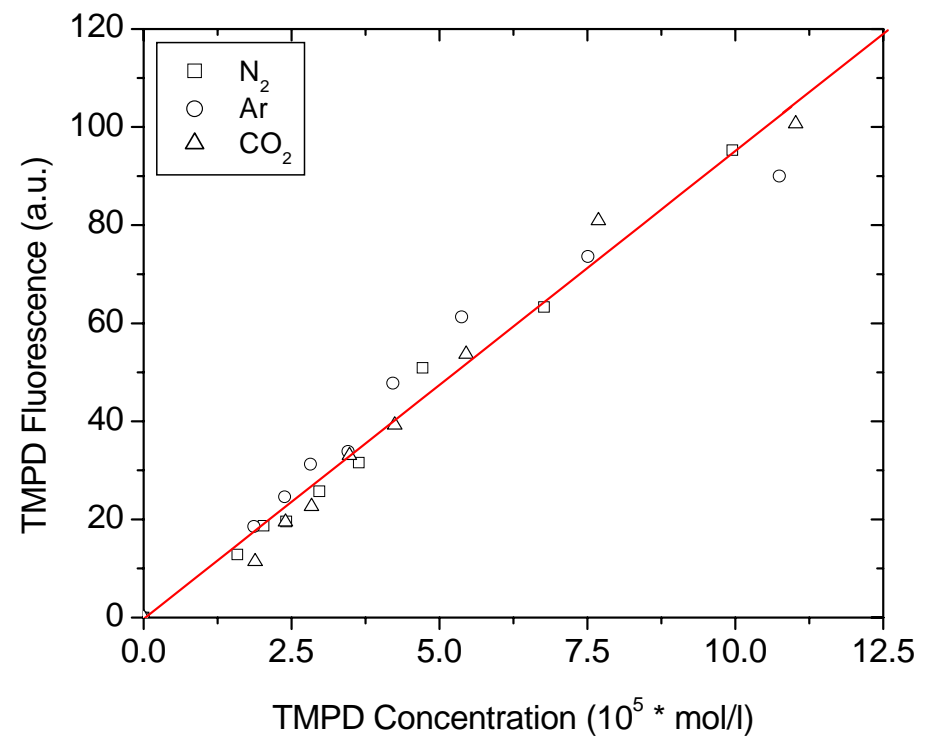

Figure 4.5 TMPD fluorescence dependence on collision partner.

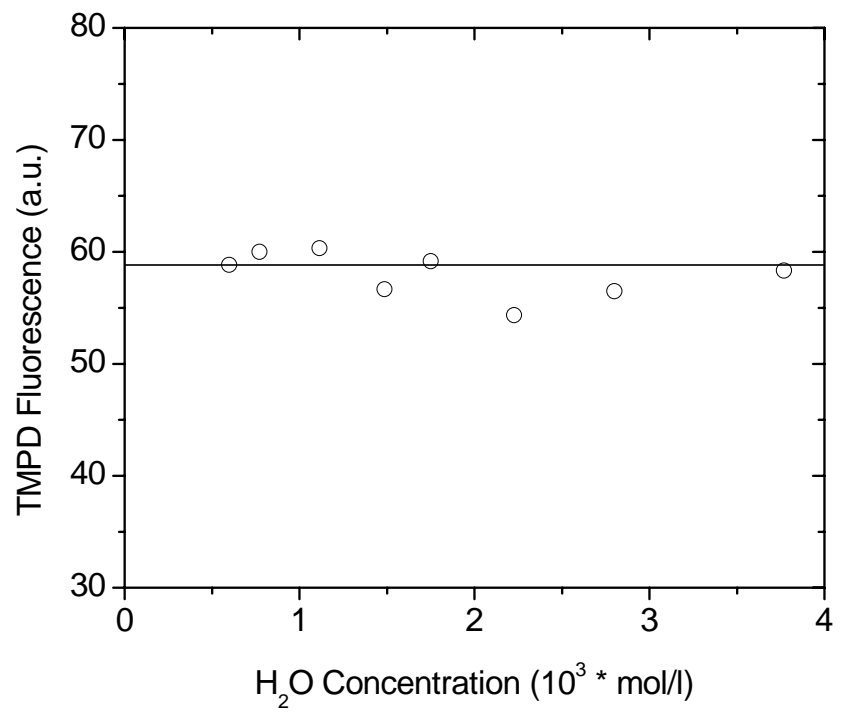

Figure 4.6 TMPD fluorescence dependence on water vapor concentration. 


\subsubsection{Temperature Effect on TMPD Fluorescence}

Temperature has been shown to significantly affect the fluorescence of TMPD in all of the previous calibration attempts in the literature. In order to investigate the effect of temperature on the fluorescence of TMPD a dual heated jet experiment was performed, see Figure 4.7. The concept of the dual heated jet experiment came from a similar application of Ghandhi et al. [57] for investigating the fluorescent behavior of ketones at high temperature. To prepare the mixture nitrogen was passed through an electrically heated TMPD reservoir. Since accurate control of the TMPD concentration is difficult to

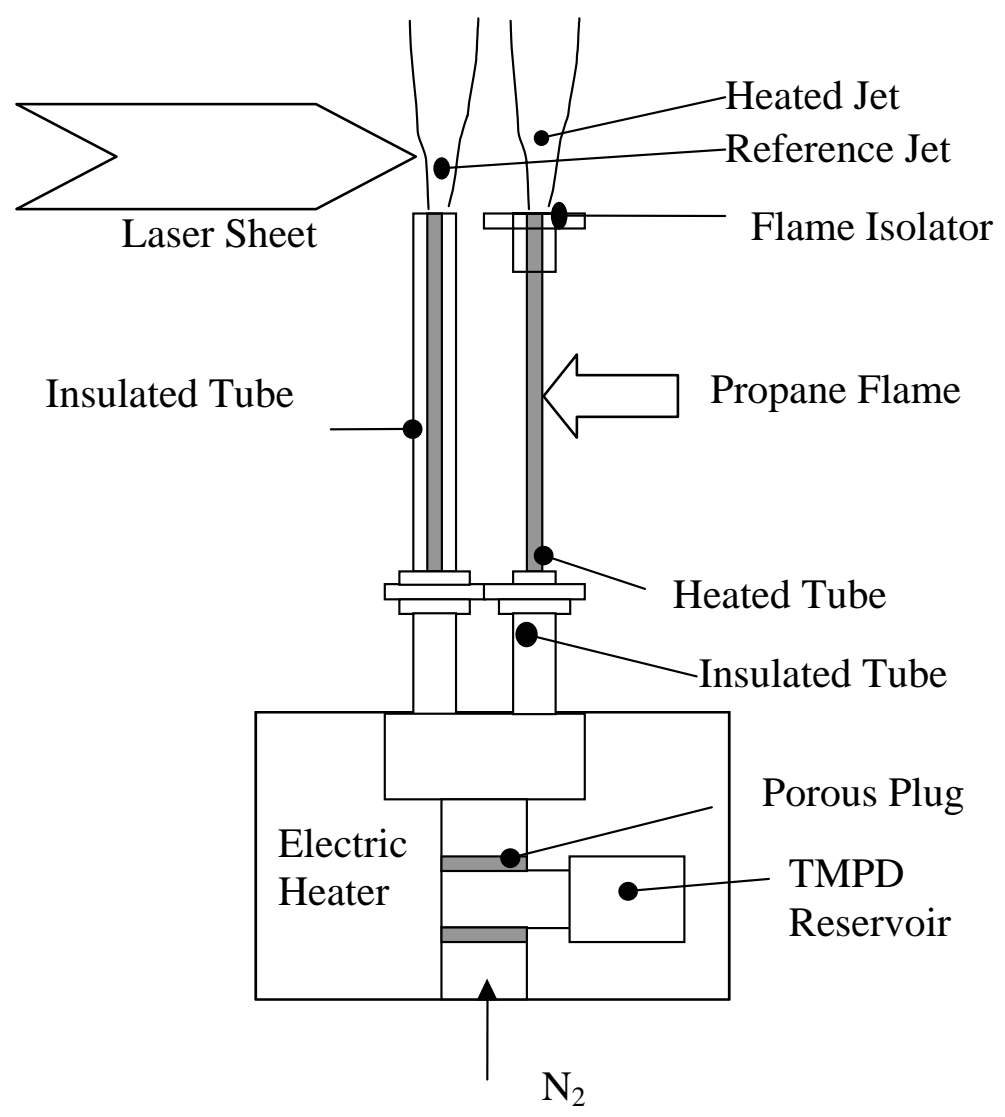

Figure 4.7 Schematic of dual heated jet system to determine the TMPD temperature dependence. 
achieve in this manner and strongly impacts the measured results, the mixture was split into two equal diameter and length parallel to the flow streams. One jet was heated with a propane flame, while the other remained at a temperature of $370 \pm 7 \mathrm{~K}$ for use as a reference through which both TMPD concentration and laser power could be simultaneously monitored. The diameter and flow rate of the jets was chosen to assure uniform concentration and temperature profiles, as well as to provide a short resident time ( $<10 \mathrm{~ms}$ ) to prevent thermal decomposition. An R-type thermocouple was used to measure the temperature of the heated jet stream.

In order to provide a higher level of accuracy, the imaging system used for the temperature experiments was a sub-cooled, unintensified 16-bit CCD camera $(512 \times 512$ pixel). An exposure time of 5 seconds was used to produce an on-chip average of 50 laser pulses, resulting in a significantly higher signal-to-noise ratio than could be achieved with a single-shot experiment using the intensified camera. A probe point close to the jet exit (corresponding to the location of the temperature measurement) was defined, and a comparison of the TMPD fluorescence at that point to that in the reference jet provided a measure of the TMPD fluorescence temperature dependence independent of the concentration and laser power. The difference between the extinction effects of the laser sheet through two jets was estimated to be small $(0.4 \%$ incident laser intensity decrease per $1 \mathrm{~cm}$ path), so that it can be negligible.

The data of this investigation clearly showed a temperature effect, but the number density is also a function of temperature at a fixed pressure, so the data needed to be corrected to account for this effect. Defining a temperature dependent function, $f$, as 


$$
f(T) \equiv{\overline{\sigma_{T M P D}}}_{T}(T) \cdot \bar{\phi}_{T M P D}(T)
$$

one can use Equations (4.2) and (4.3) and the ideal gas law, to find the ratio of the measured TMPD fluorescence in the two jets (at the different temperatures) giving

$$
\frac{N_{L I F, T i}}{N_{L I F, \text { Tref }}}=\frac{N_{T M P D, T i} \cdot f\left(T_{i}\right)}{N_{T M P D, T r e f}}=f\left(T_{i}\right) \cdot \frac{T_{\text {ref }}}{T_{i}}
$$

The function of temperature, $f\left(T_{i}\right)$, isolates the temperature dependence of the TMPD fluorescence.

Figure 4.8 shows the temperature response data taken on three different runs. The data is quite repeatable and shows that the temperature dependence of the TMPD fluorescence is not a single-valued function of temperature. The fluorescence yield increases with temperature up to $600 \mathrm{~K}$, then decreases nearly linearly with temperature with a further increase in temperature. This data reflects the trends reported in the literature which up to this point appeared to be contradictory. Felton et al. [30] reported an increase in the fluorescence with temperature and related it to an increase in the absorption cross section, but their data was acquired below $600 \mathrm{~K}$ as shown in Figure 3.10. In other studies the TMPD fluorescence was found to decrease with temperature [32,35], but this data was acquired at temperatures above $600 \mathrm{~K}$ (e.g. Figure 3.11). The multi-valued response shown in Figure 4.8 suggests that TMPD would not be a good dopant for thermometry, however, the data of Figure 4.8 will allow a quantification of the vapor concentration. 


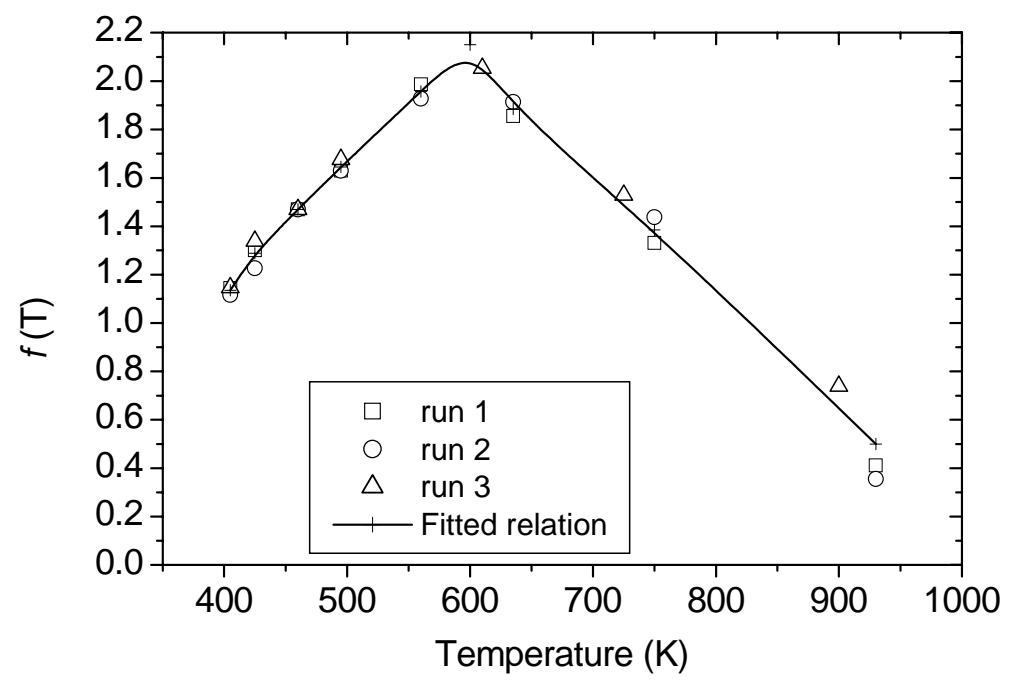

Figure 4.8 TMPD fluorescence dependence on temperature.

\subsubsection{Extinction of the Laser Sheet through the Vapor Phase}

The laser sheet travels longer distance along the spray-axis in this experiment, so the effect of laser sheet extinction should be corrected for. By the use of Lambert-Beer's law,

$$
I_{i}=I_{0} 10^{-A}, A=\int_{0}^{L} \varepsilon \cdot C_{g a s} d l
$$

where $I_{i}$ is the incident intensity at a pixel, $I_{0}$ is the initial intensity without enduring any extinction, $A$ is the absorbance of the in-cylinder gas, $L$ is a travel distance of the laser sheet $[\mathrm{cm}], C_{g a s}$, is the concentration of the in-cylinder gas $[\mathrm{mol} / \mathrm{l}]$. The extinction coefficient in the vapor phase, $\varepsilon[1 / \mathrm{mol}-\mathrm{cm}]$, is the sum of the absorption and Rayleigh scattering. In fact, Rayleigh scattering can be ignored because its cross section is usually much less than the molar absorption coefficient. Since naphthalene does not absorb 355 nm light, the absorption occurs only by TMPD. 
Thus, Equation (4.5) can be written as follows;

$$
\begin{aligned}
& I_{i}=I_{0} \exp \left(-\int_{0}^{L} \sigma_{T M P D} \cdot N_{T M P D} d l\right) \\
& \text { where } \sigma_{T M P D}=\varepsilon \ln (10) \cdot 1000 /(\text { Avogadro \#) }
\end{aligned}
$$

The laser absorption by TMPD can be estimated using the literature value of $\varepsilon$, $650 \mathrm{l} / \mathrm{mol}-\mathrm{cm}$ [47]. Assuming an equivalence ratio of 4 and total gas density of $25 \mathrm{~kg} / \mathrm{m}^{3}$ in the vapor phase, the incident intensity of the laser decreases in as much as $48 \%$ per 1cm path from Equation (4.6).

To determine the absorption cross-section under variations of temperature, images directly from the dual heated jet data (Figure 4.7) can be used, but this attempt was unsuccessful since the spatial resolution was not good enough to measure the extinction effect of the jets against estimating a 1\% incident laser intensity decrease per $1 \mathrm{~mm}$ path at a reference temperature of $400 \mathrm{~K}$. From Figure 2.11 of $\S 2.3 .2$, the absorbance of TMPD vapor was minimally affected by temeprature between 550 and $800 \mathrm{~K}$. Thus, the literature value of $\varepsilon=650 \mathrm{l} / \mathrm{mol}-\mathrm{cm}$ [47] was used as a constant independent of temperature for this study.

\subsubsection{Estimation of Local Temperature}

Since local temperature in the vapor phase is spatially varying due to liquid evaporation, and TMPD fluorescence depends on temperature (Figure 4.8), the estimation

of local temperature is one of most critical issues to make accurate measurements. The 
local temperature can be estimated with the assumption of adiabatic mixing between the fuel and air [58,2,32,35,44]. The thermodynamic analysis with this adiabatic assumption was first introduced by El Wakil et al. [58]. "Experimentally, adiabatic saturation as applied to the diesel spray would be realized by sealing a gas and a liquid that would not absorb the gas in an insulated container and allowing them to sit for a period of time until they reached thermodynamic equilibrium [58].” Using energy conservation with an assumption that the saturation temperatures and evaporating rates of the fuel and TMPD are the same, the bulk mean temperature $\left(T_{m i x}\right)$ in the region where all fuel has evaporated was calculated as follows [58];

$$
\int_{T_{\text {mix }}}^{T_{a m b}} c_{p, a} d T=\chi_{F / A}\left[\int_{T_{f, i}}^{T_{\mathrm{int}}} c_{p, \text { liquid }} d T+h_{v, T_{\mathrm{int}}}+\int_{T_{\mathrm{int}}}^{T_{m i x}} c_{p, v a p o r} d T\right]
$$

where $T_{a m b}$ is the temperature of the gas entrained into the spray $[\mathrm{K}], c_{p, a}$ is specific heat of the ambient gas $[\mathrm{J} / \mathrm{mol}-\mathrm{K}], \chi_{\mathrm{F} / \mathrm{A}}$ is the mole fraction of fuel, $T_{f, i}$ is the initial temperature of the liquid fuel $[\mathrm{K}], T_{\text {int }}$ is the intermediate temperature at which the fuel vaporizes $[\mathrm{K}], c_{p, \text { liquid }}$ is the specific heat of the liquid fuel $[\mathrm{J} / \mathrm{mol}-\mathrm{K}], h_{v}$, Tint is the latent heat of vaporization at the intermediate temperature $[\mathrm{J} / \mathrm{mol}]$, and $c_{p \text {,vapor }}$ is the specific heat of the fuel vapor [J/mol-K]. The term on the left in EQ. (4.7) expresses the decrease of thermal energy of the ambient gas; the term on the right expresses the increase in the thermal energy of the fuel. The assumption of a constant pressure process during the interested interval should be valid as discussed in $\S 3.1 .2$.

Also, the bulk mean temperature $\left(T_{m i x}\right)$ in the region where the final equilibrium mixture contains air, fuel vapor and liquid fuel in equilibrium with its vapor can be calculated as follows [58]; 


$$
\int_{T_{\text {mix }}}^{T_{a m b}} c_{p, a} d T=\chi_{F / A} \int_{T_{f, i}}^{T_{\text {mix }}} c_{p, \text { liquid }} d T+\frac{P_{f, T_{\text {mix }}}}{T_{\text {mix }}} \cdot \frac{T_{a m b}}{P_{a m b}} \cdot h_{v, T_{\text {mix }}}
$$

where $P_{f, T m i x}$ is the vapor pressure of the fuel at temperature $T_{m i x}[\mathrm{kPa}], P_{a m b}$ is the initial total pressure of the ambient gas at temperature $T_{a m b}[\mathrm{kPa}]$, and $h_{v}$, Tmix is the latent heat of vaporization at temperature $T_{\operatorname{mix}}[\mathrm{J} / \mathrm{mol}]$. However, Eq. (4.8) can not be applied in the exciplex technique since it is not possible to separate the vapor and liquid phases because of the cross-talk effect.

Thermodynamic and physical properties of the doped fuel were determined from references 60 and 61 at an assumed mixture of 90\% dodecane and 10\% naphthalene since data for TMPD was not available. The mixture data was determined using Dalton's and Raoult's laws applied to the vapor and liquid phase respectively.

The initial liquid-fuel temperature, $T_{f}$, may be higher than the fuel supply temperature, $293 \mathrm{~K}$ due to heat transfer from the premixed combustion to the injector tip as well as from viscous energy dissipation through the injector hole. Table 4.1 shows the small sensitivity of the mixture temperature according to $1 \mathrm{~K}$ uncertainty of the liquidfuel temperature. As well, since the experiment injects by single shot, the initial liquidfuel temperature may be reasonably used as the fuel supply temperature. 
Table 4.1 Estimation of $T_{m i x}$ with respect to the change of $T_{f i}$

\begin{tabular}{|c|c|c|c|c|c|}
\hline $\begin{array}{c}\text { Equivalence } \\
\text { ratio } \\
{[-]}\end{array}$ & $\begin{array}{c}\text { Density } \\
{\left[\mathrm{kg} / \mathrm{m}^{3}\right]}\end{array}$ & $\begin{array}{c}T_{\text {amb }} \\
{[\mathrm{K}]}\end{array}$ & $\begin{array}{c}T_{f I} \\
{[\mathrm{~K}]}\end{array}$ & $\begin{array}{c}T_{\text {mix }} \\
{[\mathrm{K}]}\end{array}$ & $\begin{array}{c}\text { Sensitivity } \\
\left(\mathrm{d} T_{\text {mix }} / \mathrm{d} T_{\text {fi }}\right)\end{array}$ \\
\hline 1 & 25 & $1000 \mathrm{~K}$ & $298 \mathrm{~K}\left(=T_{\text {room }}\right)$ & $883 \mathrm{~K}$ & \multirow{2}{*}{0.13} \\
\cline { 1 - 3 } & & & $478 \mathrm{~K}\left(=T_{\text {vap }}\right)$ & $906 \mathrm{~K}$ & \\
\hline 4 & 25 & $1000 \mathrm{~K}$ & $298 \mathrm{~K}\left(=T_{\text {room }}\right)$ & $700 \mathrm{~K}$ & \multirow{2}{*}{0.28} \\
\cline { 4 - 5 } & & & $550 \mathrm{~K}\left(=T_{\text {vap }}\right)$ & $770 \mathrm{~K}$ & \multirow{2}{*}{0.29} \\
\hline 4 & 15 & $1000 \mathrm{~K}$ & $298 \mathrm{~K}\left(=T_{\text {room }}\right)$ & $695 \mathrm{~K}$ & \multirow{2}{*}{} \\
\cline { 4 - 5 } & & & $523 \mathrm{~K}\left(=T_{\text {vap }}\right)$ & $760 \mathrm{~K}$ & \\
\hline
\end{tabular}

\subsubsection{TMPD Vapor Concentration Indicative of Total Vapor Concentration}

For the naphthalene/TMPD doped fuel system a single component base fuel is preferred instead of using diesel fuel since it is free from any residual fluorescence from the diesel fuel and provides easier interpretation of the data. The photophysics of exciplex excitation should be independent of the solvent (fuel) as long as one considers low molecular weight alkanes [28]. However, from the standpoint of the evaporating characteristics of the dopant as a faithful marker, the boiling point and molecular weight of the fuel should be similar to those of the dopant. The dopants and several alkanes are shown in Table 4.2. While tetradecane may be better for the viewpoint of co-evaporation, dodecane may be preferred for the similar diffusion rate as TMPD in the gas phase. The preferential rates of diffusion and evaporation may induce a system error. However, at TDC conditions with a high injection pressure, i.e. 1000 bar, turbulent mixing limited 
vaporization [1,2] may make this error negligible since the evaporation of the droplet is rapid enough due to the large amount of energy transferred and finely atomized spray.

Dopant compositions of 5 to $10 \%$ by weight of naphthalene and 0.5 to $1 \%$ by weight of TMPD were used in the literature [26-37]. Higher TMPD, such like $1 \%$, may be better to obtain sufficient vapor signals. Table 4.2 shows the selected doped fuel system in bold.

Table 4.2 Doped fuel system

\begin{tabular}{|c|c|c|c|c|c|}
\hline \multicolumn{2}{|c|}{ Doped Fuel } & \% by weight & Boiling Pt. (K) & Mol. Wt & $\begin{array}{c}\text { Density } \\
\left(\mathrm{k \sigma} / \mathrm{m}^{3}\right)\end{array}$ \\
\hline \multirow[t]{5}{*}{ Fuel } & $\begin{array}{c}\text { n-heptane, } \\
\mathrm{C}_{7} \mathrm{H}_{16}\end{array}$ & $90 / 95$ & 371 & 100 & 684 \\
\hline & $\begin{array}{c}\text { n-decane, } \\
\mathrm{C}_{10} \mathrm{H}_{22}\end{array}$ & $90 / 95$ & 447 & 142 & 730 \\
\hline & $\begin{array}{c}\text { n-dodecane, } \\
\mathrm{C}_{12} \mathrm{H}_{26}\end{array}$ & $90 / 95$ & 489 & 170 & 750 \\
\hline & $\begin{array}{c}\text { n-tridecane, } \\
\mathrm{C}_{13} \mathrm{H}_{28} \\
\end{array}$ & $90 / 95$ & 508 & 184 & 757 \\
\hline & $\begin{array}{c}\text { n-tetradecane, } \\
\mathrm{C}_{14} \mathrm{H}_{30}\end{array}$ & $90 / 95$ & 526 & 198 & 763 \\
\hline \multirow{2}{*}{$\begin{array}{l}\text { Dop- } \\
\text { ant }\end{array}$} & $\begin{array}{c}\text { Naphthalene, } \\
\mathrm{C}_{10} \mathrm{H}_{\mathbf{8}} \\
\end{array}$ & $9 / 4.5$ & 491 & 128 & 1150 \\
\hline & $\begin{array}{c}\text { TMPD, } \\
\mathrm{C}_{10} \mathbf{H}_{16} \mathbf{N}_{2}\end{array}$ & $1 / 0.5$ & 533 & 164 & 931 \\
\hline
\end{tabular}

\subsubsection{Cross-talk between the Liquid and Vapor Phase}

Since the contribution of the liquid phase signal to the vapor phase signal can not be avoided, quantitative vapor phase information is only possible for regions where all the fuel has been vaporized. Thus, during the injection period while liquid is present the vapor phase concentration may be overestimated. However, after the end of injection and past the liquid core the effect of cross talk can be negligible, and quantification of the 
vapor phase is accurate according to the fact that TMPD fluorescence is much stronger than the exciplex fluorescence in the pure vapor phase.

\subsection{Calibration Procedure}

The calibration of the raw fluorescence images was achieved by direct comparison with the absolute calibration with corrections made for the absorption of the laser sheet through the vapor TMPD, the ambient temperature at the time of injection, the local temperature due to evaporative cooling, and the nonuniformity of the incident laser sheet. The fluorescence signal at a pixel position $(x, y)$ can be rewritten from Eq (4.2), Eq (4.3) and Eq (4.6) as

$$
N_{L I F}(x, y)=K \cdot N_{T M P D}(x, y) \cdot \frac{I(x, y)}{I(0, y)} \cdot f(T)
$$

where $x$ is the distance along the laser sheet (also the spray axis) direction, $y$ is the normal distance from the spray axis, $I(x, y)$ is the incident intensity at the pixel, and $I(0, y)$ is the initial incident intensity. $I(0, y)$ is constant, $I_{0}$ which was used for the calibration, regardless of $y$ value after correcting nonuniformity of the incident laser sheet profile. The ratio of the two laser intensities is determined from Equation (4.3).

The overall calibration procedure is shown schematically in Figure 4.9. An initial estimate of the TMPD number density was made by simply applying the baseline calibration to the data (i.e. assuming no absortion and a uniform temperature). From this fuel concentration the temperature field is estimated using Equation (4.4). The vapor concentration field is then updated using the corrections for the temperature dependence 


$$
\begin{aligned}
& N_{L I F}(x, y)=K \cdot N_{\text {TMPD }}(x, y) \cdot \frac{I_{i}}{I_{0}} \cdot f(T) \\
& N_{T M P D}^{(1)}(x, y)=\frac{N_{L I F}(x, y)}{K} \quad \stackrel{\text { Energy Balance }}{\longrightarrow} \quad T^{(1)}(x, y) \\
& N_{\text {TMPD }}^{(2)}(x, y)=\frac{N_{L F}(x, y)}{K \cdot \exp \left[-\int_{0}^{x} \sigma_{T M P D} \cdot N_{\text {IMPD }}^{(1)}(x, y) d x\right] \cdot f\left(T^{(1)}\right)} \quad \longrightarrow \quad T^{(2)}(x, y) \\
& \Delta=N_{T M P D}^{(n)}(x, y)-N_{T M P D}^{(n-1)}(x, y) \leq 1 E-5
\end{aligned}
$$

Figure 4.9 Algorithm for the vapor signal calibration.

of the fluorescence and the beam extinction. This procedure is iterated until the change in the fuel concentration falls below a specified threshold.

The equivalence ratio, $\Phi$, was also obtained as

$\Phi=\frac{N_{T M P D}(x, y)}{P_{T M P D, \Phi=1} \cdot N_{\text {avog }} /(R \cdot T(x, y))}$

where the denominator is the number density corresponding the stoichiometric fuel-to-air ratio at the pixel $\left.\left[/ \mathrm{cm}^{3}\right]\right), P_{\mathrm{TMPD}, \phi=1}$ is the TMPD partial pressure corresponding the stoichiometric fuel-to-air ratio [bar], Navog is the avogardro number $\left(6.022 \times 10^{23}[/ \mathrm{mol}]\right)$ and $R$ is the gas constant $\left(83.1451 \mathrm{~cm}^{3} \mathrm{bar} / \mathrm{K} \cdot \mathrm{mol}\right)$. Here, the stoichiometric fuel-to-air ratio used was assumed with a diesel fuel as $1.35 \%$ by mole [59]. This formulation counts for the local total density change due to spatial temperature variations in the field, which impact equivaalence ratio but not the measured fuel number density. 


\section{Chapter 5. RESULTS AND DISCUSSION I}

\section{- EXCIPLEX LIF CONCENTRATION MEASUREMENTS}

This chapter is divided into five main sections. §5.1 describes the results of the exciplex application for the qualitative liquid and quantitative vapor phase, and $\S 5.2$ describes the uncertainty estimation of this study measurement. The remaining sections use the quantitative results to study physical effects. $\$ 5.3$ shows the effects of ambient gas density and temperature, §5.4 demonstrates the effects of injection pressure, and $\S 5.5$ describes the effects of nozzle hole size.

\subsection{Exciplex LIF Application for the Qualitative Liquid and Quantitative Vapor Phase}

\subsubsection{Qualitative Liquid Phase}

To verify the liquid phase exciplex data, a comparison was performed of the liquid-phase exciplex penetration data to the penetration data acquired from the Mie scattering images at the same conditions. The results are shown in Figure 5.1, which were obtained by averaging three experimental runs for each data. The Mie scattering data were acquired using the same experimental setup described in §3.2.4. A threshold of ( $3 \times$ the background noise) was used to define the spray penetration length along the spray-axis. The spray time origin was defined by linearly extrapolating to zero penetration, assuming a linear relation between the initial penetration and time. In Figure 5.1, the 95\% confidence interval error bars are shown only on the last data point for each 
technique to maintain graph clarity. The error bars shown are typical for each data point in their respective data sets. As a reference, an estimate of the intact liquid length from the Siebers' relation [2] is also shown. For this estimation, the area-contraction coefficient used was assumed to be 0.8 , and the spray-spreading angle used was obtained from the empirical relationship of ref. 2 due to difficulty defining the angle from singleshot transient spray images. Figure 5.1 shows the close correlation of the intact liquid length measured by both techniques, and the good agreement with the estimated intact liquid length. Therefore, the liquid phase extent seems to be well represented by the exciplex technique.

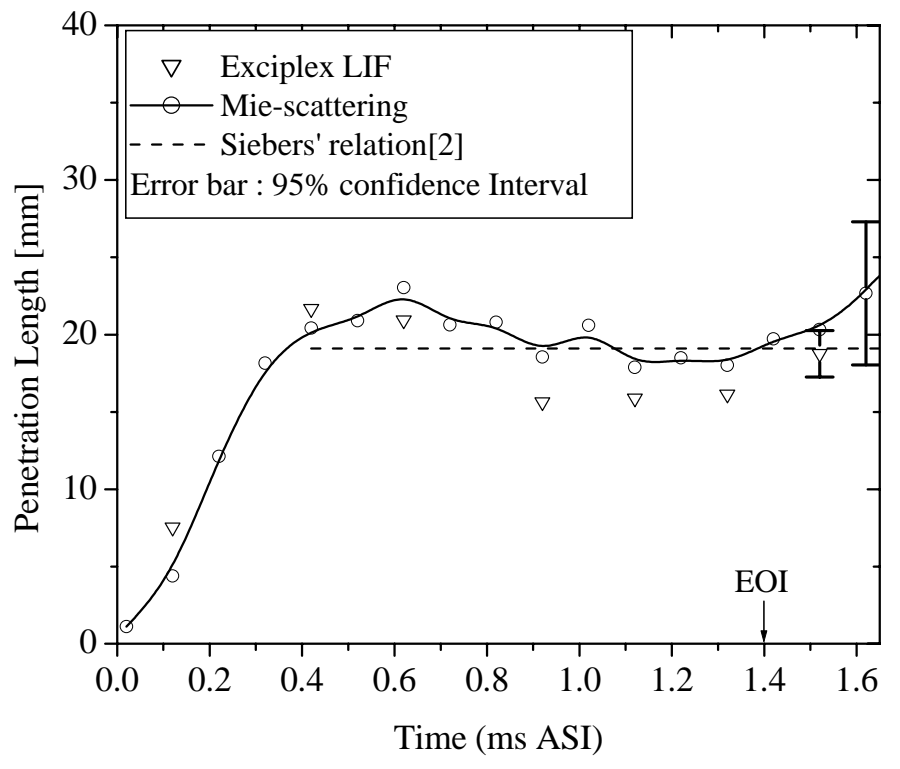

Figure 5.1 Comparison of liquid penetration length between Mie scattering signal and the exciplex (liquid) fluorescence signal at a density of $15 \mathrm{~kg} / \mathrm{m}^{3}$, and temperature of $1200 \mathrm{~K}$. 


\subsubsection{Quantitative Vapor Phase}

Figure 5.2-4 show the temporal evolution of the spatial distribution of equivalence ratio (left) and temperature (right) at a density of $15 \mathrm{~kg} / \mathrm{m}^{3}$ and temperatures of 800,1000 and $1200 \mathrm{~K}$ respectively. These images are the result of the calibration procedure mentioned in the previous chapter. As a matter of convenience, the liquid phase extent is shown graphically as an elliptical region superimposed on the image. Although the equivalence ratios and temperatures in regions containing both liquid and vapor were calculated using Equation 4.8, the results in these regions are to be discarded because of the cross-talk effect. The numbers shown on the axes are the distance from the injector tip in mm, the injector tip position is shown with a cross, and the gray scale on the right shows the temperature or equivalence ratio correspondence. The nozzle size was $158 \mu \mathrm{m}$ and the injection pressure was $90 \mathrm{MPa}$.

During the earliest stages of the injection shown in Figures 5.2-4, the penetration of the vapor phase is seen to match the liquid phase penetration. Following the initial phase of the spray penetration for which the liquid and vapor phases coexist at the leading edge of the jet, the liquid phase penetration ceases. After this time, the vapor phase continues to penetrate at the leading edge of the jet while the liquid extent actually retracts slightly. This pattern, an intact liquid region that has a finite length and the jet leading edge defined by the vapor region, persists through the remainder of the injection. The existence of a finite intact liquid length is consistent with other investigators [14-17]. Shortly after the end of injection the liquid core detaches from the nozzle, convects downstream and rapidly vaporizes. 

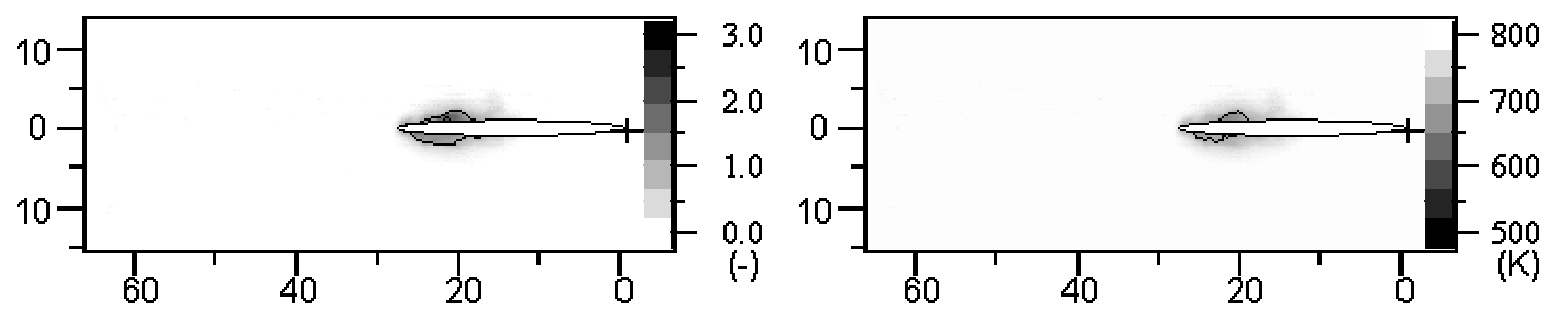

$0.4 \mathrm{~ms}$ ASI
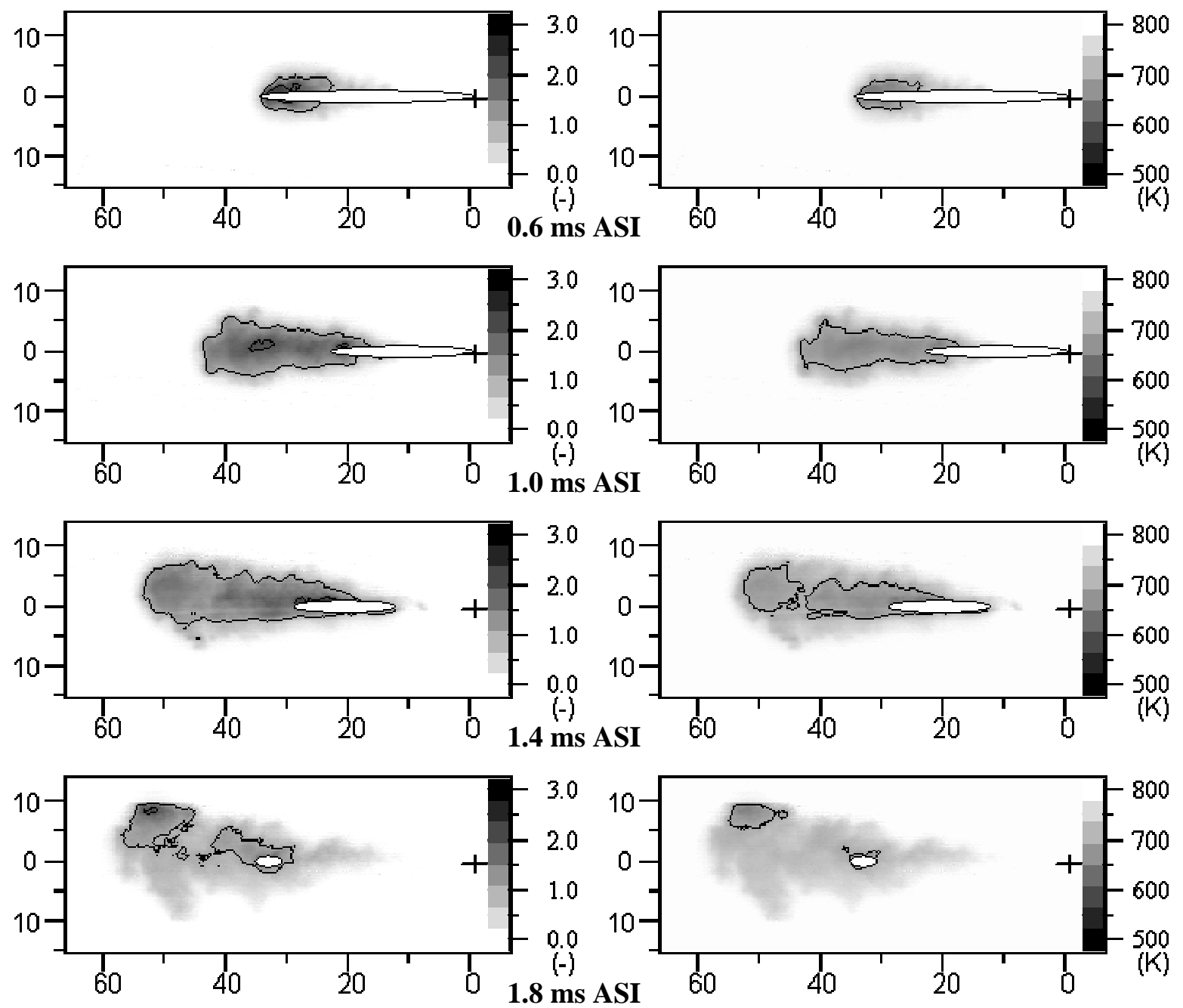

(a) Equivalence ratio

(b) Temperature

Figure 5.2 Quantitative images of equivalence ratio (left) and temperature (right) at the ambient density of $15 \mathrm{~kg} / \mathrm{m}^{3}$ and temperature of $800 \mathrm{~K}$. The solid lines in the images, shown for convenience, represent the contours with increments of 1 for equivalence ratio and $-100 \mathrm{~K}$ for temperature from the ambient values ( 0 and $800 \mathrm{~K}$ ), respectively. 

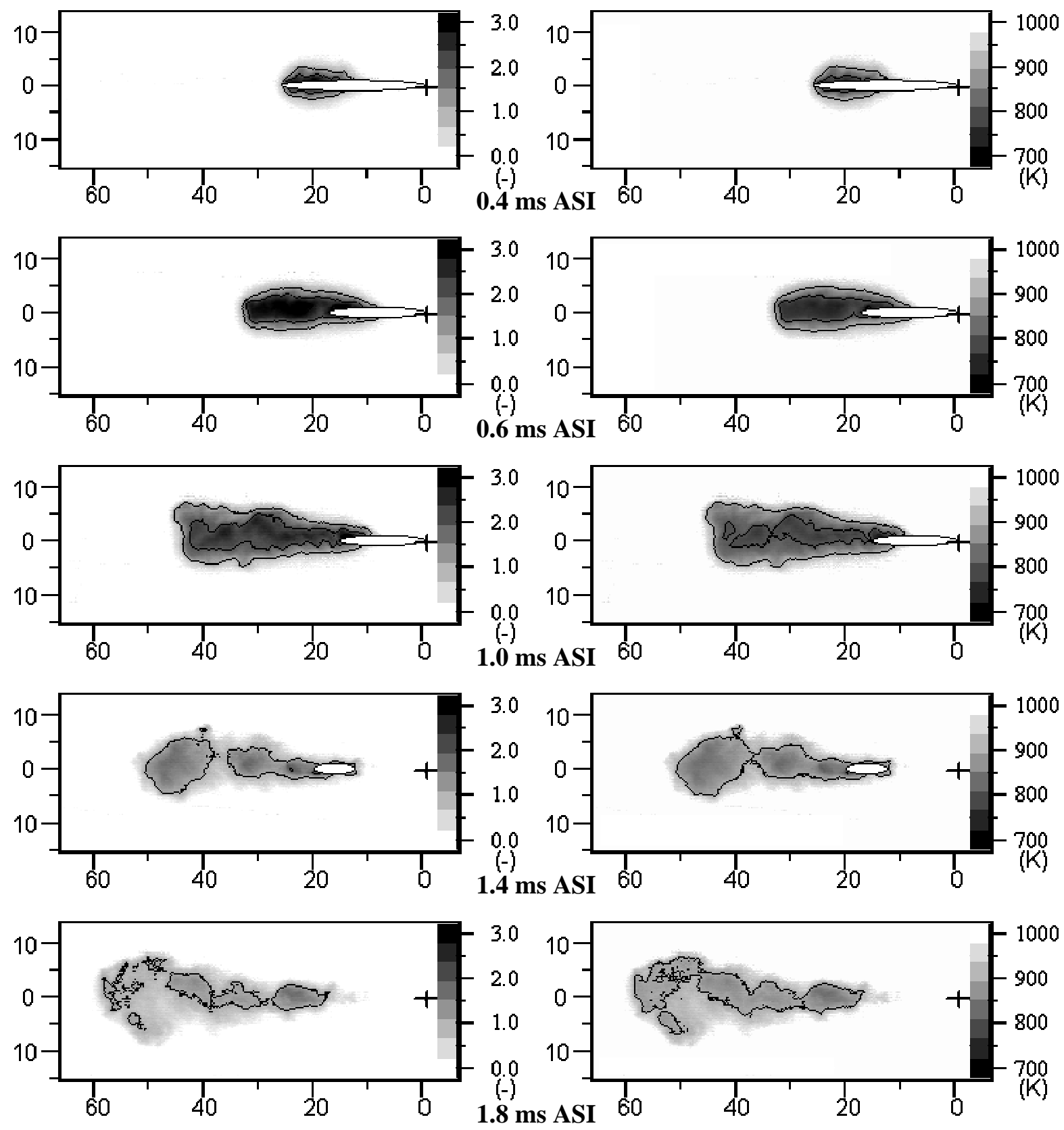

(a) Equivalence ratio

(b) Temperature

Figure 5.3 Quantitative images of equivalence ratio (left) and temperature (right) at the ambient density of $15 \mathrm{~kg} / \mathrm{m}^{3}$ and temperature of $1000 \mathrm{~K}$. The solid lines in the images, shown for convenience, represent the contours with increments of 1 for equivalence ratio and $-100 \mathrm{~K}$ for temperature from the ambient values (0 and $1000 \mathrm{~K}$ ), respectively. 

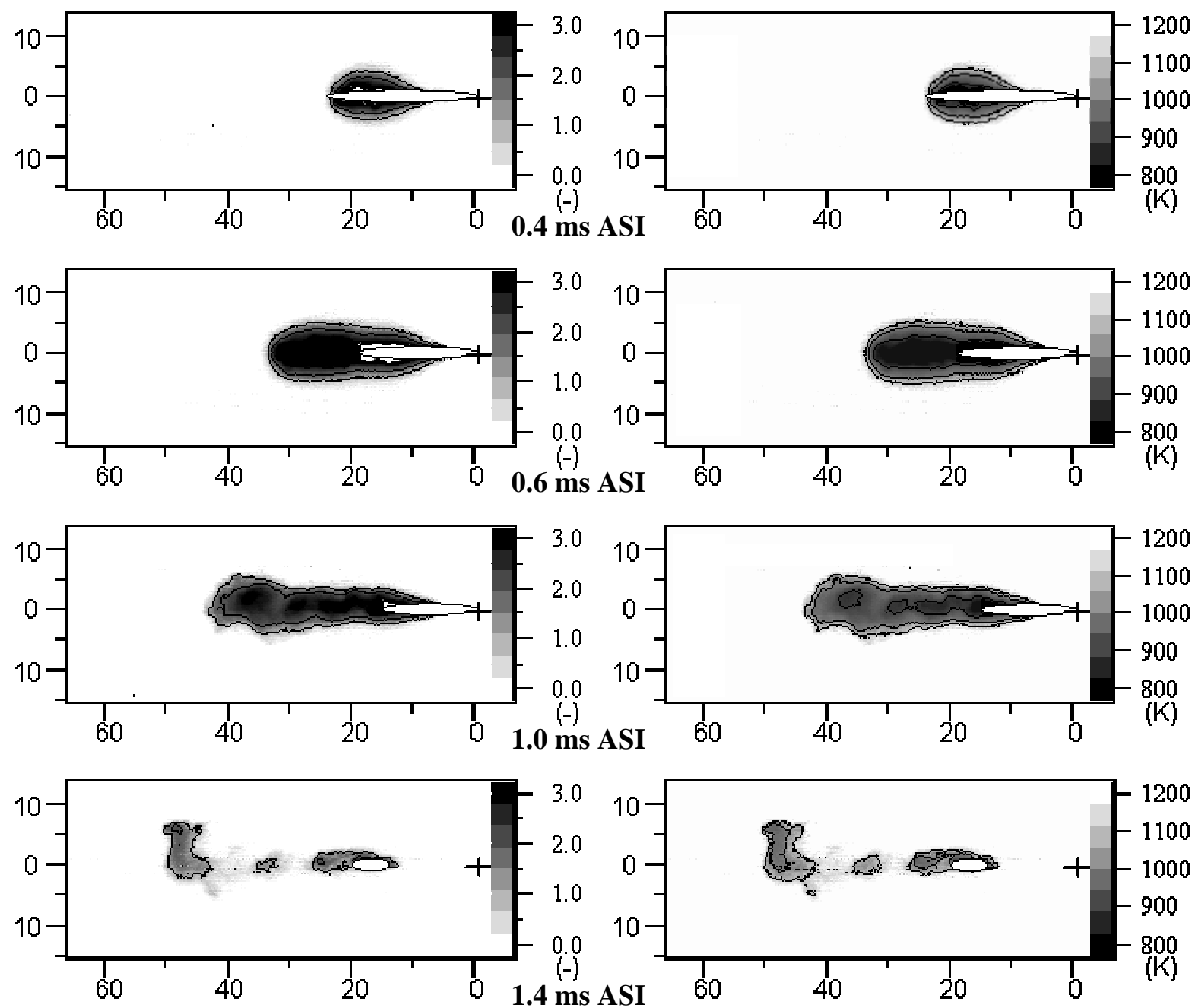

$1.0 \mathrm{~ms}$ ASI
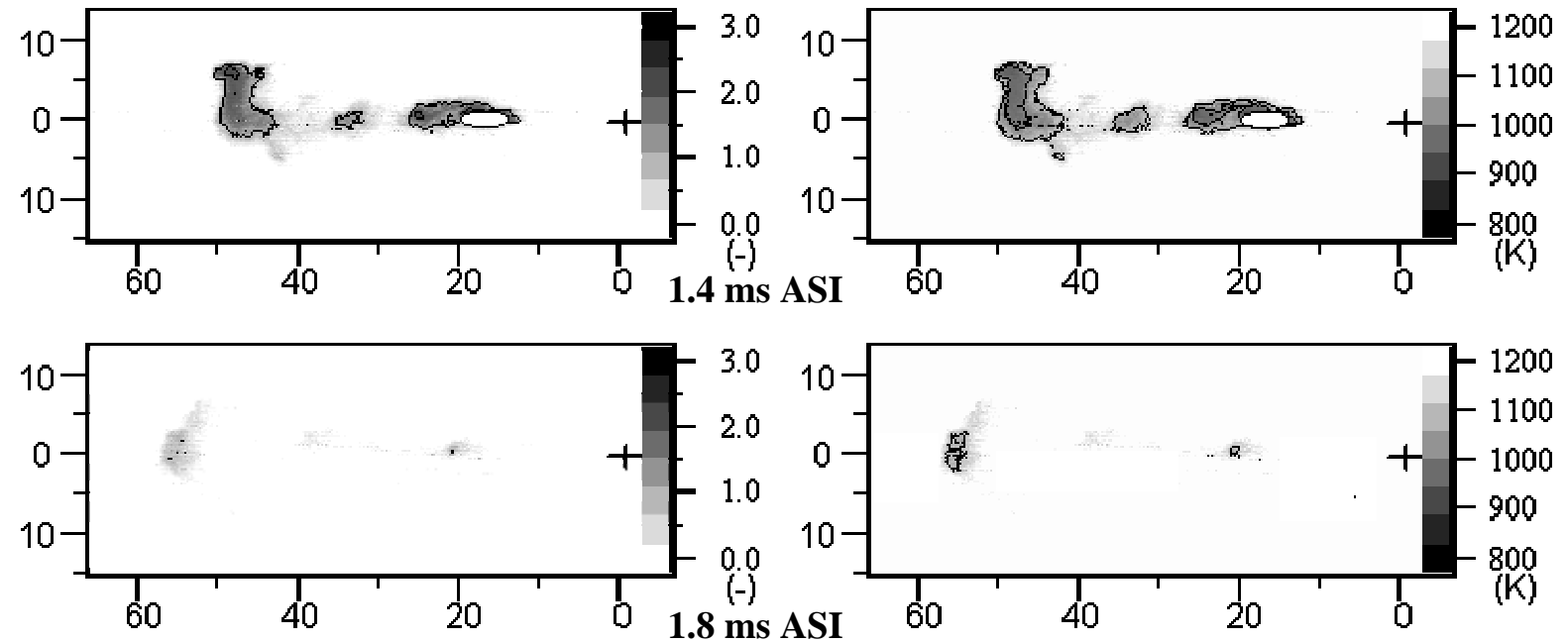

(a) Equivalence ratio

(b) Temperature

Figure 5.4 Quantitative images of equivalence ratio (left) and temperature (right) at the ambient density of $15 \mathrm{~kg} / \mathrm{m}^{3}$ and temperature of $1200 \mathrm{~K}$. The solid lines in the images, shown for convenience, represent the contours with increments of 1 for equivalence ratio and $-100 \mathrm{~K}$ for temperature from the ambient values ( 0 and $1200 \mathrm{~K}$ ), respectively. 
Several issues arise from the data at $1200 \mathrm{~K}$, shown in Figure 5.4, that need further discussion. First, the maximum temperature achieved in the dual heated jet experiment was about $950 \mathrm{~K}$, and thus the temperature dependence function, $f(T)$, was assumed to be constant above a temperature of $1000 \mathrm{~K}$ corresponding to the value at $1000 \mathrm{~K}$, or $f(T)=0.2$. Therefore, near the edge of the vapor jet where the temperature is close to the ambient, the concentrations may be under-predicted. Also, after the end of the injection, $1.8 \mathrm{~ms}$ ASI, only very weak signals are observed in the region where a high vapor density would be expected. The cause for this behavior is believed to be the thermal decomposition of the TMPD. This would imply that the timescale of thermal decomposition is on the order of one millisecond at these conditions. Therefore, the quantitative application of the exciplex technique seems to have a practical limitation to flowfields for which the temperature is below $1000 \mathrm{~K}$. However, it is believed that the data acquired at short times after injection (i.e. having a short residence time at high temperatures) and within the dense vapor region (i.e. experiencing a low temperature) are valuable.

\subsubsection{Discusssion on the Verification of the Measurement}

\subsubsection{Comparison of the Measured Mass with the Injected Mass}

To assess the accuracy of the calibration procedure, the 2-D fuel vapor concentration shown in Figure 5.2-4 was integrated and compared with the known mass of fuel that had been injected up to that time. In order to perform this, the vapor 
distribution was assumed to be axisymmetric and only the region beyond the intact liquid length was considered to avoid the cross-talk issue. The results for a density of $15 \mathrm{~kg} / \mathrm{m}^{3}$ and all three temperatures are shown in Figure 5.5.

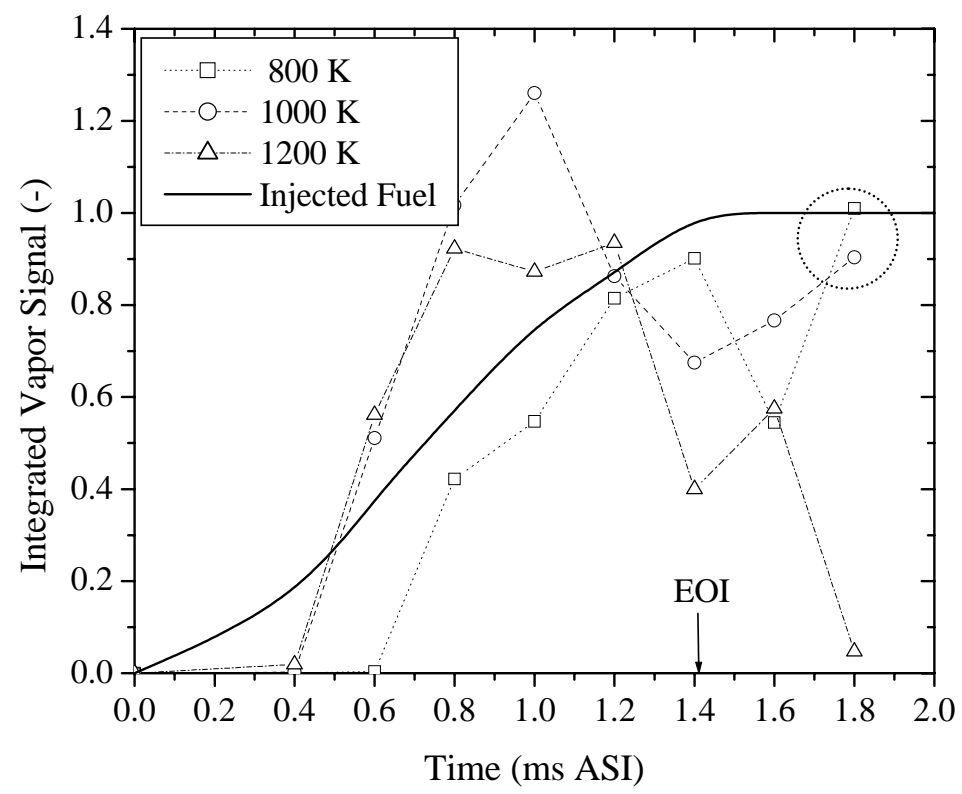

Figure 5.5 Integrated fuel vapor mass versus time after the start of injection using nozzle hole diameter of $158 \mu \mathrm{m}$ at an ambient density of $15 \mathrm{~kg} / \mathrm{m}^{3}$.

At the latest time, $1.8 \mathrm{~ms}$, when all of the fuel is expected to be vaporized and no cross-talk issues exist there is excellent agreement between the integrated vapor mass and the total injected mass for temperatures of 800 and $1000 \mathrm{~K}$ (circled). The measured mass is within $10 \%$ of the injected mass which is considered excellent considering the number of corrections that are performed (to be discussed in §5.2). The $1200 \mathrm{~K}$ integrated mass after injection is significantly less than the injected mass due to thermal decomposition of the TMPD as described previously. 
During the injection period and shortly after the end of injection, the agreement between the vapor mass measured and injected is less favorable. This could be the result of a number of issues. First, overestimation of the vapor mass could result from the crosstalk issue. The liquid phase extent is determined from the liquid exciplex data, but the concentration of liquid in the core region is quite high and the camera has a limited dynamic range. This could result in liquid phase fuel existing at positions downstream of the indicated intact liquid length, providing an overpredicted apparent vapor phase concentration due to cross-talk from the liquid signal. Secondly, the asymmetric spray structure can also contribute to the overprediction of the vapor mass. The liquid position can deviate slightly from run-to-run (to be discussed in §5.1.3.2) due to the turbulent flowfield, which would change the liquid intersection point on the thin laser sheet. This asymmetric liquid extent could lead to overprediction since the vapor mass was only calculated beyond the intact liquid length. However, the fuel vapor that is present in the jet at distances less than the intact liquid length is not included in the total amount. Finally, the absorption cross-section used in the absorption correction was a constant value as given in the literature [47]. However, this value may change with thermodynamic conditions and has not been accounted for (to be estimated in §5.2.6).

Figure 5.6 shows another result from a smaller nozzle hole size (140 $\mu \mathrm{m}$ diameter, shown in Figure 5.22) showing better agreement with the total injected fuel volume, especially during the injection period and shortly after the end of injection. More consistent trends were found using a smaller nozzle hole size, possibly the result of less interference of the liquid phase (shorter liquid length) in the vapor concentration 
measurement (see §5.5). Therefore, this indicates that overprediction of the vapor mass measured during the injection period results mainly from the cross-talk effect and the asymmetric spray structure.

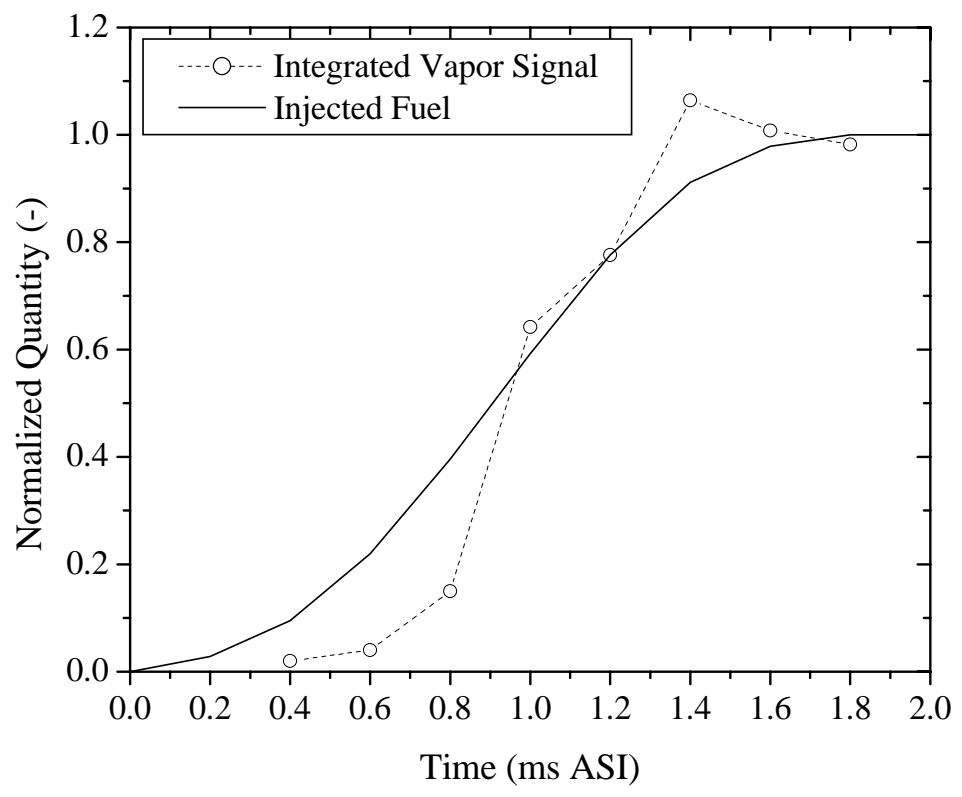

Figure 5.6 Integrated fuel vapor mass versus time after the start of injection using nozzle hole diameter of $140 \mu \mathrm{m}$ at an ambient density of $15 \mathrm{~kg} / \mathrm{m}^{3}$.

Figure 5.7 shows the integrated fuel vapor mass histogram normalized by the injected fuel mass compiled from a total of 18 images captured at the time when all of the fuel is vaporized. The integrated fuel vapor mass is the value after round-off. The 18 images resulted from different experiment dates, different injection pressures, and different hole sizes. From Figure 5.7, there is a 50\% occurrence probability that the normalized integrated mass is between 0.85 and 1.04 , and an $83 \%$ occurrence probability between 0.75 and 1.14. The averaged integrated fuel vapor is equivalent to $90 \%$ of the 
injected mass. It is possible that integrated fuel vapor did not reach $100 \%$ due to the inability of measuring the lowest equivalence ratios, which are lower than the resolution of the detection device. Additionally, the sprays were assumed to be axisymetric, when in reality they were not.

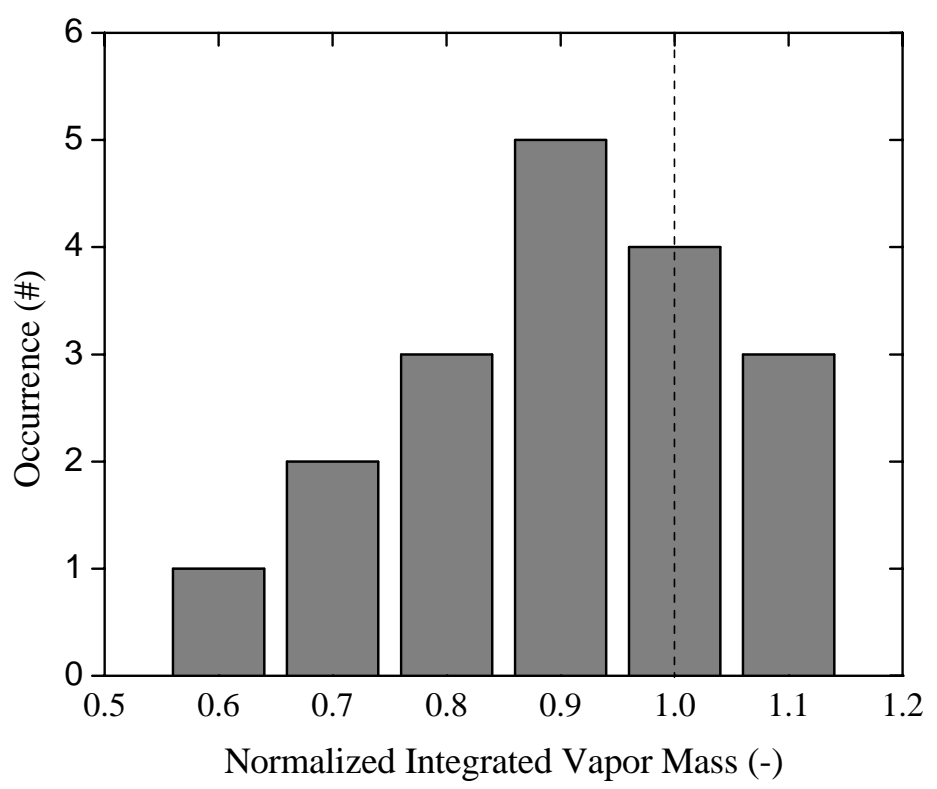

Figure 5.7 Integrated fuel vapor mass versus number of occurrences of a specific

normalized mass from a total of 18 images captured at the time when all of the fuel is vaporized.

\subsubsection{Run-to-Run Variation}

To investigate the effect of run-to-run variation, six images were acquired at the same conditions and are shown in Figure 5.8. The first 5 images in the figure were acquired on the same day, but the last image comes from Figure 5.3. It can be seen that the penetration and distribution of the vapor and liquid phases show some variability, and 
the level of variability is commensurate with that expected from a turbulent jet. The integrated vapor mass beyond the intact liquid region is also shown in the upper left corner of each image. From the mass flow rate measurement described in Figure 3.11, the run-to-run variations of the injected amount were confirmed to be less than $10 \%$. As discussed previously, the laser sheet is only $400 \mu \mathrm{m}$ thick and is nominally aligned with the spray axis. The transient asymmetric liquid position would change where the liquid intersected the laser sheet, giving rise to variations in the measured liquid phase since the vapor mass was only calculated beyond the intact liquid length.
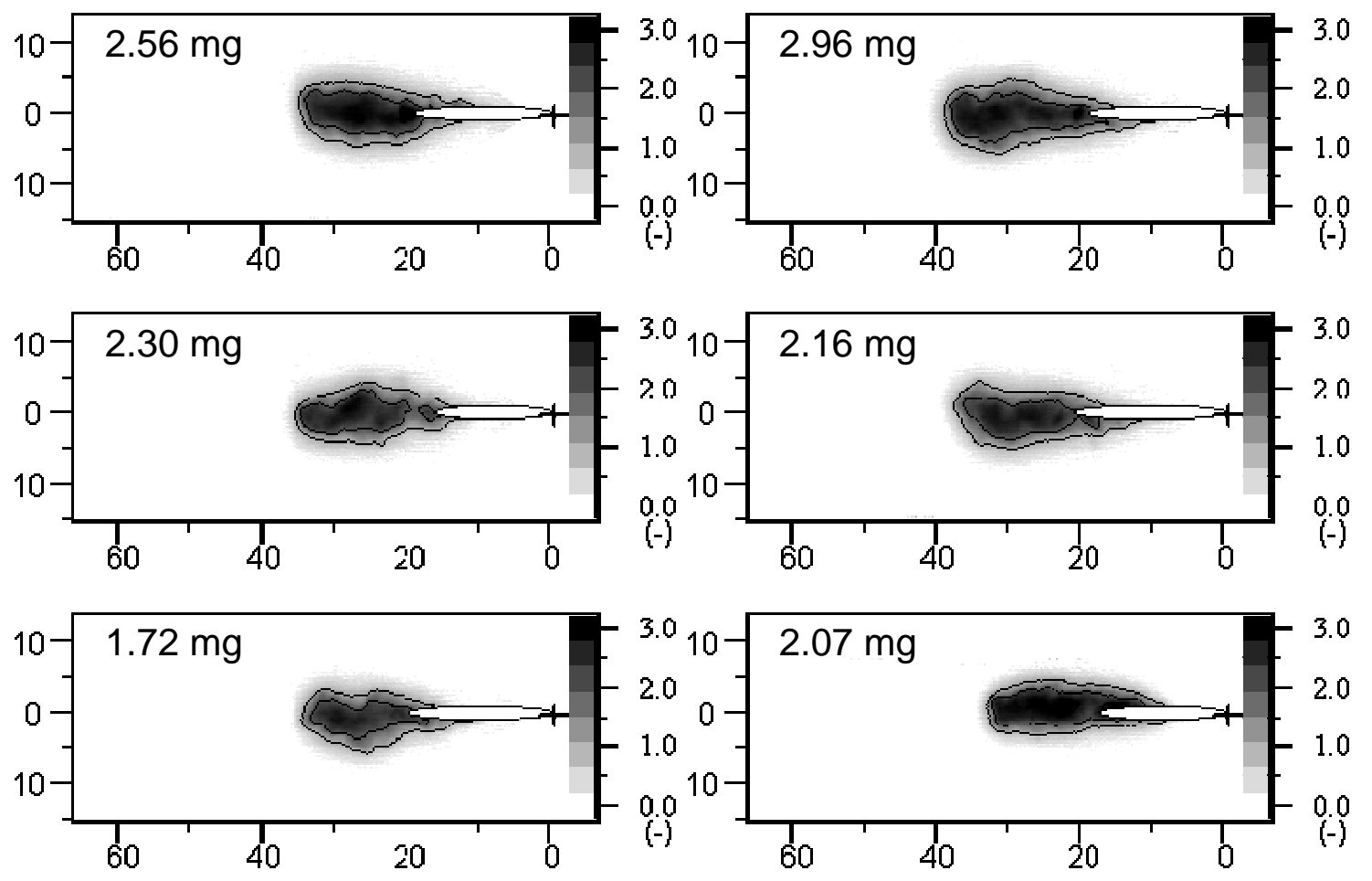

Figure 5.8 Images on run-to-run variation at a density of $15 \mathrm{~kg} / \mathrm{m}^{3}, 1000 \mathrm{~K}$, captured at $0.6 \mathrm{~ms}$ ASI. 


\subsubsection{Comparison with Other's Work}

As reviewed in §2.2, Espey et al. [44] acquired planar Rayleigh scattering images of the fuel vapor concentration past the intact liquid length on a plane oblique to the spray axis in an engine for a condition where the ambient temperature and pressure were estimated to be $1050 \mathrm{~K}$ and $5.0 \mathrm{MPa}$ (a calculated density of $16.5 \mathrm{~kg} / \mathrm{m}^{3}$ ). In their images, which were acquired near the ignition time and 0.63 ms after start of injection, the equivalence ratio in the majority of the leading portion of jet ranged from 2 to 4, and the edge of the jet was well defined with an abrupt rise from the background levels. They confirmed that the fuel was entirely vaporized in the region of their interest. Their measurements closely compare to the data at a density of $15 \mathrm{~kg} / \mathrm{m}^{3}$ and a temperature of $1000 \mathrm{~K}$ presented in Figure 5.2 (to be discussed further in chapter 6). No attempt was made to match the injection characteristics between the two experiments. From Figure 5.2 the equivalence ratio in the dense vapor region past the intact liquid length at a time of 0.6 ms ASI has a peak magnitude slightly larger than 3.0, and exhibits a large area for which the equivalence ratio exceeds 2.0. Thus, the magnitudes are in good agreement between the acquired data and those of Espey et al. [44]. However, at the edge of the vapor plume the gradients observed in the data are more shallow, giving a more Gaussian vapor profile than observed by Espey et al. These data were acquired at the same time as the data at $1200 \mathrm{~K}$, which shows much steeper gradients near the edge of the vapor plume, thus it is not expected that this result is an experimental artifact. As just noted, at higher ambient temperatures, and hence higher energy entrainment flux rates, the 
measured gradients are steeper suggesting that the top hat profile observed by Espey et al. may be predicated on these conditions.

In order to examine whether the measured gradients were correct, a series of experiments were performed at 1000 and $1200 \mathrm{~K}$ and $15 \mathrm{~kg} / \mathrm{m} 3$. The data was acquired the same day and the order was randomly chosen (see the first 5 images in Figure 5.8 for $1000 \mathrm{~K}$ case profiles). Figure 5.9 shows the equivalence ratios for a cross section of the leading portion of the diesel jet from 5 different experimental runs. For the case of 1200 K, Figure 5.9 (b), the profiles show much steeper gradients near the edge of the vapor plume (about 0.5 [/mm] for $1000 \mathrm{~K}$ and 0.75 [/mm] for $1200 \mathrm{~K}$ ). Therefore, Figure 5.9 can confirm that at higher ambient temperatures the edge of the jet has higher gradients.

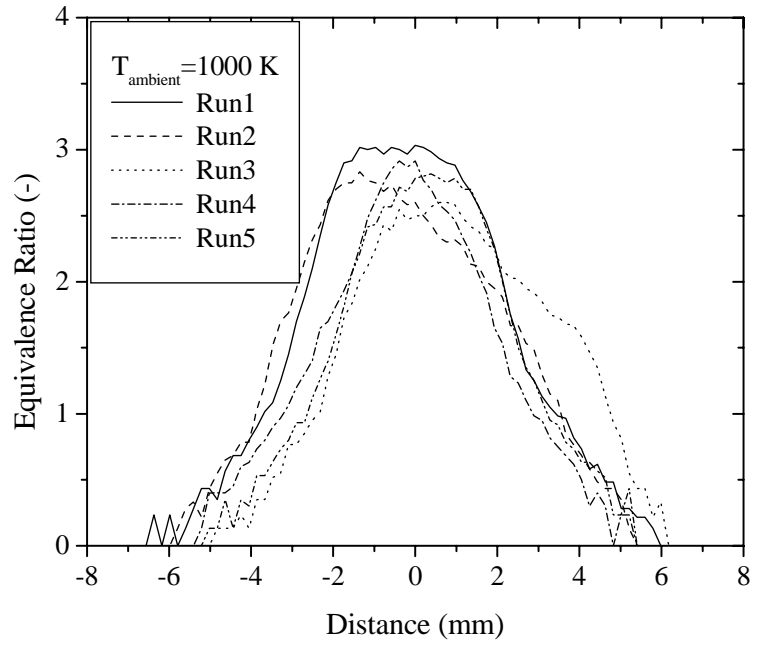

(a)

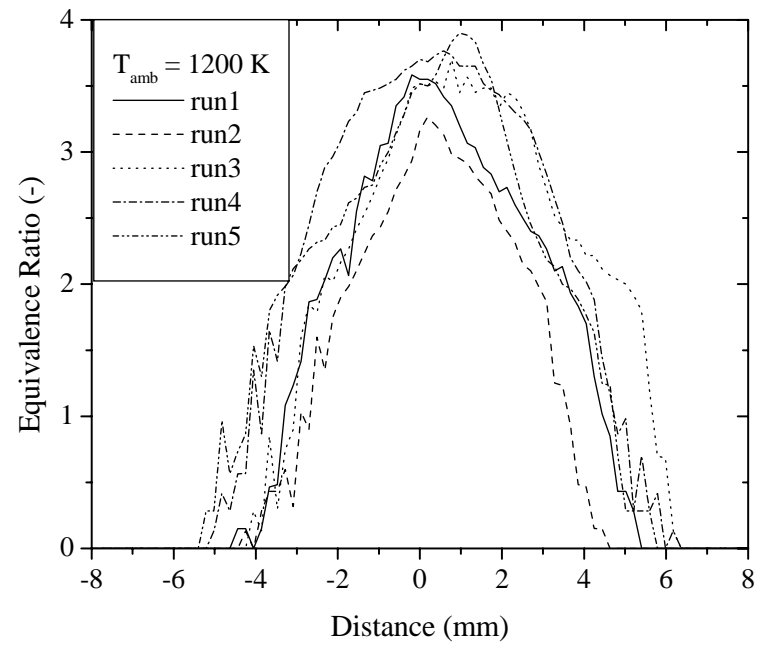

(b)

Figure 5.9 Equivalence ratios throughout the cross section of the leading portion of the diesel jet (25 $\mathrm{mm}$ downstream from the injection nozzle) around the time of start of ignition time at the ambient density of $15 \mathrm{~kg} / \mathrm{m}^{3}$, (a) at temperature of $1000 \mathrm{~K}$ and (b) $1200 \mathrm{~K}$. 


\subsection{Uncertainties in the Concentration Measurements}

If the estimated uncertainty, $\delta N_{\mathrm{TMPD}}$, in the results has the same probability of occurrence as the uncertainties in the individual measurements, it can be written as [62]

$$
\delta N_{\text {TMPD }}\left(x_{1}, x_{2}, \cdots, x_{n}\right)=\sqrt{\sum_{i=1}^{n}\left(\frac{\partial N_{T M P D}}{\partial x_{i}} \cdot \delta x_{i}\right)^{2}}
$$

where $x_{\mathrm{i}}$ is an independent variable used in the function $N_{\mathrm{TMPD}}$. Using Eq. (4.9) and normalizing the number density of TMPD and also assuming the uncertainties of the independent variables as their unit standard deviation, then Eq. (5.1) becomes

$$
\frac{\delta N_{T M P D}}{N_{T M P D}}=\sqrt{\left(\frac{\sigma_{K}}{K}\right)^{2}+\left(\frac{\sigma_{N_{L I F}}}{N_{L I F}}\right)^{2}+\left(\frac{\sigma_{I_{i}}}{I_{i}}\right)^{2}+\left(\frac{\sigma_{f}}{f}\right)^{2}}
$$

Therefore, the accuracy of the measurements depends on errors related to the quality of the calibration (§5.2.1), capturing fluorescence signals (§5.2.2), incident intensity (§5.2.3), and the quality of the temperature dependence function (§5.2.4). As well, the estimations of the temperature field (§5.2.5) and absorption coefficient (§5.2.6) may have uncertainties. The overall uncertainty in the TMPD concentration measurements for this study can be obtained using the uncertainty estimate of each section $(\S 5.2 .7)$.

\subsubsection{Uncertainties Related to Calibration Quality}

From Figure 4.2, TMPD fluorescence with respect to TMPD concentration showed a linear relationship. To estimate the value for $\sigma_{K} / K$, confidence limits for the 
least-square parameter (i.e., the slope) were used [63]. From the data from 8 runs on Figure 4.2, the value for $\sigma_{K} / K$ was estimated as $12.5 \%$.

\subsubsection{Uncertainties Related to Capturing Fluorescence Signal}

Errors related to capturing the fluorescence signal may result from shot-to-shot variations of background noise, pixel responsivity variations, shot noise of the detected photons, and shot-to-shot variations of the normalized laser sheet profile.

\subsubsection{Uncertainty from Background and Dark Noise}

To determine background noise, the experimental procedure was the same for the evaporating spray experiments, except that the injector did not operate. Background images were captured at three different instants, corresponding to gas temperatures of $1200 \mathrm{~K}, 1000 \mathrm{~K}$, and $800 \mathrm{~K}$, respectively. Since the main source of background noise seems to be the chemiluminescence of the residual fuel or soot deposits on the chamber, the noise can be almost negligible after thoroughly cleaning the chamber. To remove residual fuel in the crevice volume in the chamber, several premixed combustion runs without injection were performed. Using this remedy, background intensities for most pixels had zero pixel count except for locations (which are not in the interest region) around the laser access window and injector tip. Therefore, the background noise can be neglected in this study.

Dark noise was also negligible since most pixels had a zero pixel count, but frequently random streaks of about a 35 pixel count intensity occurred in spots in the 
images due to an unknown noise source in the lab. These were easily identified from the signals due to the streak pattern of spots. However, some images were discarded since the interference level was significant.

Therefore, the background and dark noise for this study was negligible.

\subsubsection{Uncertainty From Pixel Responsivity}

The responsivity of the detection system at each pixel is known to be constant over long periods of time. Thus, the responsivity for each pixel can be measured once, and used to correct sets of images [64]. The responsivities can be obtained by comparing the signal at each pixel on an averaged image by uniformly illuminating the detector system. For this study, the responsivity of the detection system was not corrected, but its uncertainty level was indirectly estimated in §5.2.2.4.

\subsubsection{Uncertainty from Camera Noise}

At a shot noise limited condition, uncertainties from camera noise can be estimated using the SNR (signal-to-noise) relationship [64]:

$$
S N R=\sqrt{N_{\text {photon }} \cdot \eta_{\text {det }} / k}
$$

where $k$ is the gain dependent noise factor which normally has a value between 1 and 4 , $\eta_{\text {det }}$ is the efficiency of the detector system, and $N_{\text {photon }}$ is the number of incident photons on the detector system.

For Eq. (5.3), $N_{\text {photon }}$ has to be estimated. At the thermodynamic condition of 15 $\mathrm{kg} / \mathrm{m}^{3}, 1000 \mathrm{~K}$ and stoichiometric ratio, $N_{\text {photon }}$ is estimated as $2.1 \times 10^{5}$ (see Appendix C). 
Then, assuming $k$ as 3 and $\eta_{\text {det }}$ as 0.2 , the camera shot noise $\left(\sigma_{C} / C\right)$ was estimated as $0.85 \%(=1 / \mathrm{SNR})$.

\subsubsection{Estimated Uncertainty from Normalized Laser Sheet Profiles}

The normalized laser sheet profile could experience shot-to shot variations due to laser beam profile fluctuations and low frequency vibrations in the optic equipment from seismic perturbations. To obtain the laser sheet profile, multiple images of a uniform distribution of TMPD vapor inside the spray chamber were used. To separate the effects of laser power shot-to-shot variation (to be discussed in §5.2.3) and laser sheet extinction, laser sheet profiles were normalized by the maximum intensity of each profile. Then, to perform laser sheet profile correction, the normalized profiles were again normalized by their mean profile shown in Figure 3.15.

Figure 5.10 shows the results of run-to-run variations of 16 normalized and corrected laser sheet profiles. The 16 profiles were selected from 8 images. The vertical locations of the images for the profiles were randomly selected. The laser sheet extent defined in Figure 5.10 was determined by applying a threshold of $65 \%$ of the maximum intensity since all the vapor signals in this study were confirmed to be within this laser sheet width.

The fluctuations with respect to unity on Figure 5.10 show shot-to-shot variations of the normalized laser sheet profile. As well, the fluctuations also include pixel responsivity variations and camera shot noise. Therefore, the fluctuations could give the level of uncertainty related to shot-to-shot variations of the normalized laser sheet profile, 
pixel responsivity variations and camera shot noise. Using the data of Figure 5.10, one standard deviation was calculated to be $5.0 \%$ with respect to the average of 1 . Therefore, the standard deviation, 5.0\%, could be used for the uncertainty level $\left(\sigma_{M} / M\right)$ related to shot-to-shot variation of the normalized laser sheet profile, pixel responsivity variations and camera shot noise.

Therefore, the uncertainty related to capturing of the fluorescence signal can be obtained by

$\frac{\sigma_{N_{L I F}}}{N_{L I F}}=\sqrt{\left(\frac{\sigma_{B}}{B}\right)^{2}+\left(\frac{\sigma_{M}}{M}\right)^{2}}=5.0 \%$

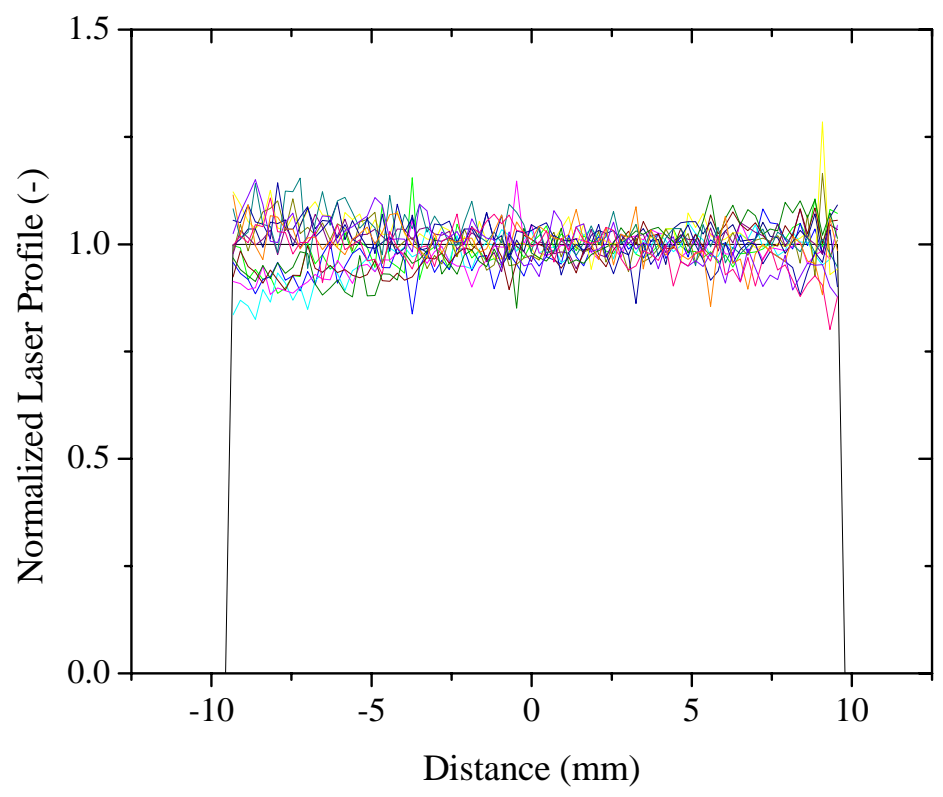

Figure 5.10 Run-to-run variation of 16 normalized and corrected laser sheet profiles. 


\subsubsection{Uncertainties Related to Incident Laser Intensity}

The laser intensity can be variable from run to run although the laser was set to give an average intensity of $13.5 \mathrm{~mJ}$ (measured by a light power meter) for this study. To determine this uncertainty, the light intensity was measured directly from reflection of the laser sheet on a portion of the injector tip. From 10 runs, the laser had 3.6\% uncertainty with respect to $13.5 \mathrm{~mJ}$.

Combustion products may deposit on the surface of laser and camera access windows. They can also interfere with laser transmission and fluorescence measurements, which causes lower fluorescence intensity for the detector system. The reflection signals of the laser sheet on a portion of the injector tip were (inadvertently) acquired for hot bomb conditions. After subtracting background noise, the intensity signals from the hot bomb case can be compared with those from the cold bomb. The standard deviation of 6 runs was $2.7 \%$ with respect to mean value, which was less than the uncertainty of laser shot-to-shot variation. Therefore, the effect of window contamination and in-cylinder gas (absorption of fluorescence) can be neglected since this effect and laser shot-to-shot variation are not independent and have a similar order of magnitude (2.7\% vs. $3.6 \%$ ).

Finally, an uncertainty related to the incident laser intensity is $3.6 \%$ of the 13.5 mJ laser power.

\subsubsection{Uncertainties Related to the Quality of the Temperature Dependence Function}

From Figure 4.8, the temperature dependence of the TMPD fluorescence between 600 and $950 \mathrm{~K}$ was almost linear. To estimate the value for $\sigma_{f} / f$, confidence limits for the 
least-square parameters (slope and y-intercept) [63] were used. From each run on Figure 4.8, the value for $\sigma_{f} / f$ was estimated as $3.6 \%, 3.7 \%$, and $3.9 \%$ at three typical temperatures of $800 \mathrm{~K}, 900 \mathrm{~K}$, and $1000 \mathrm{~K}$ respectively.

\subsubsection{Uncertainty from Estimation of Temperature Field}

From thermocouple measurements, shown in Chapter 3, a local maximum of a 50 K uncertainty, in the interested area of the spray chamber, was estimated.

Also, the local temperature estimation from Eq. 4.4 could have uncertainty. Because Eq. 4.4 is a relation for energy conservation, its spray application is based on an equilibrium state with Lagrangian description for a certain mass of the spray. Therefore, Eq. 4.4 could have better validity if a sufficient amount of entrained ambient gas is mixed thoroughly and moving with the same speed of an interested-amount-of-fuel, and if the residence time of the mass is long enough to reach an adiabatic saturation condition. A computational result from KIVA can be used to verify Eq. 4.4, but this is out of the scope of this study (so it is left for future work).

To estimate an uncertainty of the concentration measurements from the local temperature estimation, a $50 \mathrm{~K}$ uncertainty was assumed. Then, an image was reprocessed with the ambient gas temperature changed to $950 \mathrm{~K}$, the other parameters remained the same as the baseline condition (an ambient gas density of $15 \mathrm{~kg} / \mathrm{m}^{3}$ and a temperature of $1000 \mathrm{~K}$ ). Figure 5.11 shows the result. The equivalence ratio profile along the spray axis in Figure 5.3 (at 0.6 ms ASI) was compared with that obtained from recalibration with $50 \mathrm{~K}$ lower ambient gas temperature. The average difference of the two 
profiles was $15.8 \%$, which can indicate uncertainty from local temperature field estimation.

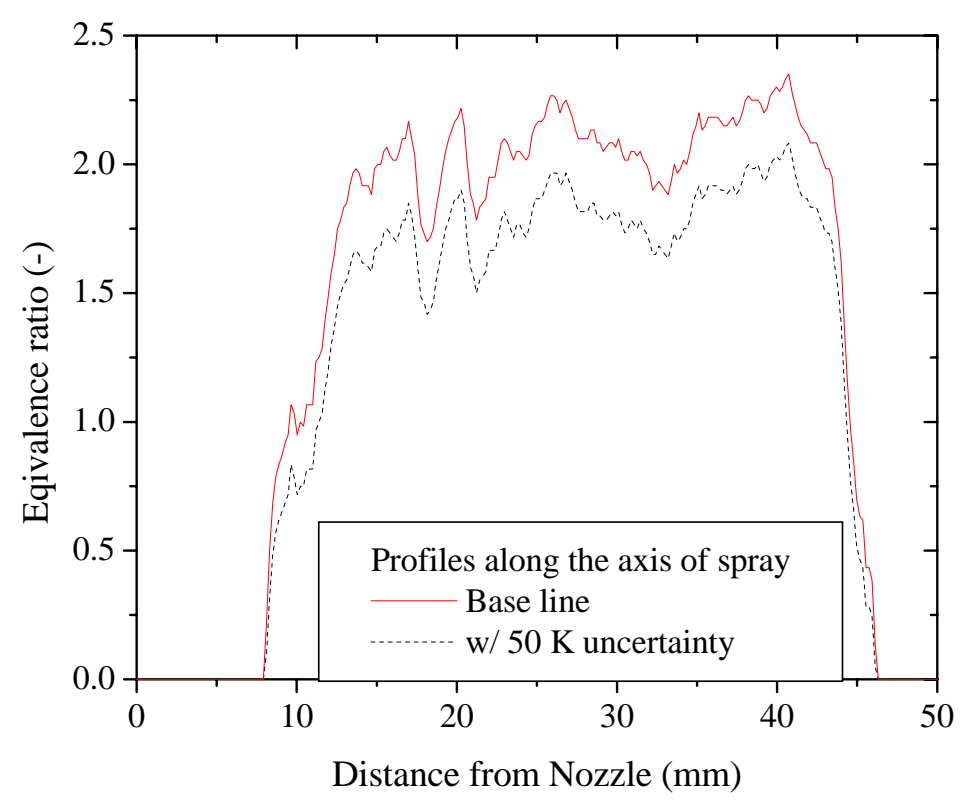

Figure 5.11 Equivalence ratio profiles along the axis of spray, obtained to see the $50 \mathrm{~K}$ uncertainty of ambient gas temperature.

\subsubsection{Uncertainty from Estimation of TMPD Absorption Coefficient}

The absorption coefficient used in this study was taken from the literature value, which was assumed to be constant with temperature. As reviewed in Figure 2.11, the absorption coefficient may not depend on temperature. However, if the TMPD fluorescence efficiency (Stern-Vollmer factor), $\phi_{T M P D}$, in Eq. 4.4 is assumed to have no temperature dependence, then the differential absorption cross-section of TMPD, $\sigma_{T M P D}$ is solely responsible for the temperature dependence of TMPD fluorescence. An image was re-processed using $\sigma_{T M P D}(\mathrm{~T})=\sigma_{T M P D} \cdot f(\mathrm{~T})$, the other parameters remained the same 
as the baseline conditions (an ambient gas density of $15 \mathrm{~kg} / \mathrm{m}^{3}$ and a temperature of 1000 K). Figure 5.12 shows the effect of TMPD absorption on temperature. The solid line shows the results from the baseline, at 0.6 ms ASI in Figure 5.3, (constant $\sigma_{T M P D}$ ). The dashed line takes into account temperature dependence $\left(\sigma_{T M P D}(T)=\sigma_{T M P D} \cdot f(T)\right)$. When compared to the solid line, the dashed line has little difference. To confirm this result, the dotted line was also plotted from calculation without the TMPD extinction effect $\left(\sigma_{T M P D}\right.$ $=0$ ), which shows a significant extinction effect except a few millimeters from the leading edge of the spray as the laser sheet passed through the vapor plume. Also, we can see that most extinction occurs in high concentration areas (above equivalence ratio of 2) and at temperatures around $800 \mathrm{~K}$. The reason for the small difference between the solid

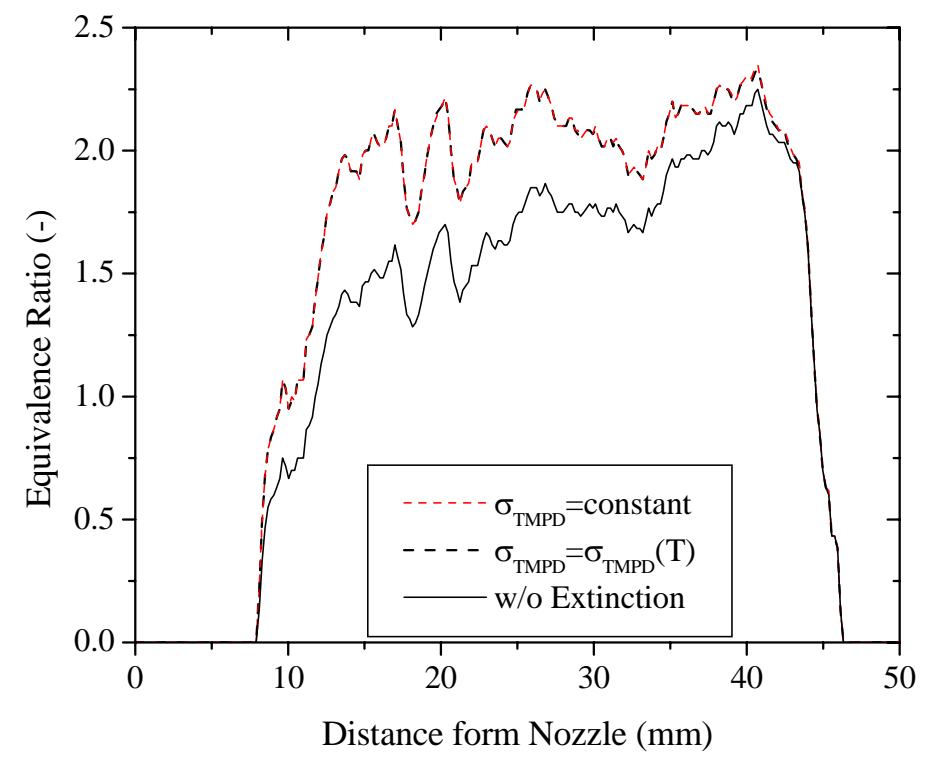

Figure 5.12 Equivalence ratio profiles on the effect of TMPD absorbance along the axis of spray. 
and dotted lines could be that $f(T)$ is around 1.0 at temperatures around $800 \mathrm{~K}$ (see Figure 4.8). Therefore, the effects of temperature on TMPD absorption are negligible especially for the baseline conditions (density of $15 \mathrm{~kg} / \mathrm{m}^{3}$ and temperature of $1000 \mathrm{~K}$ ).

\subsubsection{Overall Uncertainty for the Measurements}

Assuming that the uncertainty discussed in the previous sections are uncorrelated, the overall uncertainty in the TMPD concentration measurements can be obtained from Eq. (5.1). Based Eq. (5.2), the uncertainty for this study was estimated to be $14.5 \%$. And, based on Eq. (5.2) and uncertainties resulted from §5.2.5 and 5.2.6, then the uncertainty for this study was estimated to be $21.4 \%$. Bearing this in mind, the agreement between the measured and injected mass seen in Figures 5.5 and 5.6 is considered to be more than adequate.

\subsection{Effects of Ambient Gas Temperature and Density}

To study the effects of ambient gas temperature, Figures 5.2-4 are used again. During the early stage of the injection the penetration of the vapor phase is seen to match the liquid phase penetration (up to a time of $0.4 \mathrm{~ms}$ for 1000 and $1200 \mathrm{~K}$, and up to 0.6 ms for $800 \mathrm{~K}$ ambient temperature) and is found to be nearly independent of ambient temperature. The ambient temperature at this early time does, however, affect the radial extent of the vapor phase, with the largest radial extent observed for the highest temperature condition, $1200 \mathrm{~K}$. The corresponding distribution of local temperature displays the same spatial shape as the equivalence ratio due to the direct (albeit not 
linear) relation between the two quantities. The temperature depression in the sprays is seen to be quite significant; for instance, at $1.0 \mathrm{~ms}$ ASI it approaches 150,250 , and $350 \mathrm{~K}$ at the ambient gas temperature of 800, 1000, and $1200 \mathrm{~K}$ respectively. At higher ambient gas temperature the vapor region exhibited a wider extent with higher equivalence ratios. Also, as discussed in §5.1.3.3, for a higher ambient temperature, sharper gradients were observed in the vapor distribution. These behaviors can be explained by the larger energy transfer rate from the chamber gas entrained into the spray at the higher ambient temperature. This increases the vaporization rate while the diffusion rate is unaffected since the injected momentum is constant.

Data acquired at $7.5 \mathrm{~kg} / \mathrm{m}^{3}$ confirmed all of the trends discussed above regarding the spray structure, but integration of the vapor mass was limited by interaction with the chamber wall before all of the liquid fuel had evaporated. In addition, the longer intact liquid region limits the extent of the vapor plume at the leading edge of the spray. However, the images for $7.5 \mathrm{~kg} / \mathrm{m}^{3}$ are shown in Appendix D.

Figure 5.13 shows the liquid- and vapor-phase penetration data obtained by averaging the three experimental runs for both densities and all temperatures tested. In Figure 5.13, the typical 95\% confidence intervals for each case are shown on only one data point, again for graph clarity. The effect of cross talk is not significant on the vapor phase penetration but it may slightly deteriorate the accuracy of the liquid-phase data. Also shown in the figure are the estimates of the intact liquid length from the relation of Siebers [2]. The effect of density is shown to be very significant for both the liquid- and vapor-phase penetration lengths. The effect of temperature on the vapor-phase 
penetration is seen to be negligible, within the uncertainty of the measurements. In comparison, temperature has a large effect on the intact liquid length as has been observed previously in the literature [16,17]. Additionally, the intact liquid length predicted by Siebers' relation is found to be in good agreement with the liquid phase exciplex data. It should be noted that Siebers' relation was derived from quasi-steady spray images utilizing a long exposure time, whereas in this study a short exposure time of 100 ns can freeze to capture the instant spray structure. A long exposure can lose the transient or turbulent signal since the intensity signals for liquid in the core region is much higher and the camera has a limited dynamic range (as discussed in §5.1.3.1).

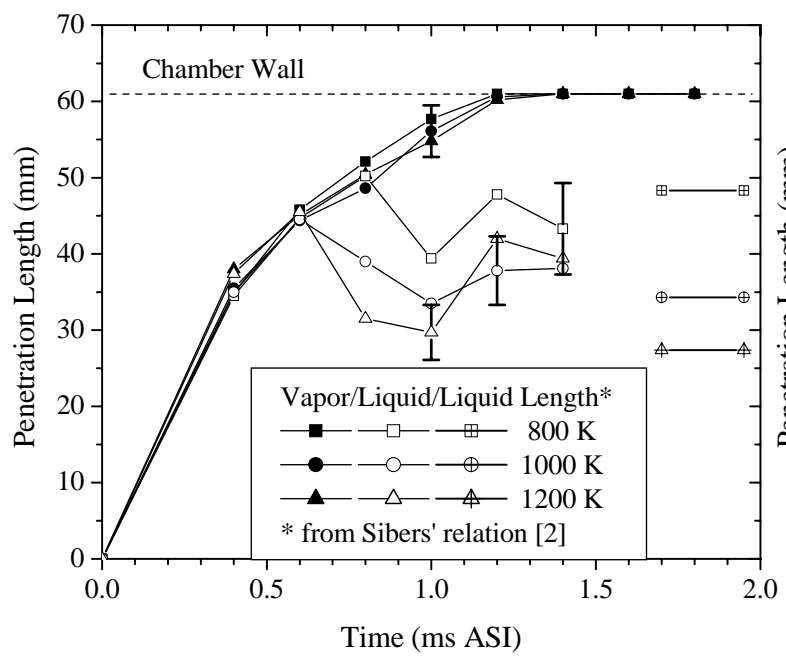

(a)

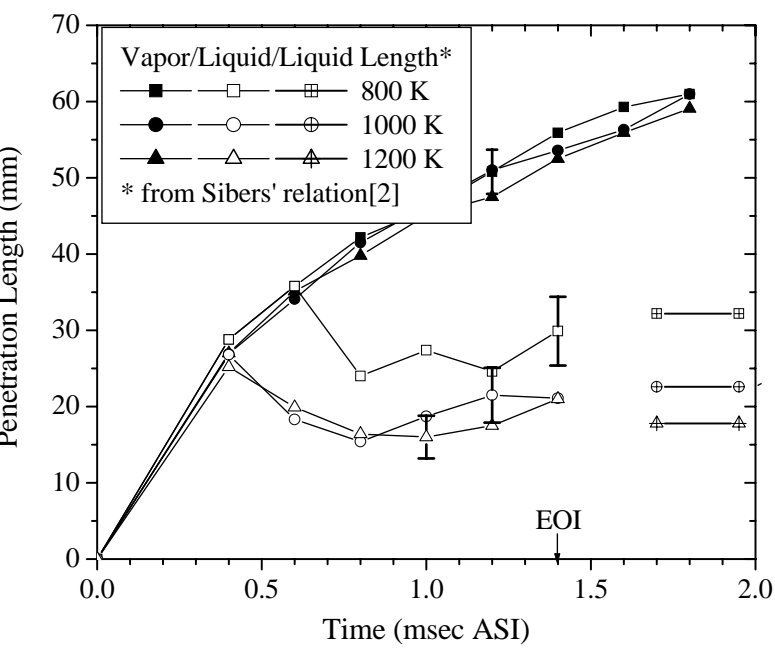

(b)

Figure 5.13 Penetration rate of the liquid and vapor phases obtained from the exciplex technique, (a) at the ambient gas density of $7.5 \mathrm{~kg} / \mathrm{m}^{3}$, and (b) at the ambient gas density of $15 \mathrm{~kg} / \mathrm{m}^{3}$. 
As mentioned in §5.1.1, the spray spreading angle used for Siebers’ relation was obtained from the empirical relationship of ref. 2 due to difficulty defining the angle from single-shot transient spray images. From the empirical relationship obtained from quasisteady spray images, the angle is only a function of the density ratio between the ambient gas and the fuel, and it is independent of the ambient gas temperature. Figure 5.14 shows that spray spreading angles from single-shot transient spray images were affected by ambient gas temperature. The spray angles were determined by drawing a line through injector tip and tangent to the regions of equivalence ratios of 0.2 at various times during injection. In Figure 5.14, a 95\% confidence interval at $0.6 \mathrm{~ms}$ ASI is shown for each case. For this calculation of the confidence interval, the six runs from Figure 5.8 were used. In this case the error bars shown are not necessarily typical for all data points, but the other uncalculated error bars are believed to be very similar to the single calculated bar at 0.6 ms. The largest radial extent of the vapor phase was observed for the higher temperature condition $(1000 \mathrm{~K})$ in the earliest portions of the injection period. However, in the later portions (EOI) the temperature effects on the angle are limited, which agrees with Seibers' empirical relationship. Therefore, it should be noted that the transient spray spreading angle might not be valid as the quasi-steady spray spreading angle for the idealized spray model such like Figure 2.3. From the model, a larger spray spreading angle corresponds to an increased amount of air entrainment. With the same injection pressure (90 MPa peak) for the two different ambient gas temperatures, the amount of air entrainment is the same so one would expect the same quasi-steady spray spreading angle. 


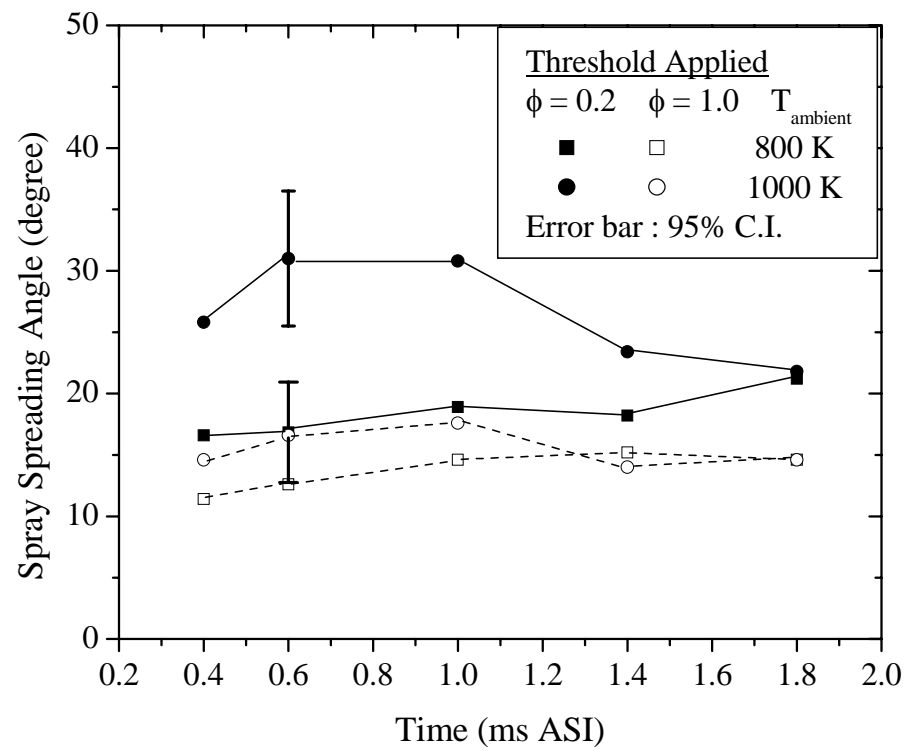

Figure 5.14 Spray spreading angle with respect to ambient gas temperature, based on vapor phase images obtained from the exciplex technique, at the ambient gas density of $15 \mathrm{~kg} / \mathrm{m}^{3}$.

If the spray angle is defined using an equivalence ratio of 1 , then the spray angles on Figure 5.14 show limited, or no, temperature dependence. This can partly explain the discrepancies between the data from this study and Siebers. The quasi-steady spray angle can lose the transient or turbulent signal.

\subsection{Effects of Injection Pressure}

To investigate the effects of injection pressure, three tests were run using peak pressures of 150, 90 and $60 \mathrm{MPa}$. Throughout this study the $90 \mathrm{MPa}$ case is used as the baseline condition. All three cases use the same injected fuel mass of $4.55 \mathrm{mg}$. Figure 5.15 shows the injection rate profiles for each pressure case. Higher injection pressure was seen to have decreased injection duration and increased mass flow rate (or injected 
fuel velocity) at the same instant time. Figure 5.16-18 shows the temporal evolution of the spatial distribution of equivalence ratio (left) and temperature (right) at a density of $15 \mathrm{~kg} / \mathrm{m}^{3}$ and peak injection pressures of 60, 90 and $150 \mathrm{MPa}$ respectively. The ambient temperature was $1000 \mathrm{~K}$ in all cases. From the figures, we can see that higher injection pressures have faster penetration rates and larger spray head volumes although the rate of increase in these parameters decreases for higher injection pressures. Additionally, the higher injection pressure case shows a richer fuel mixture with larger spray head volume for early injection times ( $<0.8 \mathrm{~ms}$ ASI) than those in the $60 \mathrm{MPa}$ peak injection pressure case. As well, the higher injection pressure had a faster vaporization rate leading to a more homogenous mixture distribution after a certain time (e.g. EOI).

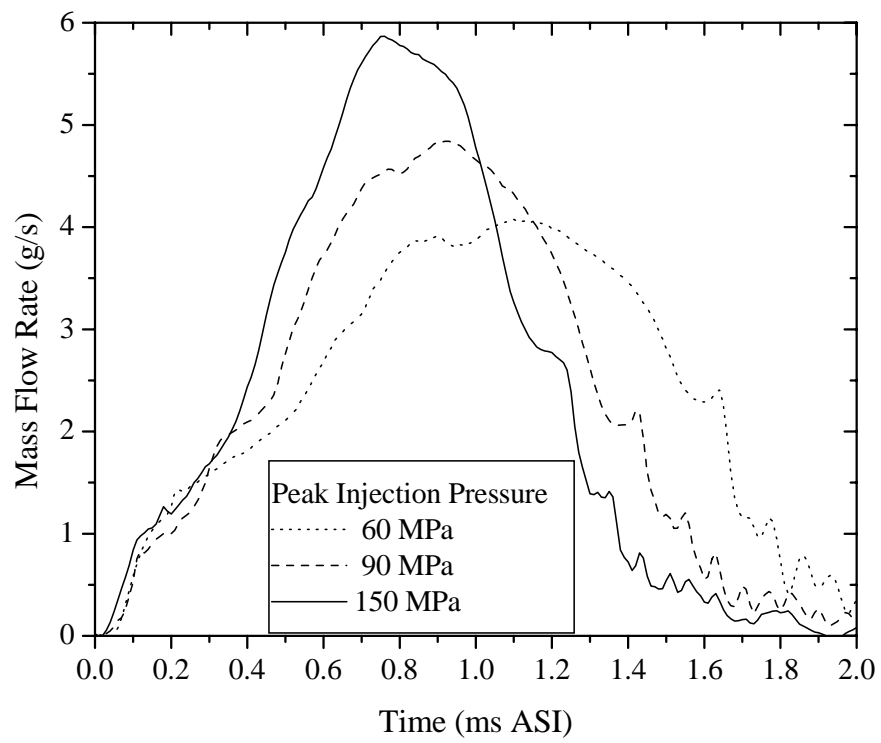

Figure 5.15 Injection rate profiles at three different peak injection pressures, obtained from Bosch-type flow rate bench experiments. 

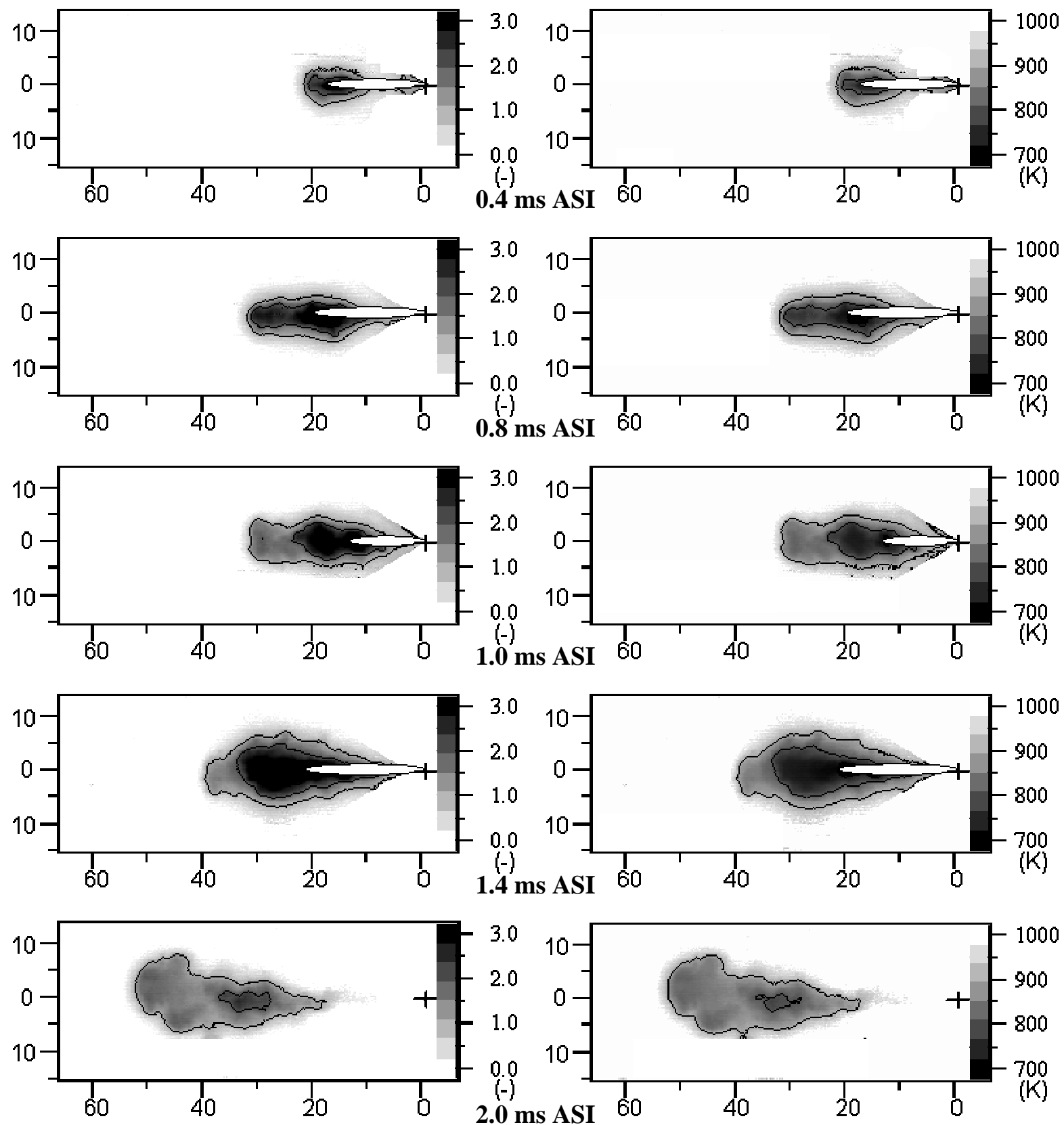

$2.0 \mathrm{~ms}$ ASI

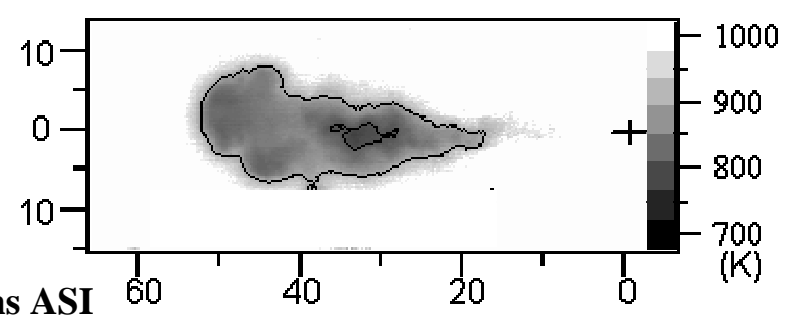

(a) Equivalence ratio

(b) Temperature

Figure 5.16 Quantitative images of equivalence ratio (left) and temperature (right) with the peak injection pressure of $60 \mathrm{MPa}$ at the ambient density of $15 \mathrm{~kg} / \mathrm{m}^{3}$ and temperature of $1000 \mathrm{~K}$. The solid lines in the images, shown for convenience, represent the contours with increments of 1 for equivalence ratio and -100 $\mathrm{K}$ for temperature from the ambient values $(0$ and $1000 \mathrm{~K})$, respectively. 

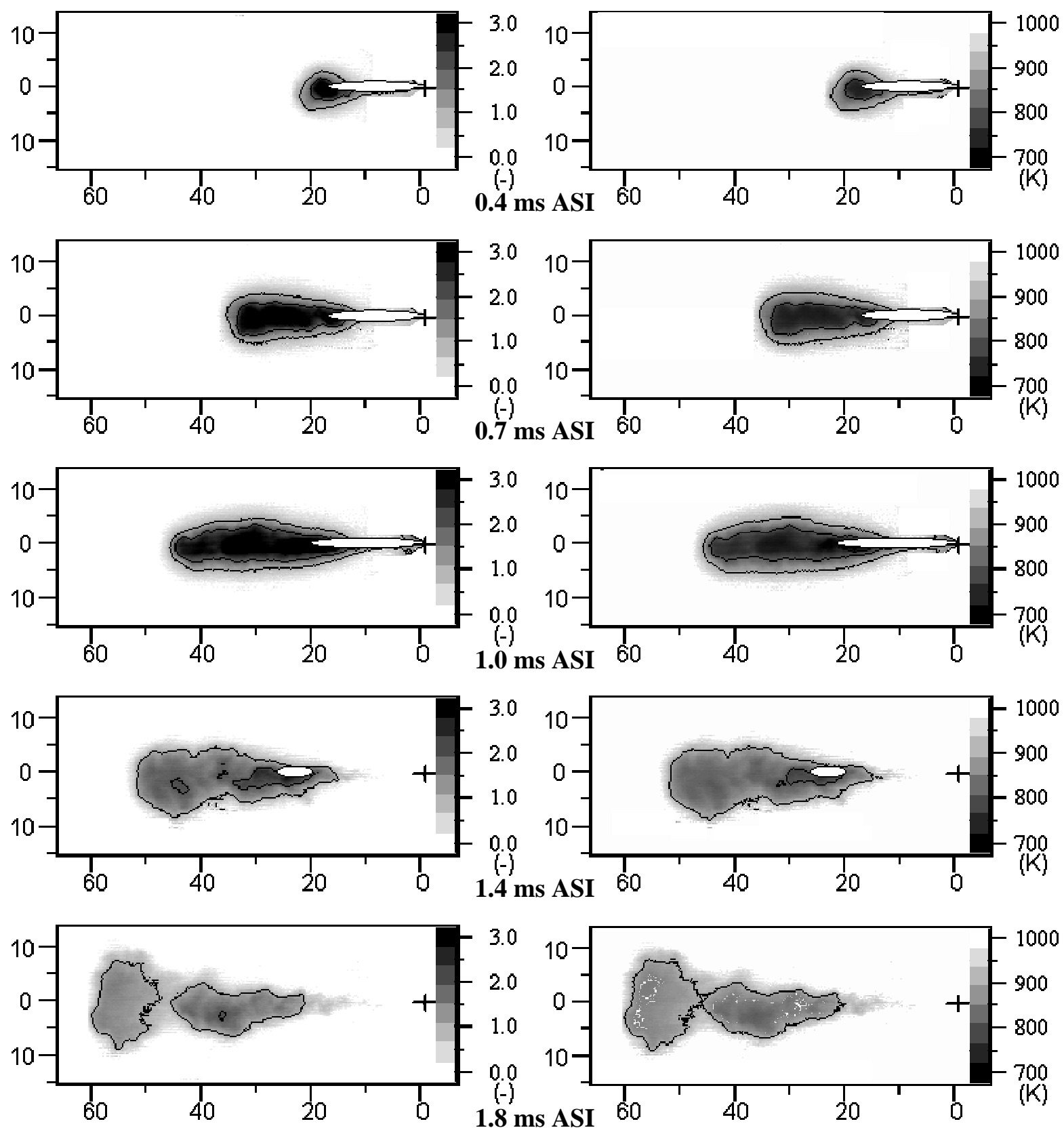

3.0
2.0
1.0
0.0
$(-)$

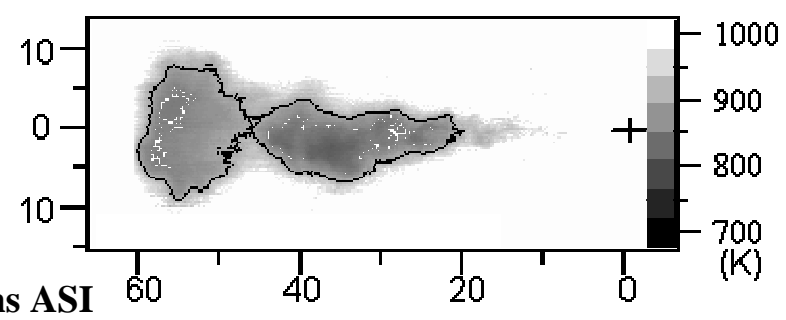

(a) Equivalence ratio

(b) Temperature

Figure 5.17 Quantitative images of equivalence ratio (left) and temperature (right) with the peak injection pressure of $90 \mathrm{MPa}$ at the ambient density of $15 \mathrm{~kg} / \mathrm{m}^{3}$ and temperature of $1000 \mathrm{~K}$. The solid lines in the images, shown for convenience, represent the contours with increments of 1 for equivalence ratio and $-100 \mathrm{~K}$ for temperature from the ambient values ( 0 and $1000 \mathrm{~K}$ ), respectively. 

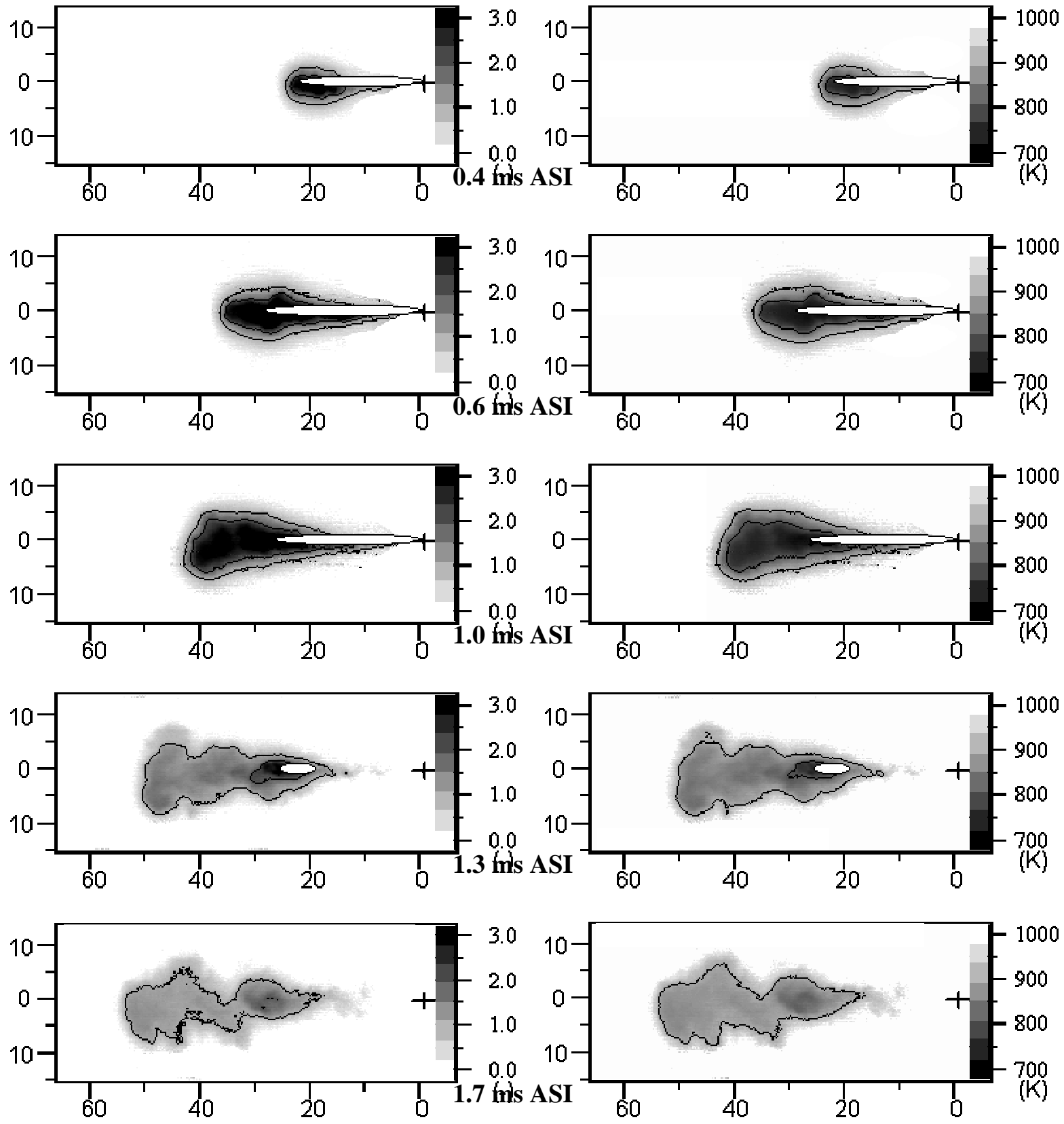

(a) Equivalence ratio

(b) Temperature

Figure 5.18 Quantitative images of equivalence ratio (left) and temperature (right) with the peak injection pressure of $150 \mathrm{MPa}$ at the ambient density of $15 \mathrm{~kg} / \mathrm{m}^{3}$ and temperature of $1000 \mathrm{~K}$. The solid lines in the images, shown for convenience, represent the contours with increments of 1 for equivalence ratio and $-100 \mathrm{~K}$ for temperature from the ambient values (0 and $1000 \mathrm{~K}$ ), respectively. 
After all the liquid has been vaporized, in all three cases, the integrated fuel vapor concentration compared favorably with the measured amount of fuel injected. With respect to the total amount of injected fuel of $4.55 \mathrm{mg}$, the measured amounts were 4.23, 4.78 and $4.58 \mathrm{mg}$ for the 60,90 and $150 \mathrm{MPa}$ respectively.

Figure 5.19 shows the liquid and vapor penetration lengths obtained by averaging the three experimental runs. In Figure 5.19, the typical 95\% confidence intervals for each case are shown on only one data point, again for graph clarity. During the early stage of the injection, the liquid (or vapor) penetrations of the three injection pressures have different injection velocities corresponding to ratios of the square root of their injection pressure (see Table 2.1). After $0.5 \mathrm{~ms}$ ASI, the liquid phase does not penetrate further but stabilizes as mentioned before. As reviewed in §2.1, the liquid length demonstrated a weak positive, or no dependence on the injection pressure (see Eq. (2.5)). From Siebers' relation [2], the liquid length was estimated as $23 \mathrm{~mm}$ (again, note that Siebers' relation was derived from quasi-steady spray images), and it is found to be in reasonable agreement with our time-averaged liquid length value after stabilization of the liquid length, although their instantaneous maximum values in Figure 5.19 were 28.5, 26.0 and $27.5 \mathrm{~mm}$ for 150, 90 and $60 \mathrm{MPa}$ respectively. However, as discussed in Figure 5.16-18, although injection pressure seems to have a minor effect on the liquid length, the temporal distribution of the vapor concentration for higher injection pressure has a faster vaporization rate with better homogenous mixing quality (larger volume spray head). This effect agrees with the previous findings [12,15] that higher injection pressures make smaller drop sizes. These facts show the possible merits of high injection pressure 


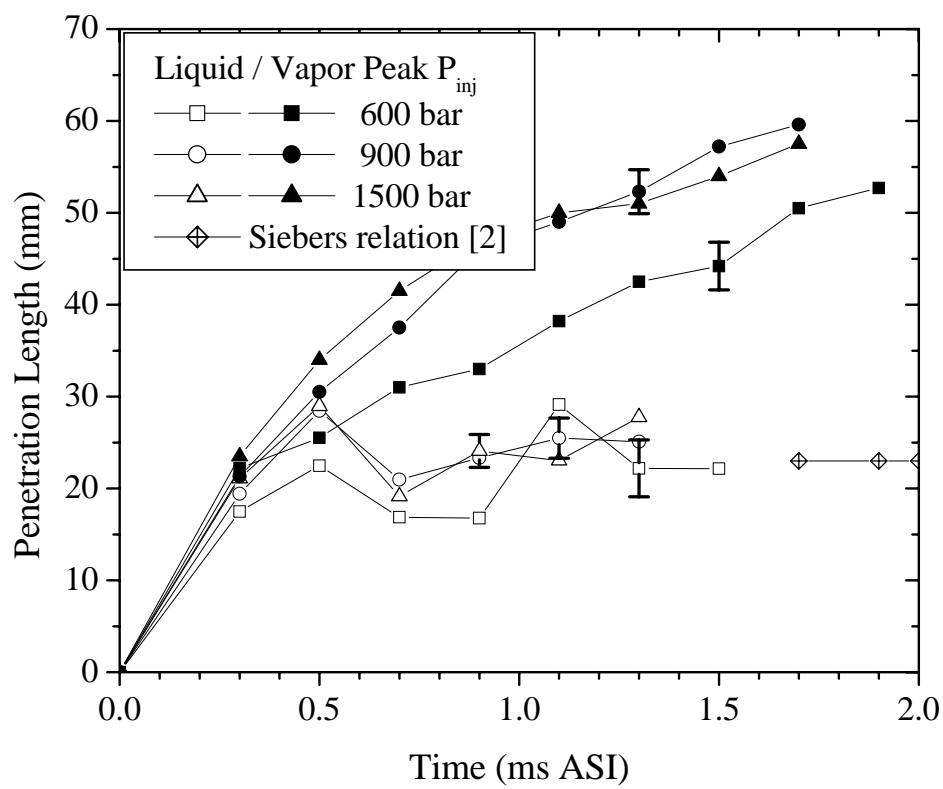

Figure 5.19 Penetration rates of the liquid and vapor phases at three different peak injection pressures, obtained from the exciplex technique.

$[15,20,21]$, specifically that higher injection pressures can reduce soot formation and shorten combustion duration (to be discussed more in §6.2.1). Also from Figure 5.19, the vapor penetration sensitivity on pressure can be seen to decrease as pressure is increased, which agrees with Kamimoto et al's result [15]. Meaning, the vapor penetration lengths at $0.6 \mathrm{~ms}$ ASI differ by about $8 \mathrm{~mm}$ between 60 and $90 \mathrm{MPa}$, but by almost doubling the pressure from 90 and $150 \mathrm{MPa}$, there is only a $4 \mathrm{~mm}$ increase in vapor penetration length.

Figure 5.20 shows that spray spreading angles from single-shot transient spray images were affected by the injection pressure. The spray angles were determined by drawing a line through the injector tip and tangent to the regions of equivalence ratios of 0.2 at various times during injection. In Figure 5.20, a 95\% confidence interval at $0.7 \mathrm{~ms}$ ASI is shown for each case and was calculated as mentioned in Figure 5.14. The largest radial extent of the vapor phase was observed for lower injection pressure (60 MPa) in 
the earliest portions of the injection period. However, in the later portions (EOI) the pressure effects on the angle are limited, which agrees with Siebers's empirical relationship. For higher injection pressures (90 and $150 \mathrm{MPa}$ ) the pressure effects on the angle are limited, and higher injection pressure seems to induce increased rate of air entrainment with the same spray spreading angle at the same time from SOI, but has larger spray head volume. Figure 5.20 also shows the same trend with different threshold for defining the spray angle (using the equivalence ratio of 1). Therefore, in the different injection pressure case, the transient spray spreading angle might not be valid as the quasi-steady spray spreading angle for the idealized spray model in the earlier portion of the injection period.

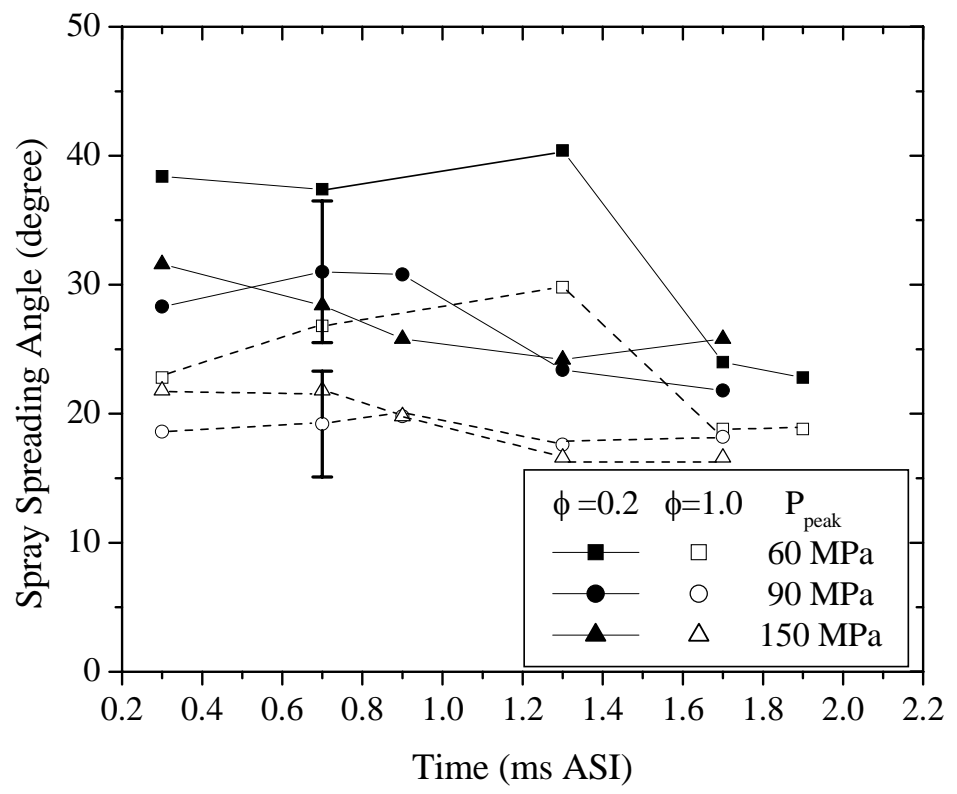

Figure 5.20 Spray spreading angle with respect to peak injection pressure, based on vapor phase images obtained from the exciplex technique. 
Su et al. [12] reported the effects of high injection pressure under cold bomb conditions, and they concluded that higher injection pressures resulted in faster spray tip penetrations, narrower spray angles, and smaller droplet sizes under a 75\% load condition. All trends of the cold bomb results seem to agree with the hot bomb results discussed in this section.

\subsection{Effects of Nozzle Hole Size}

To investigate the effects of nozzle hole size tests were run using two different nozzle hole sizes of 200 and $140 \mu \mathrm{m}$ diameter, and the results were compared with the baseline $158 \mu \mathrm{m}$ case (Figure 5.17). As described in §3.3, the injectors used for each experiment were identical to the original injectors except for the nozzle hole size on the injector tips; the spray angles and injector hole length were the same as the HEUI 90 of $158 \mu \mathrm{m}$ diameter. Caterpillar provided the injectors with three kinds of tips, which eliminated effects other than nozzle hole size.

All three cases used the same injected fuel mass of $4.55 \mathrm{mg}$. Figure 5.21 shows the injection rate profiles under the peak injection pressure of $90 \mathrm{MPa}$ for each hole size. The larger hole sizes had decreased injection durations due to the higher mass flow rates at the same instant time.

Figure 5.22, 5.17 and 5.23 show the temporal evolution of the spatial distribution of equivalence ratio (left) and temperature (right) at a density of $15 \mathrm{~kg} / \mathrm{m}^{3}$, a temperature of $1000 \mathrm{~K}$ and the nozzle hole sizes of 140, 158 and $200 \mu \mathrm{m}$ diameter respectively. 


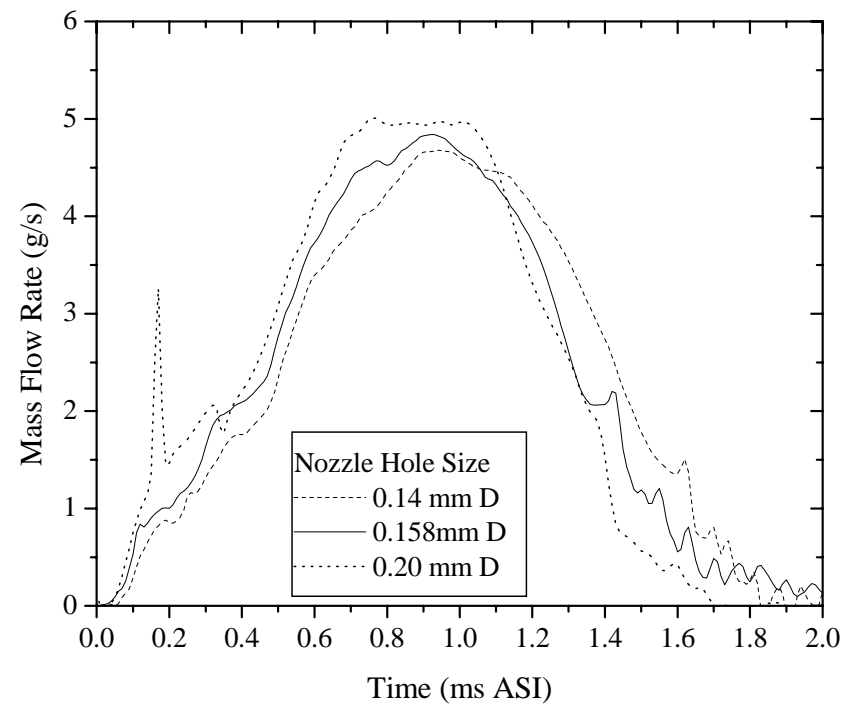

Figure 5.21 Injection rate profiles at three different nozzle hole sizes, obtained from Bosch-type flow rate bench experiments.

Larger nozzle hole sizes were shown to have faster vapor phase (or liquid) penetration rates and larger overall spray volumes, but for larger orifices the upstream location of the vapor phase extent is closer to the injector tip. Additionally, larger hole sizes are expected to experience more interference with the liquid phase due to a longer liquid length (as discussed in §5.1.3.1). The effect of the equivalence ratio distribution with respect to nozzle hole sizes will be discussed more in §6.2.2.

In the case of the $140 \mu \mathrm{m}$ diameter hole size (see Figure 5.6), the integrated fuel vapor concentration compared favorably with the measured amount of fuel injected (the measured amounts of $4.47 \mathrm{mg}$ with respect to the injected fuel of $4.55 \mathrm{mg})$. However, for the largest hole size (200 $\mu$ m diameter), the integrated fuel vapor concentration could not 

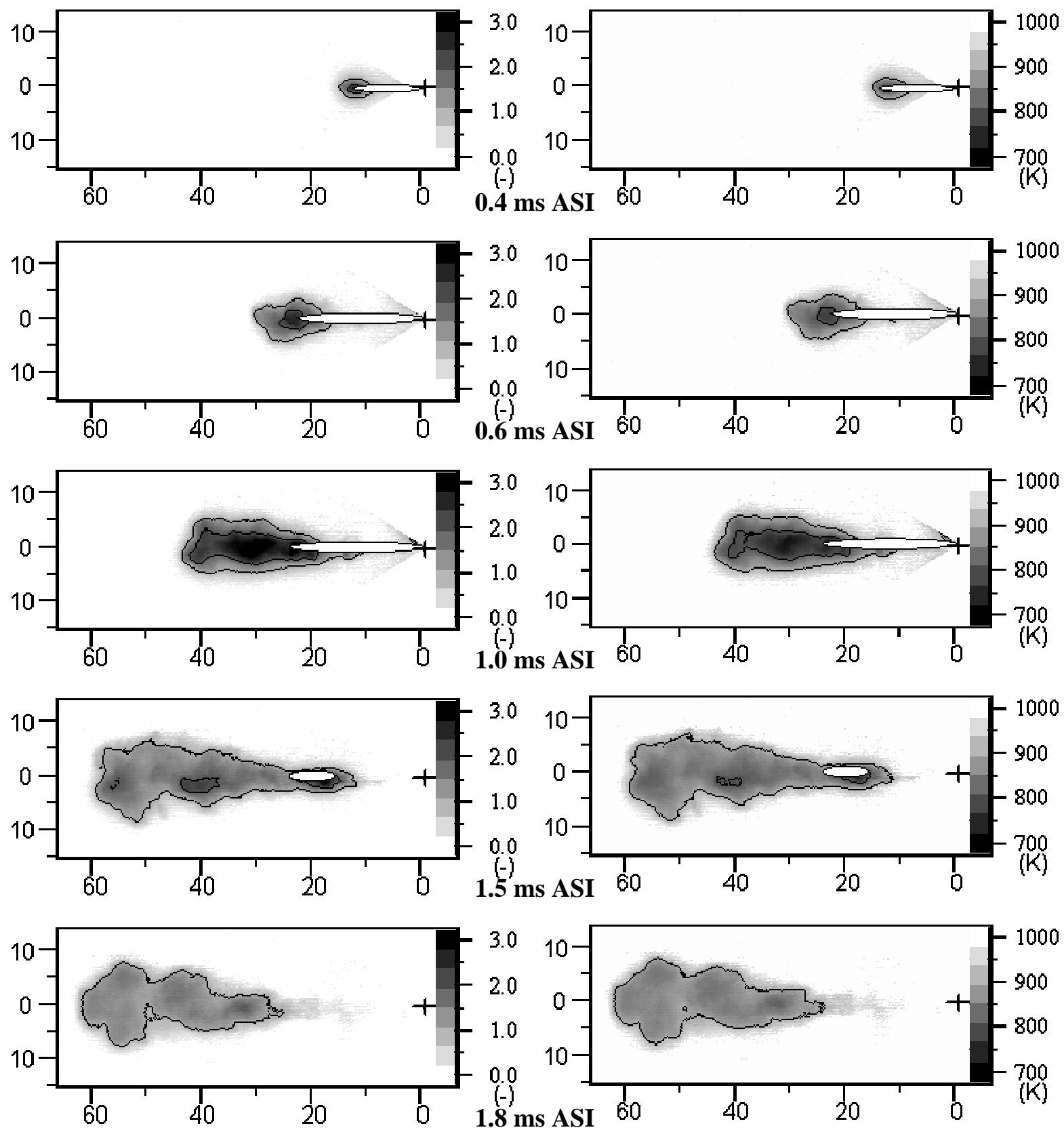

(a) Equivalence ratio

(b) Temperature

Figure 5.22 Quantitative images of equivalence ratio (left) and temperature (right) with $140 \mu \mathrm{m}$ diameter nozzle hole at the ambient density of $15 \mathrm{~kg} / \mathrm{m}^{3}$ and temperature of $1000 \mathrm{~K}$. The solid lines in the images, shown for convenience, represent the contours with increments of 1 for equivalence ratio, and $-100 \mathrm{~K}$ for temperature, from the ambient values ( 0 and $1000 \mathrm{~K}$ ), respectively. 

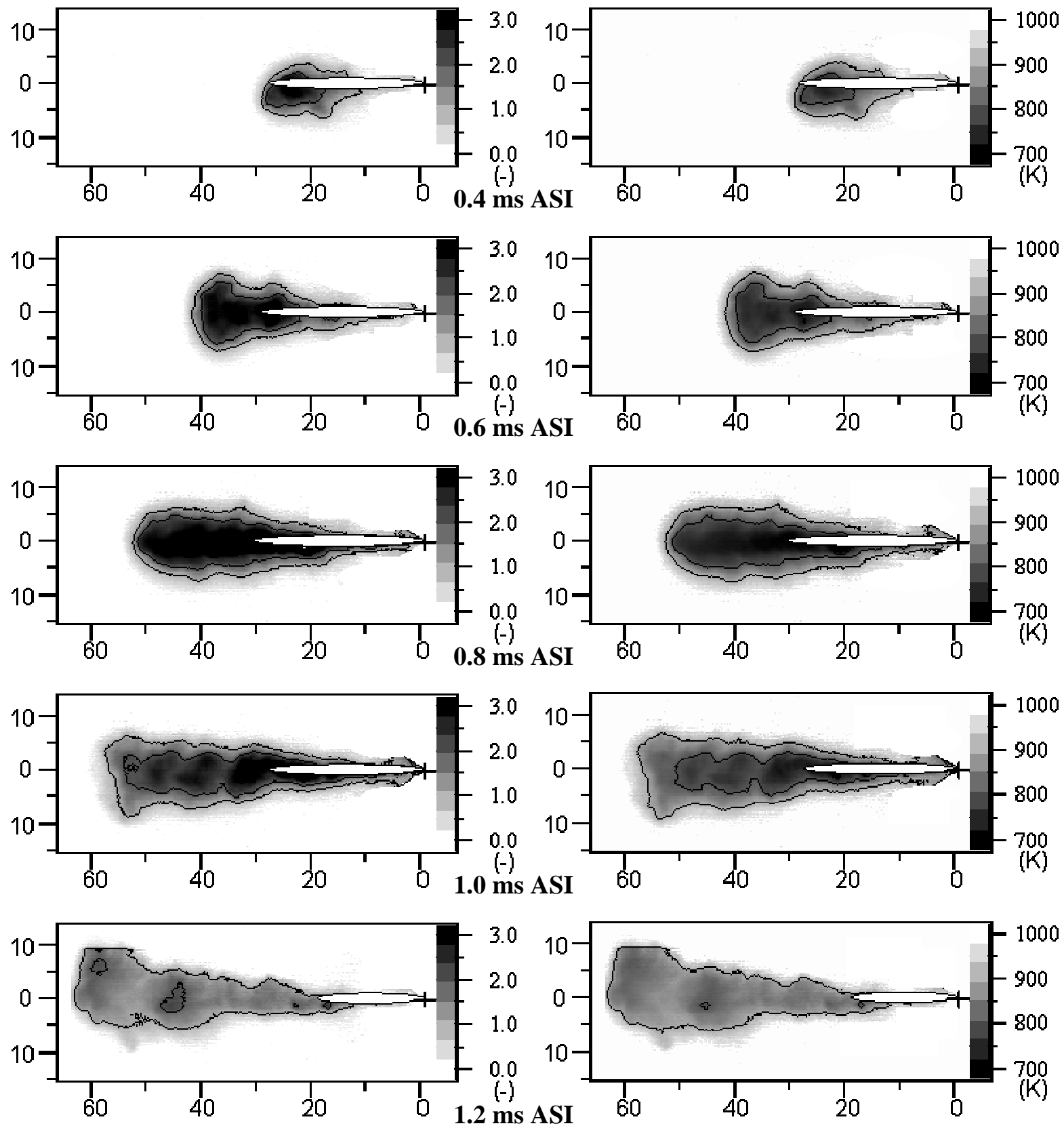

(a) Equivalence ratio

(b) Temperature

Figure 5.23 Quantitative images of equivalence ratio (left) and temperature (right) with $200 \mu \mathrm{m}$ diameter nozzle hole at the ambient density of $15 \mathrm{~kg} / \mathrm{m}^{3}$ and temperature of $1000 \mathrm{~K}$. The solid lines in the images, shown for convenience, represent the contours with increments of 1 for equivalence ratio, and $-100 \mathrm{~K}$ for temperature, from the ambient values ( 0 and $1000 \mathrm{~K}$ ), respectively. 
be obtained since the vapor had already reached the chamber wall before all the liquid had vaporized.

Figure 5.24 shows the liquid and vapor penetration lengths obtained by averaging the three experimental runs. In Figure 5.24, the typical 95\% confidence intervals for each case are shown on only one data point, again for graph clarity. During the early stage of injection, the liquid (or vapor) penetrations of the three hole sizes have different injection velocities. Under the same oil manifold pressure, the injection velocity of each injector should be the same, but the difference in injection velocity may result from different transient responses of the solenoid valve with respect to nozzle hole size (As shown in Fig. 5.21, the larger hole sizes reach the peak pressure faster).

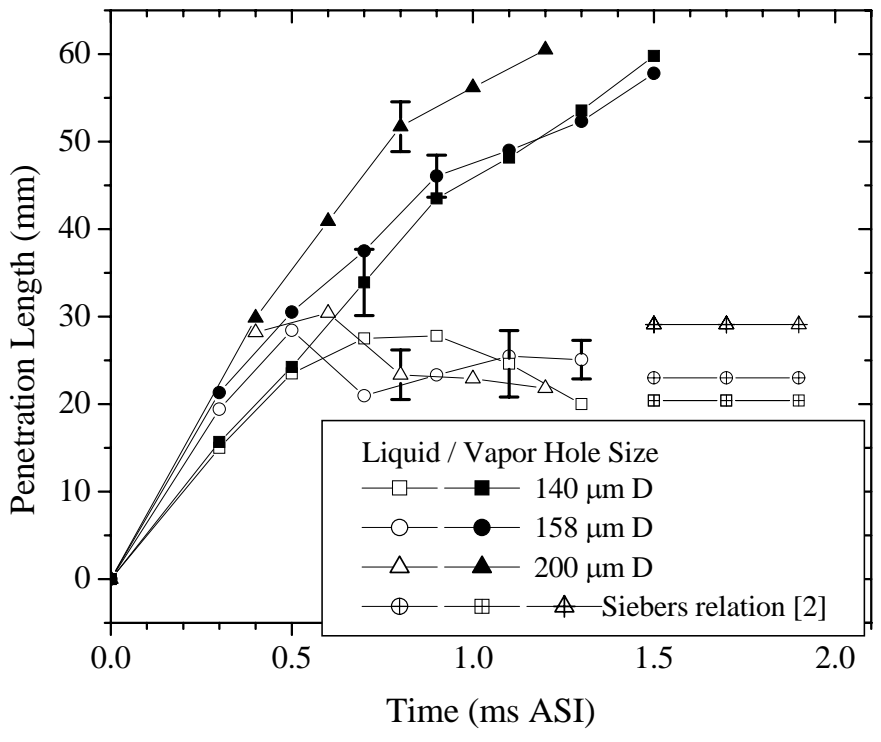

Figure 5.24 Penetration rates of the liquid and vapor phases at three different nozzle hole sizes, obtained from the exciplex technique. 
After $0.5 \mathrm{~ms}$ ASI, the liquid phase does not penetrate further but stabilizes. From Siebers's relation [2], liquid length has a linear dependence on the injector hole size, which was estimated as 29, 23, $20 \mathrm{~mm}$ for 200, 158 and $140 \mu \mathrm{m}$ diameter hole sizes respectively (again, note that Siebers's relation was derived from quasi-steady spray images), and it is found to be in reasonable agreement with our time-averaged liquid length value after stabilization of the liquid length, although their instantaneous maximum values in Figure 5.24 were 29.8, 26.0 and $25.5 \mathrm{~mm}$ for three hole sizes.

Figure 5.25 shows that the spray spreading angle from single-shot transient spray images was minimally affected by nozzle hole size. The spray angles were determined by drawing a line through the injector tip and tangent to the regions of equivalence ratios of 0.2 at various times during injection. In Figure 5.25, a 95\% confidence interval at $0.6 \mathrm{~ms}$ ASI is shown for each case and was calculated as mentioned in Figure 5.14. Except for the very early time of injection, the nozzle hole size effects on the angle are limited, which agrees with Siebers's empirical relationship. However, with respect to the variation of the nozzle hole sizes the transient spray spreading angle might not be valid as the quasi-steady spray spreading angle for the idealized spray model. Figure 5.25 also shows the similar trend of the different threshold level for defining the spray angle (using the equivalence ratio regions of 1 ). 


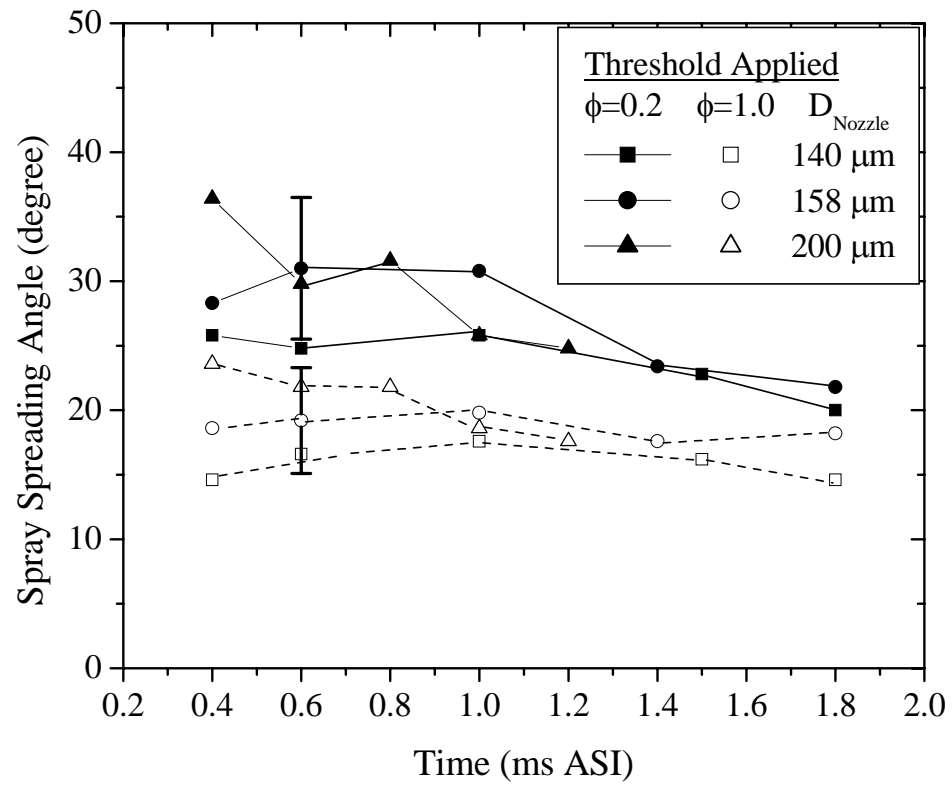

Figure 5.25 Spray spreading angle with respect to nozzle hole size, based on vapor phase images obtained from the exciplex technique.

\subsection{Summary}

Under the condition of a density of $15 \mathrm{~kg} / \mathrm{m}^{3}$ the effects of three ambient gas temperatures (800, 1000 and $1200 \mathrm{~K}$ ), three peak injection pressures (60, 90 and 150 MPa) and three nozzle hole sizes (140, 158 and $200 \mu \mathrm{m}$ ) were investigated, and the major findings are summarized as follows:

1. Using the exciplex LIF technique it was shown that this technique could quantitatively investigate the fuel vapor distribution with qualitative visualization of the liquid fuel extent in an evaporating spray. In all cases, the integrated fuel vapor concentration compared favorably with the measured amount of injected fuel for 
times when all of the liquid fuel had evaporated. In addition, the acquired data compared closely with data obtained by Espey et al in magnitude.

2. The exciplex technique was found to have limited application at temperatures higher than $1000 \mathrm{~K}$ due to thermal decomposition.

3. It was determined, by analyzing all contributing signal noise and considering uncertainty from local temperature estimation, that the estimated uncertainty of the concentration measurements was 21\%, a value larger than the typical difference (10\%) seen between the measured and injected masses in this study.

4. Through a parametric study the effects of ambient gas density, ambient gas temperature, injection pressure, and nozzle hole size on the liquid length, spray angle, vapor penetration rate and local vapor concentration were performed. The following generalizations can be made:

- The effect of ambient gas density was shown to be very significant for both the liquid- and vapor-phase penetration rates. Lower ambient density gave faster vapor penetration and a longer intact liquid length.

- At higher ambient temperatures the vapor region exhibited a wider extent with higher equivalence ratios, and the edge of the jet has higher gradients. These behaviors can be explained by faster vaporization rates at higher ambient temperatures with similar diffusion rates from the same injected momentum.

- Although the intact liquid length and spray spreading angle were only slightly affected by injection pressure, the temporal distributions of the vapor concentration show faster rates of air entrainment and fuel vaporization with 
better mixing (assuming larger spray head volumes indicates increased air entrainment).

- Larger nozzle hole sizes were shown to have faster vapor phase (or liquid) penetration rates and larger overall spray volumes, but for larger orifices the upstream location of the vapor phase extent is closer to the injector tip. However, larger nozzle sizes were shown to experience more interference with the liquid phase due to a longer liquid length. The different penetration rates may result from different transient responses of the solenoid valve with respect to nozzle hole size. The nozzle hole size effects on liquid lengths were shown to be positive. However, spray spreading angles were minimally affected by nozzle hole size.

- The effects of ambient temperature, injection pressure and nozzle hole size on the spray spreading angle show some difference at the early injection period although as injection progresses the effects seemed to decrease. At the early times during the injection, higher injection pressures have narrower spray spreading angles, higher ambient temperatures have wider spray spreading angles, and larger nozzle hole sizes have wider spray spreading angles. According to an idealized spray model, larger spray spreading angles correspond to an increased amount of air entrainment under the same penetration rate. Therefore, the steady-state spray spreading angle might not be valid for an idealized transient spray model at the early time of the injection period as the angles in this study showed transient characteristics. 


\section{Chapter 6. RESULTS AND DISCUSSION II}

\section{- REACTING DIESEL SPRAY AND FUEL CONCENTRATION}

In this chapter, natural luminosity images from reacting diesel sprays have been acquired. As discussed in Chapter 2, the local fuel-air ratio in early spray development plays an important role on ignition and pollutant emissions. The ignition that occurs at the periphery of the spray initiates the main heat release and can affect the NOx emissions. Pre-mixed ignition in fuel rich regions could be responsible for particulate precursors, PAHs (polycyclic aromatic hydrocarbons), which later form soot within the hot, oxygen depleted zone within the diffusion flame [65]. Therefore, the equivalence ratio distribution at the ignition time defines the initial flame development and combustion characteristics, and also contributes to the production of pollutant emissions.

Through the initial flame development period reacting and non-reacting sprays may have similar spray structures. Therefore, the non-reacting spray experiments in Chapter 5 can be used to understand the equivalence ratio distribution for the reacting spray during the ignition and initial flame development period. As well, transient luminosity images in this chapter can provide macroscopic reacting spray characteristics such as flame lift-off height and the ignition delay time. 


\subsection{Reacting Spray Experiments}

For the reacting diesel spray experiments (to allow the diesel spray to combust), the ambient gas at the injection time was prepared to have $21 \%$ oxygen by volume. To obtain this ratio, the molar composition of the premixed mixture was $4.7 \%$ acetylene, $32 \%$ oxygen and $63 \%$ nitrogen so that the actual ambient gas composition after combustion, and at injection time, was $21 \%$ oxygen, $64 \%$ nitrogen, $4.7 \% \mathrm{H}_{2} \mathrm{O}$ and $9.4 \%$ $\mathrm{CO}_{2}$. As a comparison the premixed gas mixture for the non reacting spray (§3.2) had a molar composition of $4.7 \%$ acetylene, $11 \%$ oxygen and $84 \%$ nitrogen, and the gas composition after combustion was $85 \%$ nitrogen, $4.7 \% \mathrm{H}_{2} \mathrm{O}$ and $9.4 \% \mathrm{CO}_{2}$.

Figure 6.1 shows pressure traces of two distinct experiments performed at the density of $15 \mathrm{~kg} / \mathrm{m}^{3}$ both with (solid) and without fuel injection (dashed) occurring at the ambient gas temperature of $1000 \mathrm{~K}$. The difference, seen as a second pressure increase following the injection time, is the result of diesel combustion from the reacting diesel spray. To determine the injection time corresponding to the ambient gas temperature of $1000 \mathrm{~K}$ with the new composition, experiments using a thermocouple were performed as described in §3.1.6. Similar to the non-reacting environment (§3.2.2), Figure 6.1 shows reliable premixed combustion with good repeatability.

For the reacting diesel spray images the total light emission from the burning diesel sprays was acquired without any filter. To record the luminosity signals from the reacting spray high-speed cinematography was used. A high-speed camera (Kodak model 4540) was oriented perpendicular to the spray axis of the single plume of interest. The frame speed was $18000 \mathrm{fps}(0.0556 \mathrm{~ms} / \mathrm{f})$. The fuel used for the reacting spray 


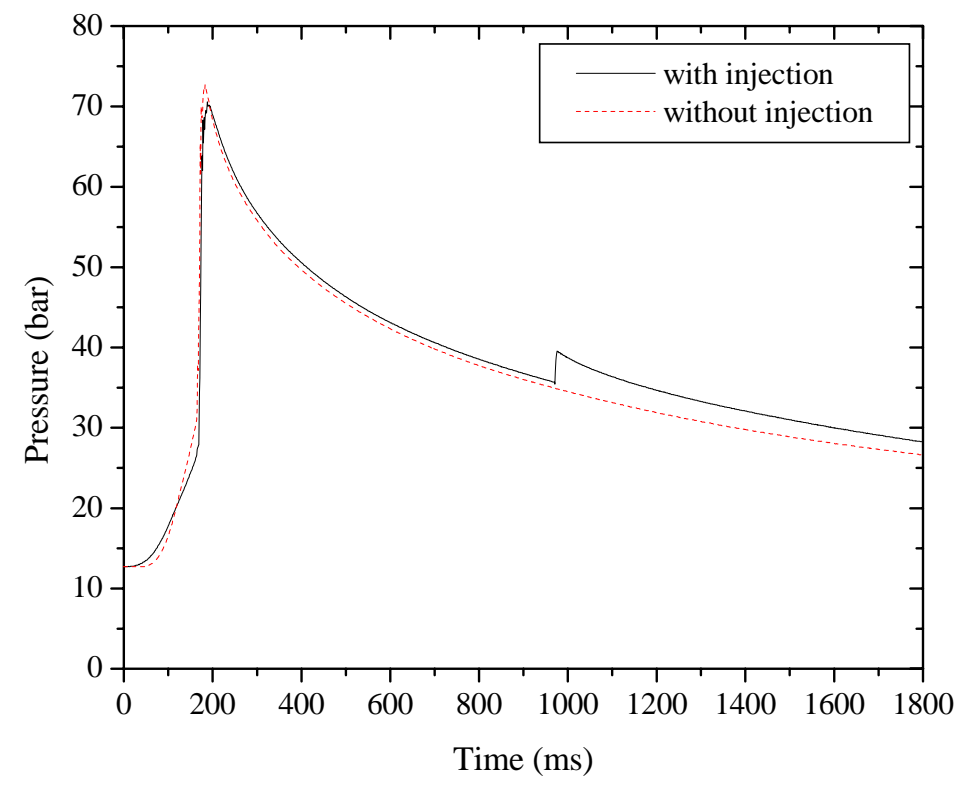

Figure 6.1 Pressure history of the combustion-type spray chamber system at the ambient gas density of $15 \mathrm{~kg} / \mathrm{m}^{3}$.

experiments was \#2 diesel fuel. There might be small errors due to different rates of diffusion and evaporation between the doped fuel used in the non-reacting spray experiments and the diesel fuel in the reacting spray experiments (see §4.2.5).

Figure 6.2 shows a temporal sequence of luminosity images, which provides information on the auto-ignition, initial flame development and overall reacting-jet penetration. The images were acquired using the $158 \mu \mathrm{m}$ nozzle hole diameter, $90 \mathrm{MPa}$ peak injection pressure, $15 \mathrm{~kg} / \mathrm{m}^{3}$ ambient gas density and $1000 \mathrm{~K}$ ambient gas temperature. In the images, the gray level is inverted, so the black is the brightest level. Near 0.51 ms after the start of injection, autoignition begins to occur in some regions in the spray. Then, combustion propagates around the spray's periphery. A turbulent 

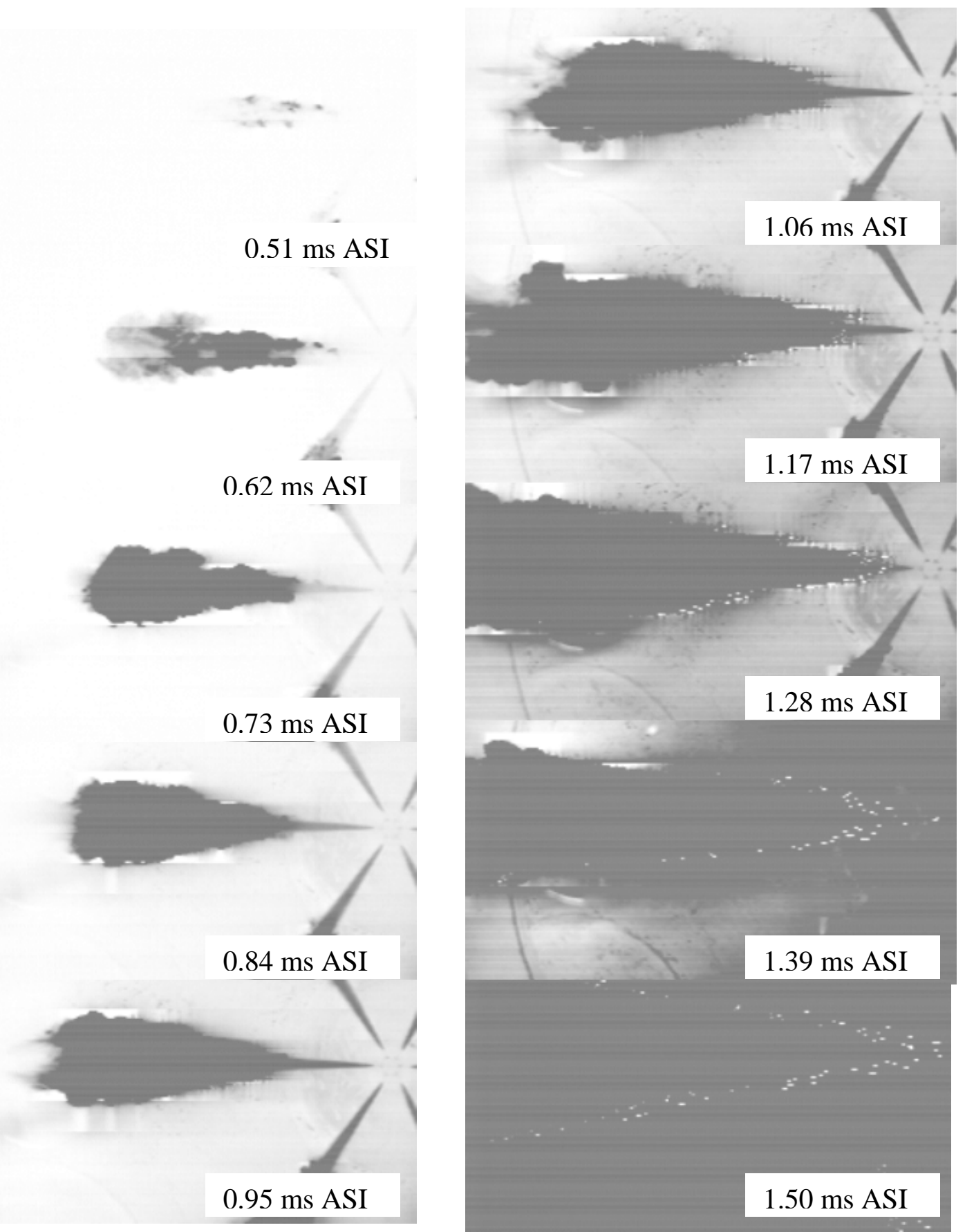

Figure 6.2 10 sequential images for reacting spray using the $0.158 \mathrm{~mm}$ nozzle hole diameter, $90 \mathrm{MPa}$ peak injection pressure, $15 \mathrm{~kg} / \mathrm{m}^{3}$ ambient gas density and $1000 \mathrm{~K}$ ambient gas temperature. The gray level is inverted, so the black is the brightest level. The later images show saturation of image detector. 
diffusion flame appears to develop fully near $0.73 \mathrm{~ms}$ after the start of injection, which clearly indicates the edge of the spray boundary. Then, the diffusion flame sheath around the periphery propagates downstream as the injection proceeds. The later images show saturation of image detector due to increasing luminosity as the volume of the reacting spray increases. From the later temporal sequence of the images, there seems to be two combustion regimes of DI diesel spray, the premixed combustion inside the spray boundary (i.e., the fuel-rich vapor region) and a turbulent diffusion combustion on the edge of the spray boundary, which agrees with the conceptual model of DI combustion by Dec [1].

\subsection{Equivalence Ratio Distribution at the Ignition Time}

\subsubsection{Effect of Injection Pressure on Reacting Spray}

Figures 6.3-6.5 show the equivalence ratio distribution of the non-reacting spray and the natural emission of the reacting spray during the ignition and initial flame development period for three different injection pressures, 60, 90 and $150 \mathrm{MPa}$ respectively. The details of the experimental conditions are the same as that of $§ 5.4$. Figures 6.3(a)-6.5(a) show two equivalence ratio distributions which were presented in $\S 5.4$ for the non-reacting spray near the autoignition period. Since a single-shot image of the equivalence ratio distribution was observed to have maximum $0.1 \mathrm{~ms}$ uncertainty in the start of injection, the two equivalence ratio distributions can be used together to estimate the equivalence ratio distribution for the reacting spray during the ignition. 
Figure 6.3 (a) equivalence ratio at 0.6 and $0.8 \mathrm{~ms}$ ASI, (b) temporal sequence of luminosity images with $0.158 \mathrm{~mm}$ nozzle hole diameter, $60 \mathrm{MPa}$ peak injection pressure, ambient gas density of $15 \mathrm{~kg} / \mathrm{m}^{3}$ and ambient gas temperature of $1000 \mathrm{~K}$.
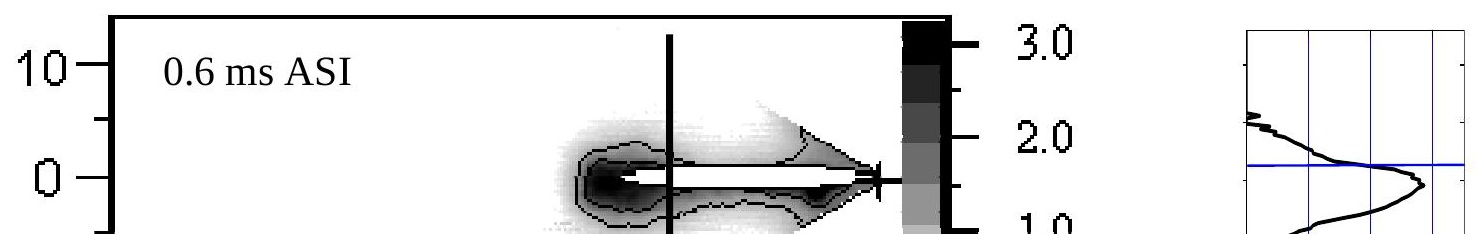
Figure 6.4 (a) equivalence ratio at 0.6 and $0.7 \mathrm{~ms} \mathrm{ASI}$, (b) temporal sequence of luminosity images with $0.158 \mathrm{~mm}$ nozzle hole diameter, $90 \mathrm{MPa}$ peak injection pressure, ambient gas density of $15 \mathrm{~kg} / \mathrm{m}^{3}$ and ambient gas temperature of $1000 \mathrm{~K}$.
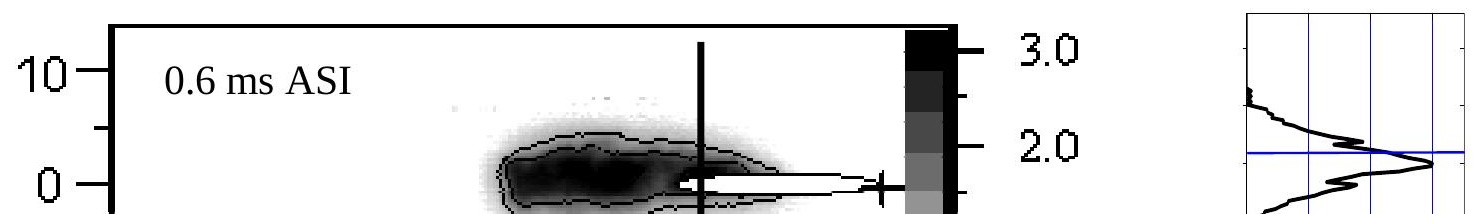
Figure 6.5 (a) equivalence ratio at 0.4 and $0.6 \mathrm{~ms} \mathrm{ASI}$, (b) temporal sequence of luminosity images with $0.158 \mathrm{~mm}$ nozzle hole diameter, 150 MPa peak injection pressure, ambient gas density of $15 \mathrm{~kg} / \mathrm{m}^{3}$ and ambient gas temperature of $1000 \mathrm{~K}$.
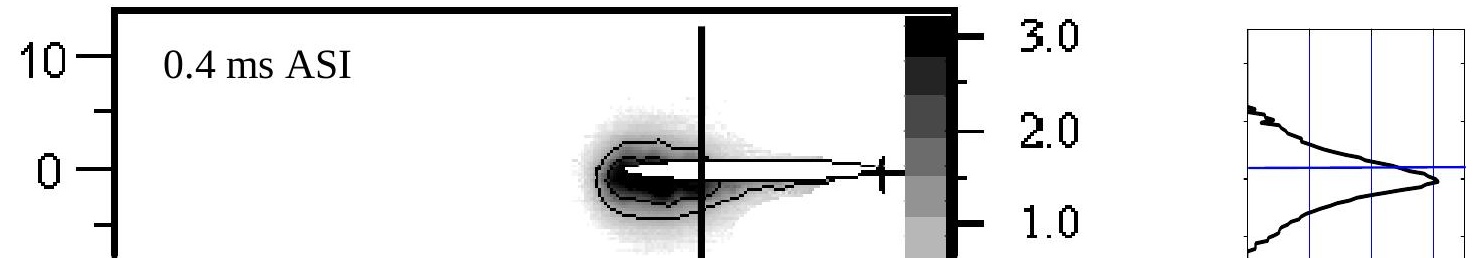
Figures 6.3(b)-6.5(b) show the reacting spray images after the start of ignition, at the same magnification as the equivalence ratio distributions. From Figures 6.3 (b) -6.5 (b) the ignition delay time and the location of the initial chemiluminescence can be determined. The ignition delay time from the temporal sequence of luminosity images was defined as the time when the chemiluminescence signals were first detected. However, at the location where autoignition occurs it was not clear whether the ignition region was limited to the periphery of the fuel rich region of the spray since the camera lacks depth perception and transfers 3-D information onto a 2-D plane (i.e., it is a line of sight measurements). From the fact that most images of the initial chemiluminescence have no signal in the spray core region, the ignition region seems to be located in the periphery of the spray core region. Additionally, the first detection of the luminosity signal appears to be located in the fuel-rich vapor region near the boundary of the liquid core.

To estimate quantitatively the equivalence ratio and temperature of the autoignition region, an intensity profile was taken along the black lines shown in the equivalence ratio distributions of Figures 6.3(a)-6.5(a). The position was defined as the same downstream position as the first detection of the chemiluminescence signals. The radial position of the first luminosity signal detection is indicated on the intensity profiles shown to the right of Figures 6.3(a)-6.5(a).

Table 6.1 shows estimates of the equivalence ratio and temperature at the location of the first detection of luminosity. The two values shown in each cell resulted from the two times shown in each of Figures 6.3(a) - 6.5(a)). The results of Table 6.1 show that the 
three injection pressures have similar autoignition conditions: an equivalence ratio slightly higher than 2 and a temperature of $800 \mathrm{~K}$.

Table 6.1 Ignition delay, equivalence ratio and temperature at autoignition.

\begin{tabular}{|c|c|c|c|}
\hline Peak Inj. Pressure & Ignition Delay (ms) & Equivalence ratio (-) & Temperature (K) \\
\hline $60 \mathrm{MPa}$ & 0.72 & $2.2 / 2.4$ & $800 / 760$ \\
\hline $90 \mathrm{MPa}$ & 0.61 & $2.0 / 2.1$ & $810 / 800$ \\
\hline $150 \mathrm{MPa}$ & 0.59 & $2.2 / 2.3$ & $800 / 790$ \\
\hline
\end{tabular}

To estimate the accuracy of this ignition point equivalence ratio and temperature, the other two runs of reacting images from each case were used as a comparison with the equivalence ratio distributions of Figures 6.3(a)-6.5(a). Since the reacting spray images lack depth perception, both the inner and outer radii of the initial chemiluminescence region were measured to define the radial range of the first luminosity signal detection. Using these radial ranges and corresponding equivalence ratio profiles, the equivalence ratios were found to be 1.84 for outer radius and 2.55 for inner radius, and the unit standard deviations of both bound equivalence ratios were 0.27 and 0.18 . The corresponding temperatures at both bounds are $820 \mathrm{~K}$ for outer radius and $730 \mathrm{~K}$ for inner radius. Therefore it can be suggested that if the cross-talk effect of the liquid phase is negligible, under ambient conditions of $15 \mathrm{~kg} / \mathrm{m}^{3}$ and $1000 \mathrm{~K}$ the injected liquid fuel is heated to a temperature of $800 \mathrm{~K}$, and rapid breakdown of the high cetane compounds begins to occur in the fuel rich vapor region with an equivalence ratio near 2 . The 
injection pressure does not affect the ignition conditions, just the location within the spray plume where they are satisfied.

The results agree reasonably with Flynn et al.'s estimation [65] based a chemical kinetics analysis and laser diagnostics using the similar condition to those in Table 2.3 (ambient gas temperature $950 \mathrm{~K}$ ). Their results show that the autoignition of vaporizing fuel occurs at about $0.7 \mathrm{~ms}$ after the start of injection with a temperature of approximately $750 \mathrm{~K}$ and the equivalence ratio of 3-4.

Table 6.1 also shows the effects of injection pressure on the ignition delay time, which was obtained by averaging three experimental runs for each injection pressure. Also, Figure 6.6 shows that for increasing pressure the ignition delay time becomes

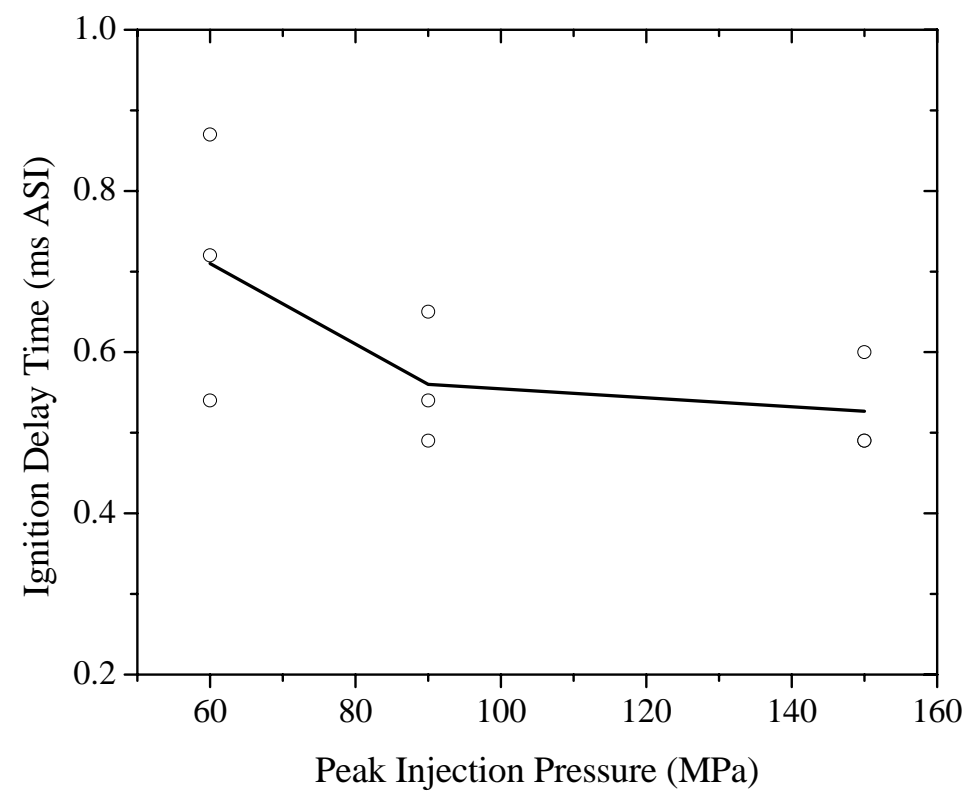

Figure 6.6 Ignition delay time vs. injection pressures for three separate runs with the 158 $\mu \mathrm{m}$ hole diameter, at an ambient gas temperature of $1000 \mathrm{~K}$ and density of 15 $\mathrm{kg} / \mathrm{m}^{3}$. 
shorter, but the delay time sensitivity on pressure can be seen to decrease as pressure is increased, which also agrees with Kamimoto et al's result [15].

From the later images in Figures 6.3-6.5 (a) and (b), a turbulent diffusion flame is observed about $0.2 \mathrm{~ms}$ after the start of ignition, and clearly indicates the edge of the spray boundary. The lift-off height after the completed ignition phase was determined from Figures 6.3-6.5 (b). The flame lift-off height is defined as the downstream location from the injector tip of the first region of combustion. To determine the lift-off height, a threshold of 25 was chosen to eliminate reflected signals from the dense liquid column detected in the images. Figure 6.7 shows the effect of injection pressure on the flame liftoff height obtained by averaging three experimental runs. For a given hole size the flame

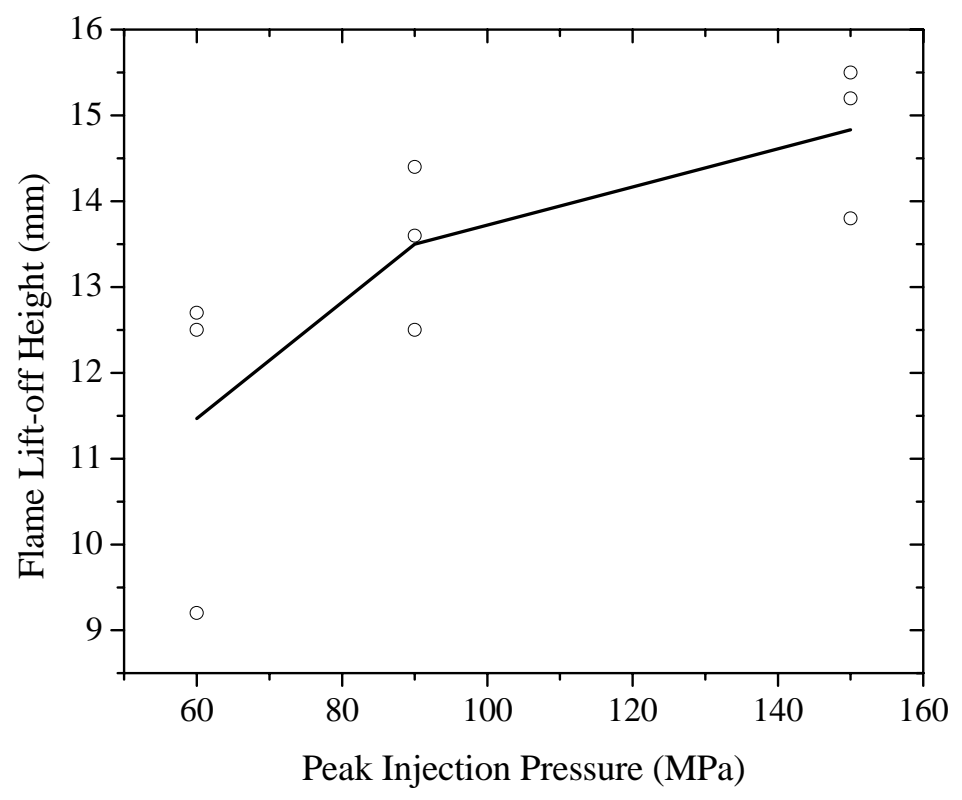

Figure 6.7 Flame lift-off height vs. injection pressures for three separate runs with the $158 \mu \mathrm{m}$ hole diameter, at an ambient gas temperature of $1000 \mathrm{~K}$ and density of 15 $\mathrm{kg} / \mathrm{m}^{3}$. 
lift off position is shown to increase with increasing pressure. These trends agree well with results from Siebers and Higgins’ quasi-steady flame lift-off measurements [66,67].

It should be noted that the first detection of the luminosity signals occurs just downstream of the flame lift-off height although the initial location moves about due to transient characteristics of the spray in this study.

\subsubsection{Effect of Nozzle Hole Size on Reacting Spray}

Figures 6.8, 6.4 and 6.9 show the equivalence ratio distribution of the nonreacting spray and natural luminosity of the reacting spray during the ignition and initial flame development period for three different nozzle hole sizes, 140, 158 and $200 \mu \mathrm{m}$ respectively. The details of the experimental conditions are the same as that of $\S 5.5$. Figures 6.8,6.4 and 6.9(a) show two equivalence ratio distributions for the non-reacting spray near the start of ignition. Since a single-shot image of the equivalence ratio distribution was observed to have a $0.1 \mathrm{~ms}$ uncertainty in the start of injection, the two equivalence ratio distributions can be used together to estimate the equivalence ratio distribution for the reacting spray during the ignition. Figures 6.8,6.4 and 6.9(b) show a series of reacting spray images after the start of ignition for three different hole sizes at the same magnification as the equivalence ratio plots. From Figures 6.8,6.4 and 6.9 the ignition delay time and the location of the initial luminosity can be determined. As in §6.2.1, the auto-ignition location seems to be in the fuel rich peripheral regions of the spray near the boundary of the liquid core. 
Figure 6.8 (a) equivalence ratio at 0.7 and $1.0 \mathrm{~ms}$ ASI, (b) temporal sequence of luminosity images with $0.14 \mathrm{~mm}$ nozzle hole diameter, $90 \mathrm{MPa}$ peak injection pressure, ambient gas density of $15 \mathrm{~kg} / \mathrm{m}^{3}$ and ambient gas temperature of $1000 \mathrm{~K}$.
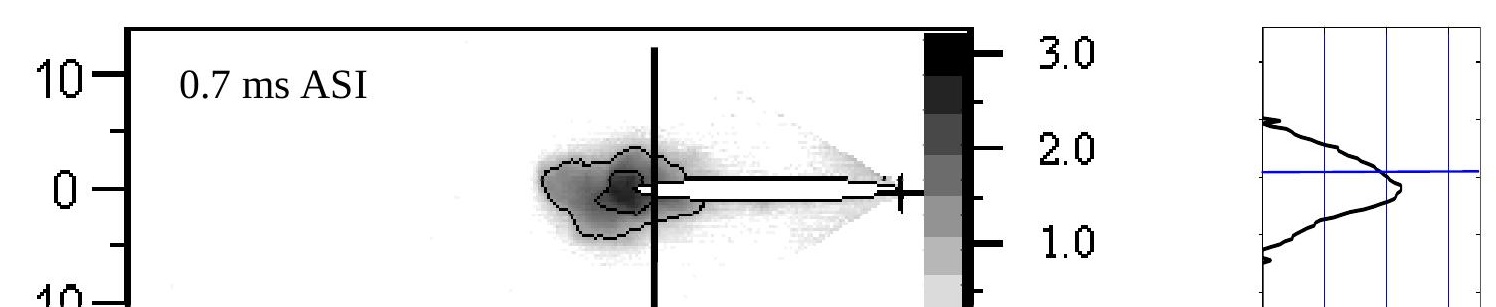
Figure 6.9 (a) equivalence ratio at 0.4 and $0.6 \mathrm{~ms}$ ASI, (b) temporal sequence of luminosity images with $0.2 \mathrm{~mm}$ nozzle hole diameter, $90 \mathrm{MPa}$ peak injection pressure, ambient gas density of $15 \mathrm{~kg} / \mathrm{m}^{3}$ and ambient gas temperature of $1000 \mathrm{~K}$.
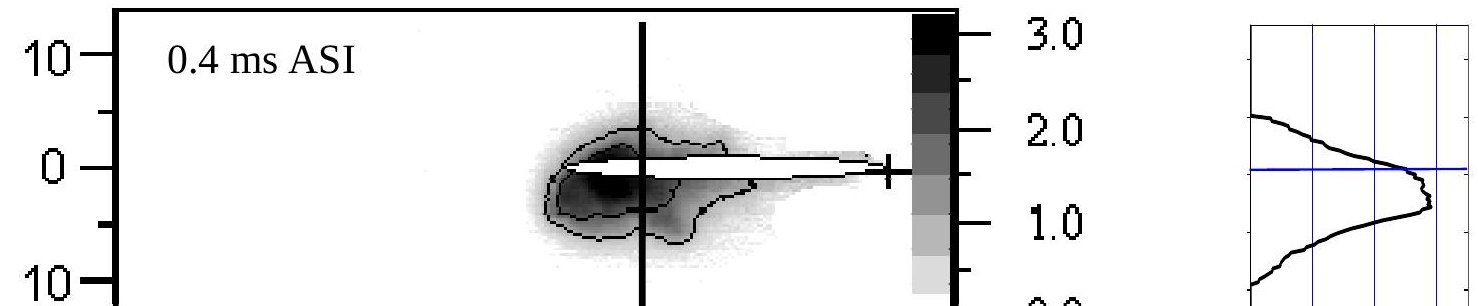
To quantitatively estimate the equivalence ratio and temperature at the autoignition region, an equivalence ratio profile taken along the black line shown in the equivalence ratio distribution is used, and is shown to the right of each image in Figures 6.8(a), $6.4(\mathrm{a})$ and 6.9(a)). The downstream and radical locations of the profile correspond to the auto-ignition region. Table 6.2 shows estimates of the equivalence ratio and temperature at the first detection of the chemiluminescence signals. The two values of each cell result from the two equivalence ratio profiles of each of Figures 6.8(a), 6.4 (a) and 6.9(a). It can be seen that the three injector hole sizes have similar autoignition condition (an equivalence ratio near 2 and a temperature of approximately $800 \mathrm{~K}$ ) as found for the three injection pressures in §6.2.1.

Table 6.2 Ignition delay, equivalence ratio and temperature at autoignition.

\begin{tabular}{|c|c|c|c|}
\hline Nozzle Size & Ignition Delay (ms) & Equivalence ratio (-) & Temperature (K) \\
\hline $140 \mu \mathrm{m}$ & 0.76 & $1.9 / 2.0$ & $820 / 800$ \\
\hline $158 \mu \mathrm{m}$ & 0.61 & $2.0 / 2.1$ & $810 / 800$ \\
\hline $200 \mu \mathrm{m}$ & 0.44 & $2.4 / 1.75$ & $780 / 830$ \\
\hline
\end{tabular}

The uncertainty of this ignition point's equivalence ratio and temperature can also be determined in the same manner as the injection pressure case in $§ 6.2 .1$ using the radial position ranges and corresponding the equivalence ratio profiles. The equivalence ratios were found to be 2.03 for outer radius and 2.45 for inner radius, and the unit standard deviations of both bound equivalence ratios were 0.36 and 0.28 . The corresponding 
temperatures at both bounds are $800 \mathrm{~K}$ for outer radius and $750 \mathrm{~K}$ for inner radius. Therefore, as mentioned in the injection pressure case, it can be suggested that the injector hole size also does not affect the ignition conditions, and under ambient conditions of $15 \mathrm{~kg} / \mathrm{m}^{3}$ and $1000 \mathrm{~K}$ the ignition point has an equivalence ratio near 2 and $800 \mathrm{~K}$ if the cross-talk effect of the liquid phase is negligible.

Table 6.2 also shows the effects of injector hole size on the ignition delay time obtained by averaging the three experimental runs for each hole size. Figure 6.10 shows that for increasing hole size the ignition delay time becomes shorter.

From the later times in the sequence of the luminosity images of Figures 6.8, 6.4 and 6.9 (b) a turbulent diffusion flame is seen to develop about $0.2 \mathrm{~ms}$ after the start of

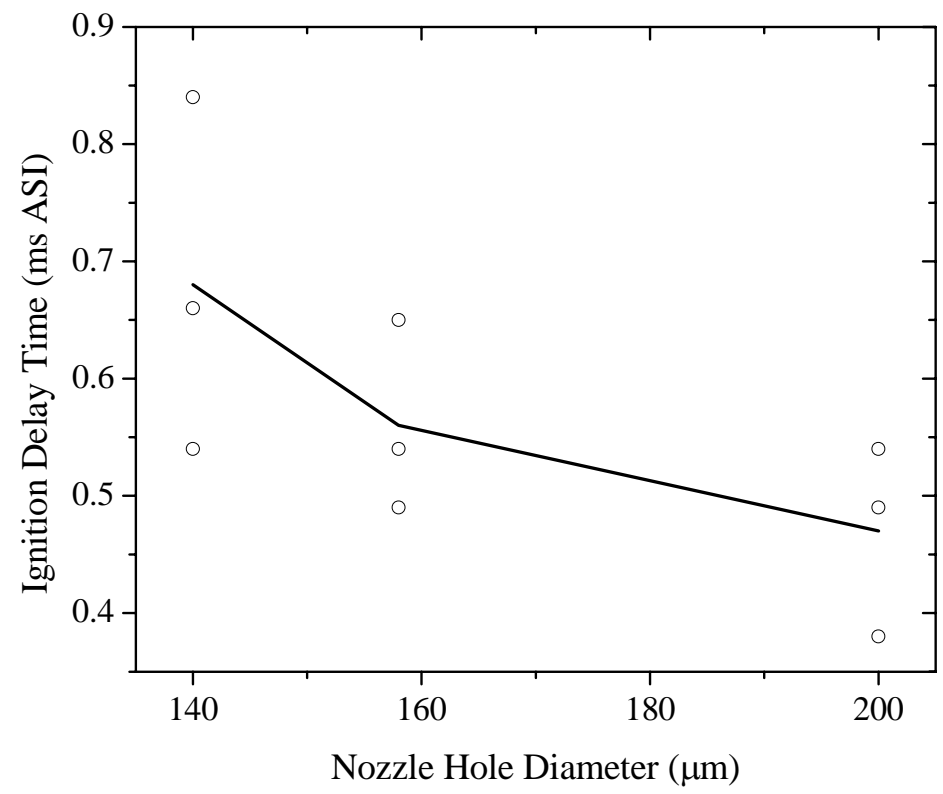

Figure 6.10 Ignition delay time vs. nozzle hole size for three separate runs with a $90 \mathrm{MPa}$ peak injection pressure and an ambient gas temperature of $1000 \mathrm{~K}$ and density of 15 $\mathrm{kg} / \mathrm{m}^{3}$. 
ignition, and clearly indicates the edge of the spray boundary, and a flame lift-off distance. The flame lift-off heights were determined using the same threshold as discussed in §6.2.1.

Figure 6.11 shows the effects of injector hole size on the flame lift-off height obtained by averaging the three experimental runs. For a given pressure the flame lift-off position is shown to increase with smaller hole sizes.

As discussed in §6.2.1, the first detection of the chemiluminescence signals with respect to different nozzle hole size also seems to be located just downstream of the flame lift-off height.

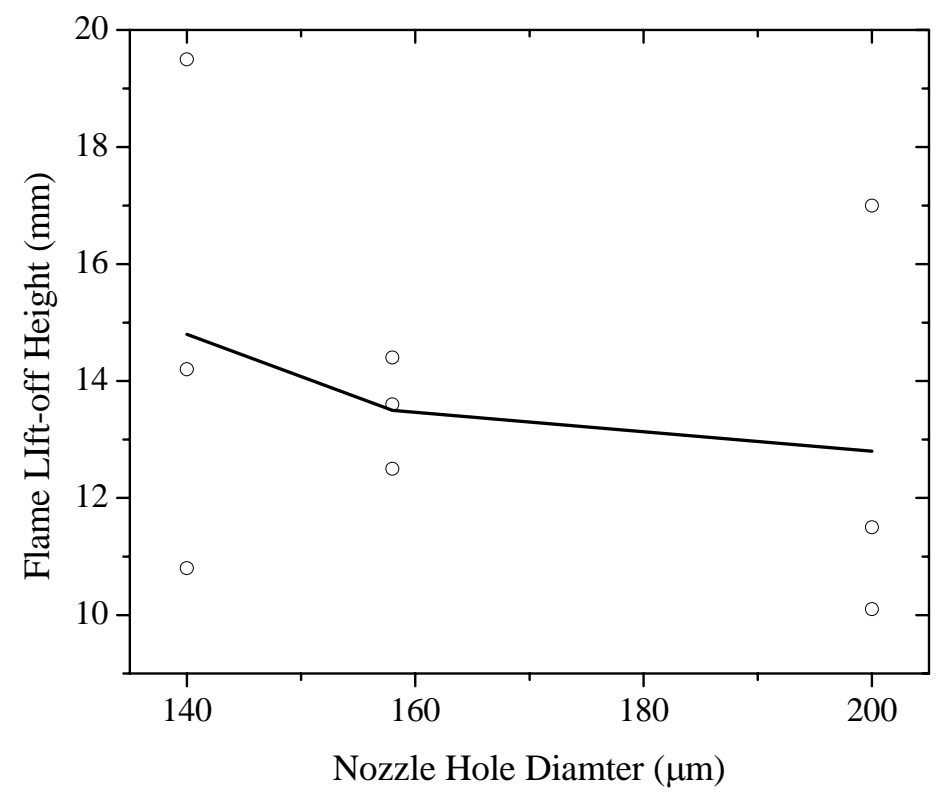

Figure 6.11 Flame lift-off height vs. nozzle hole size for three separate runs with a 90 MPa peak injection pressure and an ambient gas temperature of $1000 \mathrm{~K}$ and density of $15 \mathrm{~kg} / \mathrm{m}^{3}$. 


\subsection{Summary}

The non-reacting spray experiments in chapter 5 can be used to ascertain the equivalence ratio for a reacting spray during the ignition and initial flame development period. Under the ambient gas condition of $1000 \mathrm{~K}$ and $15 \mathrm{~kg} / \mathrm{m}^{3}$ the effects of three peak injection pressures (60, 90 and $150 \mathrm{MPa})$ and three nozzle hole sizes (140, 158 and 200 $\mu \mathrm{m})$ were investigated, and the major findings are summarized as follows:

1. The first detection of the chemiluminescence signals seems to occur in the fuelrich vapor region near the boundary of the liquid core (in most cases, just downstream of the final flame lift-off height). The equivalence ratio of the ignition region seems to be near 2. The corresponding temperature was found to be approximately $800 \mathrm{~K}$. Neither the injection pressure nor injector hole size were found to affect the ignition temperature, or equivalence ratio.

2. A turbulent diffusion flame developed about $0.2 \mathrm{~ms}$ after the autoignition period, which clearly indicated the edge of the spray boundary. Therefore, there seems to be two combustion regimes of DI diesel spray, the premixed combustion inside the spray boundary (i.e., the fuel-rich vapor region) and a turbulent diffusion combustion on the edge of the spray boundary

3. Transient luminosity images in this chapter can provide macroscopic reacting spray characteristics such as flame lift-off height and ignition delay time.

- For increasing pressure the ignition delay time becomes shorter, and the liftoff length increased. 
- Increasing hole diameter decrease the ignition delay and decreases the flame lift-off length.

4. The above findings (1 to 3 ) agree well with recent researches on DI diesel combustion. 


\section{Chapter 7. CONCLUSION AND RECOMMENDATIONS}

\subsection{Conclusion}

For this study the exciplex LIF technique and high-speed natural luminosity cinematography were applied to non-reacting and reacting diesel sprays, in a combustiontype constant-volume spray chamber to experimentally investigate evaporating sprays under conditions experienced in high speed direct- injection (HSDI) diesel engines. Using a density of $15 \mathrm{~kg} / \mathrm{m}^{3}$ the effects of three ambient gas temperatures (800, 1000 and $1200 \mathrm{~K})$, three peak injection pressures (60, 90 and $150 \mathrm{MPa}$ ) and three nozzle hole sizes $(0.14,0.158$ and $0.2 \mathrm{~mm})$ were investigated. The major results are as follows:

1. The combustion-type spray chamber developed provides conditions representative of a diesel engine at the start of fuel injection with good repeatability. Furthermore, negligible window contamination was observed.

2. A detailed set of calibration experiments were performed in order to quantify the TMPD fluorescence signal. This included development of a method for the absolute calibration of the imaging system at a reference condition, and the application of corrections to this calibration based on the local thermodynamic conditions affecting the photophysical parameters. The effects of pressure and collision partner were found to be negligible. The effect of temperature was found to increase the fluorescent yield up to $600 \mathrm{~K}$, then decrease it for further increases in temperature. These factors along with an adiabatic mixing model for the temperature reduction due to vaporization and laser sheet absorption and spatial non-uniformity were accounted for in the final calibration procedure. 
3. To verify the liquid-phase exciplex data, a comparison was performed of the liquid-phase exciplex penetration data to penetration data acquired from Mie scattering images at the same conditions. It was shown that the intact liquid lengths measured by both techniques were in good agreement, and match the predicted intact liquid length very well. Therefore, the liquid phase extent is believed to be well represented by the exciplex technique.

4. To assess the accuracy of the calibration procedure, the 2-D fuel vapor concentration was integrated and compared with the known mass of fuel that had been injected up to that time. At the time when all of the fuel is expected to be vaporized and no cross-talk issues exist, there is excellent agreement $(<10 \%)$ between the integrated vapor mass and the total injected mass. By analyzing all factors contributing to signal noise and the uncertainty from the local temperature estimation, it was determined that the estimated uncertainty of the measurements was $21 \%$.

5. During the injection period, the vapor mass measured was in some case overpredicted. This could be the result of liquid phase fuel existing at positions downstream of the indicated intact liquid length, providing an apparent vapor phase concentration that was too high due to cross-talk from the liquid signal. The concentration of liquid in the core region is quite high and the camera has a limited dynamic range. In addition, since the liquid position can deviate slightly from run-to-run due to the turbulent flowfield, this would change the position where the liquid intersected the thin laser sheet. 
6. Based on the calibrated exciplex concentration measurements, the major findings are summarized as follows:

- The data indicate that early in the injection event liquid and vapor coexist at the spray leading edge, however the liquid length reaches a terminal value and the vapor phase continues to penetrate.

- Lower ambient gas density was shown to have faster vapor penetration and longer liquid lengths.

- Higher ambient gas temperature was shown to produce a wider radial vapor extent with higher equivalence ratios, and to have higher gradients at the edge of the jet.

- Distributions of the vapor concentration for higher injection pressures showed faster fuel vaporization rates and larger spray head volumes.

- Larger nozzle hole sizes were shown to provide faster vapor-phase penetration rates and longer intact liquid lengths.

- The effects of the aforementioned parameters on the spray-spreading angle were shown to be transient in nature, although as injection progresses the effects seemed to dissipate. At the early portion of the injection period, for lower injection pressures, higher ambient temperatures or larger nozzle hole sizes the spray-spreading angle was found to be wider.

7. Natural luminosity images from reacting diesel sprays have been acquired, and compared with the exciplex image data to understand the equivalence ratio distribution within the reacting spray during the ignition and the initial flame 
development period. Additionally, transient luminosity images can provide macroscopic reacting spray characteristics such as flame lift-off height and ignition delay time.

- The first detection of the chemiluminescence signals seems to occur in the fuel-rich vapor regions with an equivalence ratio near 2 near the boundary of the liquid core. The corresponding temperature was found to be approximately $800 \mathrm{~K}$. These conditions were found to be independent of injection pressure and nozzle diameter for the condition tested $\left(15 \mathrm{~kg} / \mathrm{m}^{3}\right.$ and $1000 \mathrm{~K}$ ambient).

- For increasing pressures the ignition delay time becomes shorter, and the flame lift off height increases. For increasing hole diameter the ignition time delay was shorter, and the flame lift-off height decreased.

\subsection{Recommendations}

The following recommendations are made:

1. The estimation of local temperature is one of most critical issues to obtain accurate measurements. Precise estimation is important since TMPD fluorescence depends on temperature, and local temperatures in the vapor phase can spatially vary due to liquid evaporation. Estimation of local temperature assuming adiabatic mixing between the fuel and air which was used in the study, could have uncertainty during the injection period. Due to the nature of the Lagrangian approach, the estimate is only valid if a sufficient amount of entrained ambient gas is mixed thoroughly and moves with the same speed of an interested-amountof-fuel, and if the residence time of the mass is long enough to reach an adiabatic 
saturation condition. A numerical analysis, using a code such as KIVA, could be used to verify the assumption of adiabatic mixing between the fuel and air.

2. The TMPD absorption coefficient used in this study was taken from the literature value of $\varepsilon, 650 \mathrm{l} / \mathrm{mol}-\mathrm{cm}$, and was assumed to be constant with temperature. However, it may be important to directly measure the dependence of the TMPD absorption coefficient on temperature to validate the results obtained.

3. The HEUI 90 injector used in this study was hydraulically actuated by engine oil. After engaging the pump, the oil temperature increases with time. Variations in oil temperature seem to increase the shot-to-shot variation between injections (ex. the start of injection with respect to engaged TTL signal). Therefore, a control system for a constant oil temperature should be explored to improve shot-to-shot variations and the determination of the mechanism by which oil temperature effects injection characteristics.

4. To obtain better images of the macroscopic reacting spray characteristics, a band pass filter, installed in front of the camera lens, for a certain molecule (ex. $\mathrm{OH}$ ) might be helpful to isolate any scattering from the intact liquid phase as well as possibly alleviating the saturation problem.

5. In this study, the effects of wall interaction and swirl flow that are common in small-sized high speed DI diesel engines were not considered. To take in-cylinder flow effects into account the chamber used in these experiments can be modified to have flow motion (tumble or swirl). However, the exciplex concentration measurements might not be appropriate to investigate wall interaction since the 
local temperature estimation from the assumption of adiabatic mixing between the fuel and air could have high uncertainty, and is therefore not recommended.

6. It is recommended that the results from this study be used as inputs to improve the accuracy of injection and combustion process modeling by numerical codes, such as KIVA. 


\section{BIBLIOGRAPHY}

1. Dec, J., “A Conceptual Model of DI Diesel Combustion based on Laser-Sheet Imaging,” SAE Paper 970873, 1997.

2. Siebers, D., “ Scaling Liquid-Phase Fuel Penetration in Diesel Sprays Based on Mixing-Limited Vaporization,” SAE Paper 1999-01-0528, 1999.

3. Arcoumanis, C., Cossali, E., Paal, G. and Whitelaw, J., “Transient Characteristics of Multi-Hole Diesel Sprays,” SAE Paper 900480, 1990.

4. $\mathrm{Xu}, \mathrm{M}$. and Hiroyasu, H., "Development of a New Optical technique for measuring Diesel Spray Penetration,” SAE 902077, 1990.

5. Naber, J. and Siebers, D., "Effects of Gas Density and Vaporization on Penetration and Dispersion of Diesel Sprays,” SAE Paper 960034, 1996.

6. Hay, N. and Jones, P., "Comparison of the Various Correlations for Spray Penetration,” SAE Paper 720776, 1972.

7. Wakuri, Y., Fujii, M., Amitani, T. and Tsuneya, R., "Studies on the Penetration of fuel Spray in a Diesel Engine,” Bulletin of JSME, Vol. 3, No. 9, pp123-130, 1960.

8. Dent, J., “A Basis for the Comparison of Various Experimental Methods for Studying Spray Penetration,” SAE Paper 710571, 1971.

9. Hiroyasu, H. and Arai, M., "Structures of Fuel Sprays in Diesel Engines," SAE Paper 900475, 1990. 
10. Chaves, H., Knapp, M., Obermeier, F. and Schneider, T., "Experimental Study of Cavitation in the Nozzle Hole of Diesel Injectors Using Transparent Nozzles,” SAE Paper 950290, 1995.

11. Soteriou, C., Andrews, R. and Smith, M., "Direct Injection Diesel Sprays and the Effect of Cavitation and Hydraulic Flip on Automization,” SAE paper 950080, 1995.

12. Su, T., Farrell, P. V. and Nagarajan, R., “Nozzle Effect on High Pressure Diesel Injection,” SAE Paper 950083, 1995.

13. Reitz, R. and Bracco, F., “On the Dependence of Spray Angle and Other Spray parameters on Nozzle Design and Operating Conditions,” SAE 790494, 1979.

14. Browne, K., Partridge, I. and Greeves, G., "Fuel Property Effects on Fuel/Air Mixing in an Experimental Diesel Engine,” SAE Paper 860223, 1986.

15. Kamimoto, T., Yokota, H. and Kobayashi, H., "Effect of High Pressure Injection on Soot Formation processes in a Rapid Compression Machine to Simulate Diesel Flames,” SAE Paper 871610, 1987.

16. Espey, C. and Dec, J., “The Effect of TDC Temperature and Density on the LiquidPhase Fuel Penetration in a D.I. Diesel Engine,” SAE Paper 952456, 1995.

17. Siebers, D., “Liquid-Phase Fuel Penetration in Diesel Sprays,” SAE Paper 980809, 1998.

18. Verhoeven, D., Vanhemelryck, J. and Baritaud, T., "Macroscopic and Ignition Characteristics of High-Pressure Sprays of Single-Component Fuels,” SAE Paper 981069, 1998. 
19. Higgins, B., Mueller, C. and Siebers, D., "Measurements of Fuel Effects on LiquidPhase Penetration in DI Sprays,” SAE paper 1999-01-0519, 1999.

20. Kato, T., Tsujimura, K., Shintani, M., Minami, T. and Yamaguchi, I, "Spray Characteristics and Combustion Improvement of DI Diesel Engine with High Pressure Fuel Injection,” SAE 890265, 1989.

21. Su, T. and Farrell, P. V., "Characterization of High-Injection Pressure Diesel Sprays with Relation to Particulate and Nox Emissions,” Atomization and Sprays, vol. 8, pp. 83-107, 1998.

22. Chraplyvy, A., "Nonintrusive Measurements of Vapor Concentrations inside Sprays,” Applied Optics, Vol. 20, No. 15, pp. 2620-2624, 1981.

23. Suzuki, M., Nishida, K. and Hiroyasu, H., "Simultaneous Concentration Measurement of Vapor and Liquid in an Evaporating Diesel Spray,” SAE 930863, 1993.

24. Scheid, E., Pischinger, F., Knoche, K., Daams, H., Hassel, E. and Ruter, U., "Spray Combustion chamber with Optical Access, Ignition Zone Visualization and First Raman Measurements of Local Air-Fuel Ratio,” SAE 861121, 1986.

25. Melton, L., “Spectrally Separated Fluorescence Emissions for Diesel Fuel Droplets and Vapor,” Applied Optics, vol. 22, No. 14, pp. 2224-2226, 1983.

26. Rotunno, A., Winter, M., Dobbs, G. and Melton, L., “Direct Calibration Procedures for Exciplex-Based Vapor/Liquid Visualization of Fuel Sprays,” Combust. Sci. and Tech., Vol. 71, pp 247-261, 1990. 
27. Barsley, M., Felton, P. and Bracco, F., “2-D Visualization of Liquid and Vapor Fuel in an I.C. Engine,” SAE 880521, 1988.

28. Hodges, J., Baritaud, T. and Heinze, T., "Planar Liquid and Gas Fuel and Droplet Size Visualization in a DI Diesel Engine,' SAE 910726, 1991.

29. Bower, G. and Foster, D. "The Effect of Split Injection on Fuel Distribution in an Engine-Fed Combustion Chamber,” SAE Paper 930864, 1993.

30. Felton, P., Bracco, F. and Bardsley, M., “On the Quantitative Application of Exciplex Fluorescence to Engine Sprays," SAE Paper 930870, 1993.

31. Yeh, C., Kamimoto, T., Kobori, S. and Kosaka, H., “2-D Imaging of Fuel Vapor Concentration in a Diesel Spray via Exciplex-Based Fluorescence Technique,” SAE paper 932652, 1993.

32. Yeh, C., Kamimoto, T., Kosaka, H. and Kobori, S., “Quntitative Measurement of 2-D Fuel Vapor Concentration in a transient Spray via Laser-Induced Fluorescence Technique”, SAE paper 941953, 1994.

33. Senda, J., Fukami, Y., Tanabe, Y. and Fujimoto, H., "Visualization of Evaporative Diesel Spray Impinging Upon Wall Surface by Exciplex Fluorescence Method,” SAE Paper 920578, 1992.

34. Senda, J., Kobayashi, M., Tanabe, Y. and Fujimoto, H., “ Visualization and Quantitative Analysis of the Fuel Vapor Concentration in Diesel Spray,” JSAE Review 15, pp. 149-156, 1994.

35. Senda J. and Kanda, T., “Quantitative Analysis of Fuel Vapor Concentration in Diesel Spray by Exciplex Fluorescence Method”, SAE paper 970796, 1997. 
36. Fujimoto, H., Kusano, S. and Senda, J., "Distribution of Vapor Concentration in a Diesel Spray Impinging on a Flat Wall by Means of Exciplex Fluorescence Method In case of High Injection Pressure,” SAE Paper972916, 1997.

37. Choi, D., Iwamuro, M., Shima, Y., Senda J. and Fujimoto, H., “The Effect of FuelVapor Concentration on the Process of Initial Combustion and Soot Formation in a DI Diesel Engine Using LII and LIEF,” SAE Paper 2001-01-1255, 2001.

38. Munch, K. -U., Kramer, H. and Leipertz, A., "Investigation of Fuel Evaporation Inside the Intake of a SI Engine Using Laser-Induced Exciplex-Fluorescence with a New Seed,” SAE Paper 961930, 1996.

39. Kim, J. U., Golding, B., Schock, H. J., Keller, P. and Nocera, D. G., "Exciplex Fluorescence Visualization Systems for Pre-Combustion Diagnosis of an Automotive Gasoline Engine,” SAE Paper 960826, 1996.

40. Froba, A. P., Rabenstein, F., Munch, K. -U. and Leipertz, A., "Mixture of Triethylamine (TEA) and Benzene as a New Seeding Material for the Quantitative Two-Dimensional Laser-Induced Exciplex Fluorescence Imaging of Vapor and Liquid Fuel Inside SI Engines”, Combustion Flame, vol. 112: pp. 199-209, 1998.

41. Le Coz, J. and Hermant, L., "Quantification of Fuel Concentrations and Estimation of Liquid/Vapor Ratios in Direct Injection Gasoline Sprays by Laser-Induced Fluorescence,” SAE Paper 2001-01-0916, 2001.

42. Kosaka, H. and Kamimoto, T., “Quantitative Measurement of Fuel Vapor Concentration in an Unsteady Evaporating Spray via a 2-D Mie-scattering Imaging Technique,” SAE paper 932653, 1993. 
43. Espey, C., Dec, J., Litzinger, T. and Santavicca, D., “ Quantitative 2-D Fuel Vapor Concentration Imaging in a Firing D.I. Diesel Engine Using Planar Laser-Induced Rayleigh Scattering,” SAE Paper 940682, 1994.

44. Espey, C., Dec, J., Litzinger, T. and Santavicca, D., "Planar Laser Rayleigh Scattering for Quatitative Vapor-Fuel Imaging in a Diesel Jet,” Combustion and Flame, Vol109, pp65-86, 1997.

45. Anderson, O., Collin, R., Alden, M. and Egnell, R., "Quantitative Imaging of Equivalence Ratio in DME Sprays Using a Chemically Preheated Combustion Vessel”, SAE paper ,2000.

46. Eckbreth, A., Laser Diagnostics for Combustion Temperature and Species, $2^{\text {nd }}$ Ed., Gordon and Breach Publishers, 1988.

47. Berlman, I. B., Handbook of Fluorescence Spectra of Aromatic Molecules, $2^{\text {nd }}$ edition, Academic Press, 1971.

48. Oren, D., Wahiduzzaman, S. and Ferguson, C., “A Diesel Combustion Bomb : Proof of Concept,” SAE 841358, 1984.

49. Feierisen, J., "Design, construction and Testing of an Engine-fed Combustion chamber with Optical Acess,” MS Thesis, University of Wisconsin, Department of Mechanical Engineering, 1989.

50. The Temperature Handbook, 21th centry Ed., Revised Thermocouple Reference Table, Omega, 2000.

51. Heitor, M. and Moreira, A., “Thermocouples and Sample Probes for Combustion Studies,” Prog. Energy and Combust. Sci., Vol. 19, pp259-278, 1993. 
52. Tagawa M. and Ohta, Y., “Two-Thermocouple Probe for Fluctuating Temperature Measurement in Combustion - Rational Estimation of Mean and Fluctuating Time Constants,” Combustion and Flame 109:549-560, 1997.

53. Ieda, Y., "The Effect of Ambient Gas Composition and Temperature on Soot Oxidation Rates,” PhD thesis, Department of Mechanical Engineering, University of Wisconsin - Madison, 1999.

54. Stockner, A., Flinn, M. and Camplin, F., "Development of the HEUI Fuel System Integration of Design, Simulation, Test, and Manufacturing,” SAE Paper 930271, 1993.

55. Glassey, S., Stockner, A. and Flinn, M., “ HEUI - A New Direction for Diesel Engine Fuel Systems,” SAE paper 930270, 1993.

56. Tennison, P., Georjon, T., Farrell, P. V. and Reitz, R., "An Experimental and Numerical Study of Sprays from a Common Rail Injection System for Use in an HSDI Diesel Engine,” SAE 980810, 1998.

57. Ghandhi, J. B. and Felton, P., "On the fluorescenct behavior of ketones at high temperature,” Experiments in Fluids Vol. 21, pp. 143-144, 1996.

58. El-Wakil, M., Myers, P. and Uyehara, O., "Fuel Vaporization and Ignition lag in Diesel Combustion,” SAE 560063, 1956.

59. Heywood, J. B., Internal Combustion Engine Fundamentals, McGraw-Hill, 1988.

60. Yaws, C. L., Thermodynamic and Physical Property Data, Gulf Publishing Company, 1992. 
61. Vargaftik, N. B., Handbook of Physical Properties of Liquid and Gas, Hemisphere, 1983.

62. Moffat, R. J., “Describing the Uncertainties in Experimental Results,” Experimental Thermal and Fluid Science, vol.1, pp. 2-17, 1988.

63. Lipson C. and Sheth N., Statistical Design and Analysis of Engineering Experiments, McGraw-Hill, Newyork, 1973.

64. Taylor, A. M. K. P., Instrumentation for Flows with Combustion, Academic Press, 1993.

65. Flynn, P. F., Russell, D. P., Hunter G. L., zur Loye, A. O, Akinyemi, O.C., Dec J. E., and Westbrook, C. K., “Diesel Combustion: An Integrated View Combining Laser Diagnostics, Chemical Kinetics, And Empirical Validation”; SAE Paper 1999-010509; 1999.

66. Siebers D. and Higgins, B., “Flame Lift-off on Direct-Injection Diesel Sprays Under Quiescent Conditions,” SAE2001-01-0530, 2001.

67. Higgins, B. and Siebers D., "Measurement of the Flame Lift-off Location on DI Diesel Sprays Using OH Chemiluminescence,” SAE2001-01-0918, 2001.

68. Compressibility for the Redlich-Kwong-Soave equation of state, Chem. Eng. Science, Vol. 27, pp. 1197-1203, 1972.

69. Reid, R., Prausnitz, J. and Poling, B., The Properties of Gases \& Liquids, $4^{\text {th }}$ Ed., Mcgraw Hill, 1987.

70. Antoine, C., C.R., 107: 681-836, 1888. 


\section{APPENDIX A}

\section{LIQUID LENGTH ESTIMATION}

\section{A.1 Application of Siebers' Scaling Law}

The liquid length, S, from Siebers' scaling law [2] is

$$
\begin{aligned}
& S=\frac{b}{a} \cdot \sqrt{\frac{\rho_{f}}{\rho_{a}}} \cdot \frac{\sqrt{C_{a}} \cdot d}{\tan (\theta / 2)} \cdot \sqrt{\left(\frac{2}{B\left(T_{a}, P_{a}, T_{f}\right)}+1\right)^{2}-1} \\
& B=\frac{Z_{a}\left(T_{s}, P_{a}-P_{s}\right) \cdot P_{s} \cdot M_{f}}{Z_{f}\left(T_{s}, P_{s}\right) \cdot\left(P_{a}-P_{s}\right) \cdot M_{a}}=\frac{h_{a}\left(T_{a}, P_{a}\right)-h_{a}\left(T_{s}, P_{a}-P_{s}\right)}{h_{f}\left(T_{s}\right)-h_{f}\left(T_{f}, P_{a}\right)}
\end{aligned}
$$

where $a$ is a constant, 0.66, related to the measured angle and the idealized spray angle, and $b$ is a constant, 0.41 , derived from a best fit of the scaling law to the experiment data. The following data and relationship were used for this estimation using EES code.

\section{A.1.1 Compressibility factor (Z)}

The EES solver uses compressibility from the Redlich-Kwong-Soave equation of state [68], and requires the reduced temperature (normalized by critical temperature), reduced pressure (normalized by critical pressure), and the acentric factor ( $\omega$, which represents the nonsphericity of a molecule). From reference 69, we can obtain the data: for dodecane, $\omega=0.575$, Tc=658.2 K, and Pc=18.2 bar; for naphthalene, $\omega=0.313$, Tc=748.4 K, and $\mathrm{Pc}=40.4$ bar.

A.1.2 Enthalpy Difference in the Fuel (denominator in $2^{\text {nd }}$ term of B in EQ (2.5)) 
The enthalpy change of the pure fuel results from heating and vaporizing the liquid fuel. The doped fuel was assumed to be a mixture of $90 \%$ dodecane and $10 \%$ naphthalene since data for TMPD were not available. The mixture data were determined using Dalton's and Raoult's laws applied to the vapor and liquid phase respectively.

\section{A.1.2.1 Heating the liquid fuel}

From reference 60, we can use the following relationship to determine the amount of heating energy of the liquid fuel.

$$
\Delta H_{\text {heating }}[\mathrm{J} / \mathrm{mol}]=\int C_{P} d T
$$

where $\mathrm{Cp}[\mathrm{J} / \mathrm{mol}-\mathrm{K}]=A+B^{*} T[\mathrm{~K}]+C^{*} T[\mathrm{~K}] \wedge 2$

For liquid dodecane in a temperature range of $264-519 \mathrm{~K}, A=414.35, B=-$ $540.850 \times 10^{-3}$, and $C=137.080 \times 10^{-5}$. For liquid naphthalene in a temperature range of $353-521 \mathrm{~K}, A=226.62, B=-104.725 \times 10^{-3}$ and $C=244.123 \times 10^{-6}$.

\section{A.1.2.2 Vaporizing the liquid fuel (Latent heat)}

From reference 60, we can use the following relationship to determine the latent heat for vaporizing the liquid fuel.

$$
\Delta H_{\text {vaporized }}[\mathrm{kJ} / \mathrm{mol}]=H_{\text {vaporized } @ T 1}\left[\frac{T_{\text {crit }}-T}{T_{\text {crit }}-T_{1}}\right]^{0.38}
$$

For the liquid dodecane, $\mathrm{T}_{1}=488.6 \mathrm{~K}, \mathrm{H}_{\text {vaporized } @ \mathrm{~T} 1}=43.639 \mathrm{~kJ} / \mathrm{mol}$, and Tc=658.2 K. For the liquid naphthalene, $\mathrm{T}_{1}=491.1 \mathrm{~K}, \mathrm{H}_{\text {vaporized@T1 }}=43.263 \mathrm{~kJ} / \mathrm{mol}$ and Tc=748.4 K. 


\section{A.1.3 Determination of Fuel Vapor Pressure (Ps and Ts)}

The Antoine equation [70] was selected as a correlation of vapor pressure as a function of temperature.

$\log P s[\mathrm{~mm} \mathrm{Hg}]=A-B /(T s[C]+C)$

From the reference 60, we can obtain the data: for dodecane in a temperature range of 91 - $247 \mathrm{C}, A=6.99795, B=1639.270$, and $C=181.835$; for naphthalene in a temperature range of $87-250 \mathrm{C}, A=7.01065, B=1733.710$, and $C=201.859$.

\section{A.2 Confirmation for This Application}

Due to the different data references used for thermodynamic properties, it may be worth to compare the result with Siebers'. With fuel as cetane (hexadecane), $\mathrm{C}_{\mathrm{d}}$ of $0.84, \mathrm{~T}_{\mathrm{f}}$ of $438 \mathrm{~K}$, nozzle hole size of $246 \mu \mathrm{m}$, and the composition of the ambient gas of $89.7 \% \mathrm{~N}_{2}, 6.5 \% \mathrm{CO}_{2}, 3.8 \% \mathrm{H}_{2} \mathrm{O}$, a close agreements are shown in Table A.1.

For this study, the doped fuel was assumed as a mixture of $90 \%$ dodecane and 10\% naphthalene. The mixture data were determined using Dalton's and Raoult's laws applied to the vapor and liquid phase respectively. With hole size of $165 \mu \mathrm{m}$, the composition of the ambient gas of $85 \% \mathrm{~N}_{2}, 10 \% \mathrm{CO}_{2}, 5 \% \mathrm{H}_{2} \mathrm{O}$, an ambient temperature of $1300 \mathrm{~K}$, ambient density of $15 \mathrm{~kg} / \mathrm{m}^{3}$, and assuming $C_{d}$ and $T_{f}$ as 0.6 and $300 \mathrm{~K}$, a EES program (shown in §A.3) was used to estimate the liquid length, and reasonable agreements are seen in Table A.2. 
Table A.3 shows the sensitivity of each parameter on this estimation, and shown that significant change of the liquid penetration length could be induced with respect to the parameters investigated.

Table A.1 Confirmation on the application of Siebers’ relation

\begin{tabular}{|c|c|c|}
\hline $\mathrm{T}_{\mathrm{a}}$ & Siebers* & This calculation \\
\hline $1000 \mathrm{~K}$ & $26 \mathrm{~mm}$ & $27.1 \mathrm{~mm}$ \\
\hline $1300 \mathrm{~K}$ & $21 \mathrm{~mm}$ & $22.6 \mathrm{~mm}$ \\
\hline
\end{tabular}

* [2], p10 (Fig. 5).

Table A.2 Comparison of the liquid lengths

\begin{tabular}{|c|c|}
\hline Estimation by Siebers' relation & Our experiment data \\
\hline $15.1 \mathrm{~mm}$ & $15 \sim 22 \mathrm{~mm}$ \\
\hline
\end{tabular}

Table A.3 Parameter sensitivity on liquid length estimation

\begin{tabular}{|l|c|}
\hline Ambient gas temperature, $\mathrm{T}_{\mathrm{a}}$ & $\approx-1.75 \mathrm{~mm} / 100 \mathrm{~K}$ \\
\hline Initial fuel temperature, $\mathrm{T}_{\mathrm{f}}$ & $\approx-1.1 \mathrm{~mm} / 50 \mathrm{~K}$ \\
\hline Orifice area-contraction coefficient, $\mathrm{C}_{\mathrm{a}}$ & $\approx 2.8 \mathrm{~mm} /\left(\mathrm{C}_{\mathrm{a}}=0.6 \Rightarrow \mathrm{C}_{\mathrm{a}}=0.84\right)$ \\
\hline Turbulent effect & $\approx< \pm 11 \%$ \\
\hline
\end{tabular}




\title{
A.3 EES Program Used
}

\author{
" $* * * * * * * * * * * * * * * * * * * * * * * * * * * * * * * * * * * * * * * * * * * * * * * * * * * * * * * * * * * * * * * * * *)$ \\ "This is to estimate the liquid length for the doped fuel"

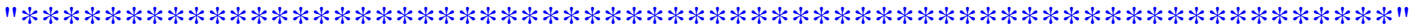

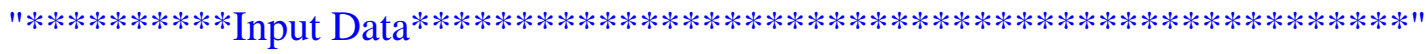 \\ $\mathrm{Pa}=19.5$ "Ambient gas pressure, bar" \\ $\mathrm{Ta}=1200$ "Ambient gas temperature, K" \\ T_1=300 "Initial fuel temperature, K" \\ rho_a=7.5 "Ambient density, kg/m3" \\ d_orifice=158e-6 "Orifice diameter, m" \\ c_a $=0.8$ "Orifice area contraction coefficient" \\ $\mathrm{a} 1=0.41 ; \mathrm{b} 1=0.66$ “constants” \\ rho_f=0.9*748+0.1*1150"@ 293K, fuel density, kg/m3"

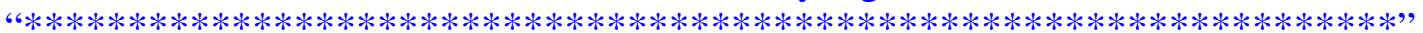 \\ “**********"Measured data of averaged spreading angle $* * * * * * * * * * * * * * * * * *$ \\ ***********oR use the Siebers' relation"**********************************” \\ \{theta $=13.2\}$ \\ $\tan \left(\right.$ theta/2) $=0.260 *\left((\text { rho_a/rho_f })^{\wedge} 0.19-0.0043 * s q r t\left(r h o \_f / r h o \_a\right)\right)$ \\ "***********Siebers' correlation for liquid length************************" \\ Liquid_legth1=a1/b1*sqrt(rho_f/rho_a)*sqrt(c_a)*d_orifice/tan(theta/2)*sqrt((2/mass \\ _ratio1+1)^2-1) \\ Liquid_legth2=a1/b1*sqrt(rho_f/rho_a)*sqrt(c_a)*d_orifice/tan(theta/2)*sqrt((2/mass \\ _ratio2+1)^2-1)

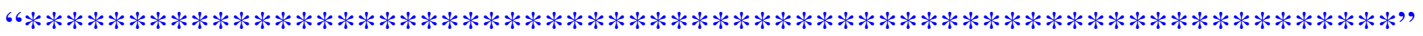

“**********************************************************************),

" $* * * * * * * * * * * * * * * * * * * * * * * * * * * * * * * * * * * * * * * * * * * * * * * * * * * * * * * * * * * * * * * * * * "$

"********* To obtain \{mass_ratio1=mass_ratio2 w.r.t. T1 $\} * * * * * * * * * * * * * * * * * * * * "$

"The below is the final value to obtain from the given parametric table"

"T1=573.5"

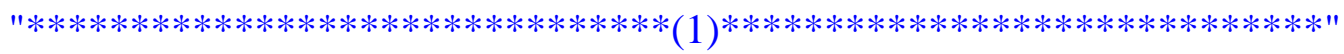

mass_ratio1 $=\mathrm{H}$ _air/H_fuel

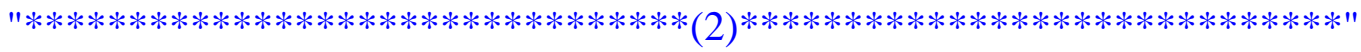

mass_ratio $=\left(0.9 * \mathrm{P} \_d o d e c a n e * M \_d o d e c a n e / Z \_d o d e c a n e+0.1 * \mathrm{P} \_n a p h t h a l e n{ }^{*} \mathrm{M} \_n a\right.$ phthalene/Z_naphthalene)/((Pa-Ps)*Ma/Za)

$\left\{\right.$ mass_ratio2 $=\left(\mathrm{P} \_\right.$dodecane*M_dodecane $/ \mathrm{Z} \_$dodecane $) /\left(\left(\mathrm{Pa}-\mathrm{P} \_\right.\right.$dodecane $\left.\left.) * \mathrm{Ma} / \mathrm{Za}\right)\right\}$

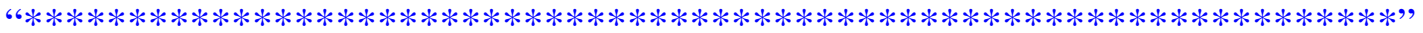




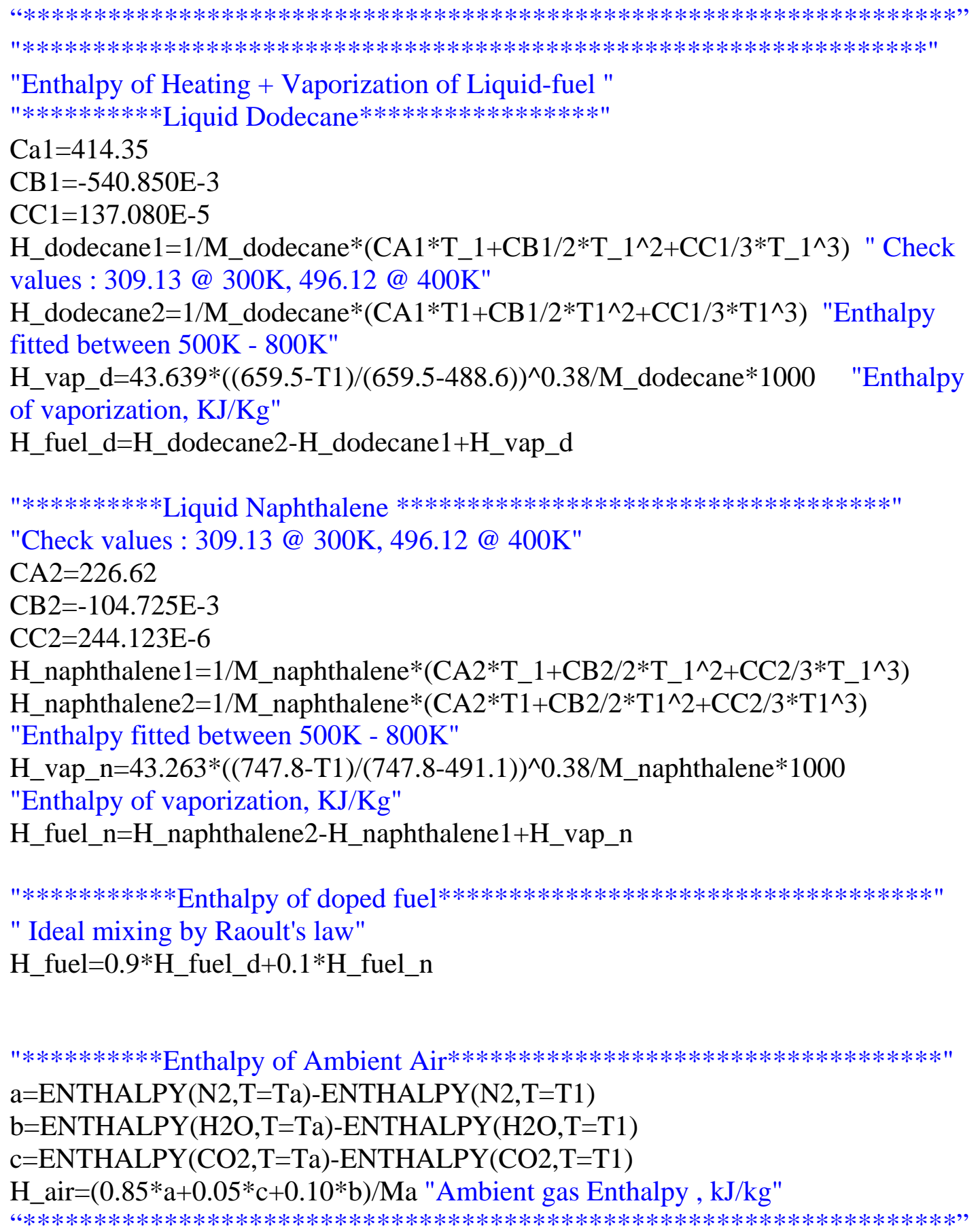
$\mathrm{Ma}=28 * 0.85+18 * 0.05+44 * 0.10$ "Ambient gas mean molecular weight , $\mathrm{kg} / \mathrm{kmol} "$ M_dodecane=170.34; M_naphthalene=128.164 


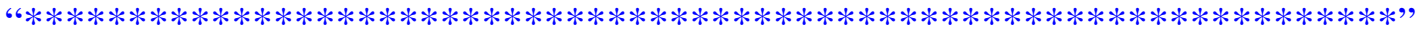

"*****Saturated Vapor Pressure $* * * * * * * * * * * * * * * * * * * * * * * * * * * * * * * * * * * * * * * * "$ P_dodecane $=1 / 760 *\left(10^{\wedge}(6.99795-1639.270 /((\mathrm{T} 1-273.15)+181.835))\right)$ "Saturated pressure fitted between $450 \mathrm{~K}$ - 600K"

P_naphthalene $=10^{\wedge}(7.01065-1733.710 /((T 1-273.15)+201.859)) / 760$ "Antoine vapor pressure equation"

"****Mixed fuel saturated pressure (by Raoult's law) ************************" Ps $=0.9 * \mathrm{P} \_$dodecane $+0.1 * \mathrm{P} \_$naphthalene

“********************************************************************,

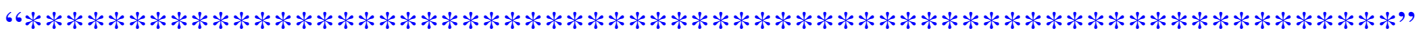

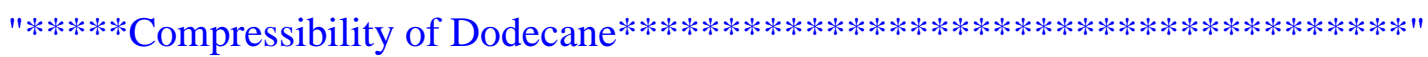
Z_dodecane=COMPRESS(Tr, Pr, 0.575) "Acentric factor is 0.575"

$\mathrm{Tr}=\mathrm{T} 1 / 658.2 \quad$ "Tcrit= 658.2 K"

Pr=Ps/18.2 "Pcrit=18.2 bar"

"****Compressibility of Naphthalene $* * * * * * * * * * * * * * * * * * * * * * * * * * * * * * * "$

Z_naphthalene=COMPRESS(Tr1, Pr1, 0.313) "Acentric factor is 0.313 "

Tr1=T1/748.4 "Tcr= 748.4 K for naphthalene"

Pr1=P_naphthalene/40.4 "Pcr=40.4 bar for naphthalene"

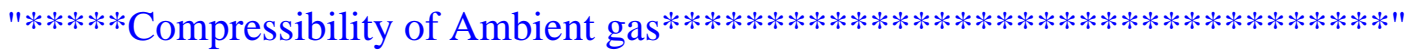

"Za= COMPRESS(Tr, Pr, Omega) compressibility for ambient gas"

$\mathrm{Za}=1$ "about 1 for compressibility for ambient gas"

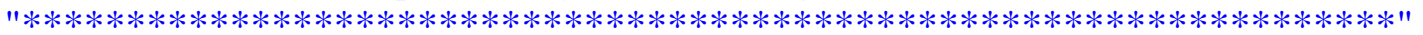




\section{APPENDIX B}

\section{CODE PROGRAM USED FOR IMAGE CORRECTION}

The C code program for image correction consists of two main parts. One is to load and save image files as a TIFF file format, and the other is to calibrate image data into vapor-fuel concentration. Instead of introducing the entire program, the two subroutines for the later part are introduced here due to their importance.

\section{B.1 Subroutine to Calibrate TMPD Fluorescence to Vapor-Fuel Concentration}

The following C language code is the subroutine to correct temperature dependence of TMPD fluorescence and laser light extinction through the TMPD vapor. As discussed in $\S 4.3$, the temperature field was determined using a simple mixing model, and the system was iteratively solved to find the concentration and temperature field including the effect of the laser sheet extinction and laser sheet profile variations. For better convergence and reduced calculating time, instead of direct calling the subroutine shown in $\S \mathrm{B} .2$ for estimating temperature field, it was used to match the vapor concentration with the corresponding temperature via a fitted curve obtained using a selected condition of ambient density, ambient pressure and ambient gas temperature.

void t_e_correct_f (double density, int Tamb, double ft)

\{

unsigned short int byte;

int i,j, iref, icount, i_max;

int index, limit; 
int len_liq;

double dummy, dummy_i, intensity, dum_cmp, e_max ;

double FA, FA_max, P, P_vap, T, Tfuel, tcmpensation, KI0;

double R, Navog, conc;

double dli, dlj,sigma, Inew,Iold,dum[245];

double N_TMPD, N_TMPD_1, N_TMPD_0, relax;

double ndensity, nweight, nweightu, nweightl, accumulu, accumull, accumulc, nmol;

double A, B1, B2, B3, B4, B5, dummy_t, fweight;

double T1, T2, Tint;

if $(($ Tamb $==1200) \& \&($ density $==15))\{$

$\mathrm{P}=40.13$

$\mathrm{A}=1200 ; / / 1199.1919$;

$\mathrm{B} 1=-289.7521$;

B2=89.52042;

B3=-21.57261;

B4=3.10912;

B5=-0.19084;

\}

else if $(($ Tamb $==1000) \& \&($ density $==15))\{$

$\mathrm{P}=34.5$;

$A=1000 ; / / 999.30967$;

B1=-266.09864;

$\mathrm{B} 2=91.90438$;

B3=-24.66166;

B4=3.93151;

B5=-0.26582;

\}

else if $(($ Tamb $==800) \& \&($ density $==15))\{$

$\mathrm{P}=29.7$;

$\mathrm{A}=800$; //799.93069;

$\mathrm{B} 1=-231.11019$;

$\mathrm{B} 2=97.19084$;

B3=-36.52486;

B4=9.00139;

B5=-0.99338;

\}

else if $(($ Tamb $==1200) \& \&($ density $==7.5))\{$

$\mathrm{P}=21 ; / / 19.5$;

$\mathrm{A}=1200$; //1196.88207;

$\mathrm{B} 1=-533.33775$;

B2=267.87266;

B3=-92.44902; 


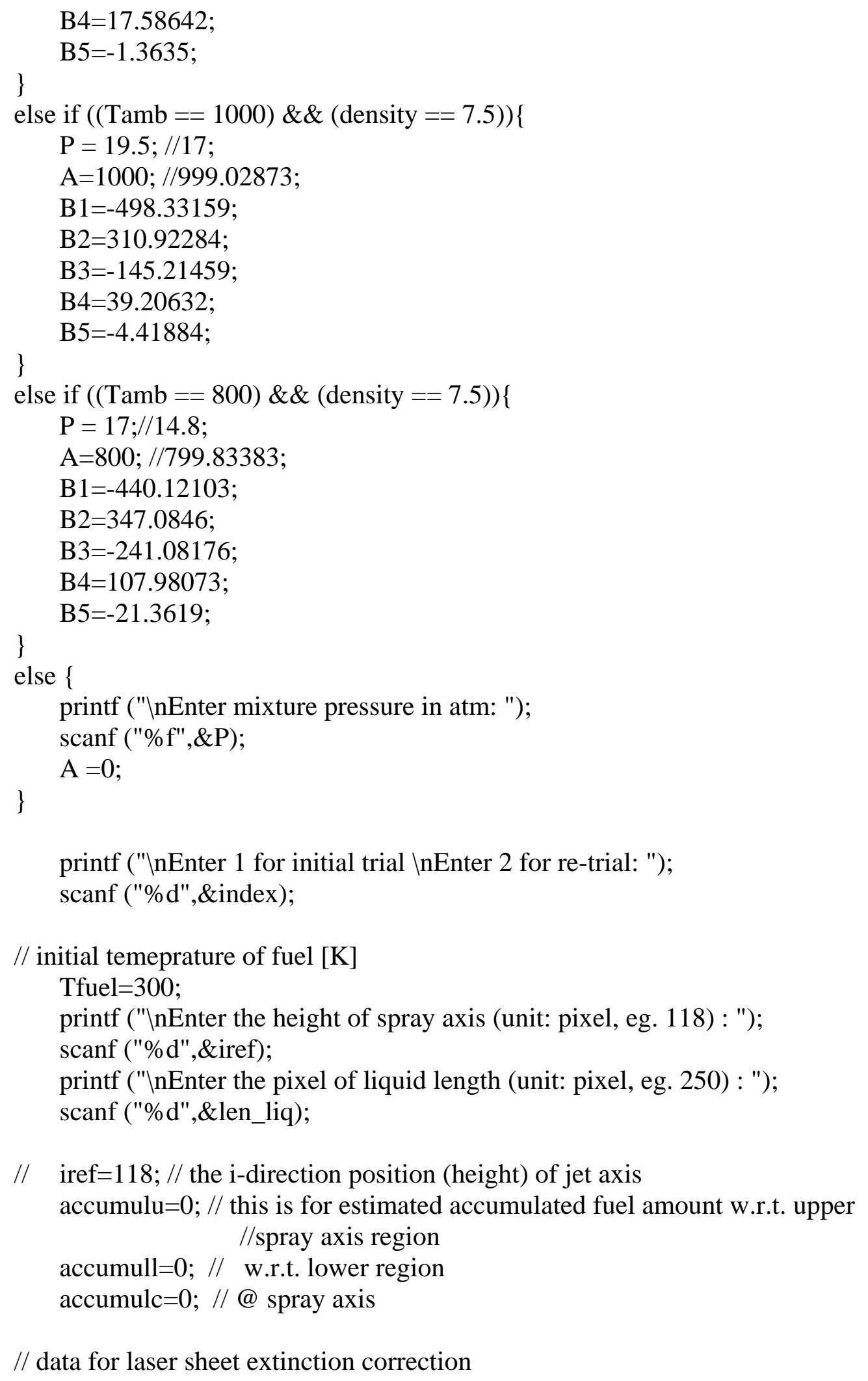


$\mathrm{dlj}=0.009849 * 2 ; / / \mathrm{cm}$ per pixel (colume of 376 or 752 )

dli $=$ dlj*2.4103/2; // corrected exact aspect ratio on y-direction (row)

sigma $=2.4854 \mathrm{e}-18$; // TMPD absoprtion coefficient from berlman , cm2

Navog=6.022e23;

$\mathrm{R}=83.1451 ; / / \mathrm{R}: 83.1451 \mathrm{~cm} 3 *$ bar $/ \mathrm{K} * \mathrm{~mol}$

// conc is the TMPD mole fraction [\%] in fuel-ambient gas mixture

conc $=0.01355 * 0.009$; / stoi FA by mole $=1.35 \%$ by mole, $0.9 \%$ by mole

//TMPD in doped fuel $(0.9 \% * 164 / 166)$

// i_max is \# of max iteration, e_max is max error bound

i_max $=10000$;

e_max $=1 \mathrm{E}-3$;

relax $=0.85$; / relaxation factor for better convergence

//!!!!!!!!!!!!!!!!!!!!!!!!!!!!!!!!!!!!!!!!!!!!!!!!!!!!!!!!!!!!!!!!!!!!!!!!!!!!!!!!!!!!!!!!!!!!!!!!!!!!!!!!!

//From absolute calibration, the term of $\left(\mathrm{K}^{*} \mathrm{I}_{0}\right)$ is determined

N_TMPD_0=6.2e-5*Navog/1000; // mol/l * \#/mol * l/ $1000 \mathrm{~cm} 3=\# / \mathrm{cm} 3$

$\mathrm{KI} 0=(65 * \mathrm{ft}) /\left(\mathrm{N} \_\mathrm{TMPD} 0 * 1.32\right) ; / / \mathrm{ft}$ is correction factor

$/ / \mathrm{K}^{*} \mathrm{I} 0=\mathrm{S} /\left(\mathrm{N} \_\mathrm{TMPD} *\right.$ tcmpsation)

// $\mathrm{S}=65$ "measured TMPD fluorescence",

// N_TMPD = N_TMPD_0, tcmpensation = 1.32 @ 430K

//!!!!!!!!!!!!!!!!!!!!!!!!!!!!!!!!!!!!!!!!!!!!!!!!!!!!!!!!!!!!!!!!!!!!!!!!!!!!!!!!!!!!!!!!!!!!!!!!!!

// laser sheet was already uniformity corrected,

// if not, you can correct it using the value of dum[i]

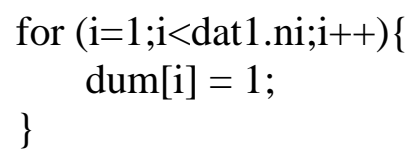

// The loop starts for correcting extinction and temperature dependence of TMPD // for y-direction

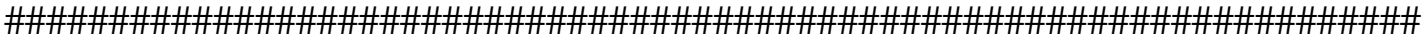

for $(\mathrm{i}=0 ; \mathrm{i}<$ dat $1 . n \mathrm{i} ; \mathrm{i}++)$

\{

Iold=dum[i];

// for deleting any signals from other spray plume

if $(\mathrm{i}<118)$ limit $=2 * \mathrm{i}+94$;

else limit $=-2 * \mathrm{i}+565$;

for $(\mathrm{j}=$ limit;j<dat1.nj/2;j++)

\{

$*($ newim $+\mathrm{i} * 376+\mathrm{j})=0$;

$*($ temp $+\mathrm{i} * 376+\mathrm{j})=255$; 


\section{// for X-direction}

$* * * * * * * * * * * * * * * * * * * * * * * * * * * * * * * * * * * * * * * * * * * * * * * * * * * * * * * * * * * * * * * * *$

for $(\mathrm{j}=0 ; \mathrm{j}<\mathrm{limit} ; \mathrm{j}++)$

\{

// read the fluorescence signal

byte $=*($ newim $+\mathrm{i} * 376+\mathrm{j})$;

intensity=(double) byte;

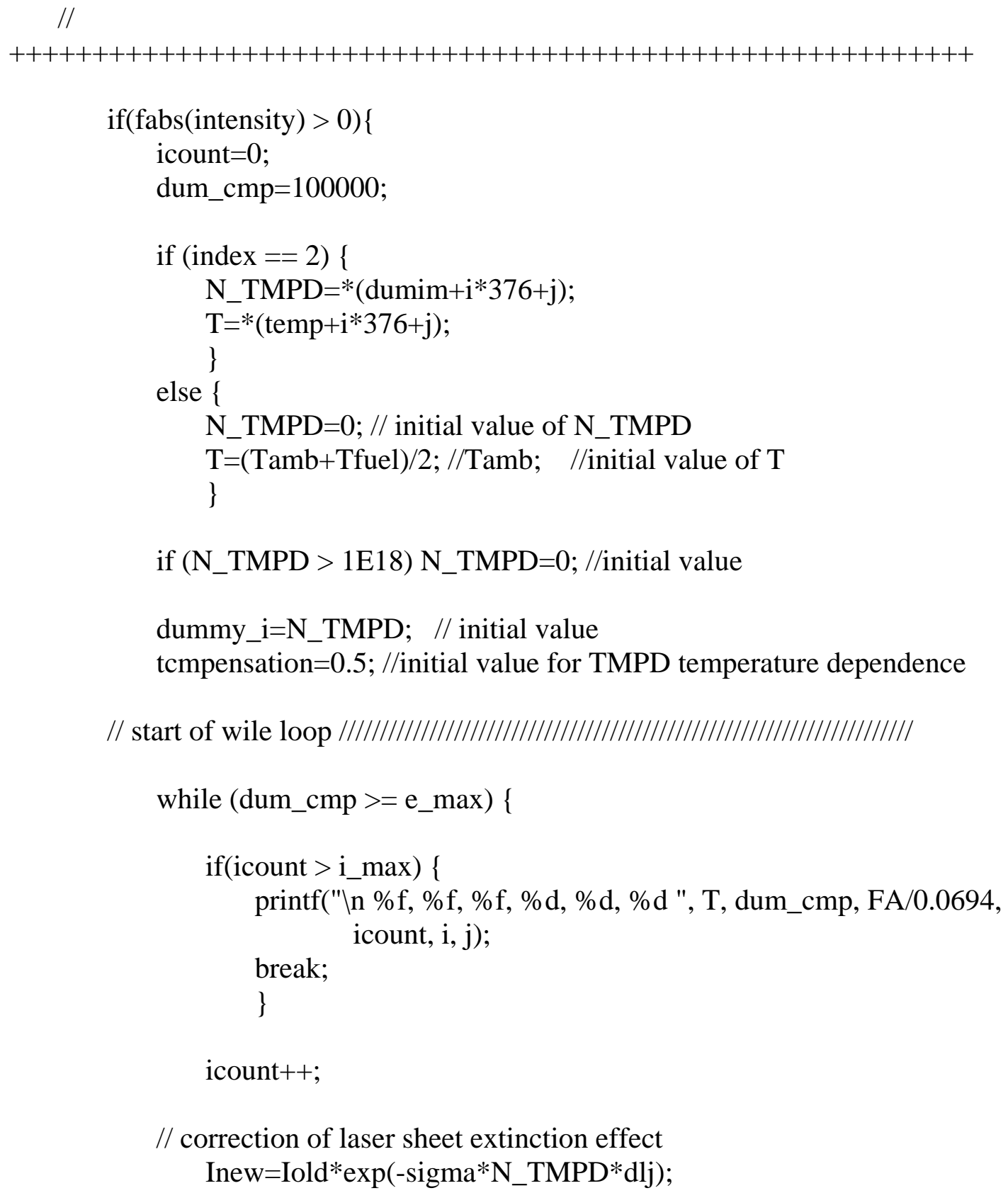


// calibration between TMPD \# density and fluorescence signal

N_TMPD_1 $=(\mathrm{P} *$ conc $) /(\mathrm{R} * \mathrm{~T}) *$ Navog; $/ /[1 / \mathrm{cm} 3]$ stoichiometric \# if (icount $>1000$ ) $\{$ relax $=0.9$;

N_TMPD $=$ relax $*$ N_TMPD $+(1-$ relax $) *$ intensity/(KI0*Inew*tcmpensation);

else $\mathrm{N} \_\mathrm{TMPD}=$ relax $* \mathrm{~N} \_\mathrm{TMPD}+(1-$ relax)*intensity/(KI0*Inew*tcmpensation);

// conversion of N_TMPD to FA and P_vap

FA=N_TMPD/N_TMPD_1 $* 0.0694$;

P_vap $=\mathrm{P} * 0.01355 * \mathrm{FA} / 0.0694$;

// determine temperature field

// curvefitted results for 15 and $7.5 \mathrm{~kg} / \mathrm{m} 3 / 1200 \mathrm{~K}, 1000 \mathrm{~K}, 800 \mathrm{~K}$ if $(\mathrm{A}==0) \mathrm{T}=$ temperature(FA, Tamb, $\left.\mathrm{P}_{-} \mathrm{vap}\right)$; else $\mathrm{T}=\mathrm{A}+\mathrm{B} 1 * \mathrm{P}_{-}$vap+B2*pow $\left(\mathrm{P}_{-}\right.$vap,2)+B3*pow $\left(\mathrm{P}_{\text {_vap }}, 3\right)$ +B4*pow(P_vap,4)+B5*pow(P_vap,5);

// assumed fluorescence temperature dependence profile if $((\mathrm{T}>=400) \& \&(\mathrm{~T}<=600))$ tcmpensation $=-0.96626+0.00527 * \mathrm{~T}$; else if $((\mathrm{T}>600) \& \&(\mathrm{~T}<=980))$ tcmpensation=4.99247-0.00492*T; else if $(T>980)$ tcmpensation $=0.17$; else tcmpensation $=1$;

// check dum_cmp for convergence of iteration dummy=N_TMPD; dum_cmp=fabs((dummy-dummy_i)/dummy);

// renewal of old variable dummy_i=dummy;

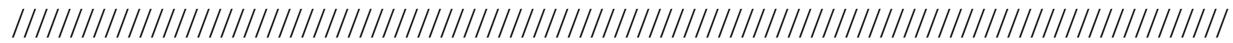

\}

// end of while loop

Iold=Inew;

*(dumim $+\mathrm{i} * 376+\mathrm{j})=\mathrm{N} \_$TMPD; // N_TMPD saved

// fix the saturation value as FA_max

FA_max $=4 * 0.0694$;

if $\left(\left(\mathrm{FA}>=\mathrm{FA} \_\right.\right.$max $\left.) \|(\mathrm{FA}<0)\right)\{$

FA=FA_max;

N_TMPD $=4 *$ N_TMPD_1;

P_vap $=\mathrm{P} * 0.01355 * 4$;

$\mathrm{T}=\mathrm{A}+\mathrm{B} 1 *$ P_vap+B2*pow(P_vap,2)+B3*pow(P_vap,3)

+B4*pow(P_vap,4)+B5*pow(P_vap,5);

\} 
/* for two phase location, determine Tint from fuel partial vapor pressure */

if $((\mathrm{FA}>0.0694 * 3.5) \& \&(\mathrm{j}>$ len_liq) $)\{$

T1=1733.710/(7.01065-log10(0.1*P_vap*760))-201.859; //Naphthalene T2=1639.270/(6.99795-log10(0.9*P_vap*760))-181.835; // Dodecane

Tint $=0.1 * \mathrm{~T} 1+0.9 * \mathrm{~T} 2$;

Tint+=273.15; // convert $\mathrm{C}$ to $\mathrm{K}$

T=Tint;

tcmpensation $=-0.96083+0.0053 * \mathrm{~T}$;

N_TMPD = intensity/(KI0*Inew*tcmpensation);

FA=N_TMPD/N_TMPD_1*0.0694;

\}

// TMPD mol density

dummy=N_TMPD/Navog; // mol / cm3 = $(\# / \mathrm{cm} 3) /(\# / \mathrm{mol})$

// calculation of the accumulated total mass \& number density

if ((FA/0.0694) >4) printf("\n \%f, \%f, \%d, \%d ", T, FA/0.0694, i, j);

if $((\mathrm{i}>70) \& \&(\mathrm{i}<170) \& \&(\mathrm{j}<$ len_liq) \&\& $((\mathrm{FA} / 0.0694)<4))$

\{

// confine laser sheet width

if ( $\mathrm{i}<$ iref) accumulu+=3.141592*abs(iref-i)*pow(dli,2)

*dlj*dummy;

if (i > iref) accumull+=3.141592*abs(iref-i)*pow(dli,2)*dlj*dummy; else accumulc+=3.141592/4*pow(dli,2)*dlj*dummy;

\}

// overwrite the concentration and temperature at each pixel dummy=FA / $0.0694 * 60$; // Equivalence ratio * 60 ;

dummy_t=(T-Tfuel)*255/(Tamb-Tfuel);

// dimensionless temperature (0 - 255)

byte=(unsigned short int)dummy;

$*($ newim $+\mathrm{i} * 376+\mathrm{j})=$ byte;

$*($ temp $+\mathrm{i} * 376+\mathrm{j})=($ unsigned short int $)$ dummy_t;

\}

$/ /+++++++++++++++++++++++++++++++++++++++++++++++++++++++++$

else $*\left(\right.$ temp $\left.+\mathrm{i}^{*} 376+\mathrm{j}\right)=255 ; / /$ w.r.t. if $($ fabs (intensity $\left.)<0\right)$

if $((\mathrm{i}>115) \& \&(\mathrm{i}<125) \& \&(\mathrm{j}==150))$

printf("\n \%f, \%f, \%f, \%d, \%d ", T, dum_cmp, Iold, i, j);

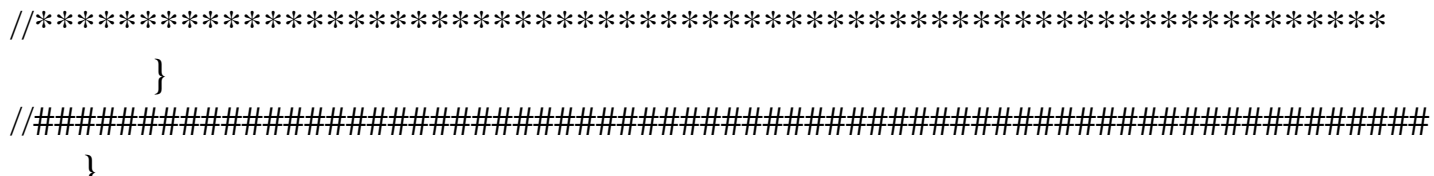


// calculating the vaporized fuel mass nmol=(accumulu+accumull+accumulc); // from absolute calibration nweightu=accumulu*164*1000; // upper part nweightl=accumull $* 164 * 1000$; // lower part nweight $=$ nmol $* 164 * 1000 ; / /$ TMPD MW= 164, TMPD = $164 / /$ total part fweight=nweight*100/0.9; // 0.9\% TMPD mass fraction w.r.t. total fuel mass ndensity=nmol*Navog; // printf("In\n TMPD injected \# \%g \n TMPD injected \t \%g mol \n TMPD injected It \%g mg (\%g + \%g) \n Fuel injected \t \%g mg In", ndensity, nmol, nweight, nweightu, nweightl, fweight); 


\section{B.2 Subroutine to Estimate Temperature Field in the Spray}

As discussed in $\S B .1$, the subroutine of this section was used only if a fitting relationship to match the vapor concentration with temperature was needed at a newly selected condition of ambient density, ambient pressure and ambient gas temperature. Figure B.1 shows an example. Thermodynamic and physical property data or relationships used in this code came from the same references in Appendix A. The doped fuel was assumed as a mixture of $90 \%$ dodecane and $10 \%$ naphthalene since data for TMPD were not available. The mixture data were determined using Dalton's and Raoult's laws applied to the vapor and liquid phase respectively.

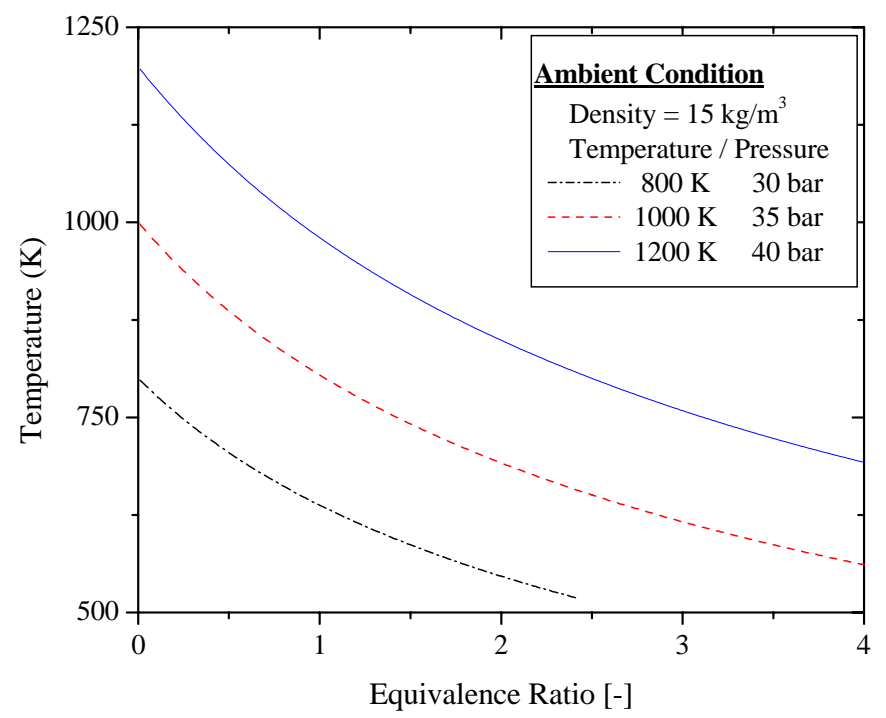

Figure B.1 Example of fitting relationships to match the vapor concentration with temperature obtained from the subroutine in this section. 


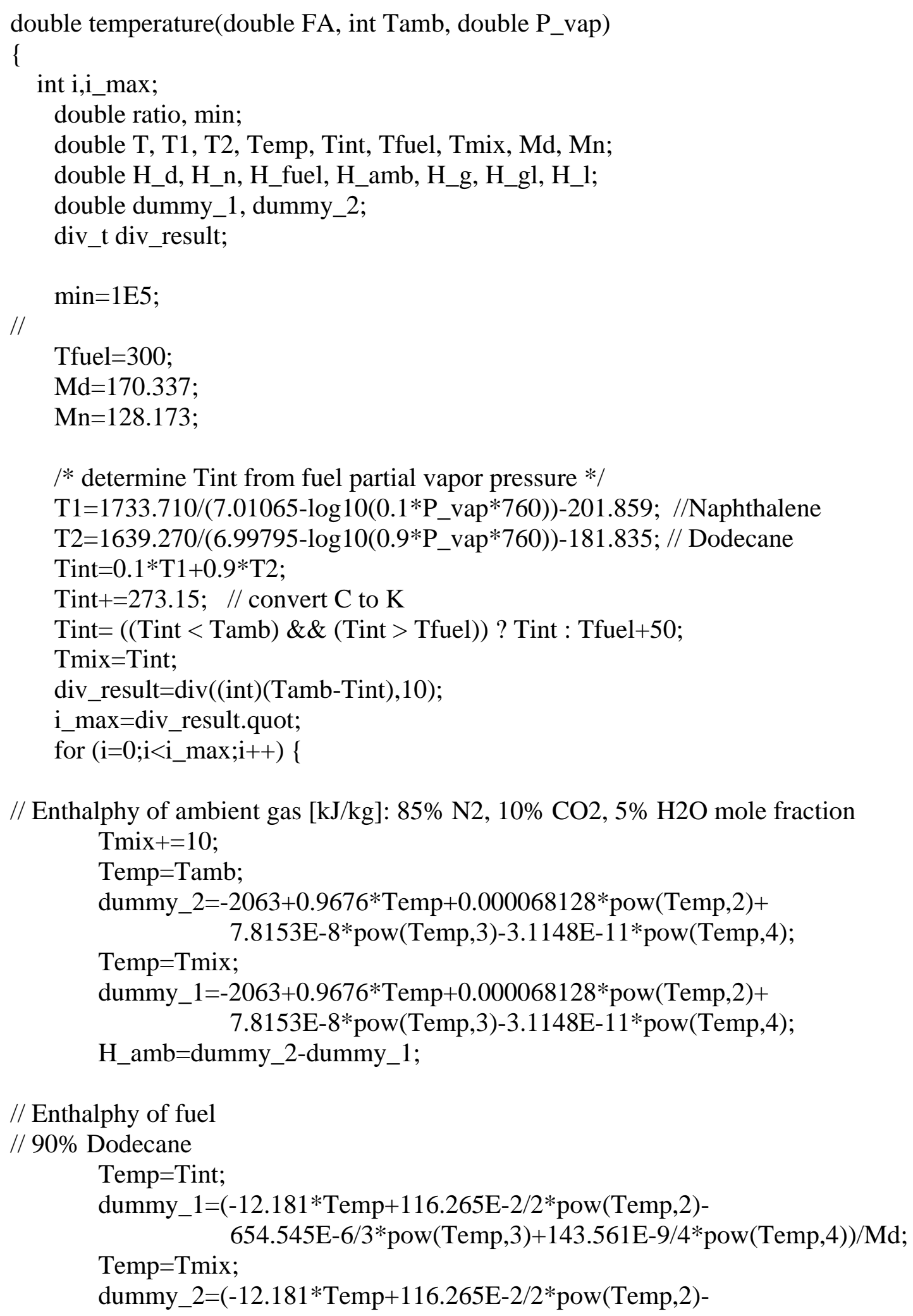

// Enthalphy of ambient gas [kJ/kg]: 85\% N2, 10\% CO2, 5\% H2O mole fraction Tmix $+=10$; 
654.545E-6/3*pow(Temp,3)+143.561E-9/4*pow(Temp,4))/Md;

H_g=dummy_2-dummy_1;

Temp=Tfuel;

dummy_1=(414.35*Temp-540.850E-3/2*pow(Temp,2)+

137.080E-5/3*pow(Temp,3))/Md;

Temp=Tint;

dummy_2=(414.35*Temp-540.850E-3/2*pow(Temp,2)+

137.080E-5/3*pow(Temp,3))/Md;

H_l=dummy_2-dummy_1;

H_gl=(43.639*pow((659.5-Temp)/(659.5-488.6),0.38))*1000/Md;

H_d=H_g+H_gl+H_l;

// 10\% naphthalene

Temp=Tint;

dummy_1=(-62.162*Temp+814.960E-3/2*pow(Temp,2)-

594.128E-6/3*pow(Temp,3)+169.264E-9/4*pow(Temp,4))/Mn;

Temp=Tmix;

dummy_2=(-62.162*Temp+814.960E-3/2*pow(Temp,2)-

594.128E-6/3*pow(Temp,3)+169.264E-9/4*pow(Temp,4))/Mn;

H_g=dummy_2-dummy_1;

Temp=Tfuel;

dummy_1=(226.62*Temp-104.725E-3/2*pow(Temp,2)+

244.123E-6/3*pow(Temp,3))/Mn;

Temp=Tint;

dummy_2=(226.62*Temp-104.725E-3/2*pow(Temp,2)+

244.123E-6/3*pow(Temp,3))/Mn;

H_l=dummy_2-dummy_1;

H_gl=(43.263*pow((747.8-Temp)/(747.8-491.1),0.38))*1000/Mn;

H_n=H_g+H_gl+H_l;

// Raoult's Law

H_fuel $=0.9 * H \_d+0.1 * H \_n$;

ratio=H_amb/(H_fuel*FA)-1;

if $(($ fabs $($ ratio $)<\min ) \& \&$ (fabs(ratio) $>0))\{$

$\mathrm{T}=$ Tmix;

\}

$\min =$ fabs(ratio);

\}

Tmix $=\mathrm{T}-8$;

for $(\mathrm{i}=0 ; \mathrm{i}<32 ; \mathrm{i}++)\{$

// Enthalphy of ambient gas [kJ/kg]: 85\% N2, 10\% CO2, 5\% H2O mole fraction $\mathrm{Tmix}^{+}=0.5$;

Temp=Tamb; 







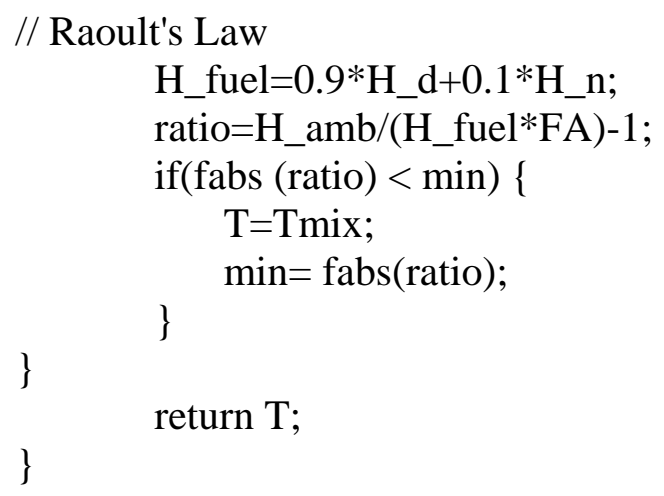




\section{APPENDIX C}

\section{CAMERA SHOT NOISE ESTIMATION}

As discussed in §5.2.2.3 the camera shot noise $\left(=S N R^{-1}\right)$ was estimated as 0.84 [\%]. The following EES code was used for this estimation. In summary, from inputs of $k=3, \eta_{\text {det }}=0.2$, stoichiometric fuel-to-air ratio, and an ambient condition

of $15 \mathrm{~kg} / \mathrm{m}^{3}$ and $1000 \mathrm{~K}, N_{\text {photon }}$ and $S N R$ were estimated as $2.1 \times 10^{5}$ and 118 respectively.

\section{D.1 EES Program Used for Camera Shot Noise Estimation}

This calculation is to estimate the camera shot noise "

"Under stoichiometric ratio, and an ambient condition of $15 \mathrm{~kg} / \mathrm{m}^{3}$ and $1000 \mathrm{~K}$ "

shot_noise=1/SNR*100 "[\%] Noise of the signal"

SNR=sqrt(N_photon*eta_det/k) "'Signal-to-Noise Ratio for the camera system"

N_photon=eta*1/16*(1/fnum $)^{\wedge} 2 * \mathrm{M} /(\mathrm{M}+1)^{\wedge} 2 * \mathrm{~S} / \mathrm{N} \wedge 2 *$ Ep/h/nu*sigma*m $1 *$ phi "Number of Photons Striking the Face of the Camera (Intensified or not)"

k=3 "Gain dependent noise factor, usually a value between 2 and 4"

eta_det $=0.2 \quad$ "Assumed 0.2 as the detector efficiency"

"To obtain Number density of TMPD" 
$\mathrm{m} 1=\mathrm{Pv}^{*} \mathrm{Na} / \mathrm{R} / \mathrm{T}$ "Number density of TMPD, \#/cm^3"

$\mathrm{P}=35$ "Ambient pressure, bar"

$\mathrm{T}=1000$ "Ambient temperature, $\mathrm{K}$ "

$\mathrm{R}=83.1451$ "(cm3 bar) / (K mol)"

$\mathrm{Pv}=\mathrm{P} * 0.0135 * 0.01$ "Partial pressure of TMPD: $\mathrm{P} \_$chamber*(fuel/total)*(TMPD/fuel)"

"Constants and Optical Parameter used"

$\mathrm{Na}=6.02 \mathrm{e} 23$ "Avagadro's number"

h=6.63e-34 "Planck's constant"

eta $=.8^{\wedge} 3^{*} .2$ "Assumed three filters' efficiency of 80\%, and 20\% Camera efficiency"

fnum=2.8 "F\# used"

M=1.2/5 "Magnified ratio"

$\mathrm{S}=1.2$ "[cm], Vertical size of the intensifier face"

$\mathrm{N}=245$ "[Pixels] in one direction on the camera array"

Ep=.0135 "Laser energy $[J] "$

nu=3e8/400e-9 "TMPD fluorescence filter used : 400 nm BPF"

sigma=2.47e-18 "TMPD absorption cross section from Berlman[47]"

phi $=0.18 * 0.2$ " Assumed $0.2 *$ fluorescence efficiency at $1000 \mathrm{~K}, 0.18=$ flourescence

quantum efficiency at a reference temperature from Berlman[47]"

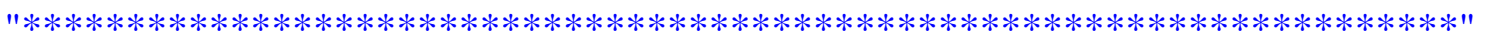




\section{APPENDIX D \\ QUANTITATIVE IMAGES FOR AMBIENT DENSITY 7.5 kg/m³}

Figures D.1-3 show quantitative images of equivalence ratio (left) and temperature (right) for ambient conditions of $7.5 \mathrm{~kg} / \mathrm{m}^{3}$ and 800,1000 and $1200 \mathrm{~K}$ respectively. The numbers shown on the axes are the distance from the injector tip in $\mathrm{mm}$, the injector tip position is shown with a cross, and the gray scale on the right shows the temperature or equivalence ratio correspondence. The nozzle size was $0.158 \mathrm{~mm}$ and the injection pressure was $90 \mathrm{MPa}$.

As discussed in $\S 5.3$ data acquired at $7.5 \mathrm{~kg} / \mathrm{m}^{3}$ confirmed all of the trends discussed above regarding the spray structure, but integration of the vapor mass was limited by interaction with the chamber wall before all of the liquid fuel had evaporated. Figures D.1-3 are shown to have faster vapor- and liquid- phase penetration rates, larger volumes of fuel rich extent and bigger overall spray sizes than that of ambient density $15 \mathrm{~kg} / \mathrm{m}^{3}$. However, some images for the ambient temperature of $800 \mathrm{~K}$ and $1000 \mathrm{~K}$ (see Figures D.1 and 2) have discontinuities on the maps for the spray (i.e. white regions for equivalence ratio and black regions for temperature). This is resulted from the existence of the liquid phase. Therefore, lower

ambient density is expected to experience more interference between the liquid- and vapor-phase. In addition, the images of the ambient temperature of $1200 \mathrm{~K}$ at 1.4 and 1.8 ms ASI (see Figure D.3) also indicate decreased signals due to thermal decomposition of the TMPD as discussed in the $15 \mathrm{~kg} / \mathrm{m}^{3}$ case. 

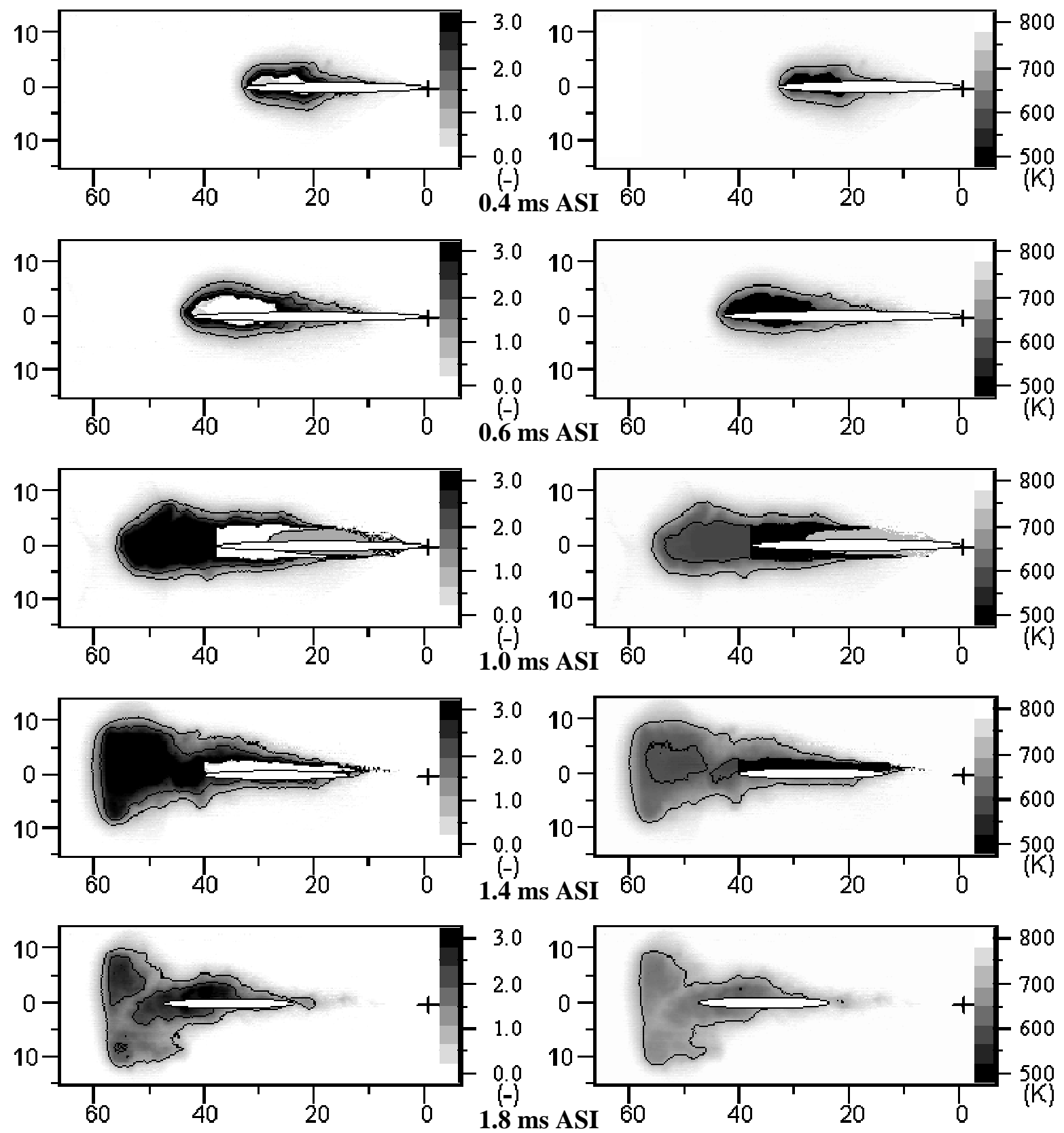

(a) Equivalence ratio

(b) Temperature

Figure D.1 Quantitative images of equivalence ratio (left) and temperature (right) at the ambient density of $7.5 \mathrm{~kg} / \mathrm{m}^{3}$ and temperature of $800 \mathrm{~K}$. The solid lines in the images, shown for convenience, represent the contours with increments of 1 for equivalence ratio and $-100 \mathrm{~K}$ for temperature from the ambient values ( 0 and $800 \mathrm{~K}$ ), respectively. 

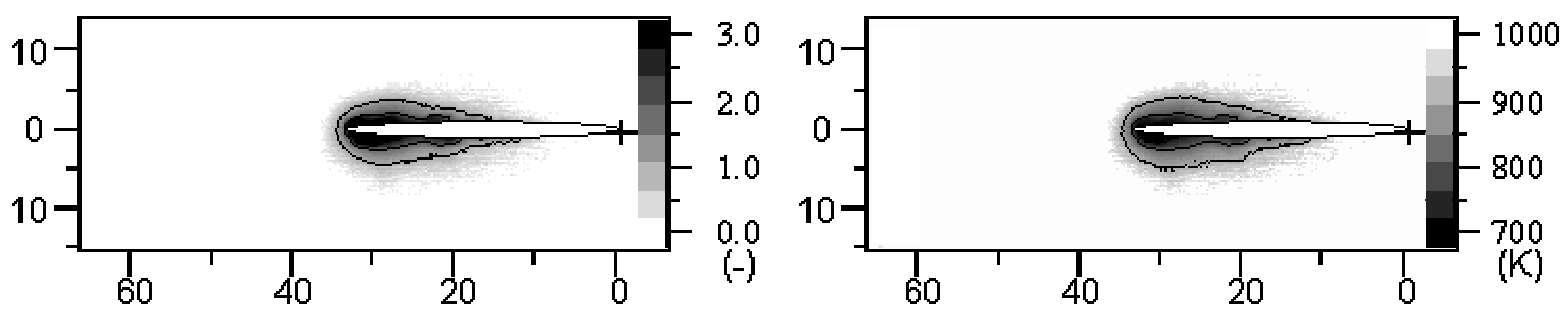

$0.4 \mathrm{~ms}$ ASI
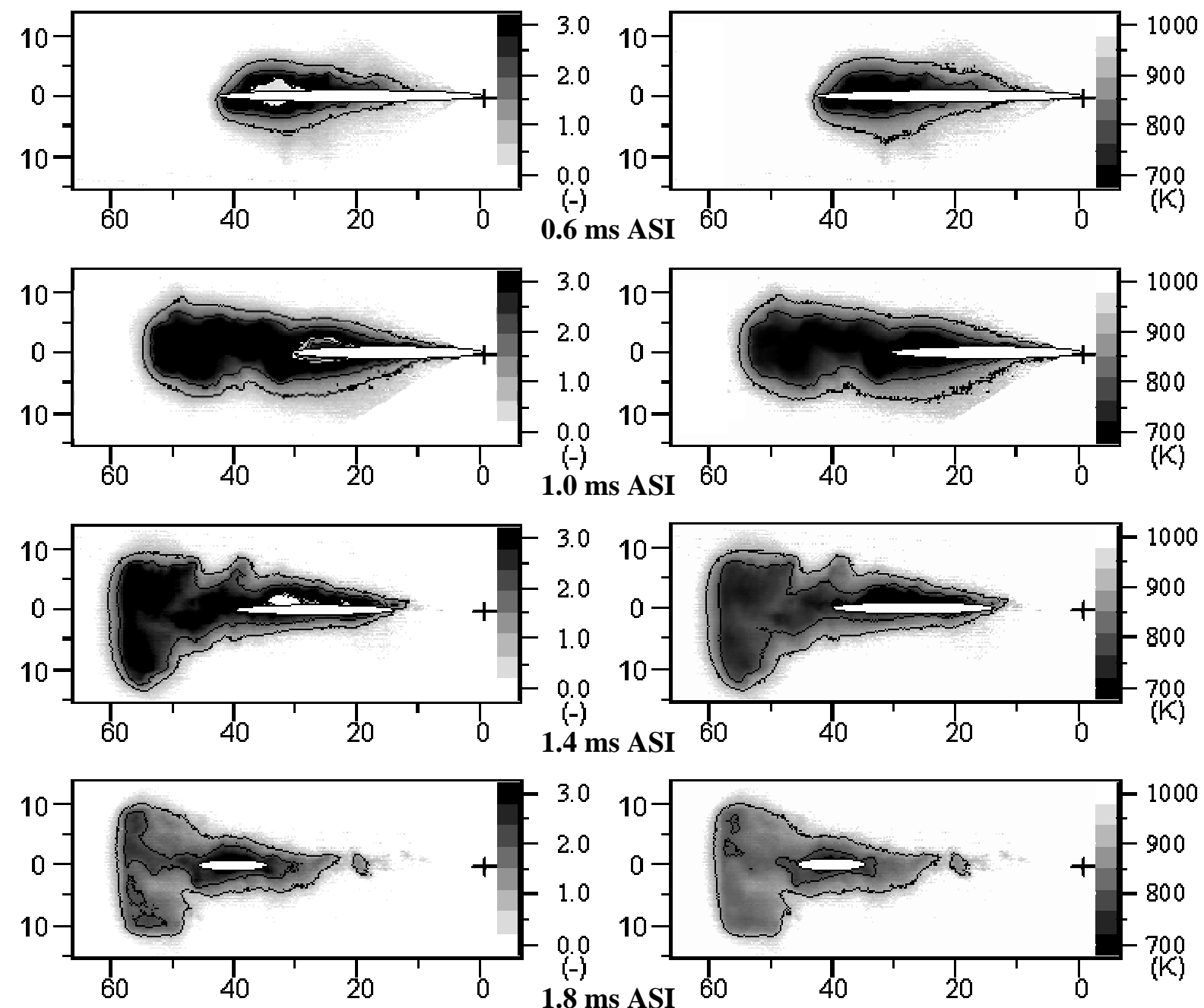

$1.8 \mathrm{~ms}$ ASI

(a) Equivalence ratio

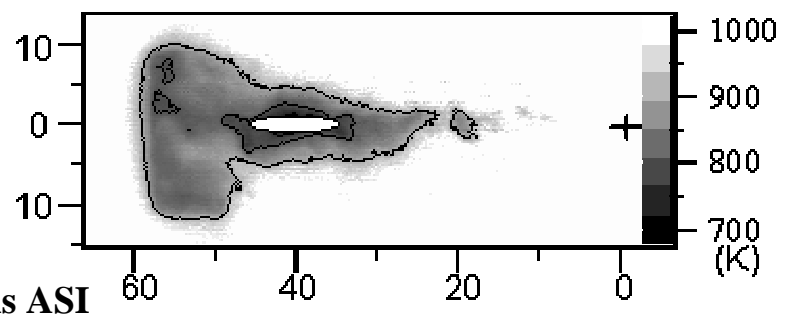

(b) Temperature

Figure D.2 Quantitative images of equivalence ratio (left) and temperature (right) at the ambient density of $7.5 \mathrm{~kg} / \mathrm{m}^{3}$ and temperature of $1000 \mathrm{~K}$. The solid lines in the images, shown for convenience, represent the contours with increments of 1 for equivalence ratio and $-100 \mathrm{~K}$ for temperature from the ambient values ( 0 and $1000 \mathrm{~K})$, respectively. 

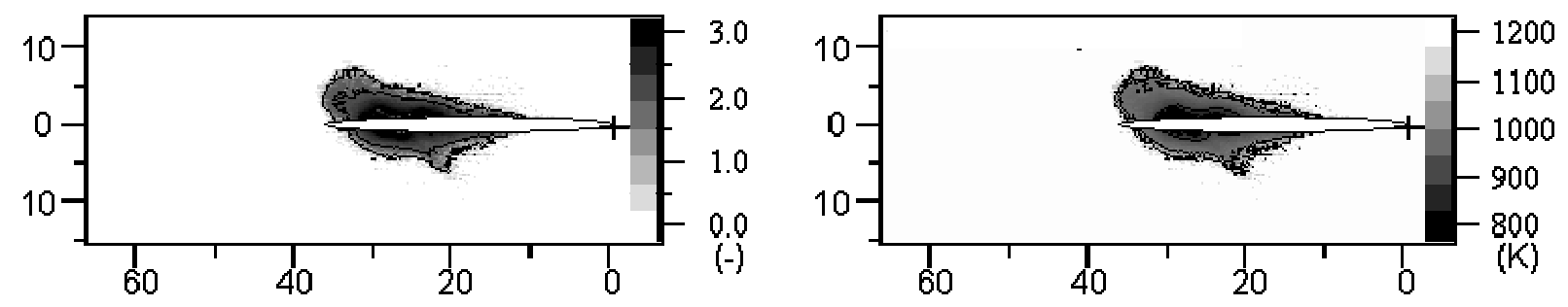

$0.4 \mathrm{~ms}$ ASI
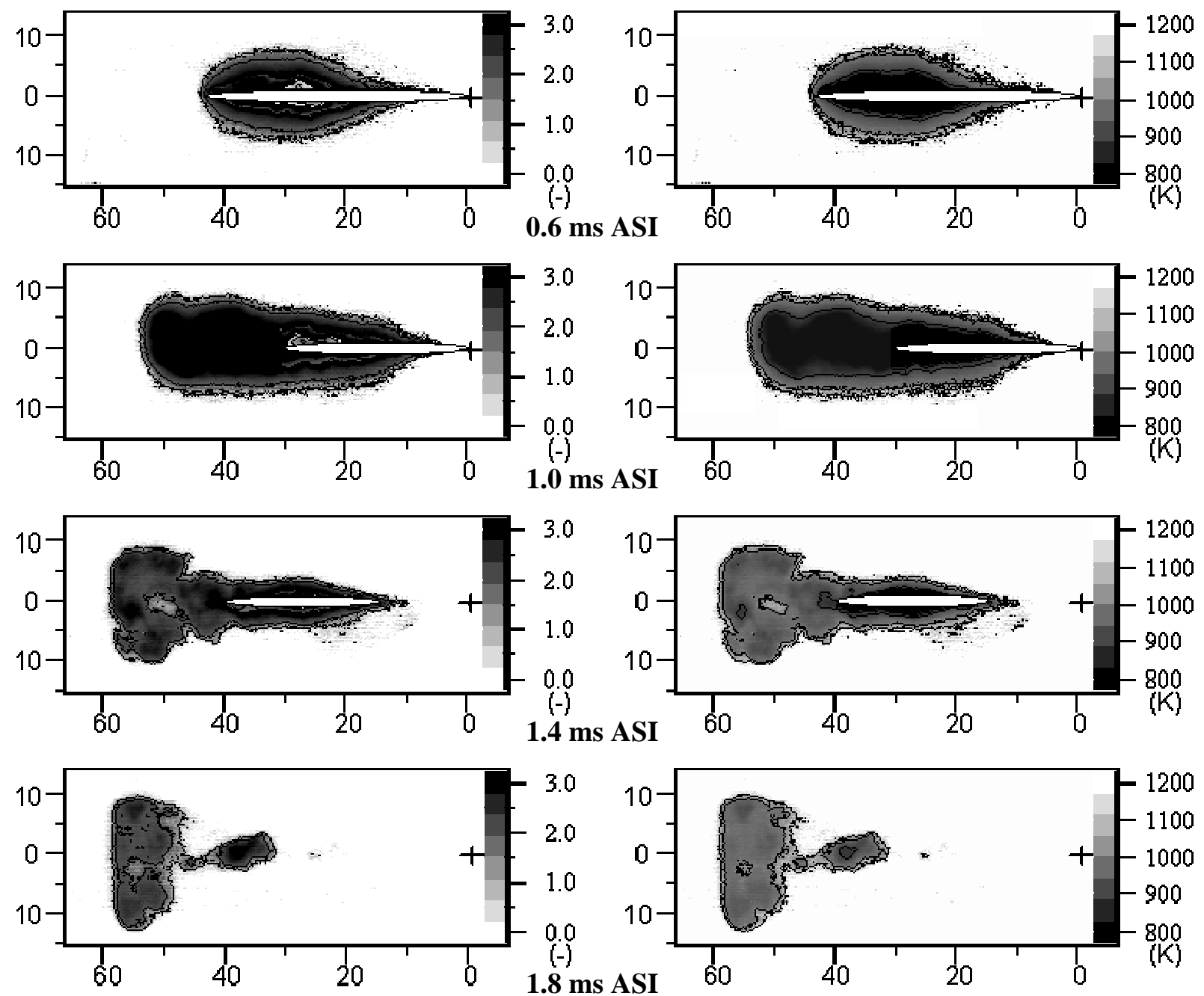

(a) Equivalence ratio

(b) Temperature

Figure D.3 Quantitative images of equivalence ratio (left) and temperature (right) at the ambient density of $7.5 \mathrm{~kg} / \mathrm{m}^{3}$ and temperature of $1200 \mathrm{~K}$. The solid lines in the images, shown for convenience, represent the contours with increments of 1 for equivalence ratio and $-100 \mathrm{~K}$ for temperature from the ambient values (0 and $1200 \mathrm{~K}$ ), respectively. 